University of Louisville ThinkIR: The University of Louisville's Institutional Repository

Electronic Theses and Dissertations

$12-2015$

\title{
A phenomenological study of anticipated intimacy and sexual expression needs of aging male and female baby boomers.
}

Charles Shawn Oak

University of Louisville

Follow this and additional works at: https://ir.library.louisville.edu/etd

Part of the Bioethics and Medical Ethics Commons, Clinical and Medical Social Work Commons, Family, Life Course, and Society Commons, Gender and Sexuality Commons, Gender, Race, Sexuality, and Ethnicity in Communication Commons, Geriatric Nursing Commons, Gerontology Commons, Health Economics Commons, $\underline{\text { Health Policy Commons, Marriage and }}$ Family Therapy and Counseling Commons, Other Social and Behavioral Sciences Commons, Place and Environment Commons, Policy History, Theory, and Methods Commons, Public Policy

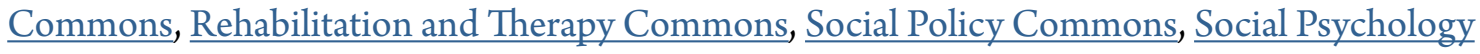
$\underline{\text { Commons, }} \underline{\text { Social Psychology and Interaction Commons, Social Welfare Commons, and the Social }}$ Work Commons

\section{Recommended Citation}

Oak, Charles Shawn, "A phenomenological study of anticipated intimacy and sexual expression needs of aging male and female baby boomers." (2015). Electronic Theses and Dissertations. Paper 2323.

https://doi.org/10.18297/etd/2323

This Doctoral Dissertation is brought to you for free and open access by ThinkIR: The University of Louisville's Institutional Repository. It has been accepted for inclusion in Electronic Theses and Dissertations by an authorized administrator of ThinkIR: The University of Louisville's Institutional Repository. This title appears here courtesy of the author, who has retained all other copyrights. For more information, please contact thinkir@louisville.edu. 
A PHENOMENOLOGICAL STUDY OF ANTICIPATED INTIMACY AND SEXUAL EXPRESSION NEEDS OF AGING MALE AND FEMALE BABY BOOMERS

\title{
By
}

Charles Shawn Oak

A.G.S. Indiana University Southeast, New Albany, Indiana 1991

B.G.S. Indiana University Southeast, New Albany, Indiana 1993

M.S.L. Louisville Bible College, Louisville, Kentucky 2001

M.S.S.W. University of Louisville, Louisville, Kentucky 2006

\author{
A Dissertation \\ Submitted to the Faculty of the \\ Raymond A. Kent School of Social Work \\ In Partial Fulfillment of the Requirements \\ For the Degree of \\ Doctor of Philosophy \\ in \\ Social Work \\ Raymond A. Kent School of Social Work \\ University of Louisville \\ Louisville, Kentucky \\ and \\ College of Social Work \\ University of Kentucky \\ Lexington, Kentucky
}

December 2015 
Copyright by Charles Shawn Oak 2015

All Rights Reserved 



\title{
A PHENOMENOLOGICAL STUDY OF ANTICIPATED INTIMACY AND SEXUAL EXPRESSION NEEDS OF AGING MALE AND FEMALE BABY BOOMERS
}

\author{
By
}

Charles Shawn Oak

A.G.S. Indiana University Southeast, New Albany, Indiana 1991

B.G.S. Indiana University Southeast, New Albany, Indiana 1993

M.S.L. Louisville Bible College, Louisville, Kentucky 2001

M.S.S.W. University of Louisville, Louisville, Kentucky 2006

A Dissertation Approved on

August 10, 2015

By the following Dissertation Committee

Anita P. Barbee, Ph.D., Dissertation Chair

Thomas Lawson, Ph. D.

Bibhuti K. Sar, Ph. D.

Leslie Harris, Ph. D.

Natalie D. Pope, Ph.D., University of Kentucky 


\section{ACKNOWLEDGEMENTS}

The doctoral education process is an adventurous journey on its own without the rocky roads, detours, and sudden left turns that appear and attempt to block us from completing the journey and at minim takes on detours that take as far away from the path we began and visualized. Fortunately, I had the fortune of selecting a tremendous mentor and dissertation chair, Dr. Anita P. Barbee, Ph. D. who helped me navigate those some very difficult times due to health, injury, and personal life crisis that kept me on going in the direction of the goal at the end of the journey. Without her confidence and understanding of how my way of being sometimes gets in the way of my success, I'm not sure that I could have finished this process to completion.

I wish to share my heartfelt thanks to you Dr. Anita P. Barbee.

I would also like to thank participants in this study who blessed me and gave me the privilege of being a witness to a very private area of their lives. It was truly an honor and indescribable gift. This individuals and the Baby Boomer generation as a whole ,who's numbers and personality as a cohort motivated me to research how intimacy and sexual expression is understood across the lifespan in this generation Without whom, this study would not have been possible. 


\begin{abstract}
A PHENOMENOLOGICAL STUDY OF ANTICIPATED INTIMACY AND SEXUAL EXPRESSION NEEDS OF AGING MALE AND FEMALE BABY BOOMERS

Charles Shawn Oak
\end{abstract}

August 10, 2015

The purpose of this study was to understand the phenomenon of how heterosexual Baby Boomers define and understand intimacy, sexual expression, along expectations and desires relating to their respective expressions across the lifespan through their individual experiences and reflections. A set of guiding questions were used in a hermeneutic phenomenological qualitative research design. Data was gathered from thirteen subjects ( $n=13$ ) using the Rappaport Time Line (RTL) that was used to develop individualized semi-structured interviews and follow-up interviews that were professionally transcribed. These were coded to identify emergent themes. Results of the study provided insight into the phenomenon of how heterosexual Baby Boomers define and understand intimacy, sexual expression, expectations and desires relating to their respective expressions across the lifespan. 


\section{TABLE OF CONTENTS}

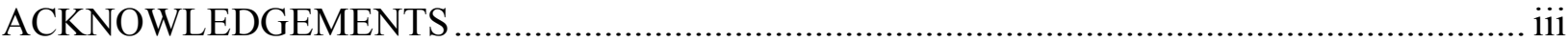

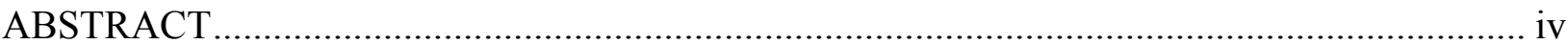

CHAPTER 1 STATEMENT OF THE PROBLEM ............................................................

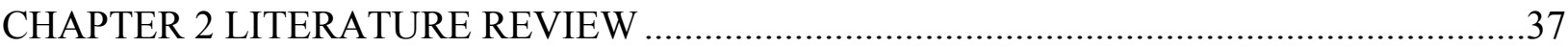

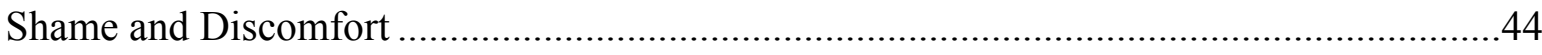

Legal obligation to prevent sexual abuse ................................................................44

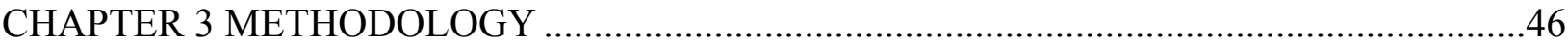

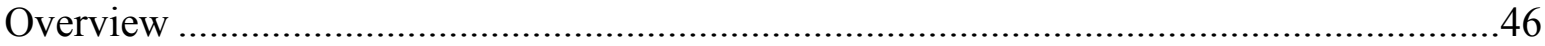

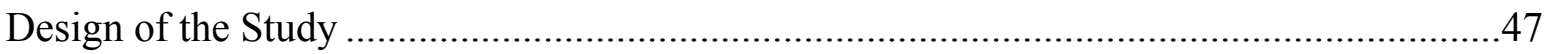

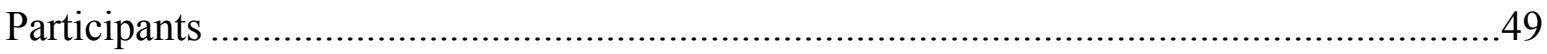

Ethical Considerations .......................................................................................... 51

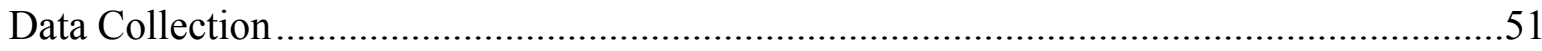

Instrumentation: Rappaport Time Line ......................................................... 51

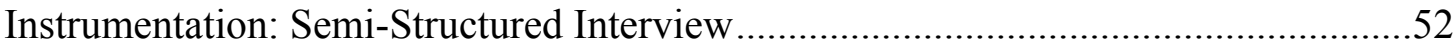

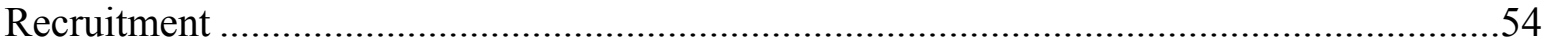

Theoretical and Conceptual Framework ......................................................................56

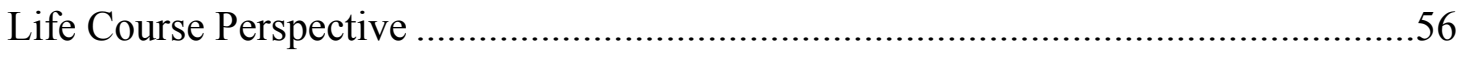

Regional Description and Demographics .................................................................58

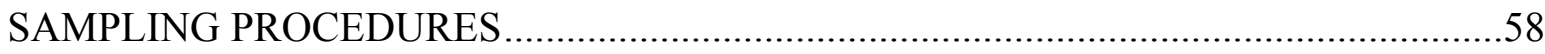

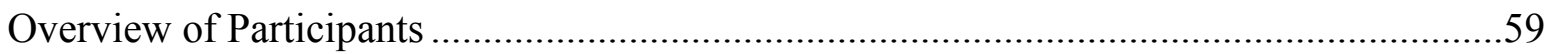

Individual Participant Descriptions .........................................................................6

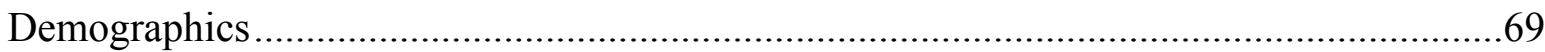

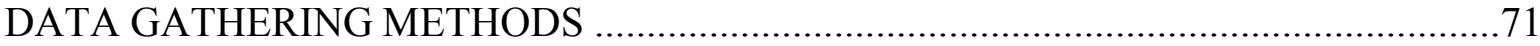




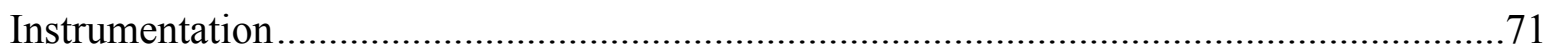

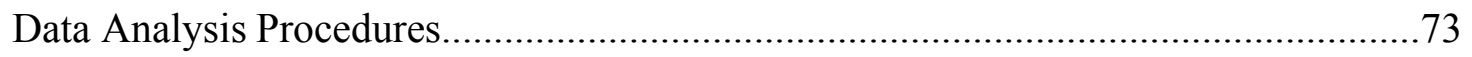

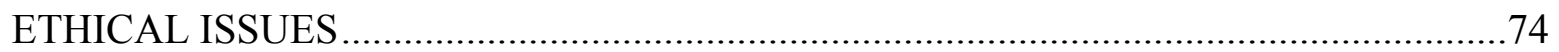

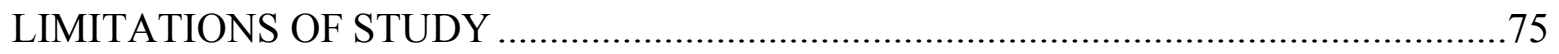

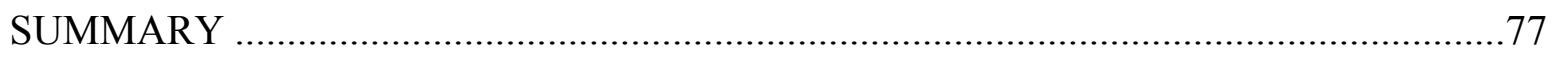

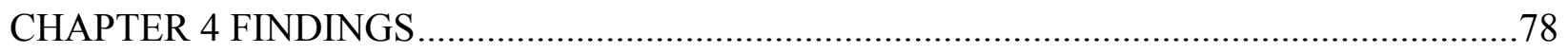

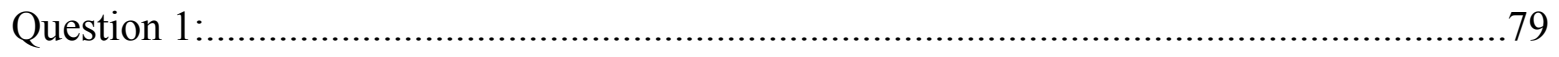

How do aging heterosexual baby boomers define intimacy and sexual

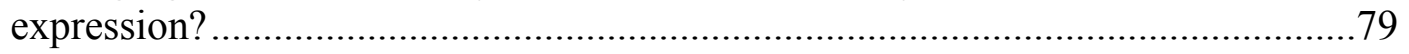

Change in views about intimacy and sexual expression over time. ......................................8 80

Viewed intimacy and sexual expression as different ………...............................................81

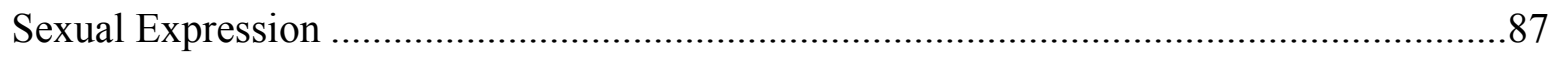

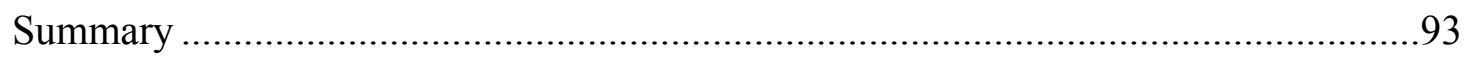

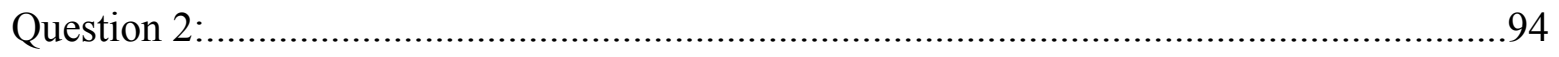

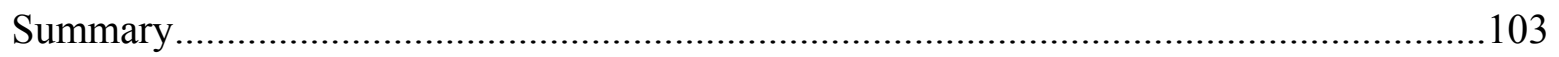

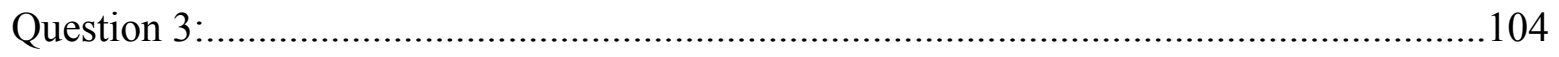

How do Baby Boomers envision defining/expressing intimacy in the future? ...................104

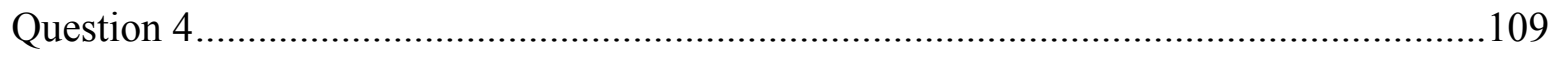

What is the intimacy and sexual expression concerns of Baby Boomer males and

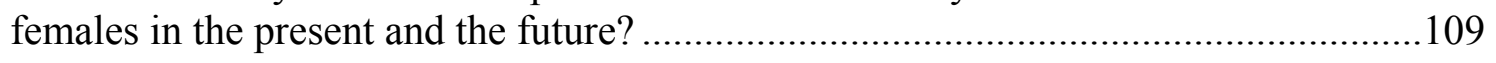

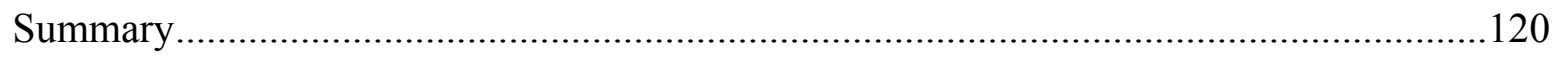

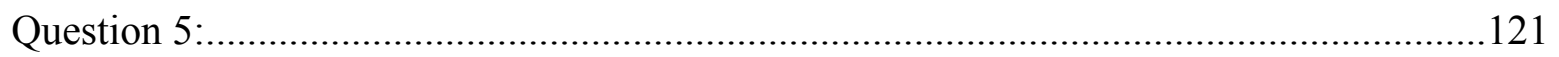

What major concerns do older adults share related to the intimacy and sexual expression issues surrounding their aging including long-term care needs in the future, and the thoughts that aging men and women have about solutions that address their major concerns?

Part 1 
Sexual Expression Has/Will Diminish

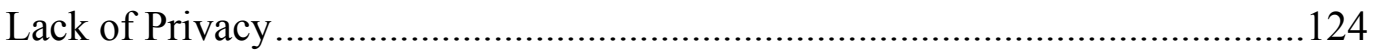

Part 2

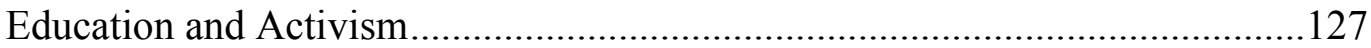

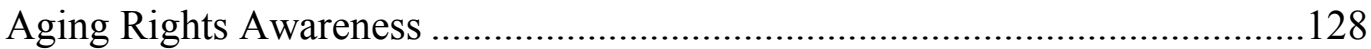

Baby Boomer Accommodations...........................................................................130

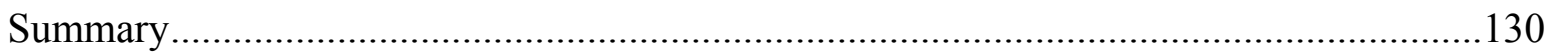

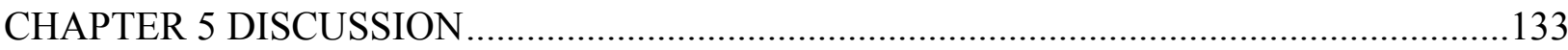

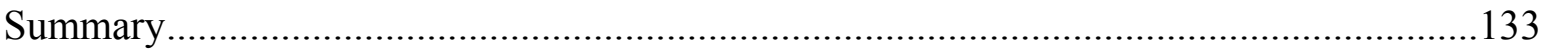

Hermeneutic Phenomenology …………………………..........................................134

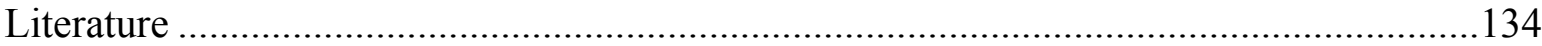

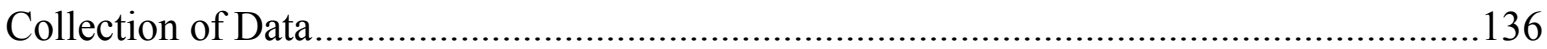

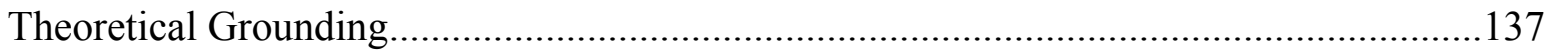

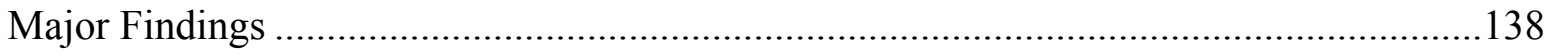

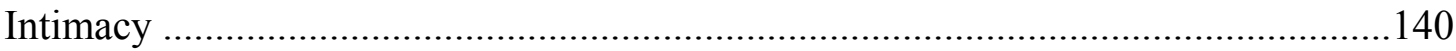

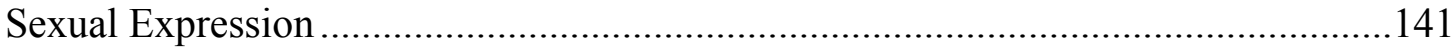

Baby Boomer definitions of intimacy and sexual expressions influenced by

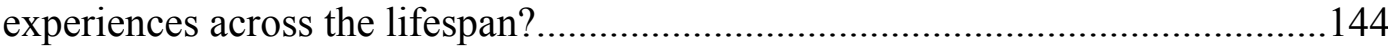

Baby Boomers Future Definition of Intimacy and Sexual Expression ........................146

Baby Boomer Intimacy and Sexual Expression Concerns: Present and Future...........148

Importance of Intimacy Exceeds Sexual Expression...........................................148

Baby Boomer LTC Intimacy and Sexual Expression Concerns ...................................151

Baby Boomer LTC Solutions.................................................................................152

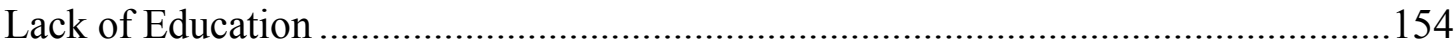

Participant Recommendations for Change ……………................................................157 


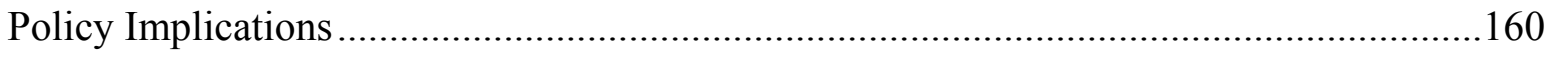

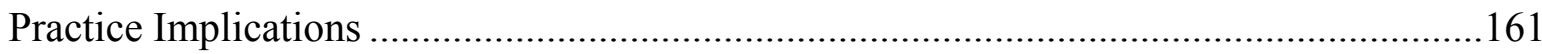

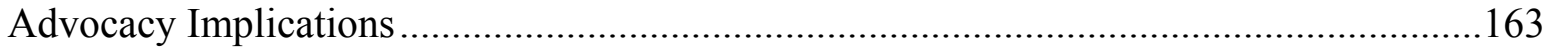

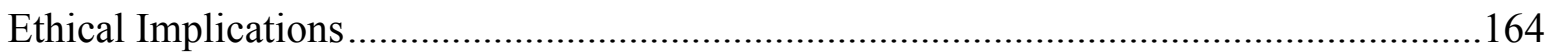

Next Steps for the Field for Research..............................................................................165

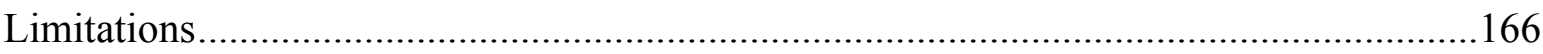

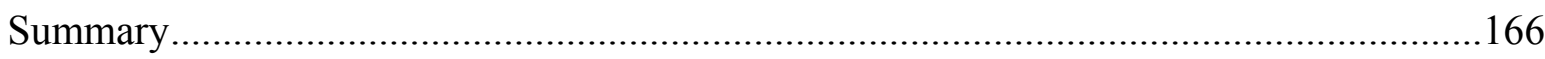

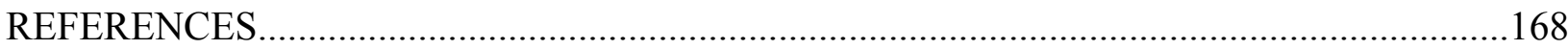

APPENDIX A University of Louisville Institutional Review Board .........................................195

APPENDIX B Recruitment Flyer...................................................................................197

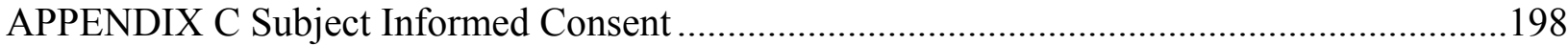

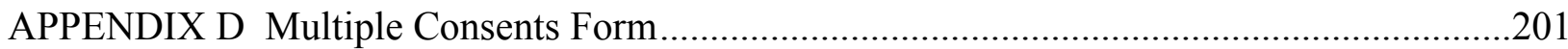

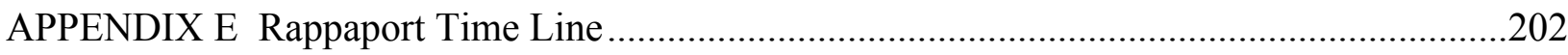

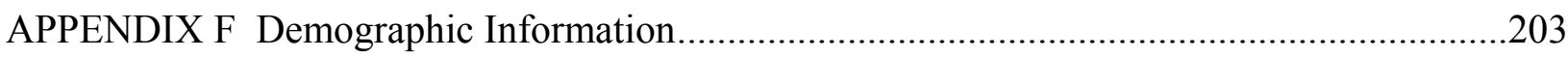

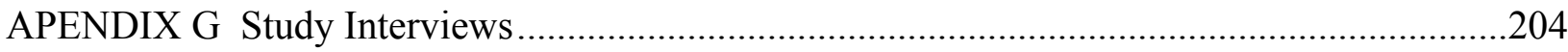

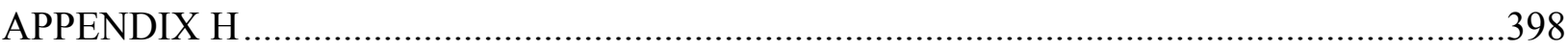

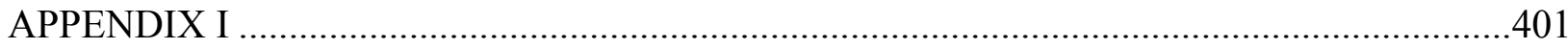

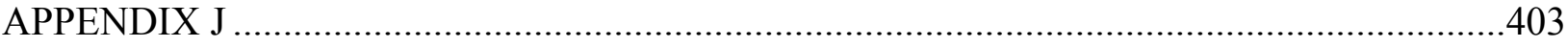

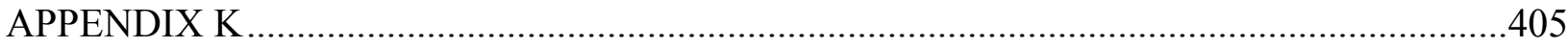

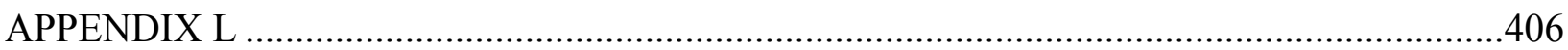

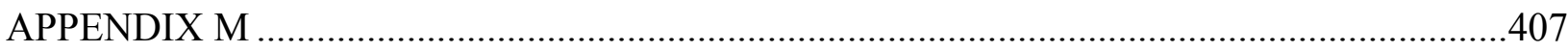

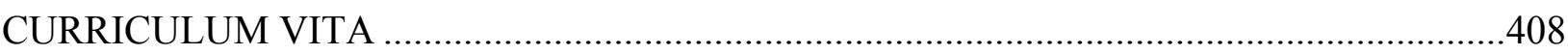




\section{CHAPTER 1}

\section{STATEMENT OF THE PROBLEM}

This chapter begins with a brief historical overview of the Aging of Americans including demographic statistics over time as they relate to long-term care. Specifically addressed will be the anticipated affects that this large influx of Baby Boomers will have on existing eldercare systems in the United States. The nature of the Baby Boomer generation will be discussed, including their accomplishments, view of themselves, ideas and beliefs around sexuality, involvement in social change, and how these are likely to generate strong interest and importance around equality and elder rights. Further, questions will be generated around what is not known, particularly, what they anticipate as they consider their long-term care needs as they look into their future. The implication for assisted living and long-term care as Baby Boomers enter this life stage will be considered, around intimacy, (specifically sexual expression) including defining intimacy, the need for intimacy, and a place for intimacy for residents. Further, discussion around how existing long-term care facilities are currently meeting the intimacy needs of their residents, including the allowance, facilitation, and time available for residents to engage in legal, consensual, sexual expression, along with issues surrounding intellectual capacity and consent is explored.

Current policies concerning self-determination, privacy, intimacy and sexual intimacy in long-term care will be discussed. These will include both federal and state regulations along with professional standards from various professions involved with the management and provision of long-term care services, and how they currently or could in 
the future, influence the policies and practices of long-term care facilities. Additionally, the potential impact of the Baby Boomers on policy and practice at the federal, state, and professional level will be discussed; specifically, how laws and policies are interpreted, along with the implementation of these interpretations in terms of procedures.

While policy is a vital aspect of any issue affecting any group of people, the ethics of these policies should not be understated. Therefore, a discussion around the ethics of current policies, laws, and procedures as they relate to the need for intimacy, (specific to sexual expression) for residents in long-term care, are included as well as a discussion of questions related to the ethical dilemmas that arise. Further, existing policies and procedures addressing intimacy, specific to sexual expression of residents in long-term care will be considered along with literature that is relevant to ethical dilemmas along with any research that comes to bear on how ethics, values, and competing values come into play around issues of self-determination, privacy, need for intimacy, and sexual expression.

As important as ethical considerations are in the development of new and within existing policy, how they, along with other factors are interpreted and understood could drive future policy and procedure decisions that affect practice in long-term care settings. Therefore, it is important to identify and apply theoretical approaches through which to interpret and gain a better understanding of how the existing policies are understood and applied. Three theoretical approaches are identified and each is discussed with regard to their selection along with the anticipated information that each will extract from the data gathered through research projects. 
Following the discussion of theoretical approaches, a review of the current research literature found on the issues of sexual intimacy in long-term care will be provided. The review will address issues around sex and aging, the effect of the Baby Boomers and the sexual revolution of the $60 \mathrm{~s}$ and 70 s, the current practices and procedures surrounding sexual expression in long-term care, how and why they vary, and how they are or are not influenced by existing federal and state policy. Issues that have been raised by other advocates and researchers will be discussed as well as what gaps exist in the literature and what information will be important to know as the Baby Boomers age.

The information gained from the literature review along with the identification of information that will be important to gather in preparation for the aging Baby Boomers, will provide the foundation for a research agenda to address the issues around sexual intimacy for residents in long-term care. In this section, a potential line of research will be presented along with a research design to explore the sexual intimacy expectations and desires of the Baby Boomers as they consider long-term care.

The chapter will conclude with a discussion of the implications of what is known about the problem from the existing data, considering context, policy, and ethics. In addition, the implications of the applied theoretical perspectives, literature, and findings of the research on the field of social work as well as other long-term care disciplines engaged in long-term care are presented. Lastly, expectations of issues around sexual expression in long-term care will be addressed, possible preparation to address these and a vision for the next steps for this line of research. 


\section{Study Background}

\section{There's Something Happening Here}

Between 1900 and 2000, the population of the United States tripled. Yet, until recently, the growth rate of those ages 65 and older exceeded that of the total population (Hobbs \& Damon, 2015). While the rate of growth of those age 65 and older has slowed in the past few years, Baby Boomers (1946-1964), the radical revolutionaries of the 1960s, are expected to begin crashing into the U.S. with the first wave of a tsunami of unparalleled proportions. Beginning in February 2011, the first wave of 3.2 million Baby Boomers reached age 65 , becoming eligible for full social security retirement and Medicare benefits (Wolf, 2007). The population of those age 65 and older is expected to reach 70 million by 2030 with nearly 8.5 million age 85 years and older, expected to climb to 18 million, possibly as high as 27 million by 2050 (United States, 2002). The growth rate of this population of aging Americans and the demands it will place on aging services is not fully known. It is anticipated, however, that if current nursing home use rates continue, roughly 3 million individuals will be residents of $U$. S. nursing homes by the end of the next 15 years (Gabrel, 2000). Compounding the emergent long-term care needs of this population is their 60 plus year history influencing every aspect of U.S. society.

From their appearance beginning in February 1946 through the present, this anomaly of U.S. population trends has undergone scrutiny from nearly every imaginable perspective. Baby Boomers' sheer numbers along with refusing to accept the status quo of the social and political system during the 1960s and 70s, and the Baby Boomers' 
distrust of "the man," (representative of any authority perceived to be oppressive) (Stills, 1966, track 1) shook the U.S. political establishment to its core. They fought against the Vietnam War, for women's rights, for a reduction of the age of voting eligibility from 21 to 18 and won, adopted and promoted a new genre of music, helped repeal segregation, supported the Civil Rights Movement, understood the power of collective organization and applied it, irreversibly changing the face of U.S. socio-political culture. Moreover, this generation of Americans rebelled against the sexually repressive mores held by their parents along with the prevailing anti-sexual cultural mores originating from the nation's Puritan ancestors (Goodson, 1991). This group not only generated the slogan, "Make love, not war" they lived it by experimenting and promoting the concept and practice of free love, rejecting what they perceived as the sexual banality of their uptight parents.

This liberated view of sexuality not only promoted a sexual revolution, it was further fueled by the growing availability of "the pill," a new method of birth control that gave women more control over their fertility. This new form of birth control provided the ability to space births or postpone pregnancy. Thus, creating an environment where they were freer to pursue higher education or a career (Katz, 1988). The actions of the Baby Boomers in the 60s and 70s appeared to be the result of a movement for change. This change, for the most part, resulted in positive and unintended outcomes resulting from the Boomer's activities directed toward the assurance of a brighter future (Wattenberg, 2007). It is this drive for the assurance of a brighter future that suggests that Boomers will rebel against the sexually repressive policies and practices employed 
by the owners and administrators of long-term care facilities, whether overtly or covertly enforced.

Since this group had little difficulty challenging the prevailing anti-sexual cultural mores of the $60 \mathrm{~s}$ and $70 \mathrm{~s}$, there is little to suggest that they will have any difficulty in challenging the prevailing anti-sexual cultural mores that strongly discourage sexual activity among residents of long-term care facilities, despite the protections included in federal law (Omnibus Budget Reconciliation Act, 1987). This law along with other laws enacted at the state level, allows residents of long-term care facilities the right to privacy for intimate relationships, including sexual intimacy. In our society, adults have a right to engage in legal and consensual sexual relationships with other adults (Penner, 1991). However, health care institutions, including hospitals and long-term care facilities, seem to discourage rather than encourage or support the sexual intimacy of the residents. Whether overtly or covertly, the intimacy and sexual expression needs of older people has been devalued in western culture (Brown, 1989; Cameron, 1970; "Denial of Residents'," 1995; Dupras \& Poissant, 1987; Pfeiffer \& Wang, 1968; "Staff Should Accept," 1995). McKinley and Drew (1977) Assigned responsibility for the death of sexual expression to long-term care facilities, and Kassel (1983) wrote that these facilities produce "a serious destructive effect on sexuality" (p. 168).

Boomers as a cohort during the 60 s and 70 s were not focused on breaking the rules or rocking the boat for the sake of change, as much as they were resisting and overturning barriers to self; barriers, which they viewed as erected by their parents and imposed by society at-large, inhibiting their ability to freely experience life. Just as they 
resisted and overturned barriers to self irreversibly during the $60 \mathrm{~s}$ and $70 \mathrm{~s}$, Boomers more than any other generation, will shape the future of aging services and long term care.

\section{Post W.W.II Population}

\section{Baby Boomers (1946-1964)}

There is no universal agreement about the chronological parameters that identify the Baby Boomers as a generation among demographers. However, the U.S. Census Bureau, (2006) has defined the period between January 1, 1946 and December 31, 1964, as the Baby Boom generation. The period following World War II, between 1946 and 1966 saw the birth of 76 million Baby Boomers, representing the largest single sustained population growth in the history of the United States. It has and continues to be the most analyzed and scrutinized generation in the United States (Gillon, 2004).

The booming post-World War II economy nurtured the belief that all things were possible, with a great many Boomers growing up with a vision of unlimited opportunity. As a group, Boomers had a cultural experience shared across the nation through the new medium of Broadcast television. This new medium not only created an environment of shared experience through its programming with the feel good television shows such as Father Knows Best and Howdy Doody, it also stunned the nation by bringing race riots and the Vietnam war into the living room of nearly every home. Additionally, Boomers experienced a new approach to child rearing that placed emphasis on the child's needs, first nurturing independent thinkers and a drive for self-fulfillment, the latter being a characteristic for which this cohort has oft been criticized. Yet, with a cohort composed 
of 78 million in the workplace with whom they must compete, Boomers are not entirely hedonistic- defining themselves by their work.

According to the Del Webb 2010 Boomer Survey, (2010) Boomers believe that old age officially begins at 80 , their mental attitude makes them feel much younger, the difference between their real and perceived age grows, more than $50 \%$ of the participants exercise regularly, and consider health care access and cost of living more important in their migration patterns than warm climate. The migration findings of this survey contradict U.S. Census Bureau migration predictions. The U.S. Census Bureau (2005) report states that Boomers are likely to continue the preference of relocating to warm climates for retirements, suggesting that by 2020 , Florida would replace New York as the third most populated state, with Georgia moving into fifth place over Illinois and Nevada shifting from $29^{\text {th }}$ to $16^{\text {th }}$.

In 2006, Baby Boomers age 42 to 60 totaled an estimated 78.0 million and comprised 26.1 percent of the total U.S. population. The sex ratio for Baby Boomers was $96.4 \%$, meaning that there were that there were approximately 96 male Baby Boomers per 100 female Baby Boomers. The marital status of Baby Boomers indicated that 65.6 percent are married, 2.7 percent were widowed, 17 percent were divorced, 3.0 were separated, and 11.7 percent have never married. Lastly, Boomers as a generation have higher levels of education, with 28.8 percent completing a bachelor's degree, 28.9 percent with some college, 29.8 percent completing high school, and 12.5 percent with less than a high school education (U.S. Census Bureau, 2006). 


\section{HISTORICAL CONTEXT}

According to the National Center for Health Statistics, the risk of nursing home placement increases with age. Thirty-one percent of those who are severely impaired and between the ages of 65 and 70 receive care in nursing homes compared with $61 \%$ of those aged 85 and older (Gabrel, 2000). In 2004, estimates suggest there were 1, 317,200 people age 65 or older living in nursing homes nationally. Of the population aged 65 and over in $1999,51 \%$ of the nursing home population was aged 85 or older compared with $36 \%$ age $75-84$, and $13 \%$ aged $65-74$. Between 1985 and 1999 the number of adults age 65 and older living in nursing homes increased from 1.3 million to 1.5 million (National Center for, 2007). February 2008 witnessed the first wave of the 3.2 million baby boomers generation (1946-1964) who will turn age 62 and eligible for early Social Security retirement benefits. In 2011, this beginning wave will turn age 65 and will be eligible for Medicare (Wolf, 2007). By the year 2030, 70 million people in the United States will be 65 years old and older and nearly 8.5 million will be 85 years or older. If current nursing home use rates continue, there will be roughly three million residents in nursing homes by the end of the next 22 years. These will nearly double the number currently living in nursing homes. Not only will the existing long term care facilities be taxed for space, the cost of providing care for this generation will be staggering (United States, 2002).

Historically, people in the US, including caregivers, have held a view that the older adults, and especially residents of nursing homes, no longer have any interest in sexual expression. In addition, over the years, health care institutions, including hospitals 
and long-term care facilities, seem to discourage rather than encourage or support intimacy and sexual expression of the residents. Societal myths regarding sexual behavior of aging Americans generate false ideas in American culture and many people are shocked to learn that older Americans still have sexual needs and that sex is not just for the young (Hillman \& Stricker, 1994; Kessel, 2001; Pangman \& Sequire, 2000; Woodard \& Rollin, 1981). Along with this misconception comes the belief that seeking sexual fulfillment while living in a long-term care facility is somehow immoral or even illegal. The right to sexual expression does not change simply because an individual lives in a nursing home or assisted living facility.

Sexual expression of older people has been devalued both overtly and covertly through the influences of owners, administrators, staff, and the family members of consumers (Brown, 1989; Cameron, 1970; "Denial of Residents," 1995; Dupras \& Poissant, 1987; Golde \& Kogan, 1959; Pfeiffer, Verwoerdt, \& Wang, 1968; "Staff Should Accept," 1995). McKinley \& Drew (1977) assigned responsibility for the death of sexual expression to long-term care facilities, while Kassel (1983) wrote that these facilities produce "a serious destructive effect on sexuality" (p. 168). Though a significant amount of time has passed since publication of most of these studies, progress to accommodate, support, or facilitate intimacy and sexual expression among older people in long-term care has been negligible. Roach (2004) found that sexual expression by residents and responses of staff were influenced by the staff's level of comfort related to sexuality issues, "and the ethos of the organization where they worked" (p. 371). The study concludes that management and staff need to work collectively to develop an 
environment that is supportive of residents' right of sexual expression and promotes a culture in which all people involved become comfortable with issues related to sexuality (Roach, 2004). Many long-term care facilities keep residents' doors open most of the day. Further, differing ideas are held by residents and staff defining acceptable sexual behaviors for older adults. Long-term care staff may discourage intimacy and sexual expression by separating residents by sex, barring sexual activity, or belittling residents' relationships (Low, Lui, Lee, Thompson, \& Chau, 2005).

Because of these findings, and in preparation for the first wave of Baby Boomers entering long-term care, it is essential that collaboration between policy makers, owners, administrators, consumers, family members, and professional disciplines in the field of gerontology occur. The focus of this collaboration is to develop universal policies and models of practice to address the intimacy and sexual expression needs and demands of this aging cohort.

\section{Aging Boomers Effects on the Health Care Systems}

Since the Baby Boomers reached age 65 in 2011, they are expected to have the same kinds of effects on the health care system as they have had on other parts of society. By the time the youngest baby-boomer reaches 65 in 2030, health care needs, social service needs, homecare, assisted-living, and residential long-term care facilities, we will have experienced the full effect of this enormous wave. The health care system must begin preparing to meet the needs and the demands of the boomers. There will not only be more of them, they will be older than previous generations entering this life stage. By 2030, life expectancy for women will be approaching 90 and life expectancy for men will 
be approaching 80 . Moreover, an increase in life expectancy is inevitably accompanied by an increase in disability along with a decline in health status and quality of life (Siegal, 1996).

Unlike past generations, Boomers might not have the luxury of turning to their informal support system of adult children, other relatives, friends and neighbors, (historically women) when they develop disabilities. While it is possible that the utilization of informal support systems will continue, size and structural changes of families, along with an increase in the number of women in the workforce is likely to affect the availability of informal supports (Arno, 2002; Family Caregiver, 2001 National Alliance, 1997). The level of influence these changes will have on the existing health care system is unknown. It is certain, however, that health care services and infrastructure for older people must expand in response to the overwhelming number of Boomers entering this phase of the life span as well as identifying and implementing programs and policies that are attractive to this population.

An inescapable truth the existing health care system must face is that consumerism will play an even larger role in the choice of care options as the Baby Boomers, with their history of individualism, flood the elderly health care system. Unlike the Silent Generation, Boomers are accustomed to being the target population of Madison Avenue and will expect health care providers at all levels to provide programming, services, and amenities to attract their business (Gillon, 2004; Langer, 2009). Educated guesses can be made regarding some of the expectations of the Boomers, yet nothing is known about their wants and desires regarding intimacy, 
specifically, sexual expression in long-term care. If, in fact, the best predictor of future behavior is past behavior, society can be confident that when it comes to intimacy and sexual expression, Boomers shall, "Rage, rage against the dying of the light," resolving to “... not go gentle into that good night," (Thomas, 1971, p. 122) when they enter longterm care.

\section{The Nature of the Baby Boomers \\ First to Do Many Things}

As a generation that came of age during the 1960s, the Baby Boomers are a generation of firsts. Boomers were the first generation reared with television; adopted and expanded a new style of music to express their generational identity with rock and roll Boomers are the first to not only challenge the mores of the past, they fundamentally changed and transformed them. In addition, they promoted social justice and social conscience as a movement, and ushered in the sexual revolution. The efforts of this generation helped expand individual freedoms, including civil rights, the feminist cause of the 1970s, rights for the disabled, gay rights, and advanced the right to privacy (Schuman \& Scott, 1989).

Baby Boomers are redefining what it means to be "old", which used to mean reaching the age of 50. The first wave of boomers is already well past this former benchmark that used to define old. Thus, they do not view themselves as getting older, and causes motivate them; they expect to continue to be active participants in society. Mary Furlong, founder of Thirdwave.com, notes that Boomers have a sense of being trendsetters and innovative in their own way (Voight, 2000). Given the significant 
impact that this generation has had on social and civil policy in the U.S. and throughout the world, it is reasonable to expect this generation will exert as much, if not more energy continuing to drive change. Change, through longevity and diversity to secure their desired quality of life including intimacy and freedom of sexual expression within longterm care facilities, as they enter this phase of human development.

\section{IMPLICATIONS FOR ASSISTED LIVING AND LONG-TERM CARE}

\section{Defining intimacy}

Intimacy, as a complex and heterogeneous concept, has generated an assortment of definitions. Intimacy, as is used in the common vernacular, is often used interchangeably with sexual expression. Yet, sexual expression is only one of many manifestations of intimacy within relationships. Intimacy is exposing one's innermost being, or essence. It is the revelation of one's authentic self as it relates to one's strengths, vulnerabilities, weaknesses, competencies with others, singularly or within a group (Erber \& Erber, 2001; Frank, 1996; Lerner, 1990; McAdams, 1989; Piorkowski, 1994; Sternberg, 1987; Weingarten, 1992). Intimacy is not only the exposure of one's innermost being; it is the experience of encountering the wholeness or the recognition of

the innermost nature of another person. It is more akin to the process of inserting oneself into another person's reality; risking change by that experience, than merely absorbing them into oneself (Bennett, 2000; Dowrick, 2002; Tolstedt \& Stokes, 1983; Wilner, 1982). While all of these definitions provide strong contributions toward a definition of intimacy, Waring (1981/1988,) in his definition of marital intimacy as, " a multi-faceted interpersonal dimension which describes the quality of a marital relationship at a point in 
time" (p. 23) best aligns with my own term and working definition of holistic intimacy: A dynamic, multi-tiered, multi-faceted, multi-dimensional morphogenic interaction between human beings, mutually influencing each other on a linear, multi-causal, multieffect continuum of relational facets through which they expose their authentic selves to be fully known, seeking to fully know another.

\section{The need for intimacy}

Intimacy, including sexual expression, is a human need. Multitudes of studies have found that intimacy contributes to well-being and overall quality of life. Intimate relationships have been found to have a positive effect on health and longer life (Berkman, 1995; Giles, Glonek, Luszcz, \& Andrews, 2005; Zeis \& Kasl-Godley, 2001). In a study conducted by Miller \& Lefcourt, (1983) participants lacking intimacy during the study had a predisposition toward experiencing emotional disturbances. Moreover, intimacy aids in the reduction of stress, specifically through physical contact such as hugging and holding hands. These behaviors assist in the release of oxytocin, a hormone produced by the brain found to be associated with pair bonding, social memory, and mate guarding, resulting in a variety of health benefits (Grewen, Girdler, Amico, \& Light, 2005). A study of males in a Virginia long-term care facility reported that social intimacy was most important to them. Emphasis was placed on finding with whom they might share their interests. The male participants also reported that satisfaction with their lives while residing in long-term care was associated with the ability to have intimate social, physical, and intellectual relationships (Bullard-Poe, Powell, \& Mulligan, 1994). Despite the psychosocial and health benefits of intimacy, specifically sexual expression 
in long-term care, several impediments have been identified that include: illness, medication, lack of partners, separation from spouse/partner, staff attitudes, mental illness, family member attitudes, self-image, physical sexual health, and privacy (Hajjar \& Kamel, 2003; Parker, 2006).

\section{Place and time for intimacy}

A significant impediment to intimacy and sexual expression for residents/patients in long-term care is privacy (Bauer, 1999; Kaas, 1978; McCartney, Izeman, Rogers, \& Cohen , 1987; Mulligan \& Palguta, 1991; Starr \& Weiner, 1981; Szasz, 1983; Wasow \& Loeb, 1979; White, 1982). Lack of privacy includes such issues as the lack of freedom to secure the door to their rooms, staff entering without knocking, shared rooms, and privacy of information of a the resident's/patient's intimate life and relationships (Bauer, 1999; Edwards, 2003; Rheaume \& Mitty, 2008). Further, Hajjar \& Kamel, (2003) suggest that privacy of time is often overlooked as a "constricting factor", (p. 578) due to the highly regulated scheduling of long-term care facilities that limit the opportunities for intimacy to predetermined periods of the day.

While there seems to be some movement toward making allowance and facilitating intimacy, including sexual expression in long-term care facilities, it is just getting started. The Hebrew Home for the Ages, in Riverdale, NJ, who developed policies and procedures to meet the intimacy and sexual expression needs of their residents in 1995, continues to lead the nation on this issue (Miles \& Parker, 1999; Sisk, 2009). Although efforts to educate and train long-term care staff to accommodate and facilitate intimacy and sexual expression is beginning to occur, change appears to be 
slow. A significant challenge to the forward progress of long-term care facilities to meet intimacy and sexual expression needs centers around dementia's effect on capacity and consent (Kamel \& Hajjar, 2004; Kirkland \& Seal, 2008; Mayer, 1998).

\section{CURRENT POLICIES}

\section{Self-Determination, Privacy, Intimacy, and Sex in Long-term Care}

Intimacy and sexuality are basic human needs that are often overlooked in discussions about well-being and quality of life of residents of nursing homes, long-term care institutions, assisted living centers, and other types of residential care environments. Numerous studies support the conclusion that older men and woman continue to have sexual interests and remain sexually competent into their 80 s and 90 s (White \& Catania, 1982). Sexual identity intermingles with one's self-worth; denying sexuality can destructively affect self-image, mental health, and social interactions and one's sex life (Kamel \& Hajjar, 2004).

\section{OBRA 1987}

The Nursing Home Reform Act (NHRA), part of the Omnibus Budget Reconciliation Act of 1987(OBRA 1987), requires nursing homes to "promote and protect the rights of each resident" and places a strong emphasis on individual dignity and self-determination (Nursing Home Reform, 1988, P. 17). Thus, a person living in a longterm care facility maintains the same rights as a person living in the community. Yet, many long-term care facility owners, administrators, and staff members both overtly and covertly, discourage intimacy and sexual expression between residents citing such issues as liability, space limitations, bed size, staff morals and values, and the resident's familial 
objections (Brown, 1989; Dupras \& Poissant, 1987; McKinley \& Drew, 1977; Parker, 2006). While resident safety is a concern and evaluating consent might prove challenging with those residents experiencing dementia, long-term care facilities who have adopted policies and practices (covertly or overtly) to discourage intimacy and sexual expression are violating and ignoring resident rights of self-determination, privacy and confidentiality, dignity, respect, and freedom specified in the NHRA (Nursing Home Reform, 1988).

\section{States and Resident/Patient Rights}

Resident/patient rights laws and regulations, beyond those enumerated in OBRA 1987, are as varied as there are states. Kane \& Cutler, (2007) report that states differ significantly with regard to specificity, length, accessibility, and organization. The study also found that most are filled with cross references to other state statutes and regulations that address these services, rights, reporting, and safety codes. Further, these researchers noted that while state laws and regulations differ, they are also more specific and prescriptive than the federal laws and regulations of OBRA 1987.

While state laws and regulations are more specific and prescriptive, the lack of a national universal understanding and application suggests that the ambiguity of the language contained in the provisions of OBRA 1987 contributes to the different interpretations and applications. Of interest is the finding that myths and erroneous beliefs have been a source of restrictions placed on nursing home residents rather than any existing statues or regulations (Kane \& Cutler, 2007). Adding further confusion to the ambiguous nature of the language contained in OBRA 1987 are contradictions as they 
relate to provisions calling for resident choice and individualization in contrast to others requiring protocols for safety. Repeatedly, even when state laws and regulations interfered with resident choice, regulators ruled that those states were within their rights to make "more precise safety rules than were federally required—even though these rules interfered with resident choice" (Kane \& Cutler, 2007, p. 8). Laws related to intimacy and sexual expression also differ among the states.

\section{Laws Specific to Sexual Expression}

States vary in, if, and how they address intimacy and sexual expression for residents/patients of long-term care facilities. Eighteen states (Alaska, Colorado, Delaware, Idaho, Illinois, Iowa, Kentucky, Maryland, Michigan, Mississippi, Missouri, New Jersey, New Mexico, North Dakota, Rhode Island, South Carolina, Virginia, and Wisconsin) clearly address the issue of married couples sharing rooms or having conjugal visits. Only four states (Colorado, New Jersey, Rhode Island, Vermont) use language that recognizes other kinds of partnerships and the possibility of sexual relationships with someone other than a spouse. These include sexual relationships between persons of the same gender. Only Colorado clearly recognizes the right of long-term care residents/patients to "private consensual sexual activity" (para. 30) regardless of marital status (NH Regulations Plus, 2009).

\section{PROFESSIONAL STANDARDS: POTENTIAL BEARING ON LTC}

Beyond federal and state policies, laws, and regulations, there are the professional standards or ethical codes established by each discipline's professional organization that influence or should influence the interactions, decisions, and practices of the 
representatives of their respective professional associations as they work with the resident/patients of long-term care. The disciplines chosen are those involved in policymaking or the application of policy within the long-term care facility that affect the residents/patients include:

- The American College of Health Care Administrators (ACHCA)

- American Medical Director's Association, (AMDA)

- American Nursing Association, (ASA)

- National Federation of Licensed Practical Nurses, (NFLPN)

- National Association of Social Workers (NASW)

The respective codes of ethics of each of these professional associations are compared with each the four identified areas of policy identified as self-determination, privacy, intimacy, and sexual expression.

\section{SELF-DETERMINATION/AUTONOMY}

Self-determination is identified in all of the respective codes of ethics, either specifically, or referenced by statements requiring the adherence to existing laws, regulations, and standards (American College of Health Care Administrators, 2010; American Medical Directors Association, 2010; American Nurses Association, 2001; National Association of Social Workers, 2008; National Federation of Licensed Practical Nurses, 1979). The American College of Health Care Administrators (2010) code states, "Operate the facility consistent with laws, regulations, and standards of practice recognized in the field of health care administration" (para. 3). The American Nurses Association (2001) code states in section 1.4, "The right to self-determination - Respect for human dignity requires the recognition of specific patient rights, particularly, the right 
of self-determination" (para. 22), and, ... Individuals are interdependent members of the community. The nurse recognizes that there are situations in which the right to individual self-determination may be outweighed or limited by the rights, health, and welfare of others, particularly in relation to public health considerations. Nonetheless, limitation of individual rights must always be considered a serious deviation from the standard of care, justified only when there are no less restrictive means available to preserve the rights of others and the demands of justice (para. 24).

The American Medical Directors Association (2010) code states, "Shall respect the law while recognizing the responsibility to seek changes in the law for the best interests of the people entrusted to their care" (para. 7), and "Shall respect the individual's right to autonomy in decision making" (para. 11). The National Federation of Licensed Practical Nurses (1979) code states, "Shall have a personal commitment to fulfill the legal responsibilities inherent in good nursing practice" (para. 26). Similarly, the National Association of Social Workers (2008) code states, "Social workers respect and promote the right of clients to self-determination and assist clients in their efforts to identify and clarify their goals. Social workers may limit clients' right to selfdetermination when, in the social workers' professional judgment, clients' actions or potential actions pose a serious, foreseeable, and imminent risk to themselves or others" (para. 24).

It appears that all of these codes share a common ethic either adhering to existing laws and regulations or specifically valuing and upholding an individual's right of selfdetermination. However, as the statements of these different ethical codes illustrates, 
there is no universal definition of self-determination between the professional organizations or how those that reserve the ability to limit self-determination make those determinations.

\section{PRIVACY}

Privacy is also identified specifically or indirectly through references to the adherence to existing laws, regulations, and standards. Those ethical codes explicitly identifying privacy include the ANA and NASW (American Nurses, 2001; National Association, 2008). Those referencing privacy indirectly by adhering to and upholding federal and state laws include the ACHCA, AMDA, and the NFLPN (American College of Health Care Administrators, 2010; American Medical Directors Association, 2010; National Federation of Licensed Practical Nurses, 1979). The ANA (2001) ethical code specifically addresses privacy as follows.

3.1 Privacy - The nurse safeguards the patient's right to privacy. The need for health care does not justify unwanted intrusion into the patient's life. The nurse advocates for an environment that provides for sufficient physical privacy, including auditory privacy for discussions of a personal nature, policies, and practices that protect the confidentiality of information (para.17).

The descriptive behavior of a nurse's advocacy efforts toward an environment providing sufficient physical privacy appears to be consistent with the spirit of OBRA 1987, and suggests that this advocacy is inclusive of privacy for long-term care resident/patients to have intimacy and the freedom of sexual expression of long-term care. 
The NASW ethical code specifically addresses privacy in section 1.07 , subsection (a), "Social workers should respect clients' right to privacy" (National Association, 2008, para. 41). In a broader sense, the ethical code suggest the promotion of a client's right to privacy is consistent with the promotion of social welfare, generally through both local and global societies, as well as the fulfillment basic human needs. According to section 6.01 of the this code,

Social workers should promote the general welfare of society, from local to global levels, and the development of people, their communities, and their environments. Social workers should advocate for living conditions conducive to the fulfillment of basic human needs and should promote social, economic, political, and cultural values and institutions that are compatible with the realization of social justice (National Association, 2008, para. 161).

Additionally, the code indirectly addresses privacy through efforts to prevent or eliminate the exploitation or discrimination of any person, group, or class, which includes the older people and disabled who are residents/patients in long-term care facilities. According to section 6.04, subsection d, of this code,

Social workers should act to prevent and eliminate domination of, exploitation of, and discrimination against any person, group, or class based on race, ethnicity, national origin, color, sex, sexual orientation, gender identity or expression, age, marital status, political belief, religion, immigration status, or mental or physical disability (National Association, 2008, para. 167). 
The ACHCA, AMDA, and the NFLPN ethical codes indirectly address the residents'/patients' right to privacy according to the same codes related to adhering to existing laws, regulations, and standards as those that support resident's/patient's right to self-determination. Thus, suggesting that while all of these professional organizations support or promote a resident's/patient's right to privacy, there is no universal policy or practice that provides a mechanism for those in long-term care to exercise their right of privacy with regard to intimacy and sexual expression.

\section{INTIMACY \& SEX}

Intimacy and sexuality are not specifically identified in any of the chosen ethical codes. It seems that the ethos of all four professional organizations address these needs indirectly through statements on discrimination, advocacy, adherence to existing laws, regulations, and standards, or specific human rights of the individual. The ethical code of the ACHCA (2006) address these needs through their statement on the adherence to existing laws and through their statement on discrimination, "Take appropriate steps to avoid discrimination based on race, color, sex, religion, age, national origin, handicap, marital status, ancestry, or any other factor that is illegally discriminatory or not related to bona fide requirements of quality care" (para.6).

The AMDA (2010) code addresses the behaviors indirectly through the adherence of existing law and through their statement regarding intimacy, "Shall be an advocate for all persons who reside in the facility" (para.3). Similarly, the NASW (2008) ethical code indirectly addresses these needs through its statement on social and political action and its statement on discrimination, in section 4.02, 
Social workers should not practice, condone, facilitate, or collaborate with any form of discrimination based on race, ethnicity, national origin, color, sex, sexual orientation, gender identity or expression, age, marital status, political belief, religion, immigration status, or mental or physical disability (para.136).

While the ANA (2001) code addresses these needs indirectly through the statement on respect for human dignity,

1.1 Respect for human dignity - A fundamental principle that underlies all nursing practice is respect for the inherent worth, dignity, and human rights of every individual. Nurses take into account the needs and values of all persons in all professional relationships (para. 17).

While the challenges to institutions, such as long-term care facilities in meeting the intimacy and sexual needs of their resident/patients has a long history, little progress seems to have been made to satisfactorily address these needs in terms of developing a universal policy and practice for the respective professions to apply in an effort to comply with their respective ethical codes.

\section{IMPACT ON POLICY}

\section{Impact of Baby Boomers on Policy: Federal, State, and Professional Level}

A 2005 Newsweek story reported that Boomers defined "old age" as beginning three years after the average American is dead. J. Walker Smith, President of Yankelovich Partners, the polling company said, "boomers don't consider themselves bound by the laws of statistics; they 'fully expect that advances in health care and genomics are going to enable them to live past 100,'" (Adler et al., 2005, para. 5). As the 
oldest Baby Boomers entered their $65^{\text {th }}$ year in 2011 , they are seeking to reinvent aging. Because of the size of this generation and its anticipated impact on long-term care, policy makers, owners, administrators, and staff have little choice but to reevaluate existing policies and practices around long-term care and patient rights, specifically to meet the types of long-term care options that this group of master consumers will demand.

\section{HOW LAWS AND POLICIES ARE INTERPRETED}

At present, the Omnibus Reconciliation Act of 1987 addresses intimacy and sexual expression for residents of long-term care through the specific references to a patient's right to privacy and self-determination/autonomy. However, the language used addressing these rights is of an ambiguous nature and contradictory to requirements calling for resident choice and individualization that are disparate to others requiring protocols for safety. As previously mentioned, whenever state laws and regulations interfered with resident choice, regulators interpreted the federal laws in such a way as to allow states to establish rules that that seem to violate the spirit of OBRA 1987 when these rules interfere with resident choice (Kane \& Cutler, 2007). This reveals the absence of a clear universal definition and application of the federal laws addressing patient/resident rights. Consequently, laws related to intimacy and sexual expression also differ among the states.

\section{STATE INTERPRETATION}

In light of the ambiguous language contained regarding privacy and selfdetermination/autonomy in OBRA 1987, states have been free to interpret the meaning of the law and define them in ways that best serve themselves and not necessarily in ways 
that best serve the patients/residents for whom it was created to protect. While some states interpret and apply federal patient rights law similarly, others interpret and apply them in ways that exclude same sex couples, unmarried individuals, and others from enjoying the privacy and self-determination rights that the law was established to protect and to ensure that protection. Comments posted on behalf of and presumably with the approval of the National Health Regulations PLUS, (2009) website in reference to the various interpretations and applications of OBRA 1997 state:

In the Federal Regulation 483.10 (j), access and visitation rights, (1), "the resident has the right and the facility must provide immediate access to "immediate family or other relatives of the resident; and "(viii) others who are visiting with the consent of the resident." This would seem to include providing "immediate access" to spouses or intimate friends. Further, under 483.10 (m) the federal regulations state that "the resident has the right to share a room with his or her spouse when married residents live in the same facility and both spouses consent to the arrangement. However, under $483.10(\mathrm{e}$, privacy and confidentiality, the Federal regulations include privacy rights for multiple purposes, including visits, but add, "This does not require the facility to provide a private room for each resident." With explicit recognition that private rooms are not required for residents, the right to conjugal and sexual relationships is difficult to fulfill, as is even the right for "immediate access" to visitors of the residents' choice. Additional State regulatory language in this area could clarify and expand these rights but often seems to contract them by inserting clauses about possible medical contraindications or other 
"reasonable" limits to consensual sexual activity. Medical contraindications for room sharing would seem highly subjective.] (para. 31).

This opinion suggests that the language of the federal law makes clear that patients/residents have privacy rights for multiple purposes. Many states, however, have interpreted OBRA 1987 in ways that exclude making space and privacy provisions available toward facilitating intimacy or sexual expression within their facilities.

Facilities, themselves have little leeway to interpret either federal or state law. All states require long-term care facilities to meet strict licensing requirements and must, adhere to federal and state laws and regulations, including OBRA 1987. It seems, however, that some long-term care facilities make interpretations and in doing so, deny residents/patients their rights to privacy and self-determination, particularly when it comes to intimacy and sexual expression (Brown, 1989; Dupras \& Poissant, 1987; McKinley\& Drew, 1977; Nursing Home Reform, 1988; Parker, 2006). 


\section{ETHICAL ISSUES}

\section{Existing Laws, Policies, and Procedures Related to Intimacy and Sexual Expression}

The existing laws, policies, and procedures addressing the need for intimacy, while identifying the individual's right to self-determination (autonomy) and privacy are seemingly contradictory with the responsibility of long-term care facilities to provide a safe environment for all residents/patients. The definitions of these rights and how policies providing direction to balance these rights with their legal responsibilities continue to be universally vague and unclear. Further, the lack of established universal guidelines around the issues of intimacy and sexual expression foster a fear-based environment within long-term care facilities around the issues of capacity, privacy rights, and the moral judgments of others. A recent survey found that $26 \%$ of the population over 76 years of age reported being sexually active (Lindau et al, 2007).

\section{ETHICAL DILEMMAS}

The concept of self-determination is deeply rooted in American history as influenced by the ideas of freedom and liberty emergent during the Enlightenment (Freedberg, 1989). While the principle of self-determination is highly valued, it is in competition with a community's maintenance and protection, social welfare, and general safety. The tension between these competing interests requires the ability to negotiate a manageable balance between mutually exclusive goals of personal freedom and societal well-being in our thinking and examination of ethics (Hugman, 2003).

This struggle plays out within long-term care facilities between residents' rights to intimacy and sexual expression and individual and communal safety. Social workers 
practicing in long-term care facilities are frequently called upon to negotiate this struggle in their multiple roles as client advocates, agency employees, risk managers, and family advocates. There is no current research available regarding what social workers think and feel about self-determination, specifically self-determination surrounding intimacy and sexual expression. How long-term care facilities, and specifically, social workers, resolve this dilemma is an essential component of how they rationalize supporting or denying the facilitation of intimacy and sexual expression for residents of long-term care facilities and the decision's impact on resident health and life satisfaction.

\section{Personal rights: Self-determination, privacy vs. protection}

An ongoing concern for long-term care providers with regard to resident intimacy and sexual expression is how to protect and meet each resident's right to selfdetermination while protecting the residents themselves and from each other. While the Patient Bill of Rights federal regulations mandate that residents have the right to freely associate and communicate privately with persons of his or her choice, including other patients (Public Health, 1991), the sexual needs and behaviors of residents might place other residents' safety at-risk and place long-term care facilities in precarious situations.

Long-term care facilities are obligated to provide residents freedom to interact with others, including freedom to interact intimately and sexually. At the same time, residents must be protected from abuse, injury, and neglect. Identifying an approach that strikes a balance between the resident's right to self-determination, privacy, and protection, and the protection of other residents, has eluded long-term care providers. The absence of a universal policy and practice model addressing this issue, especially 
with regard to intimacy and sexual expression, is confusing. It inhibits long-term care providers in their efforts toward finding a way to meet their responsibilities and honor individual rights.

Further complicating the issue is negotiating the prevailing social moral values and their influence on staff, residents, and the families (Kamel \& Hajjar, 2004). Nursing staff in one study reported confusion, anger, embarrassment, denial, and helplessness when they found residents having sexual relations, along with feeling conflicted between personal moral norms and their obligation to provide residents' rights (Ehrenfeld, Tabak, \& Bergman, 1997).

Capacity and consent is at the forefront of this issue with regard to the balance of resident rights and resident safety (Morris et al., 1990). The Center for Practical Bioethics (2006) recommends that determinations of an individual's capacity to make decisions and to provide consent for intimacy and sexual expression be evaluated using the Resident Assessment Instrument (RAI). While these guidelines begin to establish a foundation toward a universal policy and model of practice, the language is still open to interpretation, and does not take into consideration what legal instruments exist or should be developed to address intimacy and sexual expression needs for residents who are determined to be incapable of giving consent.

\section{EXISTING POLICIES AND PRACTICES ADDRESSING INTIMACY (SPECIFIC TO SEXUAL INTERACTION)}

Universally, there exist no policies and procedures to address intimacy and sexual expression within long-term care facilities. Each state and correspondingly, each 
individual long-term care facility interpret OBRA 1987 in their own way, according to their individual preferences, regardless of the effects these interpretations have on the resident's rights. Federal regulators, as previously mentioned, have consistently sided with the interpretation of the states, which is facilitated by the ambiguous language used in OBRA 1987 (Minimal effort has been made to develop a more intimacy and sex positive environment in long-term care facilities through education and training for longterm care providers and their staff (Mayers \& McBride, 1998). Only three groups have developed guidelines to address intimacy and sexual expression. Lichtenberg and Strzepek (1990) were the first to describe guidelines implemented in their organization to assess the competency of residents who desired to participate in sexually intimate relationships. Sloan, (1993) described a national chain that organized a task force to develop guidelines for their dementia care units. Lastly, Hebrew Home for the Aged in Riverdale, New York, developed a set of guidelines and a training manual to address the intimacy and sexual expression needs of their residents (Holmes \& Fairchild, 1995).

Although, these efforts exist, there is little consensus regarding policy and practice, even between providers with the most relaxed attitudes toward intimacy and sexual expression of residents (Ford, Rosenberg, Holsten, \& Boudreaux, 2003).

\section{LITERATURE RELEVANT TO ETHICAL DILEMMAS}

There is a growing body of literature surrounding intimacy and sexual expression in long-term care that has identified common barriers that inhibit the sexuality of older residents. These barriers seem to fall into the following categories such as physical health/limitations, privacy, self-esteem, and staff/family attitudes (Kamel \& Hajjar, 
2004). Despite the growing interest in this subject, there is a great paucity of information with regard to intimacy, sexual expression, and ethos within long-term care facilities. A review of the literature identified eight peer-reviewed articles that discuss issues related to sexual expression in long-term care and ethics.

An ongoing concern for administrators of long-term care facilities with regard to resident sexual expression is liability. While the Patient Bill of Rights federal regulations mandate that residents have the right to freely associate and communicate privately with persons of his or her choice, including other patients (Public Health, 1991), the sexual needs of residents might place long-term care facilities in precarious situations. Longterm care facilities have an obligation to provide residents freedom to interact with others, including freedom to interact intimately and sexually. At the same time, residents must be protected from abuse, injury, and neglect. Additional complications for this issue are related to the prevailing social mores and values held by caregivers, staff, and the families (Ehrenfeld, Tabak, \& Bergman, 1997; Kamel \& Hajjar, 2004). Another study conducted to observe the effects of integrating a long-term care facility by mixing genders on each floor rather than segregating the residents by gender generated a more cheerful climate and enhanced the personal grooming habits of male residents. However, the most resistance to the study originated with staff resulting from their own personal bias surrounding ageism and intimate behavior (Silverstone \& Wynter, 1975). Brown recounts a clinic for social workers held at a geriatric care center in which the theme was, "The Search for Intimacy: Relationships and Sexuality in Later Life." Within the context of that clinic, someone reported that most facilities had no double beds. The response to 
questions for reasons why was, "we have no double sheets". Further inquiry found that staff did not want to deal with sexual behavior in the centers (Brown, 1989, p. 82). The available literature reveals a dearth of knowledge regarding the ethical principle of selfdetermination supported by social workers within this client population. Consequently, it is unclear how social workers practicing in long-term care facilities, along with administrators and care staff, make decisions whether to support or deny the intimacy and sexual expression needs of residents in accordance with the ethical principles of the National Association of Social Workers (NASW) or the ethical codes of the various professional disciplines of self-determination and autonomy.

\section{THEORETICAL AND CONCEPTUAL FRAMEWORK}

\section{Life Course Perspective}

Within the life course paradigm, aging is viewed as a developmental process of changing events and socio-cultural meanings that move across time but within the historical and cultural context of the cohort (Giele \& Elder, 1998). The life course paradigm incorporates four distinct areas of social life that when brought together tell a story of aging. The four elements, which make up the paradigm, are: 1) lives in time and place, 2) human agency, 3) the timing of lives, and 4) linked lives (Elder, 1994; 1996). These elements, based upon the premises of symbolic interactionism, combine to form the life course view of aging.

Symbolic interactionism (Blumer, 1969) is based upon three premises. According to Blumer, people act based upon the meaning objects and events have for them. Second, the meaning that is assigned is based upon their interaction with other people, and third, 
people select objects and events out of their environment, and they process them through time to make meaning. When a person is asked about an event in their childhood, they tell a story that may appear random, but because it was selected, it holds meaning to that person who has processed it over time. This indicates their story is not extraneous. It tells about their interaction with other people within a specified time and place. Those interactions are interpreted and conveyed through their stories, which provide information about their sense of human agency, how the timing of events affects them, and what the time and place they lived was like. The stories about how they chose to act or not to act throughout life provide a series of events and associated meanings that tell about aging.

The life course paradigm enables the researcher to understand the developmental changes baby boomers experience and provides the researcher with a useful tool for understanding the meaning of intimacy and sexual expression from the perspective of heterosexual baby boomer men and women.

The life course paradigm is consistent with narrative inquiry as a way of making sense of the world, at times equated with experience, time, history and life itself, which is highly relevant when studying the effects of aging (Georgakopoulou \& Goutsos, 2000, pp. 64-68). The major assumption of the life course paradigm, which is based on the importance of past events on present life pathways, can be explained with Husserl's description of how we shape our present and future based upon past perceptions. According to Husserl (1999), when time is viewed as individual consciousness, it is the medium of existence that passes without regard in the present. It takes form through a 
stream of perceptions while allowing us to anticipate the future and bring the past into the present. Our perceptions in the present ultimately become recollection and are brought forward as recollection but never as perception repeated (Husserl, 1999). The perceptions that have past remain in our past despite new perceptions, but the past perceptions become objectified within the mind (Husserl, 1999). The human function of objectifying past perception makes up our identity, reality, and history. Our every moment is placed in sequence by time with death reminding us of its end (Berger \& Luckman, 1966). The objectification of past events as recollection makes the experience of events in time knowledge, and this knowledge forms our history and makes us aware of the limitations of our biology. Gertz, in his work with the Balinese, wrote that time could be marked in many ways to gain an understanding of its passage, yet the "most important is by the recognition in oneself and in one's fellowmen of the process of biological aging, the appearance, maturation, decay, and disappearance of concrete individuals" (1973, p. 389). After all, aging occurs with time, and time is the horizon in which all interpretation is made (Heidegger, 1962). 


\section{CHAPTER 2}

\section{LITERATURE REVIEW}

\section{Current Literature: Intimacy and Sexual Expression in Long-Term Care}

The current literature addressing intimacy and sexual expression in longterm care includes research related to barriers that affect residents' intimacy and sexual expression and barriers that effect providers from supporting and facilitating residents' intimacy and sexual expression. Specific issues that inhibit residents/patients living in long-term care facilities from enjoying intimacy and sex expression include: lack of privacy, lack of opportunity, negative attitudes of others, physiological and psychological limitations, biological and physical capability, advent of treatments (Viagra ${ }^{\mathrm{TM}}$, Cialis $^{\mathrm{TM}}$, Levitra ${ }^{\mathrm{TM}}$ ) lack of access to sexual therapies and treatment modalities, negative attitudes of others, and psychological and physiological limitations (Rebec, Karnjus, Licen, \& Babnik, 2015 ; Youngkin, 2004, p. 45). Reasons for intimacy and sexual expression limitations or absence in long-term care include provider's perspectives of their legal obligation to prevent sexual abuse, education and training deficiencies, shame and discomfort, and prevention of an environmentally chaotic health care setting. Literature from both categories of research is discussed in the following two sections. 


\section{RESIDENTS' BARRIERS TO INTIMACY AND SEXUAL EXPRESSION}

\section{Negative Attitudes of Others}

The lack of intimacy, freedom of sexual expression, and negative attitudes toward older adults continues to be a dominant theme and is a component of ageism (Griffiths, 1988). Societal myths and misconceptions regarding the sexual desires and behaviors of older people abound. One such myth is that if older people are not asexual, they should be along with a false assumption that physical attractiveness is dependent on youthful good looks (Henry \& McNab, 2003). A number of studies reflect a common myth that the older people, specifically, residents of long-term care facilities, should not or are no longer sexually expressive with a partner or partners (Langer, 2009). Ludeman (1981) cited one study by LaTorre and Kear in 1961 that was related to an attitude suggesting that young adults viewed stories of older people engaged in coitus as less credible and less moral than similar stories with younger people as the main characters. They further viewed stories of older people engaged in masturbation as more credible than those stories about older people engaging in coitus. Moreover, Falk \& Falk (1980) asserted the belief that only the young should be allowed sexuality pervades both younger and older generations.

Sex is commonly viewed as only for the young, good-looking, and fit.

Individuals not meeting this criterion are expected to become asexual (Becker, 1984; Brown, 1994; Cort, 1998; Evans, 1999; Pederson, 1993; Saretsky, 1987; Williams, 1999; Zeis \& Kasl-Godley, 2001). Consequently, older, unattractive, and physically weak individuals frequently come to believe that their sexual needs and desires should cease. Society, Tilley (1996) believes, views older people and disabled as not entitled to love, 
imposing barriers that encourage older adults to stifle their sexuality. It is not uncommon for individuals who encounter these opinions to develop feelings of shame and anxiety around normal sexual urges (B.C. Coalition of the Disabled, 1990; Karlen \& Moglia, 1995; Pederson, 1993; Schrover \& Jensen, 1988; Tallmer, 1984; Tilley, 1996; Woodard \& Rollin, 1981). Further, it is not uncommon for administrative staff and caregivers to consider intimacy and sexual expression between residents, regardless of their marital status or sexual orientation, as immoral or illegal (Brown, 1989; Cameron, 1970; "Denial of Residents," 1995; Dupras \& Poissant, 1987; Earle, 2001; Golde \& Kogan, 1959; Kempton \& Kah, 1991; Langer, 2009; McAuliffe, Bauer, \& Nay, 2007; Pfeiffer, Verwoerdt, \& Wang, 1968; Schrover \& Jensen, 1988; Shakespeare et al., 1996; "Staff Should Accept," 1995).

\section{PSYCHOLOGICAL AND PHYSIOLOGICAL LIMITATIONS}

Although psychological and physiological limitations might have a negative effect on an individual's sexual activity, several studies have revealed that education and support can help these individuals to benefit from successful and fulfilling sexual lives (Alexander, Sipski \& Findley, 1993; Barrett, 1982; Basson, 1998; Courtois, Charvier, Leriche \& Raymond, 1993; deMey, 1998; Sipski \& Alexander, 1997a; Sipski, Alexander, Rosen \& Raymond, 1995). A study of sexual development and behavior of individuals with disabilities found that most disabilities do not reduce interest in sex or the capacity for sexual function (Reinisch \& Beasley, 1990). In contrast, some research outcomes reveal that age and physical limitations might increase the need for intimacy (Dressel \& 
Avant, 1983; Reinisch \& Beaseley, 1990; Starr \& Weiner, 1981). Physical and psychological sexual dysfunctions or impairments such as erectile dysfunction, early or lack of ejaculation, anorgasmia, impaired lubrication, dyspareunia, spasticity, fatigue, bowel and bladder incontinence, negative self-image and body image, and communication challenges between partners, can be improved through psychological counseling and physiological treatments and therapies (Ekland, Griffin, Copeland, Elliott \& Nigro, 1998; Elliott, 1998; 1999; 2002a,;2002b; Elliott \& Krassioukov, 2006; Forman, Gilmour-White \& Forman, 1996; Fowler, 1999; Hennessey, Robertson, Swingler \& Compston, 1999; Leiblum, 1980/2006; Maurice, 1999; Metz 1998; Rines \& Breen, 1991a, 1991b; Roe, 1999; Sipski \& Alexander 1993a, 1993b, 1997b; Slater, 1999; Tepper, 1999; Wincze \& Carey, 2001; Zorzon et al., 1999).

A concern for most residents is the decline in physical functioning. Additionally, it is typical for the frequency and level of disability in long-term care residents to be much higher. However, studies have found that residents' functioning is helped by their adapting behavior to function (Kaiser, 2003; Morely \& Tariq, 2003).

Although psychological and physiological therapies and treatments are available, including pharmacological treatment to address erectile dysfunction in males, Medicaid allows states to exclude the coverage of medications for the treatment of sexual or erectile dysfunctions. Any coverage is contingent on their being used to treating a condition other than sexual or erectile dysfunction, for which the agents have been approved by the Food and Drug Administration (Congressional, 2008). Medicare also allows Medicare drug plans to exclude erectile dysfunction medications from their plans (U. S. Department of, 2009). In contrast to these two federal health care programs, the 
Department of Veterans Affairs has made erectile dysfunction medication, Levitra ${ }^{\mathrm{TM}}$, (Vardenafil) available through the Veterans Administration Formulary (VISN 20 P \& T Committee, 2009).

\section{LACK OF OPPORTUNITY}

A primary reason for long-term care residents' absence of sexual activity is a lack of opportunity (Wasow \& Loeb, 1979). McCracken (1980) found that when older adults stopped sexual interactions, it is typically not because of incapacity or lack of interest. Frequently, sexual interactions cease because of the loss of sexual partners. Regardless of the lack of opportunity, some research studies have documented that a significant percentage of long-term care residents have an interest in sexual expression. In a study of United States nursing home residents, White (1982) found that 17 percent of sexually inactive residents had a desire to have sexual lives. Fielden, (1997) found that 70 percent of males and 60 percent of females age 65 or more reported that they enjoyed sexual intercourse on a regular basis. Mulligan and Palguta (1991) found that institutionalized geriatric males remain especially interested in sexual intercourse. Lastly, Bretschneider \& McCoy (1988) found that 60 percent of males and 30 percent of females had sexual intercourse at least sometimes and 26 percent of the males and ten percent of the females were reported to have intercourse several times a week to several times a month in their study of sexual interest in healthy 80 to 102 - year-olds.

\section{LACK OF PRIVACY}

Geoffrey Fisher (1959) stated, “There is a sacred realm of privacy for every man and woman where he makes his choices and decisions-a realm of his own essential rights and liberties into which the law, generally speaking, must not intrude" (n.p.). Privacy is 
"the ability to control the degree to which people and institutions encroach upon one's life" (Marshall, 1974, p. 255). Control of one's private space is "the ability to control interaction, to have options, devices and mechanisms to prevent unwanted interaction and to achieve desired interaction" (Altman, 1975, p. 17). Without a commitment to protecting each individual's right to privacy, rights to accurate sexual information and sexual expression are "meaningless" (Brown et al., 1994, p. 1).

Individuals residing in institutions seldom have their privacy needs acknowledged, neither do they have access to or control over private space (Bauer, 1999; Bermarm, 2003; McCann, 2000). Kaas' (1978) study found that long-term care residents and staff both cited lack of privacy as the primary reason for stifled sexual expression. Similarly, Spector \& Fremeth (1996) found that the absence of properly equipped private rooms in long-term care facilities had a negative effect on residents' sexual activity.

PROVIDERS' BARRIERS TO RESIDENTS' INTIMACY AND SEXUAL

\section{EXPRESSION NEEDS}

\section{Preventing an environmentally chaotic health care setting}

Irene Barnes (2001) describes a provider's unwillingness to accommodate the desire for sexual expression between residents with intellectual disabilities out of concern for the chaos that might ensue. Her report confirms Dupras and Poissant's (1987) finding that the stifling of sexual expression in health care facilities is the result of provider's desires to prevent a chaotic environment. Further, their study found that altercations most often occur between staff and patients when staff members perceive that the patients' sexual activity has disturbed the facility's environment, while the patients' experiences are those of being inappropriately observed and controlled. 


\section{LACK OF EDUCATION}

Lack of education and knowledge about sex and sexuality, as research has shown, results in LTC staff trying to curtail residents' sexual activity (Dupras \& Poissant, 1987). Some studies suggest that nurses, who have strong negative attitudes toward, or inadequate knowledge about, sex and sexuality, are unlikely to provide support for residents' intimacy or sexual expression needs (Gamel, Davis \& Hengeveld, 1993; Garrett, 1994; Lewis \& Bor, 1994; Webb, 1988). Without sex education programs, caregivers often have inconsistent attitudes toward the intimacy and sexual expression needs of residents, frequently experience uncertainty in how to redirect inappropriate sexual activity, and might be reluctant to embrace positive attitudes toward the intimacy and sexual expression needs of residents resulting from lack of knowledge and legal liability fears (Abramson, Parker \& Weisberg, 1988; Doyle, Bisson, Janes, Lynch \& Martin, 1999; Turnstull \& Henry, 1996).

Although the literature supports a need for staff education, few programs exist to deliver this type of education or training (Daniels, Cornelius, Makas \& Chipouras, 1981; Mayers \& McBride, 1998; Steinke, 1977). This lack of programming disregards the fact that the identification of effective methods to teach health care providers about sex and sexuality has been recommended to address the lack of sexual care for residents/patients (d'Ardenne, 1988; Gamel, Hengeveld, Davis \& Van Der Tweel, 1995; Gripton \& Valentich, 1983; Hodge, 1995; Joseph, 1991; Karlen \& Moglia, 1995; Latimer, 1981; Pollard \& Barker, 1985; Schuler, 1982; Webb, 1988). Studies have shown that staff education programs are quite effective in eliciting support for residents' sexual lives, and help in the reduction of staff and resident tensions related to the intimacy and sexual 
expression needs of residents (Doyle et al., 1999; Lewis \& Bor, 1994; Mayers \& McBride, 1988; Steinke, 1997; Turnstull \& Henry, 1996;). The efforts are particularly successful when they are centered on helping caregivers learn how to separate their personal and professional values (Lewis \& Bor, 1994).

\section{Shame and Discomfort}

Physicians' embarrassment and inadequate training inhibits their ability to obtain adequate sexual histories of residents/patients; under girded by the belief that sexuality is not relevant to the medical problem being presented to them. Ehrenfeld, Tabak, \& Bergman (1997) reported caregivers experienced confusion, anger, embarrassment, denial, and helplessness when encountering residents having sexual relations. Further, they reported these caregivers as experiencing feelings of conflict between their own moral norms and their obligations to honor residents' rights. Other studies have found that caregivers sense of cultural mores and values are challenged (Kuhn, 2002; Mossmann, Perlin, \& Dorman, 1997; Rheaume \& Mitty, 2008).

\section{Legal obligation to prevent sexual abuse}

Long-term care providers are disinclined to facilitate intimacy and sexual expression fearing that it might hamper their legal obligation to prevent sexual abuse and exploitation (Dupras \& Poissant, 1987; McSherry \& Somerville, 1998). This response is appropriate considering that impaired persons have a higher risk of being abused

physically, sexually, and emotionally and is more likely when the dependency needs can only be met through the reliance on others (Ducharme \& Gill, 1997; Marchant \& Page, 1993; Westcott, 1994). In addition, individuals with severe disabilities have difficulty 
articulating their abuse, may not be believed, and possibly lack the capacity to understand when abuse has occurred (Sant Angelo, 2000). 


\section{CHAPTER 3}

\section{METHODOLOGY}

\section{Overview}

As the baby boomers enter long-term care, it is anticipated that the demand for care providers to accommodate the intimacy and sexual expression needs of residents will significantly increase. In order to acquire as much usable material as possible about the definitions and understanding of intimacy and sexual expression across the life course by heterosexual Baby Boomers, a qualitative research design was chosen. Qualitative inquiry effectively allows the researcher to explore meaning, interpretations, and individual experiences (Stake, 2005). Thirteen participants from diverse backgrounds were asked to complete the Rappaport (1990) Time Line (RTL), identifying relationships involving intimacy (sexual and non-sexual) and those involving sexual expression during each stage of their life course. They each were interviewed about their definition and understanding of intimacy and sexual expression across each stage of their life using a semi-structured interview method developed from their individually completed RTL.

\section{Guiding Questions}

The purpose of the current qualitative study is to explore how heterosexual Baby Boomer men and women define and understand intimacy, sexual expression, expectations and desires relating to their respective expressions across the lifespan and specifically as they think about their current future considering long-term care, and common concerns and issues relating to these two areas facing heterosexual men and women as they age. The development of a sound set of guiding questions is critical in 
any form of qualitative research. Creswell, (2007) emphasized developing questions before settling on the specific qualitative approach to gathering data (Creswell \& Plano Clark, 2004). In order to understand the phenomena of how heterosexual Baby Boomers define and understand intimacy and sexual expression, the concept of generalizing and particularizing to research design proposed by Maxwell (2005), the study asks the following questions:

1. How do aging heterosexual Baby Boomers define intimacy and sexual expression?

2. How are Baby Boomer definitions of intimacy and sexual expressions influenced by experiences across the life course?

3. How do Baby Boomers envision defining/expressing intimacy in the future?

4. What are the intimacy and sexual expression concerns of Baby Boomer males and females in the present and the future?

5. What major concerns do older adults share as relates to the intimacy and sexual expression issues surrounding their aging including long-term care needs in the future, and the thoughts that aging men and women have about solutions that address their major concerns?

\section{Design of the Study}

This phenomenological method concerns itself with the experiences of heterosexual baby boomers regarding their current and future intimacy and sexual expression and healthcare needs, both individually and collectively. Giorgi (1997) pointed out that phenomenology "refers to the totality of lived experiences that belong to a single person" (p. 236). This "totality" makes phenomenology an appropriate research method for this study. 
Amadeo Giorgi (1997), building upon the work of pioneer Edmund Husserl, asserted that the method consists of three elements: 1) reduction, 2) description, and 3) search for essences (p. 237). These methods allow the researcher to acquire a large volume of information, refine that information into usable chunks, and then gain insight into the experiences of the subjects more effectively than by other methods that are purely descriptive or analytical in nature. Sanders (1982) pointed out that the phenomenological method provides a way of "viewing what is genuinely discoverable and potentially there but unseen" (p. 357). Additionally, Sanders stated that the research gained from this process could affirm or question the research gained by other methods. Giorgi (2009) asserted that phenomenology adds an element of rigor to the study of phenomena. A hermeneutic phenomenological method will be utilized to identify, define, and explore the intimacy and sexual expression expectations, desires, fears, concerns, and plans of heterosexual baby boomers as they approach old age. The expected outcome of this study is a description of shared concerns that attempts an understanding of the phenomenon of aging expectations as it relates to the intimacy and sexual expression needs and desires as described by the representatives of the population.

The hermeneutic phenomenological research approach attempts to acquire comprehensive descriptions from research participants and provide a foundation for a reflective structural analysis that illustrates the essence of the experience (Moustakas, 1994). The experiences of planning, expectation, and concern are subjective in nature, and difficult to quantify. This hermeneutic phenomenological study approach allows aging heterosexual male and female baby boomers to discuss topics in relative privacy. The intimate setting of the study design allowed for confidentiality and open flow of 
thoughts, lived experiences, concerns, and ideas to form and be articulated. As repetitive themes and ideas emerged from several research participants, a description of the collective experiences and concerns were developed that embodied the collective data from the participants.

Moustakas (1994) suggests that characteristics of qualitative research include acquiring descriptions of experience through first-person accounts and understanding that the data of experience is essential to understanding human behavior. It is the systematic and creative analysis of raw data that will be identified and related concepts that became apparent from talking with heterosexual baby boomer men and women. The analysis will create a description of intimacy and sexual expression issues identified by heterosexual baby boomer men women as they age.

The research was a study of Baby Boomers consisting of heterosexual individuals (single or married), born between January 1, 1946 and December 31, 1964. The intent of this study is to identify and describe the definitions, understandings, attitudes, concerns, values, and expectations around intimacy and sexuality of the Baby Boomers at various stages across the life course, including, past, present and as they consider their future long-term care needs.

\section{Participants}

Consistent with recommendations of Steeves (2000), who wrote that prior studies and empirical knowledge drive sample size selection; the necessary sample was estimated to be 10 to 15 participants. In a study of older women, Kahn (1999) reached saturation after 13 intensive interviews. The sample size consisted of eight male boomers and five 
female boomers. The total number of participants was 13. Sampling continued until saturation was reached and the data was complete. The researcher knew that saturation was reached when each additional interviewee added little to nothing to what was being revealed in the interviews (Rubin \& Rubin, 1995). Given that I had multiple interviews combined with observations, a large amount of data was collected without need for a larger sample since the participants talked at length about their experiences (Morse, 2000). The selection criteria of participants for this study required that their selfidentified sexual orientation be heterosexual. All participants were competent and free of any diagnosed cognitive impairments (mental retardation, dementia, Alzheimer's, brain injury, drug/substance induced). No potential participants were of questionable competency. Further, participants resided independently in their own homes, in an assisted living, or a long-term care facility, and resided in the Kentucky and south central Indiana region, up to and including, Indianapolis, Indiana. Purposeful sampling was utilized to guide the sample size. Patton (2002) describes these as samples within samples and suggests that purposeful samples can be stratified or nested by selecting particular units or cases that vary according to a key dimension. (p. 238). Further, Boyd (2001) regards two to 10 research participants as sufficient to reach saturation, while Creswell (1998) recommends long interviews with up to 10 people for a phenomenological study. Saturation means that no additional data are being found. As similar instances are repeated, the researcher becomes empirically confident that saturation has occurred.

There were no foreseeable physical risks to the participants engaged in the interview. There were no foreseeable psychological risks outside of the possibility that 
others may not like the attitudes of the participants. There were no social risks of participation; no specific information received from or related to individual participants will be released to any person outside the research team or requisite oversight body (U of L IRB).

There were no economic risks associated with the surveys. There were no foreseeable legal risks to participation in this research. Respondents identifying information including names or contact information was not included on the data collection forms.

\section{Ethical Considerations}

All identifying information was maintained in a locked file cabinet at the researcher's office and assigned a code identifier corresponding with the demographic data and the completed transcribed interviews. Only basic demographic information (age, gender, educational background, rural/urban setting of residence, etc.), and structured interview questions were asked of the participants.

\section{Data Collection}

\section{Instrumentation: Rappaport Time Line}

Face-to-face semi-structured interviews informed by relationships identified on each individual's completed size modified Rappaport Time Line reduced from 24 inches to 14 inches and the life course perspective was conducted with 13 individual participants in three stages - completion of their individual time line, initial interview, and 'validity check' interview. These interviews were guided by a semi-structured interview schedule and remained 
flexible to allow for an interactive process that was used to describe the lived and anticipated experience of each participant. The Rappaport Time Line (RTL) method (Rappaport, 1990) evolved from researchers using various time lines, including "Cohen, Hansel, \&Sylvester, 1954; Cottle \& Pleck, 1969; Rychlak, 1972” (as cited in Rappaport, 1990). The Rappaport Time Line procedure involves presenting subjects with a 24 -inch strip of paper, which they are told represents their entire life, and to mark off particular time intervals on an essentially "empty" timeline of their lives. A timeline is a participatory data collection method for gathering time-related information (Weiss \& Bolton, 2000).The RTL for this study was modified and reduced from 24 inches to 14 inches. The timeline was marked from childhood through adolescence, early adulthood, middle adulthood, present time, and future time. The participants were asked to mark the time line with regard to romantic relationships (including those that are simply sexual and those that include closeness but no sexual expression) for each category asking them to mark significant life experiences and their age as related to intimacy and sexual expression on the line. Thus, the instrument applies an events test or experiential inventory methodology to a spatialized, time-line format, according to Cottle (1968) (as cited in Rappaport, 1990).

\section{Instrumentation: Semi-Structured Interview}

The semi-structured interview questions were informed by the responses of the participants on the RTL and the life course perspective. These interviews were electronically recorded with the permission of the participants. The interviews took place in the subject's place of residence, (home, assisted living center, or long-term care facility) place of business, or at locations of the participants' choosing. 
The interview schedule consisted of a combined interview approach. This approach began with basic, non-threatening fixed demographic questions. Following these questions, a standardized open-ended conversational approach was applied with several open-ended generative questions geared to answering the research questions enumerated above, including probes and transitions. These questions included, "What was your understanding of intimacy during this first 19 year period of your life?, What was your understanding of sexual expression during this same period?, and With regard to intimacy, in what ways did these experiences impact your understanding of intimacy?.” The informal conversational interview approach was used to pursue information that emerged through observation or participant responses that flowed from the immediate context of the interview (Patton, 1990/2002). Participants were not asked specifically about their sexual practices. However, some voluntarily shared any information that they felt was relevant in answering the interview questions. The interview instrument was aligned with the research questions. In addition to the interview, the researcher also made notations about the participants' body language and kept a record of the changes in their gestures and mimics when speaking. Once an initial data analysis was completed, participants were contacted via email to perform a 'validity check' to verify that the essence of the interviews was captured correctly and possibly to ask additional questions based on the responses of participants to the initial interview (Hycner, 1999, p. 154). Necessary modifications, if any, are made because of this 'validity check'. After final themes had been identified, they were emailed to the participants to collect 
input, questions, or concerns. None of the participants offered input regarding the identified themes.

\section{Recruitment}

Varying approaches were used to obtain participants for the study. Flyers were created and distributed to assisted living centers, long-term care centers, day program facilities, KIPDA, service clubs, fraternal organizations, (Elks, Moose, Eagles, VFW, American Legion, Freemasons, Odd Fellows) along with health care facilities, (hospitals, private practice, clinics) throughout the south central Indiana and Louisville, Kentucky Metropolitan area. Further, the snowball sampling technique was systematically applied to identify other participants from the targeted populations. Snowball sampling is a method of increasing the sample by querying one informant or participant to recommend others for interviewing (Babbie, 1995; Bailey, 1996; Crabtree \& Miller, 1992; Holloway, 1997). This technique is useful in finding hidden populations or groups not readily accessible (Patton, 1990; 2002). In addition, efforts were made to develop relationships with organizational leaders and gatekeepers to work in consultation with them to help identify and recruit potential participants. A word of mouth approach through professional colleagues who agreed to approach potential participants on behalf of the researcher was also employed. Gledhill, Abbey, \& Schweitzer (2008) found that word of mouth recruitment yielded the largest number of participants and was the simplest mode of recruitment for older people for a study of sexuality. Advertising, including a local news article seeking participants, flyers, and a news media release, was the second most successful method in recruiting, followed by community seminars as the third best method of recruitment (Appendix 1) A strong effort was made to include any institutions 
where participants already reside and others in the geographic area where the participants of the generational cohort could end up in the future.

\section{Data Analysis}

The analysis of phenomenological data begins with the methodology of reductions, the analysis of topics, categories, and a search for all possible meanings. I relied on instinct, imagination, and ideas to portray the experience (Miller \& Salkind, 2002). In hermeneutic analysis, the researcher reviews the written text and looks for the meaning of text for people in their situation, using their words, telling their stories (van Manen, 1997). After the voice records were transcribed, these transcripts were combined with observation notes, RTL, and the raw data obtained. The interview transcripts were then processed with the assistance of the qualitative analysis software MAXQDA in conjunction with Colaizzi process for phenomenological data analysis (cited in Sanders, 2003; Speziale \& Carpenter, 2007).

1. Each transcript should be read and re-read in order to obtain a general sense about the whole content.

2. For each transcript, significant statements that pertain to the phenomenon under study should be extracted. These statements must be recorded on a separate sheet noting their pages and lines numbers.

3. Meanings should be formulated from these significant statements.

4. The formulated meanings should be sorted into categories, clusters of themes, and themes.

5. The findings of the study should be integrated into an exhaustive description of the phenomenon under study.

6. The fundamental structure of the phenomenon should be described.

7. Finally, validation of the findings should be sought from the research participants to compare the researcher's descriptive results with their experiences. 
The process was enhanced by the utilization of MAXQDA (2015) software. The software, specifically designed to assist in analysis of qualitative data, displayed and analyzed relationships among processes, concepts, and people. The software allowed extensive use of memos and allowed editing and annotation of collected data.

\section{Theoretical and Conceptual Framework}

\section{Life Course Perspective}

Within the life course paradigm, aging is viewed as a developmental process of changing events and socio-cultural meanings that move across time but within the historical and cultural context of the cohort (Giele \& Elder, 1998). The life course paradigm incorporates four distinct areas of social life that when brought together tell a story of aging. The four elements, which make up the paradigm, are: 1) lives in time and place, 2) human agency, 3) the timing of lives, and 4) linked lives (Elder, 1994, 1996). These elements, which are based upon the premises of symbolic interactionism, combine to form the life course view of aging.

Symbolic interactionism (Blumer, 1969) is based upon three premises. According to Blumer, people act based upon the meaning objects and events have for them. Second, the meaning that is assigned is based upon their interaction with other people, and third, people select objects and events out of their environment, and they process them through time to make meaning. When a person is asked about an event in their childhood, they tell a story that may appear random, but because it was selected, it holds meaning to that person who has processed it over time. This indicates their story is not extraneous. It tells about their interaction with other people within a specified time and place. Those interactions are interpreted and conveyed through their stories, which provide 
information about their sense of human agency, how the timing of events affects them, and what the time and place they lived was like. The stories about how they chose to act or not to act throughout life provide a series of events and associated meanings that tell about aging. The life course paradigm enables the researcher to understand the developmental changes Baby Boomers experience and provides the researcher a useful tool for understanding the meaning of intimacy and sexual expression from the perspective of heterosexual Baby Boomer men and women.

The life course paradigm is consistent with narrative views of time, which is highly relevant when studying the effects of aging. The major assumption of the life course paradigm, which is based on the importance of past events on present life pathways, can be explained with Husserl's description of how we shape our present and future based upon past perceptions. According to Husserl (1999), when time is viewed as individual consciousness, it is the medium of existence that passes without regard in the present. It takes form through a stream of perceptions while allowing us to anticipate the future and bring the past into the present (Husserl, 1999). Our perceptions in the present ultimately become recollection and are brought forward as recollection but never as perception repeated (Husserl, 1999). The perceptions that have past remain in our past despite new perceptions, but the past perceptions become objectified within the mind (Husserl, 1999). The human function of objectifying past perception makes up our identity, reality, and history. Our every moment is placed in sequence by time with death reminding us of its end (Berger \& Luckman, 1966). The objectification of past events as recollection makes the experience of events in 
time knowledge, and this knowledge forms our history and makes us aware of the limitations of our biology. Gertz, in his work with the Balinese, wrote that time could be marked in many ways to gain an understanding of its passage, yet the "most important is by the recognition in oneself and in one's fellowmen of the process of biological aging, the appearance, maturation, decay, and disappearance of concrete individuals" (1973, p. 389). After all, aging occurs with time, and time is the horizon in which all interpretation is made (Heidegger, 1962).

\section{Regional Description and Demographics}

The sample of 13 Baby Boomers was from both metropolitan and rural communities extending from Elizabethtown, Kentucky to Indianapolis, Indiana. The participants in the study represented communities classified from small cities to large urban metropolitan area (three from three small cities, four from two midsized cities, and seven from one large urban area). The researcher found participants that represented a good cross section of the South Central Region of Indiana and North Central Region of Kentucky, including the Louisville Kentucky Metropolitan Area. The participants ranged in age from 51 to 69 .

\section{SAMPLING PROCEDURES}

The intent of this study was to find a theoretical sample of ten to fifteen heterosexual baby boomers born between January 1, 1946 and December 31, 1965. Theoretical sampling was most appropriate for this study as confirmed by Patton, (1990/2002) who defines theoretical sampling as the process of selecting, "incidents, slices of life, time periods, or people on the basis of their potential manifestation or representation of important theoretical constructs" (p. 238). Further, the snowball 
sampling technique was systematically applied to identify other participants from the targeted populations. Snowball sampling is a method of increasing the sample by querying one informant or participant to recommend others for interviewing (Babbie, 1995; Bailey, 1996; Crabtree \& Miller, 1992; Holloway 1997). This technique is useful in finding hidden populations or groups not readily accessible (Patton, 1990/2002).

\section{Overview of Participants}

This study sought to explore how heterosexual Baby Boomer men and women define and understand intimacy, sexual expression, expectations and desires relating to their respective expressions across the lifespan and specifically as they think about their current future considering long-term care, and common concerns and issues relating to these two areas facing heterosexual men and women as they age. Silverman (2006) recommended that the qualitative researcher first determine the "parameters of the population that we are interested in and choose our sample case carefully on this basis" (p. 306). All participants in this study were heterosexual Baby Boomers, residing independently in their own homes, in the Kentucky and south central Indiana region, up to and including, Indianapolis,

Indiana. Ages range from 51 to 69 years, eight of the participants was male, five were female, all but two were Caucasian. One of the participants had less than a high school education, five participants graduated from high school, and seven of the participants had varying levels of college education, (two Associates degrees, one BA/BS, two MA/MS, and two Ph.D.s), The 
design of the study was such that efforts were made to focus upon the unique experiences, definitions, and understanding of intimacy and sexual expression across the lifespan, beginning from childhood through adolescence (Age 0-19), early adulthood (Age 20-40), Middle Adulthood (Age 41-64), and Future Time (Present Age Forward).

\section{Individual Participant Descriptions}

\section{Lila}

Lila, is a 62 year-old Caucasian female, reared in the Roman Catholic Church, holds two post-graduate degrees, has been married and divorced twice, the mother of one child, currently single, and is employed as an actress, She has experienced a variety of relationships over the past 62 years. On her timeline she wrote, "first marriage" at age 18 . Next, at age 22 she wrote, "one time sex with a man who primarily identified and lived as gay." Between ages 23 and 28 she wrote, "multiple partners (some only once) approximately 8 total”. At age 28 , she wrote, “ $2^{\text {nd }}$ marriage". Between ages 48 and 52 she wrote. "nearly 0 sex or intimacy," then from age 55 to age 60 she wrote, "One partner a self-professed bisexual male". From age 59-61, she wrote, "several nonsexual but very intimate relationships". From age 62 and beyond, Lila wrote, "I hope to find an intimate partner!" Lila described her mother and father's relationship saying, “... my parent's marriage was a little sick and twisted. My dad was an alcoholic and he obviously adored my mother, drunk or sober, and it wasn't like he was drunk all the time. And he did adore my mother, but he behaved very inappropriately in front of us. Fondling her in front of us. That's one thing. He didn't have much in the way of boundaries. 


\section{Sarah}

Sarah is a 55 year-old, bi-racial female, has earned a post-graduate degree, identified no religious affiliation, married once and never divorced, and is a mother with adult children who no longer live at home. She and her husband live in a single-family home located in a south central Kentucky city. She wrote on her timeline, age 12, lost virginity, between ages 12 and 26 she wrote that she had multiple partners that were only sexual. She identified on her timeline that between the ages of 23 and 25 that she had a long-term relationship with a man 28 years her senior and at age 26, she married her current husband. Sarah was a victim of sexual abuse by her stepfather that lasted throughout out part of her childhood until late adolescence.

\section{Karen}

Karen is a 51 year-old Caucasian female, affiliated with the Roman Catholic Church, has earned an Associate's degree, married four times and divorced three times, she is currently married to Ed, they reside in a single-family home located in a midcentral Indiana city. Karen began writing on her timeline at the age 17 mark. She wrote that she has her first sexual experience at that age besides kissing and at age 18, she had sexual intercourse for the first time. Entering early adulthood, at age 20 she wrote that she "had several sexual partners, mostly friends, not boyfriends and one night stands" exclaiming, "Loved it!'. She also wrote that she was married at age 20 and that her husband was abusive, raping her several times. At age 21, she wrote, "had daughter, left husband, divorced". From age 21-23, Karen wrote, "more sexual partners". At age 24, she wrote, "I got cancer and also got married." She wrote that her son was born when 
she was age 25 and that this marriage ended in divorce at age 27 . She then wrote, "I had lots of sexual partners, married again at age 29." At age 45, Karen wrote, “there were years without sex, he was emotionally abusive and it was 15 years of living in a blackhole, he was emotionally closed off, got divorced, moved in with boyfriend and had cancer that lasted 5 years." At age 50, she wrote, "broke up, met new boyfriend, got married, I don't really want to have sex, I'm very sick." At age 51, she wrote, "I would like to want sex more. Love intimacy. " Karen wrote that she wanted to be with her husband in their own home in the future time phase of the timeline, she wrote, " I would never want to be separated from him."

\section{Margaret}

Margaret is a 59 year-old Caucasian female, no religious affiliation, who earned a high school diploma, a mother, was married and divorced once, resides in an apartment and is currently single. Margaret wrote within the childhood through adolescent phase of the RPL between age 2 and 13, "sexually abused by my father" At age 15, she wrote, "raped by a stranger." She also wrote that during year 16, "had sex with a boy I liked." Between ages 16-20, Margaret wrote, "sex with many partners, most acquaintances, some friends, " and at age 18 wrote, "met man I married." During the early adulthood phase of the RPL, at age 21 Margaret wrote, “married.” At age 22, she wrote, "had sex with a stranger." At age 33, she wrote, "left husband" and at 35 wrote, "divorced." At age 35 she wrote, “romantic relationship with a woman.” During this phase, at age 37 she wrote, "Celibate, masturbated, read porn," and that this practice extended until age 46. 
During the middle adulthood phase of her timeline, she indicated that her period of celibacy continued until age 46 . At age 47 she wrote, "sex with friend-friends with benefits." She wrote, "very sexually active, sex with boyfriend." from age 53 through 59. At age 59, she broke up with her with her boyfriend of six years adding, "before breakup we added another woman to our relationship. She was with us for about 5 months before break up. She is still with him." As she approaches the end of this phase of the life course, Margaret writes, "would like to find a person in my life to be sexually active with. Not opposed to brief sexual encounters."

The future time phase of Margaret's RPL included one statement where she wrote, "Intend on staying sexually active until I die."

\section{Lisa}

Lisa is a 63 year-old Caucasian female, affiliated with the Roman Catholic Church, has earned two post graduate degrees, is a mother of one child, has been married twice and divorced once. She is currently resides in a single-family home with her husband within large urban city in north central Kentucky. During the childhood through adolescent phase of the RTL, Lisa wrote at age 11, " ${ }^{\text {st }}$ crush, age 14, "I ${ }^{\text {st }}$ boyfriend," age $15, " 1{ }^{\text {st }}$ kiss," and age $29, "{ }^{s t}$ marriage." During the early adulthood phase at age 27 Lisa wrote on her RTL, "2 ${ }^{\text {nd }}$ crush," age 31, " $1^{\text {st }}$ marriage divorce," age 36, "dated 3 or 4 individuals, 3 sexual partners," and at age 36, "2nd marriage 1987.

In the middle adulthood phase of the RTL, Lisa wrote at age 40 through age 60 , "many male friends of varying degrees of intimacy but no sex except with spouse." At age 47 she wrote, "close male friend for 3 years, no sex." At age 53 she wrote about 
another relationship that she has maintained for 12 years, "close, (intimate) male friend, no sex." She includes a comment spanning ages 36 through her present age, "sexual activity diminishing over time, fidelity intact, still married 27 years." Lisa made no notations or comments within the future time phase of the RTL.

\section{Gary}

Gary is a 62 year-old, African American male, a Protestant Christian, has earned a Bachelor's degree, a Vietnam era naval veteran, is a father of adult children, he has been married twice and divorced once. He lives with his wife in a single-family home in a south central Indiana city. Gary wrote on his timeline, "At age 13 my thoughts and desires were very obvious," and at age 15 he wrote that he had his "first sexual encounter". Between the ages of 40 and 61 , he wrote on his timeline, "still exhibit a strong desire and very active". Gary did not write much information on his timeline thus the interview questions were general rather than specific as with most of the participants.

\section{Michael}

Michael is a 61 year-old Caucasian male, reared in the Roman Catholic Church, holds three postgraduate degrees, and has been married twice and divorced once. He lives with his wife and one child still at home and his other two children are on their own and have their own lives. Michael shared much on his timeline about his childhood relationships with girlfriends, his first experience with sexual intercourse, and his first marriage at age 21. Michael also wrote about having two extramarital affairs during his first marriage at age 25 and again at age 30 . He indicated that he met his second wife at age 41 and married her three years later. By age 55, he wrote on his timeline concerning 
his marriage, "There is no sex and no intimacy". He also wrote on his timeline between ages 41-51 about having “... a very intimate relationship with a friend with no sex involved and no sex with current wife for the past seven years."

\section{Dave}

Dave is a 54 year-old Caucasian male, grew up in the Baptist Christian faith tradition and converted to Roman Catholicism before he married. He earned an Associate's degree, and is the father of three children who all live on their own. He has been married once, is currently separated from his wife and in the process of a divorce. During the childhood through early adolescent phase of his RTL he wrote, at age 12, "Boyhood friend introduced me to masturbation." At age 13, he wrote, "Church deacon molested me." At age 15, he wrote, "Began short relationship with a girl, same age, no sex," and "introduction to porn print material." At age 19 he wrote, "Had sex for the first time with girlfriend who later engaged to. " During early adulthood, Dave wrote at age 20, "One night stand." From age 20 through age 34r he wrote, "Frequent sex with wife. At age 35, he wrote, "Close relationship with involved another close couple, several occasions we had sex in the same area together. Light swapping on a couple of occasions, one serious, visited a nudist [venue] together, and the female and I had one failed attempt at sexual intercourse." Additionally within that phase at age 43 he wrote, "Neighbor across the street and I had romantic interest, kissing, hugging, fixed things in her house, never any real sex (phone sex once)." His timeline indicates the relationship with the other couple continues to exist in the middle adult phase and the relationship 
with his neighbor continued into that phase until age 53. Dave made no comments or notations beyond this phase into the future time phase of the RTL.

\section{Richard}

Richard is a 65 year-old, Caucasian male, a member of the Roman Catholic Church, lives alone in an apartment in an urban area and is currently confined to a wheelchair while recovering from hip surgery. He is the father of one male child, has been married and divorced twice, and has earned a high school diploma. He shared much information when he completed his RTL citing a number of dating and sexual relationships including having over 30 sex partners between ages $25-31$. Richard wrote during the early adulthood phase that his first marriage "included lots of sex, but no love and no closeness." At age 31, his second marriage was the result of getting one of his two girlfriends pregnant. He wrote. "There was love and sex and not a lot of time together" Yet, just prior to his second marriage he wrote of his two girlfriends, "I chose the wrong one and regret it to this day". The second marriage ended after he entered the middle adulthood phase of the life course when he was age 42. He wrote, "single-parent, lots of dates and sexual relations, " until 51 when his son became of legal age. He has remained unmarried since end of his second marriage, still dates, and has no serious romantic relationship at the time of the interview. Richard made no notations or comments within the future time phase of the RTL.

\section{Andrew}

Andrew is a 60 year-old, Caucasian male, raised a Roman Catholic, has earned a high school diploma, and has been married twice and divorced once. He currently resides 
in a single-family home with his second wife in a rural area of south central Indiana. He wrote on his timeline that at age 35 "it was the first time he was unfaithful to his wife" in his first marriage. He went on to write, that he had numerous sexual partners, maybe 10 and that he had given up on the marriage. He wrote that between ages $40-49$ that he had several partners. At age 42, he wrote on his timeline, "I got a girl pregnant, divorced my wife, and just wanted to have fun". At age 50 on his timeline he wrote, "I had a light stroke and sex became unimportant". He has experienced some health problems over the past few years and due to his wife's current health problems, is not sexually active.

\section{Frank}

Frank is a retired 68 year-old Caucasian male, no identified religious affiliation, did not finish high school, a father of five children, has between married twice, divorced one, and is a widower. He resides in a single-family home, and is currently single. Within the childhood through adolescent phase of the life course, he wrote at age 15 on his RPL, " $1^{\text {st }}$ girlfriend, no sex.” At age 16 he wrote, " $1^{\text {st }}$ sexual encounter." At age 18 he wrote, "married $1^{\text {st }}$ wife." Age 20 he wrote, "divorced $1^{\text {st }}$ wife, married $2^{\text {nd }}$ wife." During early adulthood, frank wrote one entry at age 23, “affair child born.” No other information was included.

During the middle adulthood phase of his RPL, he wrote at age 57, "death of wife." At age 60 Frank wrote, "online dating and fix ups" and "met Susie" At age 61 he wrote, "Susie moves in." and finishes at age 68 writing, "single, dating again." Frank makes no notations or comments within the future time phase of the RPL. 
Sam

Sam is a retired 69 year-old Caucasian male, no religious affiliation, has a high school education, is the father of seven children, two biological, and five adopted. A naval veteran, he has been married twice, his first marriage ended with the death of his then wife and he is currently married to his second wife. They reside in a single-family home located in a south central Indiana city. Sam wrote no comments during any phase of his RTL. He did make several marks along the phases of his life course denoting ages when he experience intimate or sexual relationships.

\section{Ed}

Ed is a 56 year-old Caucasian male, affiliated with the Baptist Christian faith tradition, a veteran of the United States Army, and has earned a high school diploma, He is the father of two children, has been married and divorced once resides in a singlefamily home with his wife Karen (also a study participant) located in a mid-central Indiana city. During the childhood through adolescent phase on his RTL, at age 10 he wrote, "had my first crush." At age 16, he wrote, "had first real girlfriend, there was dating, kissing, and exploring your bodies." At age 17, he wrote on his time line, "had first experience with sexual intercourse, it was nervous and awkward." At 18, he wrote, "had sex with the sister of the lady I had sex with when 17." Along with that comment, he wrote, "I cared deeply about her, she was a better lady than I deserve. Didn't know how to commit to something so beautiful."

During the early adulthood phase of his RTL, Ed wrote at age 20, "had sex with

future wife." Additionally, at age 26, he wrote, "felt wonderful for 4 years." At age 30, 
Ed wrote, "my beautiful children were with me and I pursued many people." Age 31, he wrote, "had first sexual relationship after divorce." Adding, "she was a wonderful woman but I was still in love with my ex-wife." At age 35, he wrote, had third sexual relationship after the divorce."

In middle adulthood, at age 40, Ed wrote on his RTL, "I had sex with the sister of a good friend I had known since school." At age 42, he wrote, "had sex with my bank teller, led to a nice romance." At age 44, he wrote, "that resulted in an unexpected pregnancy and my son was born from that relationship." At around age 48 , he wrote, " $a$ lady at work, a brief romance, a mistake. My heart is better but a part of my heart still aches for my ex-wife." Then at age 54, Ed wrote, "Met the sweetest lady that I married," adding, "totally committed to loving."

The future time phase of Ed's RTL contained a single comment. He writes, "Be with my wife and cherishing each day as a gift from God. He made her just for me."

\section{Demographics}

There were $13(n=13)$ participants in this study were composed of eight males, and five females. Eleven were Caucasian, one African American, and one Bi-racial. Seven of the 13 participants were married, two of them to each other. The other six had all been married and were currently single. Seven of the participants had earned college degrees, five had earned high school degrees and one did not finish high school. Eight of the participants had been married twice in their lives. One had married three times, and one other had married four times in their lives to date. Three of the participants had been

married once in their lives to date. With regard to divorce, seven of the participants have 
been divorced once, three have been divorced twice, and one experienced three divorces.

Two of the participants had experienced the loss of a spouse. Six of the participants reported having extra-marital affairs, and one reported having friend with benefits relationships. The mean age of females was 58 and the median age, 59. In males, both the mean and median age was 62 . The mean age for the overall study was 60.38 , and the median age was 61 (see fig 1).

\begin{tabular}{|c|c|c|c|c|c|c|c|c|c|c|c|c|c|}
\hline $\begin{array}{l}\text { Participa } \\
\text { nt }\end{array}$ & Age & $\begin{array}{l}\text { Rac } \\
\text { e }\end{array}$ & $\begin{array}{l}\text { Gende } \\
r\end{array}$ & $M$ & D & w & $E$ & CA & EA & MA & PT & EM & FWB \\
\hline Lila & 62 & $\mathrm{C}$ & $\mathrm{F}$ & 2 & 2 & 0 & MA & 1 & 2 & 10 & 0 & 0 & 0 \\
\hline Sarah & 55 & BR & $\mathrm{F}$ & 1 & 0 & 0 & MS & 5 & 11 & 1 & 1 & 0 & 0 \\
\hline Karen & 51 & $C$ & $\mathrm{~F}$ & 4 & 3 & 0 & AS & 0 & 17 & 2 & 1 & 0 & 0 \\
\hline Margaret & 59 & C & $\mathrm{F}$ & 1 & 1 & 0 & HS & 3 & 3 & 2 & 0 & 1 & 2 \\
\hline Lisa & 63 & C & $\mathrm{F}$ & 2 & 1 & 0 & $\begin{array}{l}\mathrm{PH} \\
\mathrm{D}\end{array}$ & 0 & 5 & 1 & 1 & 0 & 0 \\
\hline $\begin{array}{l}\text { Female } \\
\text { Subtotals }\end{array}$ & 290 & NA & 5 & $\begin{array}{l}1 \\
0\end{array}$ & 7 & 0 & NA & 9 & 38 & 16 & 3 & 1 & 2 \\
\hline $\begin{array}{l}\text { Female } \\
\text { Mean }\end{array}$ & 58 & NA & NA & 2 & 1.4 & 0 & NA & 1.8 & 7.6 & 3.2 & $\begin{array}{l}.0 \\
6\end{array}$ & 0.2 & 0.4 \\
\hline $\begin{array}{l}\text { Female } \\
\text { Median }\end{array}$ & 59 & NA & NA & 2 & 1 & 0 & NA & 0 & 7.6 & 2 & & & \\
\hline Gary & 62 & AA & $M$ & 2 & 1 & 0 & $\begin{array}{l}\mathrm{BG} \\
\mathrm{S}\end{array}$ & 1 & 11 & 6 & 1 & 0 & 0 \\
\hline Michael & 61 & C & $M$ & 2 & 1 & 0 & $\begin{array}{l}\text { PH } \\
\text { D }\end{array}$ & 0 & 4 & 1 & 0 & 2 & 0 \\
\hline Dave & 54 & $C$ & $M$ & 1 & 1 & 0 & AS & 3 & 1 & 1 & 0 & 0 & 0 \\
\hline Richard & 65 & C & $\mathrm{M}$ & 2 & 2 & 0 & HS & 1 & 30 & 9 & 0 & 6 & 0 \\
\hline Andrew & 60 & C & $\mathrm{M}$ & 2 & 1 & 0 & HS & 0 & 11 & 9 & 0 & 10 & 0 \\
\hline Frank & 68 & C & $M$ & 2 & 1 & 1 & ND & 2 & 3 & 1 & 5 & 1 & 0 \\
\hline Sam & 69 & $C$ & $M$ & 2 & 0 & 1 & HS & 6 & 2 & 1 & 1 & 1 & 0 \\
\hline Ed & 56 & $C$ & $M$ & 3 & 2 & 0 & HS & 1 & 2 & 3 & 1 & 0 & 0 \\
\hline
\end{tabular}




\begin{tabular}{|c|c|c|c|c|c|c|c|c|c|c|c|c|c|}
\hline $\begin{array}{l}\text { Male } \\
\text { Subtotal }\end{array}$ & 495 & NA & 8 & $\begin{array}{l}1 \\
6\end{array}$ & 9 & 2 & NA & 14 & 64 & 31 & 8 & 20 & 0 \\
\hline $\begin{array}{l}\text { Male } \\
\text { Mean }\end{array}$ & 62 & NA & NA & 2 & $\begin{array}{l}1.1 \\
3 \\
\end{array}$ & .25 & NA & $\begin{array}{l}1.7 \\
5 \\
\end{array}$ & 8 & $\begin{array}{l}3.8 \\
8 \\
\end{array}$ & 1 & 2.5 & 0 \\
\hline $\begin{array}{l}\text { Male } \\
\text { Median }\end{array}$ & 62 & NA & NA & 2 & $\begin{array}{l}1.1 \\
3 \\
\end{array}$ & .25 & NA & $\begin{array}{l}1.7 \\
5 \\
\end{array}$ & 8 & $\begin{array}{l}3.8 \\
8 \\
\end{array}$ & 1 & 2.5 & 0 \\
\hline Total & 785 & NA & NA & $\begin{array}{l}2 \\
6 \\
\end{array}$ & 16 & 2 & NA & 21 & 102 & 38 & 11 & 21 & 2 \\
\hline Mean & $\begin{array}{l}60.3 \\
8 \\
\end{array}$ & NA & NA & 2 & $\begin{array}{l}1.2 \\
3 \\
\end{array}$ & $\begin{array}{l}0.15 \\
3 \\
\end{array}$ & NA & $\begin{array}{l}1.7 \\
6 \\
\end{array}$ & $\begin{array}{l}7.8 \\
5 \\
\end{array}$ & $\begin{array}{l}2.9 \\
3 \\
\end{array}$ & $\begin{array}{l}.8 \\
5 \\
\end{array}$ & $\begin{array}{l}1.6 \\
2 \\
\end{array}$ & $\begin{array}{l}0.15 \\
4 \\
\end{array}$ \\
\hline Median & 61 & NA & NA & 2 & 1 & 0 & NA & 1 & 4 & 2 & 1 & 0 & 0 \\
\hline
\end{tabular}

This table represents participant demographics including age, race $(\mathrm{C}=$ Caucasian, $\mathrm{BR}=$ Bi-racial, AA= African American), gender, marriages (M), divorces (D), widow/er (W), education (E), and number of sexual partners in each phase of the lifespans identified by the participants on their RTL. Childhood - Adolescent (CA), Early Adulthood (EA), Middle Adulthood, (MA), and Present Time (PT). Additional information identifying extramarital relationships (EM), and friend with benefits (FWB) are included.

Where participants wrote "Multiple Partners" within age ranges in any of the phase, they were calculated as one partner per year of the of the participants identified age time frame.

\section{DATA GATHERING METHODS}

\section{Instrumentation}

Study participants were asked to complete The Rappaport Time Line prepared specifically to gather data across four phases of the life course, including childhood through adolescent, early adulthood, middle adulthood, and future time. This involved presenting subjects with an 8.5 inch $\mathrm{x} 14$ inch sheet of paper that had been prepared with a timeline clearly identifying the different phases of the life course and an enclosed box of timeline instructions that read, 
Mark the timeline with regard to romantic relationships (including those that are simply sexual and those that include closeness but little if any sexual expression) for each category. Please mark significant life experiences and their ages related to intimacy and sexual expression on the life. Participants were told that the timeline represents their entire life, and asked to place significant life experiences on the line. The participants were asked to mark off particular time intervals on an essentially empty time line. The only contextual cues were provided by the researcher identifying developmental phases across the life course.

Lengthy, semi-structured interviews were conducted with the sample heterosexual Baby Boomers using a list of initial questions with the understanding that the interviewer would probe as necessary. Fontana and Frey (1994) suggested that the role of the semi- structured interviews with a somewhat directive approach by the interviewer are most appropriate for gaining phenomenological data. They further suggested that the interviewer capitalize on the role of participant in order to get beyond the simple details of an event in order to discover the motivations leading up to the event. In this context, the researcher becomes part of the interview process, rather than a detached observer, which is characteristic of hermeneutic phenomenology. This approach is recommended whereby 'in trying to understand the 'other' we learn about (our) 'selves,' reaching the hermeneutic circle, that is, the circle of understanding" ( $\mathrm{p}$. 714). Each interview was audio taped and transcribed verbatim. The intention of the interviews was to reveal shared experiences that may be unique to the Baby Boomer generation. 


\section{Data Analysis Procedures}

The transcribed interviews provided a tremendous amount of data from the thirteen subjects that required close examination and careful coding in order to find emergent themes and deeper meanings. The interviews consisted of a prepared set of open-ended directed questions along with questions generated unique to each participant's comments on their individual RTL with the option to probe where appropriate. The research used these questions to direct the course and topic of the interview, while attempting to reduce the possibility of prompting by the researcher. The interviews lasted approximately one hour; with data being time stamped for accuracy, and was audio taped using a digital tape recorder. Each interview was later transcribed, word-for-word by a contracted transcriptionist. The researcher then reviewed each recording against the transcribed document. During the interviews, twocolumn memoing was utilized in order to separate commentary from the subjects from thoughts of the interviewer in an effort to reduce bias. It was the researcher's intention as a member of the Baby Boomer generation himself to record both pre-conceived notions prior to gathering data and his thoughts and reactions as the data was being

gathered. This approach provided a lens by which the experiences of the subjects may be viewed and interpreted.

The coding process consisted of open coding initially of all data without consideration for types and number of categories followed by a focused coding used in order to review the collected data (Lofland \& Lofland, 1995). The second researcher reviewed the codes and emerging themes from an unbiased perspective testing the compatibility of themes the first researcher identified 
with the whole of the text in order to build reliability in themes analysis coding (Hosmer, 2008) . It was necessary to reject some portions of the data and combine other portions in order to create specific categories and reveal these emergent themes. After final themes had been identified, they were emailed to the participants to collect input, questions, or concerns. This strategy was employed to add rigor to the study such as "member checking" which was achieved by getting agreement from the participants on the emerged results (Creswell, 1994; Creswell 2009; Marshall \& Rossman 2006; Speziale \& Carpenter, 2007). Again, none of the participants offered input regarding the identified themes An audit trail method was utilized in order to demonstrate the raw data as well as the decision making process along the course of the research. At the conclusion of this process, all data was carefully analyzed and compiled for the findings chapter. The theoretical framework that supported this research was continuously examined in light of the findings and current literature by other researchers was compiled over the course of this study. Finally, recommendations for further research were suggested along with the findings of this study.

\section{ETHICAL ISSUES}

This study examined the perceptions of thirteen heterosexual Baby Boomers. As these individuals were the focus of the research, careful measures were taken to respect the privacy and confidentiality of the participants of this study. Fontana and Frey (1994) pointed out that great care must be taken to ensure that each participant has been provided with informed consent, the right to privacy, and protection from physical, emotional, or any other kind of harm. Each participant in this study was made aware, in writing, of the intent and scope of this research, and was by no means 
compelled to participate. University of Louisville Institutional Review Board (IRB) procedures were followed as human subjects were involved in this study. Pseudonyms were used in the place of real names and participants were given opportunities to review interview responses for accuracy before any data was reported.

\section{LIMITATIONS OF STUDY}

There were several limitations to this study. The first limitation was that all participants are heterosexual. The participants were drawn from only seven communities, which are located in rural and suburban areas in the north central portion of the State of Kentucky and the south and the mid-central portion of the State of Indiana. The variety of these communities provided a snapshot of Baby Boomers in various settings and yet was by no means complete. Adding to this limitation was a lack of ethnic diversity, with ten of the twelve participants being Caucasian, one being African- American, and one of mixed Caucasian American-Japanese descent. These numbers were fairly consistent with the minority population in the two states, and nation; however, they did present a limitation based on the possibility of overgeneralizations that may be drawn from the small sample of minority participants.

Other limitations can be found in the nature of qualitative research. As the researcher was heterosexual Baby Boomer himself, certain biases may have had some influence on the findings of this study. Although, it was not the intent of this research to bracket out the experiences of the researcher, it was imperative that each participant be allowed to share and reflect upon their experiences in addition to, rather than in light of, the perspective of the researcher. In addition, the researcher drew conclusions based 
upon the time lines and interviews of the subjects, which may ultimately lead to more questions, rather than answers. It is important to note here, however, that the intent of this research was to examine intimacy and sexual expression across the life course of heterosexual Baby Boomers with regard to their intimacy, sexual expression concerns and expectations in the future. Specifically, those understandings and expectations within the context of long-term care, the process of doing so, and the experiences that have shaped their current understanding, definitions, and expectations No hypotheses were formulated, no statistical data was computed, and there was no effort to generalize the results to other settings.

It is possible that the findings will be useful for long-term care providers, geriatric sexuality education programs, state and federal policy makers, administrators who may be preparing to meet the needs and expectations of the Baby Boomers that will come crashing into their programs. However, the purpose of the study is to understand how heterosexual Baby Boomers understand, define, experience, and expect their intimacy and sexual expression needs to be met as they enter into this phase of the life course. As expressed by Ary et al. (2006), "the ultimate goal of this type of inquiry is to portray the complex pattern of what is being studied in sufficient depth and detail so that someone who has not experienced it can understand it" (p. 450). In many ways, qualitative studies are the telling of stories. With that in mind, it was important that these Baby Boomers were allowed to tell their stories with the objective of providing data. At the same time, recognizing that it may not necessarily be generalized to larger audiences, may nonetheless provide valuable information for other researchers, long-term care providers/administrators, geriatric educators, social work 
practitioners, as well as state and federal policy makers.

\section{SUMMARY}

The purpose of this study was to understand the phenomenon of how heterosexual Baby Boomer men and women define and understand intimacy, sexual expression, expectations and desires relating to their respective expressions across the life course through their individual experiences and reflections, Specifically as they think about their current future considering long-term care, and common concerns and issues relating to these two areas facing heterosexual men and women as they age. A set of guiding questions were developed and a qualitative research design was chosen. Data was gathered from thirteen subjects through their Rappaport Time Line and a lengthy, semi-structured interview, and follow-up interviews.

Transcription of interviews, as well as coding, sought to identify emergent themes and areas for further research. The study provided insight into the phenomenon of how heterosexual Baby Boomer men and women define and understand intimacy, sexual expression, expectations and desires relating to their respective expressions across the life course and into future as they relate to potential residency in long-term care. 


\section{CHAPTER 4}

\section{FINDINGS}

Over the course of many hours of interviews of these 13 baby boomers, the researcher has sought to answer five important questions. These guiding questions are as follows:

1. How do aging heterosexual Baby Boomers define intimacy and sexual expression?

2. How are Baby Boomer definitions and expressions of intimacy influenced by experiences across the life course?

3. How do Baby Boomers envision defining/expressing intimacy in the future?

4. What is the intimacy and sexual expression concerns of Baby Boomer males and females in the present and the future?

5. How do older adults share major concerns related to the intimacy and sexual expression issues surrounding their aging including long-term care needs in the future, and have the aging men and women developed thoughts regarding solutions that address their major concerns?

After the data was collected and coded, a number of specific themes began to emerge that would provide answers to the questions guiding this research. This chapter is structured with a review of each research question being addressed, the themes extracted from the answers of male and female participants to each question, illustrative stories and quotes exemplifying each theme and some summary comments regarding each question. In addition, since each of the 13 participants created timelines of their sexual experiences 
over the course of their lives, additional themes and insights gained from those timelines are included as a part of the responses to the questions.

\section{Question 1:}

\section{How do aging heterosexual baby boomers define intimacy and} sexual expression?

I first examined participant descriptions of intimacy. One overarching finding was that it was difficult for participants to simply define intimacy without also relating it to the concept of sexual expression. In addition, participants tended to discuss how they came to understand intimacy across the lifespan, since for many of them, their understanding of intimacy changed over time, even if that change was slight. Finally, while the roles for men and women were changing over the course of the lives of Baby Boomers, the tone and content of the responses was often different for men and women. Thus, the answers for men and women were examined within gender clusters as well as individually. Two themes emerged regarding how participants understood intimacy 1) Change in views about intimacy and sexual expression over time: Two male and one female participant began defining intimacy and sex as the same or intimacy as an exchange for sex, but changed that opinion later in life. As they developed their understanding of relationships, they came to understand intimacy as being one thing and sexual expression as another. 2) Consistently viewed intimacy and sexual expression as different: Five male and four female participants learned in adolescence or early adulthood that intimacy and sex were different. They essentially always saw intimacy and sex as different (few people talked about views before adolescence). Later they come to think of intimacy 
as having many attributes stemming from "being in love," or stemming from love. Once the themes regarding how participants came to understand the meaning of intimacy in their relationships were explored, additional themes regarding how intimacy was defined emerged and follow a deeper examination of the timing of intimacy understanding (Appendix I).

\section{Change in views about intimacy and sexual expression over time.}

Andrew explained that until he was in his late 20's, he saw no difference in intimacy and sex. After that time, Andrew emphasized the importance of romantic love and identified both verbal and physical expressions. He said, I think it came down to two people being in love. You really couldn't be intimate with anybody other than someone you loved. Kissing, holding, telling them you love them. I don't know what else to say. Sam indicated that in his first marriage, his understanding of intimacy was an exchange for sex and maintained that understanding until his second marriage. Sam described his understanding and meaning of intimacy in his first marriage saying, I got close to her because if I wanted sex, I got my sex. In his second marriage, he has added to his definition of intimacy saying, We'll, kiss on a goodbye. Kiss on a hello. Anytime we talk to each other, "Okay, I love you. I love you a whole lot.

Margaret described her understanding and meaning of intimacy before age 47 saying, Intimacy [meaning sex] was how I expressed that I loved somebody and that's because having been molested by my dad for so long and at such a young age, that's just how I equated love. I don't think I really thought anything different. I mean, that's just how it was supposed to be. I believe I was intimate with my husband, but I don't think I had [known] the difference between sex and intimacy. 
Margaret made a distinction between intimacy and sex during middle adulthood at age

47. She disclosed her understanding and meaning of intimacy identifying a need for

emotional, physical connection, spending time together, and shared interests. She said,

We would just sort of stare into each other's eyes and I had never had as much feeling and intimacy from another person as I did with this person. We would cuddle. We would hold hands. Just sit and listen to music together with our arms around each other. We fit together very well even though he was like 18 years younger than I [was].

\section{Viewed intimacy and sexual expression as different}

The majority of participants viewed intimacy consistently across the lifespan as involving a number of attributes such as listening, sharing everything, being supportive, being committed, being authentic, emotionally safe, emotionally protected, and affectionate as illustrated in the following quotes. Ed understood sex and intimacy to be different during his adolescent years. He described at age 17 that it was important to listen, genuinely care, be a friend, sharing anything and everything in addition to any sexual interactions saying, ...being a good listener. I tried to be like friend. Sharing anything and everything. I tried to genuinely care about somebody before I [gave] myself like that. He eloquently expressed his understanding and meaning of intimacy saying,

Yeah, I liked to spend a lot of time getting to know what I was getting into and it was kind of fascinating to me how a particular [girl] ticked or how different [they were] about their emotional needs or depending on what their life experience had been or how that molded them. It's kind of fascinating.

He also included how important, sharing anything and everything, was in his definition of intimacy as well as both verbal and physical expressions as he stated,

I tell her I love her all the time, but she doesn't have to ... It's easy for me to tell her. Show her. It makes me happy to do for her. She appreciates it. I know she does. It's good to completely, I mean, I'm hers, she's mine. You know? She's my heart's desire. She makes me happy. 
Dave explained his definition of intimacy at multiple levels separating intimacy from sex during his adolescent years. He said,

I don't think I really understood much about intimacy until I was probably during that age of 16-17. Me and some friends that I lived close to, close friends with, we started going up to a town skating rink and we were introduced to a lot of girls. Some of my friends started dating at that time. That's, they started getting into deeper relationships and that's probably when I would really perceive the notion of having a long-term relationship with someone of the opposite sex. The relationship meant that you were a couple and you were sharing things. You know, that kind of an intimacy ... To achieve that intimacy, you got to have trust and faith and commitment ... I think intimacy potentially grows and that intimacy may include other people than just your wife.

Richard made a distinction between intimacy and sex while in early adulthood in his late 20's and described his understanding and meaning of intimacy saying,

You have to share your feelings, not just your body. He also emphasized the communication was required when reflecting on his failed marriage, saying ... it let me know how important communication was to intimacy.

Gary also made a distinction between intimacy and sex during early adulthood during his late 20 's. He described his understanding and meaning of intimacy as being "in tune" with his spouse, saying,

Meaning, I'm more in tune to whether she wants to or not and I'm more conscious of her desires more so than mine. I guess I'm more in tune now. He also shared the importance of including physical and verbal expressions as being part of an intimate relationship saying, touching, hugging, holding, and even just a conversation of one, to get into a good conversation could be an intimate relationship.

Michael's distinction between intimacy and sex occur during early adulthood in his late 20's. He shared his meaning and understanding as being a deep relationship that would ideally include sex, though it is not necessary saying,

That if someone would have intimacy you got to have the sexual intimacy but you also have that heart intimacy where you both are on the same page and if you can get those two together, you're lucky. You hit the jackpot.

He expanded his understanding of intimacy saying, 
This deep, deep friendship. It's interesting because now intimacy is switched from the sexual act to more of a heart connection. So, it would be nice if there was something who I could have both, but since I don't, this heart connection that I have with my friend seems to fulfill me. It is very intimate. She's someone that I can call and complain to and I can tell I had a miserable day and she won't try and fix me. She'll just listen to me. What I consider more of an adult intimacy.

These five men viewed intimacy as expressing love, being connected, being supportive and being reassuring about their level of commitment to the other person. The women's responses paralleled those of the men regarding descriptions of intimacy and for the most part were more descriptive. Sarah made a distinction between intimacy and sex in early adulthood during her mid 20's. She shared several elements in how she understood intimacy and the importance for communication, intellectual, and affectionate connection, saying,

You really need to have that communication. I think we were able to talk about different things. I felt comfortable talking to him about different things. I talked to him about my father and growing up being lost and such. He worked in a women's prison as one of his numerous jobs. We would share stories and things. Actually, I wish I could have that relationship with a man today because being in social work I'm in a lot more different, I could pick his brain in a lot of different areas than I did ... I think it's the affection. That touch on the arm or that squeeze. He likes to come by and squeeze my.

Lila made a distinction between intimacy and sex during early adulthood when she was

22. She described her understanding and meaning of intimacy as including being wanted, being emotionally and intellectually authentic, and not just about sex saying,

Somebody wanting you in their presence. Somebody who was, as we say to our own children, I'm so glad you are here with me. That was what I wanted. From family, from friends, from certainly boys. Not so much from girls. There's somebody that I can have that level of being completely myself and he's completely himself and we know each other's shit and it doesn't matter and he enjoys me and I enjoy him. I liked and so it became very quickly after that, after that started happening where I felt like this person really saw who I was and enjoyed who I was and it wasn't just about the sex which was amazing. It wasn't just about the sex. It was an intimacy of the minds as well and I felt like in some ways this was my soul mate. 
Karen made a distinction between sex and intimacy during early adulthood in her early 20's. She disclosed the importance of being able to be emotionally safe, intellectually and emotionally authentic, and complete acceptance, saying,

Emotional and physical safety. That you could express yourself. That you could totally be yourself and the other person would be accepting ... understands all of those things that I'm able to tell him. You know, those things. So, I got sick again in October. Just this last October. In 3 weeks, gained 45 pounds. When you got somebody who already had a body issue because she gained 10 pounds, you know what I mean? Now, I can't lose it because of the way my body is, it's not strong enough. They can't figure out what's wrong with me, but something's wrong with me. I can't do a lot of the same things that I used to do. I just got comfortable with Ed and this part of me whenever I got sick and got fatter and it's like, if you don't feel good about yourself then it's hard to you know? He's like, I love you, and it doesn't matter. I still see you the way I saw you the first day. I'm sure he'll probably say something like that. He doesn't see that extra, well some of it did go away because it was fluid or whatever. He doesn't see the extra 35 pounds like I do.

Lisa made a distinction between intimacy and sex during adolescence. She discussed her understanding and meaning of intimacy as spending time together, self-disclosure, being physically close, honesty, sexual/physical intimacy, kindness, acceptance, and supportive saying,

Intimacy, closeness, getting to know each other, caring about each other, being physically close, sitting next to each other in the car, holding hands, making out, that kind of stuff. Well, I think closeness as in honesty, as in physical intimacy, physical/sexual intimacy, sexual expression, but a lot of it would be just closeness as in honesty, kindness, acceptance ... To be supportive of him.

In examining all of the responses regarding the definition of intimacy, besides the themes for the definitions of what constitutes intimacy in relationships, it was evident that those that differentiated between intimacy and sexual expression relatively early in life (at the beginning of romantic relationship formation in adolescence and early adulthood), had richer definitions of what it means to be intimate with another person. For example, the three participants that changed their views of intimacy across time all described one 
type of intimacy- that of expressing love verbally and physically. This type of intimacy is the closest to sexual expression of the four types described by participants in this study. So, while these three folks did grow a bit in their understanding of intimacy, it was largely physical in nature along with some expressions of love. But, those that differentiated the idea of intimacy and sexual expression the longest, also describe in some detail three additional types of intimacy. Thus, four major themes arose regarding the understanding of what intimacy is.

Theme 1) Expressions: verbal (e.g., saying "I love you") and physical expressions of affection and love (such as holding hands, hugging, cuddling, kissing, staring into each other's eyes). Illustrative quotes describing expressions of intimacy include: Kissing, holding, telling them you love them (Andrew); We'll, kiss on a goodbye. Kiss on a hello. Anytime we talk to each other, "Okay, I love you. I love you a whole lot (Sam); We would just sort of stare into each other's eyes and I had never had as much feeling and intimacy from another person as I did with this person. We would cuddle. We would hold hands (Margaret); I tell her I love her all the time, but she doesn't have to ... It's easy for me to tell her (Ed); I think it's the affection. That touch on the arm or that squeeze (Sarah), and being physically close, sitting next to each other in the car, holding hands, making out, that kind of stuff (Lisa).

Theme 2) Connection: having an authentic connection with the other person which can include honest disclosure about personal details of one's life as well as disclosure of values, hopes, dreams and who you are as a person. When intimacy is present, both types of disclosure (or communication) are met with acceptance and lead to 
feelings of closeness. Connection also includes sharing interests, spending time together, being friends and being "in tune" with each other. Some illustrations of connection are: Just sit and listen to music together (Margaret); ... it was kind of fascinating to me how a particular [girl] ticked or how different [they were] about their emotional needs or depending on what their life experience had been or how that molded them. It's kind of fascinating (Ed); it let me know how important communication was to intimacy (Richard); I guess I'm more in tune now (Dave); This deep, deep friendship. It's interesting because now intimacy is switched from the sexual act to more of a heart connection... (Michael); You really need to have that communication. I think we were able to talk about different things. I felt comfortable talking to him about different things. I talked to him about my father and growing up being lost and such (Sarah); There's somebody that I can have that level of being completely myself and he's completely himself and we know each other's shit and it doesn't matter and he enjoys me and I enjoy him... I felt like this person really saw who I was and enjoyed who I was and it wasn't just about the sex which was amazing... It was an intimacy of the minds (Lila); That you could express yourself. That you could totally be yourself and the other person would be accepting... (Karen), and Intimacy, closeness, getting to know each other... Well, I think closeness as in honesty... acceptance (Lisa).

Theme 3) Caring and Social Support: expressions of caring by listening, being there for the other person and giving emotional support when the other is in distress, giving tangible support such as advice, fixing a problem, doing things for the other person, and sharing possessions with the other person all make the couple feel cared for 
and supported. Some respondents discussed signs of caring. ... being a good listener... Sharing anything and everything. I tried to genuinely care about somebody before I [gave] myself like that (Ed); She's someone that I can call and complain to and I can tell I had a miserable day and she won't try and fix me. She 'll just listen to me (Michael); [after she gained 45 pounds] He's like, I love you, and it doesn't matter. I still see you the way I saw you the first day.... (Karen), and ... To be supportive of him (Lisa).

Theme 4) Commitment: having a commitment to each other which is the basis of trust, emotional and physical safety. A promise to complete an action, to follow through with expressed intent, dedication to relationship, devotion to a person or ideal, loyalty or faithfulness, fully giving of oneself to another. Some respondents expressed these signs of commitment ... It's good to completely, I mean, I'm hers, she's mine. You know? She's my heart's desire (Ed); He was like a rock, like an oak ... A solid foundation and I was more creative and much more flowery but more flexible in the wind and So, what is intimacy at this point? Wow. To be where I am. To be supportive of him (Lisa); To achieve that intimacy, you got to have trust and faith and commitment (Dave), and Emotional and physical safety (Karen).

\section{Sexual Expression}

After completing the examination of participant descriptions of intimacy, I examined their descriptions of sexual expression and unearthed four themes. Just as in the discussion of intimacy, sexual expression was also described, sometimes as being the same thing as intimacy and sometimes as a contrast with intimacy. It was difficult for some participants, especially some of the female participants, to simply define sexual 
expression without also relating it to the concept to intimacy. As with intimacy, participants also discussed how they came to understand sexual expression across the lifespan. Finally, there was some discussion of how men and women differ with regards to sexual expression. Frank observed, Men are men and women are women, you know. Men like it more than women, my experience. Dave said he learned from one sexual partner that the woman wants it as bad as a guy does. That's what it taught me because we had sex more than once that night and I just knew she had a voracious appetite [for] sex. It taught me that women were no different than I was really when it came to sex, and Richard said, Oh, I got this funny. I'm like a woman. Certain weeks of the month I get horny but the rest of the time I'm wrapped up in other stuff and don't even think about it. One set of themes focused on how sex was expressed and included: 1) Sexual intercourse: 2) Oral sex; 3) Multiple forms of physical touch (any form of loving touch, i.e. hand holding, caressing of the face, putting an arm around someone, wanting to be close, and to touch), and, 4) Masturbation. As expected, all of the male participants alluded to or specifically identified sexual intercourse as part of their definition of sexual expression, but other men and the women included other forms of sex play and signs of affection in their definition of sexual expression. For example, Dave identified several things as being a part of his understanding and meaning of sexual expression such as touching, kissing, private time, or could be expressed with or without intercourse...

Theme 1) Sexual Intercourse: where sex involved physical penetration. Some respondents expressed sexual intercourse ... I don't know. Just something I got used to. I like it [meaning sexual intercourse] and I wanted to continue it (Frank); sexual expression was intercourse (Gary); We didn't, we sort of, we would try different positions and 
different things like that but it was mainly missionary position. I hate the word 'normal,' but normal sex (Margaret). Describing his experience when serving in the United States Navy, one man said, We had left that port and went to another port and right off the bat he says, "Come on, you're coming with me today." He took me out and I guess it was a whorehouse. I don't remember what the heck it was, but he went and paid for all that and said, "Now, you got this girl. Take them and do the works." So, I learned a lot (Sam);

Theme 2): Oral Sex: Four of the women mentioned oral sex as a way that they express sexuality. Sarah said,

My role has been, the last few years, has been that I take care of him and I take care of myself. That's kind of a wrong way to look at it but it works for us. I'm okay with that. I wasn't okay with it in the beginning when it started happening. When he started having difficulty performing. I kind of felt like this is not good for me and on the rare occasion it's good for you so there's something wrong here. I had to really work on myself and say okay what's acceptable to me? In probably the course of the last, it's probably evolved into that, I would think it's probably due to lack of desire on his part to please me. It's just, I decided for myself that I'll take care of him and I'll take care of me and I'm okay with that. I've always been a big proponent of self-serving. When I talk to teenagers, it's like you have got to self-serve rather than hump all these girls especially when you're riding bareback. You need to learn that if you've got to jack off 5 times a day, that's okay. That keeps you from going out and sleeping with 5 girls in one day because you're horny and you figure somebody else needs to. I've always had that, you should be able to self-serve. I think sexual expression, like I said; I have no problems with taking care of my own needs.

Theme 3): Other types of touch included holding, caressing, kissing and cuddling and sometimes was a precursor to intercourse, ... we did a lot of holding and hugging and kissing and fondling if you want to call it that until at one point, I think it was one night, we discussed having sex with each other. We, by then, we both acknowledged that we were both virgins and I recall we actually made a planned date for that occasion (Dave), All I wanted was just to be able to hold and kiss and love a woman (Andrew); ... it 
ranged from every kind of loving touch whether it's holding hands or the gesture on the face or just you know, putting the arm around you, just sort of you know, I want to touch you, I want to be close to you, I want to physically to be close to you ... That was sexual to me. It actually kind of still is. I can get very turned on very quickly by those sorts of things (Lila); He was very cuddly. I, we would touch a lot (Margaret).

Theme 4): Masturbation in-between relationships, as part of sex play within a relationship, or anytime. For example, Richard included masturbation in his definition of sexual expression as a means of managing his need for sexual release saying,

There's a lot of mutual masturbation more than actual sex. Sex [intercourse] was such an effort that, you know, going to dinner and then going to make out ended up with some mutual masturbation more so than actual sex.

Michael identified masturbation as being an important part of his definition of sexual expression as well, in order to meet his sexual needs and maintain his health saying,

For me, I do masturbate. I do that for health reasons, to tell you the truth, more than anything but also to keep myself still, I still want to be sexually active and involved in my life. But, for me I have to make a choice, like it's like balancing my life right now. Just the way it is and it doesn't mean as I get older that won't change. Maybe there will be a relationship that I'll be able to express my sexual self within the relationship, but for now, it's just not there. Nor do I want it to be there.

Sarah was passionate and shared her inclusion of masturbation into her definition of sexual expression saying,

My role has been, the last few years, has been that I take care of him and I take care of myself. That's kind of a wrong way to look at it but it works for us. I'm okay with that. I wasn't okay with it in the beginning when it started happening ... I've always been a big proponent of self-serving. When I talk to teenagers, it's like you have got to self-serve rather than hump all these girls especially when you're riding bareback. You need to learn that if you've got to jack off 5 times a day, that's okay ... I've always had that, you should be able to self-serve. I think sexual expression, like I said; I have no problems with taking care of my own needs. 
Lisa identified masturbation as sexual expression in response to a question about how she met her sexual needs saying, Oh heck. I learned to masturbate.

Another set of themes focused on who one has sexual relations with. Most respondents described sexual encounters within the context of a relationship while others described sexual encounters that spanned the boundary of a relationship. Some participants even noted who they thought was an appropriate sex partner. Sam noted above having his first sexual experiences with a prostitute and Dave noted that sex could be explored with a married partner,

... it was something that was private between me and one other person. At the time, someone that I was in love with... But eventually came to embrace swinging, ... I felt that I was still learning and growing as far as sexual expression. I had explored a little bit and wanted to continue to explore. I enjoyed sharing sexual expression with my wife. You know, when we were with the other couple all the parties always seemed to enjoy each other's company and enjoyed having that sexual expression.

One of the more interesting aspects of the discussion of sexual expression was how they viewed the purpose of sexual expression. Most saw at least one purpose of sex was to receive (and/or) give pleasure. But, some respondents also described other purposes such as 2) using sex as a way to achieve intimacy, closeness and bonding with their partner and 3) using sex as a tactic to control their partner (punish, manipulate, as something to exchange to obtain what they wanted).

Receive or give pleasure: I wanted to please her and I wanted her to please me. That was basically, what went on. It was a kind of mutual understanding of, I'll be good to you, and you'll be good to me (Andrew); I tried to make my ladies that I was with feel fulfilled (Ed); ...wanting to please someone (Dave); There's a lot of mutual masturbation more than actual sex. I wanted to make her happy and I wanted to have fun because I 
think that's part, if it's not fun it's just doing it because you have to then no joy for either partner. She was kind of moody, still is but we didn't have sex all the time but when we did it was, we had fun (Frank); It was a desire. It was a relieffrom desire, not a relief, but sort of like even a goal to have that relieffrom having intercourse. Sexual gratification. Being able to have as much sex as I wanted. Being able to achieve that climax. Being able to live out my sexual fantasies and desires (Gary); .

Achievement of closeness and bonding through affection and respectful behavior: Ed explained his understanding and meaning of sexual expression to include respect, kindness, holding and bonding saying,

I tried to make my ladies that I was with feel fulfilled, but then I loved the after, us holding or bonding with her. You know, instead of just getting up like I'm done and go get a sandwich. I just because my mother and my grandmother, I was raised by women. I was taught to respect women ... I just, I was trying to go out of my way to treat a lady with kindness and not a piece of meat or whatever.

Others shared this view. Some examples include: a form of love and caring for the other individual (Dave); ... having a good feeling inside and that if someone was willing to be sexual with me, that they cared about me (Michael); All I wanted was just to be able to hold and kiss and love a woman (Andrew); ... it went to being with one person who loves you and who protects you and who was safe emotionally and you had sex when you wanted to have sex and if you wanted to lay on the couch and cuddle, you did that (Karen).

Control Tactic: It felt like sex was something their wives or girlfriends, usually wives, used against them (Andrew). 


\section{Summary}

Based on the majority of descriptions of the participants in the study, heterosexual Baby Boomers define intimacy and sexual expression as dynamic and ever changing across the lifespan. This is especially true with regard to differentiating between intimacy and sexual expression. With the exception of one participant; all study participants made that distinction. The definition of intimacy to heterosexual Baby Boomers include: A relationship with a partner of the opposite sex that includes expressions of being in-love, verbal declarations of love, cuddling, hugging, touching, kissing, and caressing, having a connection through shared interests, spending time together, being a friend and receiving complete acceptance after sharing ones intellect and emotions, and being authentic, caring and being supportive through listening, kindness, and giving both emotional and tangible support and being committed as a foundation for trust, faith, and both emotional and physical safety. A male single outlier participant could not separate the concept of intimacy and sex and defined these two terms the same across the lifespan. It was as if he could not understand the question of how to define both intimacy and sexual expression.

Frank used the terms intimacy and sex interchangeably and did not make distinctions between them at any time during the interviews. He indicated that he did not have a specific meaning or understanding for intimacy, but emphasized how much he enjoyed intimacy saying,

"I didn't really know for sure, but I knew after the first time that I was damn sure going to like that," and added, "I still think it's gratifying. It's far and in between, I still enjoy it when it happens. 
Heterosexual Baby Boomers in this study defined sexual expression as follows: A physical relationship with one's self or between one or more partners, individually or inclusive of more than one partner at a time. These interactions may include sexual intercourse (vaginal penetrative sex), oral sex, other forms of touching and affection and masturbation by one's self and mutual masturbation with one's partner(s). It includes treating partners with kindness and respect recognizing that both genders can have such desire, is for the purpose of pleasure and/or bonding but sometimes can be used negatively to control the partner's behavior. Participants expressed the beliefs that sex can be enjoyed either in the confines of one relationship or can be in the context of an open relationship so that sexual expression is allowed with other partners besides one's spouse. Moreover, it was recognized that some people have a voracious appetite for sex that both genders can have such desire, or either gender may experience low sexual desire across the lifespan or periodically across time.

\section{Question 2:}

\section{How are Baby Boomer definitions and expressions of intimacy influenced by experiences across the life course?}

We next examined the participant descriptions of intimacy within in each phase of the life course as each identified them on the RTL. In turn, participants also discussed how they came to understand intimacy across the lifespan. One male, Frank, could not identify a source that influenced his definition of and understanding of intimacy saying,

I didn't really know for sure, but I knew after the first time that I was damn sure going to like that. It come natural.

Nine themes emerged from the three phases of the life course that include

childhood through adolescence, early adulthood, and middle adulthood (Appendix I). 


\section{Childhood through Adolescence}

In this phase of the life course, we identified three themes that influenced the definitions and expressions of intimacy. 1) Parents: 2) Peer Relationships: and, 3) Girl Friend Relationships. Only the males included a "dating" type relationship along with parents, and peers as influencing their definitions and expression of intimacy. Females identified parents and peers as their influence. One male, Frank, could not identify a source that influenced his definition of and understanding of intimacy saying,

I didn't really know for sure, but I knew after the first time that I was damn sure going to like that. It come natural.

\section{Parents}

Both males and females identified their parents, whether two-parent or single parent, families as an influence to their understanding and definition of intimacy. Some of these parents influenced their children with positive, warm, examples of intimate behavior and others provided examples that were inappropriate. Ed revealed that his mother influenced his definition and understanding of intimacy saying,

My mother had a big influence on my life because my father passed. She had 5 kids and that was a lot of baggage for anybody else to want to get involved with her. Taking on 5. A lot of the good in my heart, I got from my mother.

Lila talked about how her father influenced her understanding of intimacy during this phase of her life course saying,

I wanted to be wanted. I did not feel wanted in my family. Even though I was the oldest and I knew my dad loved me a great deal. My mother did. But again, daddy was inappropriate. Particularly when he was drinking. I felt a great deal of intimacy with him. There was nothing untoward sexually that happened. That I recall anyway. I'm pretty sure nothing did. I've been through years of therapy so I'm pretty sure where that would have come up. But, it was just wanting, somebody wanting to be around you. Somebody wanting you in their presence. Somebody who was, as we say to our own children, I'm so glad you are here with me. That was what I wanted. 


\section{Peer Relationships}

Dave shared that what he knew about intimacy came from his peers saying,

My understanding of intimacy throughout this. I don't think I really understood much about intimacy until I was probably during that age of 16-17. Me and some friends that I lived close to, close friends with, we started going up to a town skating rink and we were introduced to a lot of girls. Some of my friends started dating at that time. That's, they started getting into deeper relationships and that's probably when I would really perceive the notion of having a long-term relationship with someone of the opposite sex

\section{Girlfriend Relationships}

Sam shared his experience with a young lady during this phase of his life course as well as its effects on him saying,

That's when a girl, a year younger than I was, was paying a lot of attention to me. Beautiful looking girl and I'm a shy guy, so I kind of somewhat ignored her. It was on Broadway, which first thing in the morning I used to go to work at that age before I went to school because school was 6 blocks away from where I was right there on Broadway at my dad's business and I'd walk a block down to go to work. She was with her mother in a store next door. Of course, every morning I'd walk by, nothing but smiles. You know I'd smile back and keep on walking. I'm shy and went to work. Well, this one morning she had me pinned down at the bus stop waiting to catch a bus to go to her school. "Hi!" It started and we just hooked up. I was scared to death. I guess I was 15, but scared. I don't know nothing about it. I don't know nothing about it.

\section{Early Adulthood}

In this phase of the life course, we identified three themes that influenced the definitions and expression of intimacy. 1) Marital Relationships 2) Casual Relationships and, 3) Friend Relationships. Similar to the previous life course phase, Frank continued to make no distinction between intimacy and sexual expression as illustrated in his response to a question regarding what intimacy meant to him during this phase of the life course saying,

No meaning to it. Just a one shot deal. 


\section{Marital Relationships}

Frank 's response to how much his marriage influenced his understanding of intimacy saying,

\section{Good relationship.}

When I asked him to explain what that meant, he added that it meant both of them getting along and not fighting.

Ed discussed how much his marital relationship affected his understanding of intimacy during this phase of his life course saying,

Well, made me really selective of who I gave myself to or who I allowed in my life. I'm not scared to death to get involved or take a chance or give your heart to somebody [more] cautious, you know. [Methodical] but don't just jump into something. Yeah, I liked to spend a lot of time getting to know what I was getting into and it was kind of fascinating to me how a particular ticked or how different [they were] about their emotional needs or depending on what their life experience had been or how that molded them. It's kind of fascinating. You know, listening to their life stories and what molded them and how that kind of entwined with mine and what got me where I am today [ in life]. It's kind of remarkable how life has a way of [kicking] people sometimes. If it doesn't kill you, it makes you stronger.

Karen shared how her marital relationship influenced her understanding of intimacy and what it was not saying,

I mean, he was incredibly abusive. The emotional abuse was worse than the physical abuse because that stays in your head. I had a pretty good understanding somehow, of, I mean, I never thought anything was my fault or I never thought I should stay. My mom's response was you made your bed; you have to lie in it. I thought, like hell I do. She didn't even believe me that he was abusive until we actually got divorced. I divorced him as soon as I could. I got pregnant with Jacklyn, we were married for 3 months, and I got pregnant because everybody in his family said if he has a baby, he'll settle down and I believed that. I believe them, you know? That only made it 10 times worse. Back then, in Indiana you couldn't get a divorce when you were pregnant. I had to wait until I had Jacklyn. He was good for about a month and then one time he shoved me while she was in my arms and I left that day and I never looked back. 


\section{Casual Relationships}

Richard discussed how a casual relationship with a woman influenced his

understanding of intimacy in this phase of his life course saying,

Friend, I would just say we were on the same wavelength on values, actions towards others, we weren't afraid to share our thoughts with each other. There's been women that even at that time, you had to watch what you said because you didn't want to get, you were enjoying the sex so much that you didn't want to stop it. But with Billie, that was her name, it was more of a just natural.

He also discussed how casual relationships continued to influence his understanding of intimacy saying,

I learned that sex and intimacy was two different things. As in, very few cases was I intimate and I learned that in order to have a real relationship you have to be intimate. You have to share your feelings, not just your body. I was a little bit manipulative; it was you know, a keeping score kind of thing. Then again, that was the 70 s.

\section{Friend Relationships}

Michael described a friendship with a female outside of his marriage that was more than

casual and not marital that greatly influenced his understanding of intimacy saying,

One of the people that I had an affair with, I really did fall in love with her and it was the first time that I felt that I really wanted to be with somebody and share a life with somebody, but I was already married and it was complicated.

Lila talked at length about the impact of a relationship that she had with a friend during this phase of her life course saying,

I was beginning to understand. I was still married to my husband and actually this gentleman and his partner were friends of his that he had introduced me to and I loved these guys. I thought they were fabulous and they were so unlike anybody else that I, that we, ran around with. I was beginning to understand and to have been able to observe even among friends but especially with these two men not, I was beginning to understand that intimacy was this desire for the other person and didn't always have to be about sex.

I'll tell you the story of that and maybe that will help. I don't know. This was 1970 but the marriage was almost over. We'd been friends with and I was dropping something off at their apartment and I knew that James had been sick quite some time. And nobody knew about AIDS but it was around and nobody just knew and I walked into a situation 
where I knew he'd been sick and I knew he was feeling better physically. I'm very embarrassed by this story and I don't know why, maybe I've never told it to a gay man. They had had a terrible, terrible, terrible fight, terrible fight evidently and he was just beside himself. I mean, just mourning and just worrying you know, oh my god he's going to leave me. You know, it was that bad of a fight. I was, we were close enough that we hugged on occasion and it was pretty much our parting gesture and all that kind of stuff. We were sitting on their couch and I was just kind of, you know it's okay, letting him cry on my shoulder and talk and blah, blah, blah. It was literally one thing led to another and I was shocked, shocked. Not shocked in a bad way but just overwhelmed by "what do you mean this is moving along?" I mean, I didn't say it but in my mind I was like, this is going to go somewhere, you know? He kissed me and said oh thank you and the kiss became something else and blah, blah, blah. We ended up having sex.

He didn't tell me a while back that he had been with women prior to coming out. We ended up having sex. I remember him insisting that he wear a condom. I was like, I'm on birth control pills and it's no, I need to wear a condom. I couldn't quite understand it but I was like whatever makes you comfortable is fine. The sex was so different, very different. There was a lot more appreciation of my body than I had felt from my husband. Kind of an awe of my body and a lot of talk and slowness. It was like something just opened up inside of me. I didn't know anything could be like this and I'm not in love with this guy. I mean, I loved him but I'm not in love with this guy. He has this partner and their going to work this out. I found out later that, in fact, he had what we would now call AIDS. And because he and his partner were both biochemists they sort of had an inkling that there was something that was going on.

But, that particular experience was a great leap forward for me in terms of understanding. If we had not even completed the act, it would have felt like the most intimate thing I had ever with anyone. Especially the emotional height of it because I was truly concerned for him. I mean, he really seemed like he was desperate because of this terrible, terrible fight which I never did completely understand what it was about to be honest. So, from that particular incident, that was the beginning of the end of that marriage. It was, I didn't know it was almost over, but it was in fact. I was like, why should I put up with this when that is available. Not with him, but that is out there. There's somebody that I can have that level of be completely myself and he's completely himself and we know each other's shit and it doesn't matter and he enjoys me and I enjoy him. There's a lightness as well as an intensity and that may have been because I knew he was a gay man and I was very curious about how he lived and how they had sex. I mean, I knew how they had sex but you know what I'm saying.

... I guess I understood for the first time that there could be intimacy. That having sex wasn't just sex. That there could actually be something called intimacy. Which I don't think I had even probably, I'd started to understand that it existed because I observed other people's relationships and saw that they had a way of communicating and a way of knowing each other and a way of looking at each other even in a room full of other people. It made me increasingly dissatisfied with what I had with my husband, which didn't hold any of that. Our life was kind of day to day, to day, to day, and what did you 
do today? Oh great. What are we going to do now? There wasn't any talk of plans or future or what do you really want out of life or anything like that. I didn't know people could do that. So, I'd started to see it and then the time, and watching John and Steve and the whole time it was so interesting.

I remember saying to him after this was over and we were getting dressed and I said, I have a feeling you love Steve. You guys were meant to be together. I mean, you guys are wonderful together and you adore him and he adores you. He said well, this is kind of; it's not time for that. It's just you and me. I remember crying. I want to cry right now. I remember sitting there crying and crying and crying. He said I'm sorry. Did that bother you? I said no, you're just showing me something. I remember saying you're just showing me something and I didn't know what it was to be honest with you. I'm watery. So, I think it did. It just rocked my world in terms of there is something out there that's more important than just getting laid.

Karen shared how her relationships with male friends influenced her understanding of intimacy during this phase of her life course saying,

There was a degree of very good friendship with those people. There were four of them total, in my life. They were my friends and they kind of ended up being fuck buddies. They were not, I guess we had intimacy like in a friendship you would have. Like, support and they wouldn't let anything ever happen to me or anything like that. They would be a little protective in that kind of thing, but the sex was totally separate.

\section{Middle Adulthood}

In this phase of the life course, we identified three themes that influenced the definitions and expression of intimacy 1) Marital Relationships 2) Casual Relationships and, 3) Friend Relationships.

\section{Marital Relationships}

Ed shared how his marital relationship with Karen has influenced his understanding of intimacy at this phase of his life course. He described feeling lonely and unfulfilled, questioning if it was his fate to be alone and had begun wondering if he was better off alone when it happened saying,

It's like she took my breath away. It was like we'd known each other forever it seemed like. It was just, it was so easy. I guess it was supposed to be like that with your perfect one. I never thought, you hear people say that a relationship takes work. You have to 
work at it. I never thought with the right person that it would resemble anything like work. It ought to be pleasant.

Ed described how intimacy with Karen deepened as she experienced health problems and challenges with her self-esteem and how it takes time for her to feel safe opening up to him about things,

I just, I love that she told me her past a long time ago. She doesn't feel good about herself right now in a lot of ways. Her letting me in takes a bit. The joy of being by her side and talking to her, listening to her, it is good for her soul. I like finding that happy spot with her.

His face lights up as he tells me who Karen is to him saying,

She's my best friend. She's my soul mate. She's my very good lover. She's very giving.

Gary emphasized being more focused on his relationship and being in tune with his spouse has influenced his understanding of intimacy in this phase of his life course saying,

Intimacy, I understand intimacy more so now as it's more about a personal relationship, being more into a relationship versus just sex, the touch, it's just more of a relationship now between the male and female viewpoint. I'm more so now in that age frame that you're talking about less self-gratification and more in tune with my partner.

\section{Casual Relationships}

Richard discussed how his casual relationships with females during this phase of his life course influenced his understanding of intimacy saying,

I still think intimacy is sharing yourself, heart and soul, not necessarily physical sex or anything. Letting the walls come down. That kind of thing. In order to that, you have to get to know somebody. Like I said, ladies my age they have this bubble around them that some of them have had husbands who passed away they had to take care of them and stuff and now they want to be out and about without that burden. So, they want to deal with somebody like me. That kind of thing. I don't know, they want to be taken to dinner and flowers and all that kind of stuff. I used to do that and I know what to do, I just don't feel like doing it. 


\section{Friend Relationships}

Michael spoke about the depth of his relationship with a friend and how it has affected

his understanding during this phase of his life course saying,

It's interesting because that friend probably, I've been able to discuss more about intimacy than anybody in my whole life. We have an intimate relationship, yet have never had sex. So she's someone that I call every day. She calls me or I call her and we talk about spiritual matters. We talk about life. We talk about the kids. Our daughters were best friends. They went through grade school and high school together, so we became friends. She divorced her husband and I divorced my first wife and then she never married but then I married. No sexual attraction between us. She may have a sexual attraction towards me but I don't really have a sexual attraction towards her nor do I want to have a sexual attraction because then I think it would mess up this friendship that we've developed. This deep, deep friendship. It's interesting because now intimacy is switched from the sexual act to more of a heart connection. So, it would be nice if there was something who I could have both, but since I don't, this heart connection that I have with my friend seems to fulfill me. It is very intimate. She's someone that I can call and complain to and I can tell I had a miserable day and she won't try and fix me. She'll just listen to me. What I consider more of an adult intimacy.

Sarah discussed how relationships during her 40s influenced her understanding of

intimacy saying,

I think that's when my friendship with other women were important. I'm not saying sexually. I'm just saying to be able to talk to someone about intimate things. Maybe with your partner or with your kids. I think that became important to me. I've had different sets of friends that I do different things with. It's kind of interesting. I've had some that I see maybe once or twice a year but when we see each other, it's like we never, I have college friends that I see once or twice a year. I think around age 40 is when those kind of relationships become important. You know, outside of your partner. When you're in your 20s, because I started so late, when you're in your 30s its more about the kids. You're so and so's mom and when you get together with other people you're talking about kids. That's usually what it revolves around. I think when you start getting into your 40s and the kids are older and doesn't necessarily need you as much, rely on you as much, I think you start broadening this other horizon maybe. You try to find other women that share interests that you like to go shopping or go traveling with or go sightseeing with or whatever.

Margaret shared how her experiences with a friend during this phase of life influenced

her how she was able to put a label on her understanding of intimacy saying, 
That relationship was very intimate. I never really had had a relationship quite like that relationship. I never really, I mean, when I was in high school and all that, I never really dated. We would go out as a group but I never really went out on a date with anyone. This person really wooed [?] me and took me out on dates. We'd go out to lunch together and I would pick up the tab. That was very different for me. That was like because we'd always gone Dutch, you know everybody had gone Dutch. We would just sort of stare into each other's eyes and I had never had as much feeling and intimacy from another person as I did with this person. Just sit and listen to music together with our arms around each other. We would hold hands. We did a lot, a lot of things that I never really thought of as being intimate.

\section{Summary}

The descriptions of the heterosexual Baby Boomer participants in the study of their understanding of intimacy in each of phase of the life course suggest that their understanding is greatly influenced by their relational experiences. Marital relationships are the predominant experiences within the early adulthood and middle adulthood phase that influence their understanding of intimacy. With regard to gender, peer relationships influenced males the most during childhood through adolescents phase whereas females were more influenced by their parents during that same phase of the life course. During the early adulthood phase, male understanding of intimacy was more influenced by their marital relationships whereas casual relationships influenced female understanding of intimacy. Similarly, in the middle adulthood phase of the life course, the male understanding of intimacy was also influenced the most by their marital relationships. Likewise, females described their marital relationships as influencing their understanding of intimacy the most. 


\section{Question 3:}

\section{How do Baby Boomers envision defining/expressing intimacy in the future?}

We further examined the participant descriptions of intimacy within the future time phase of the life course. The study participants responded to questions related to the future time phase identified on the RTL concerning how they envisioned defining and expressing intimacy as they consider that phase of their lives.

\section{Future Time}

In this phase of the life course, three themes emerged that influenced the definitions and expressions of intimacy. 1) Mutual Support: Three male and three female participants shared their future definitions and expressions of intimacy that included being considerate of the health and involvement of a spouse, being present and involved with their spouse, and to locate a partner/spouse with whom they can talk, touch one another, sleep together, share their lives, emotionally and physically supportive, and being together. 2) Friendship: Three males and three females discussed how important they viewed having friendly relationships, investing time with other people in a variety of contexts, whether one-one-one, within social, recreational, or educational groups, as a means of service to others who are alone or lonely and in need of friends. Others expressed having "friends with benefits" situations that include casual sex, seeking out others with opposite political positions to foster stimulating and challenging conversations, and simply being open to any type of friendship regardless of gender or context. 3) Multiple Forms of Physical Connection: One male and three female participants expressed their future definitions and expressions of intimacy to involve physical touch (sexual and nonsexual), including hugs, holding hands, holding another 
person, cuddling, and sitting closely to others. All of them placed a great deal of

emphasis on their need and desire to touch and to be touched by others (Appendix K).

\section{Mutual Support}

Andrew shared that his definition and expression of intimacy involved

consideration for his wife saying,

Well, I feel like my needs and expectations are the same. I sure want to have sex. My wife is a pretty lady and I don't know what to do. I feel like I'm not in the same boat because there was nothing physically wrong with my first wife. This wife, there is something wrong so I don't want to feel like, I feel like I would be very selfish to only want what I want. I think if I only think of myself then I'm not being fair to the marriage. Andrew

Ed envisions his definition and expression of intimacy to be focused on his wife, Karen saying, My intimacy is being there for her. Holding her hand and comforting her and holding her. I just, I just want to be by her side. While Dave had difficulty envisioning how he would define and express intimacy in the future saying,

I don't know what the next phase will be. I would hope that, to meet an interesting lady eventually and hope I find someone who's a match that I can feel intimacy with and lead to sexual expressions. I want a future. I want a partner. I don't like loneliness. I want to have someone to talk to when I come in from work or during the day. I want that person that I love that loves me back. That I care for that person and hopefully [they] feel the same way.

Sarah discussed how she felt that intimacy would become a higher priority than sexual expression describing how she envisions intimacy being expressed with the assurance that she has a partner with her.

I think the intimacy part will grow. Like I said, I think that's going to be more important in the future. The sexual expressions, I know there are people that are in their 80s that are still having intercourse that are still having sex and probably very sexually satisfying lives. I don't view that as a top priority. I think the intimacy part is going to be more 
important. I think being able to weather future storms is important. Know that I got a partner with me if there's a health issue or it's for the kids or those kinds of things.

Lisa also shared that being supporting of each other is an expression of intimacy that she also envisions, saying, To be where I am. To be supportive of him. Karen envisions her definition and expression of intimacy to evolve with time as it has over her life course.

That part was hard for me. How can you put events down in the future when you don't know what's going to happen? I just want to be able to, when I'm not able to take care of myself or when Ed is not able to take care of me, or he needs taken care of beyond what I can do, that we can still be together someplace. I still want to have that same intimacy that we have now. I want to be able to have, and of course, still be sexually active. I don't want that to ever go away. I don't expect that to ever go away. It might slow down, but it's already slowed down a little bit. You know what I mean? So, I think more things will become more important than intercourse. Just like I think, him just being there, and being emotionally safe and being able to have intimate conversation and other physical cuddling and sleeping together and being together like that will become more important and I don't ever want to lose that. Does that make sense?

\section{Friendship}

Dave also described relationships with others besides one's partner is part of his definition and expression of intimacy saying $I$ think intimacy potentially grows and that intimacy may include other people than just your wife.

Richard described his participation in a church program and that he envisions friendship as a strong expression of intimacy saying,

[I'm] an official befriender. A minister, years ago, Catholic, started this for people in hospitals and nursing homes and life in general that just want to be listened to, especially women. They don't want you to solve their problems. They just want somebody to listen to them. So, we have a group at church that are befrienders and we went through extensive training to learn how to be listeners.

Michael related how he envisions his definition and expression of intimacy as being more friendship focused, whether one-on-one or with a group of other people saying,

It's interesting because now intimacy is switched from the sexual act to more of a heart connection. I think that they'll grow from now. I think that they'll mature more and that they'll be something that I'm going to want, not only from another person, but from a lot 
of people. A larger group. So that intimacy maybe in the beginning was on a one-to-one basis but now, I'm finding the older I get, is that I'm getting that intimacy energy from groups of people. From different friends and different things that I do, from a book that I read. It's morphing. It's interesting to watch it. It's morphing from, I think back to when I was a kid, where screwing was my intimacy to now, I'm like wow. If I take a meditation class or something with five people in the room, that can be as intimate as anything that I could want. So, I see myself pursuing that and growing into that, as I get older.

Lila indicated that she had no real interest in sex anymore and was much more interested

relationships. If sex became part of an intimate relationship, she is open to it should their occur an opportunity saying,

I don't give a shit about gender anymore although I have no idea if I would be interested in having sex with a woman. I've never experienced it so how would I know. But I'm certainly open to it. I am hoping for somebody to come along or to fall into my life or for me to stumble over, or whatever, because I can't do the online thing. I've got to be with someone who finds me interesting and who I find interesting and who I want to touch and who wants to touch me. I don't care particularly what they look like. That's different. I mean, I guess if I saw somebody and I was repulsed by them then it would be different. But, I'm not particular about looks, age. I've never been particular about age. I, somebody that doesn't have to live with me and I don't have to live with them and we can maintain households. As long as that can be made to work. That wants to spend some of their free time with me. That enjoys spending some of their free time with me. Who's going to be there if I need him and who knows that I'll be there. To me, all that's intimate stuff. We don't even have to agree on things. I could deal with a Republican, it's fine. That would make life really interesting. An intelligent Republican, I'm fine with that. Yeah, that's what I'm kind of hoping for. I mean, my sexual desire has not backed off much. I don't really know if that's because I haven't had any sex for so long and so it's still there or what that's about. I can get aroused pretty easily, so I'm hoping for an active sex life, which doesn't necessarily have to mean, you know, it could mean what it means. I mean, I'm open to, you know, how could sex work for two people as they get old. I don't know how that works.

Lisa describes how friendships affect her and why she envisions them as a part of her expression of intimacy saying,

Doing things that give me life. That give me energy. I'm not draining, that kind of stuff. I think on this fear of sexual/intimacy and I see that the same way. All of those things, I consider myself a rather whole person in that it's kind of they're all woven together, you know? My physical, emotional, intellectual, spiritual, sexual intimate needs are all kind of together and I don't think I'm going to be driving myself towards a sexual or intimacy target but to be open because there are relationships that could really evolve. 
Margaret indicated that friendships were important to her definition of intimacy and yet they didn't fully satisfy her intimacy needs saying, I have friends and we give each other hugs and kisses when we greet but it's and that meets some of my intimacy needs but it doesn't meet the way I would like for them to be met.

\section{Multiple Forms of Physical Connection}

Gary identified hugging, touching, and holding are important expressions of intimacy saying, I got to the point where I understood what just being intimate was, touching, hugging, holding, or even just a conversation of one, to get into a good conversation could be an intimate relationship.

Like Gary, Lila shared that physical touch was important to the definition of intimacy and its expression she envisioned saying, Physical intimacy, not just sexual physical, but just you know, the want to touch, the need to touch, the need to be around each other. The most intimate. The most intimate without having any sexual anything. I mean, there's a lot of hugging and touching

Lisa joined Gary and Lila as she described hugs and physical touch as being part of how she envisions expressing intimacy saying, So, but for the most part hugging is an expression of caring and sharing and touching and good stuff, but with this person I feel more than intimate so for my own boundaries sake I try to...

Similarly, Margaret 's vision of intimacy being express aligned with other participants being as she described an elderly couples she saw saying,

The intimacy part, I don't know that that is going to be as difficult because in my head it's like, 'Oh, look at those two! They're so cute!" You know when they're holding hands with the cane in one hand and the holding your sweeties hand or sitting on the sofa together or hugging. I don't see that I would miss the cuddling. 
She also expressed that the hugs and kisses she received from friends were important expressions of intimacy though not fully meeting her intimacy needs adding, I have friends and we give each other hugs and kisses when we greet but it's and that meets some of my intimacy needs but it doesn't meet the way I would like for them to be met.

The descriptions of the heterosexual Baby Boomer participants in the study of how they envisioned the definition and expression of intimacy in the future time of phase of the life course suggest that they identify placing greater emphasis on mutual support, deeper friendships, and multiple forms of physical touch than in the current and previous phases of the life course.

\section{Question 4}

\section{What is the intimacy and sexual expression concerns of Baby Boomer males and}

\section{females in the present and the future?}

We further examined the participant intimacy and sexual expression concerns of the male and female study participants in the present and future time phases of the RTL. A few of the participants shared concerns about Ageism and how it could get in the way of their needs and desires: Michael expressed concern and frustration of how social culture in the United States of America, particularly younger members categorizing and dismissing older adults. He lamented their loss and missed opportunities for knowledge available from those who have tasted real intimacy saying,

... I think for me, what I'm learning too in life is that when you're older, once you reach 60, it's like people don't think you have sex anymore. So, it becomes problematic because we're programmed to be a certain way. So you have a whole world out there that's looking at youth and they're not looking at older adults as being able to have traversed this path from this sexual act to what real intimacy is, this knowledge that we have and it saddens me that people think we're going to stop having sex. I mean, I have 
had people, clients, who have been 80-years-old and they're still having sex. Better sex than they were having when they were 20-years-old. It troubles me that society still has a vision of the way we should be. The other part that troubles me is that we're not allowed to talk about it. It's still very much taboo. It's still very much a taboo subject that we can't talk about sex. We just can't talk about it. It's difficult to talk about. It's a difficult conversation.

Lila's concern was about how younger generations view and dismiss older people who reach their 60 s saying,

So, it's a cultural thing and it's not just the culture of the, of that institution. It's the culture generally. Reach your 60s and the culture out there in the world, the young culture particularly, ignores you. You don't exist anymore. You're in the way, you're too slow, you don't know how to text, you still think you have to balance a checkbook. They haven't done that.

Margaret was also concerned about the perceptions and beliefs that are held by young adults regarding seniors saying, Well, number 1 they need to acknowledge that it's a fact of life. That seniors are sexual beings and are sexually active. Sarah was concerned about independence who said,

I think at this point in our lives, my biggest concern is more of the health issues and my inner fear with us being able to be independent. Lisa offered her concerns about touch how she misses it in the present saying, I don't appreciate it but don't resent it but I do struggle with as he's aged and now he has dementia, the beginning stages of Alheimer's. He has no interest in even hugging or touching or nothing and I'm starving. It's very hard.

Beyond these concerns, four themes emerged from the individual RTLs and interview responses. 1) Importance of Intimacy Exceeds Sexual Expression: Four males and four females expressed a variety of concerns related to their health and aging as it is affecting their sexual expression in the present and the future. These concerns include physical health affecting performance ability, how illness such as dementia affects intimacy, both expressing and the ability to receive, and the importance of sharing space and time. 2) Sexual Expression Continues to be Important (including masturbation): 
While intimacy becomes more important than sexual expression, it is still strongly desired both in the present and future time. Six males and four females expressed their sexual expression concerns that include, sexual performance, erectile dysfunction, affects physical and mental health, aging, 3) Dynamic and Expanding Conceptualizations of Intimacy (more often to include friends, family, and others). How heterosexual Baby Boomers conceptualize intimacy and sexual expression are ever changing. They have shifted from one-on-one relationships to become more inclusive and embracing much deeper relationships with family, friends, and those of whom they have little knowledge. Two males and two females shared their concerns about intimacy and how they have expanded their definition to be more inclusive with regard to intimacy and sexual expression. 4) A Desire for Companionship (even if not the ideal situation): Several of the study participants expressed concerns of being alone in the present as well as in the future. Four males and four females expressed concerns about being alone, by themselves and expressing a need for companionship (Appendix L).

\section{Importance of intimacy exceeds sexual expression}

Andrew shares that both he and his wife are concerned about his health and how sexual expression might endanger his life, suggesting that the intimacy he shares with her is more important saying,

Well, health wise I'm not the guy I used to be but that doesn't mean I still don't want to, really it's been, it's not too long after my stroke. Possibly, I think that could be part of her problem is that she thinks sex would be hard on me. I do get winded very easy and where I could use to be able to perform for a long time, I don't know about now. I don't want to endanger myself. 
Frank shared that while in the present he is still capable of engaging in sexual expression, it is not as important as it was in the past saying, It don't mean as much to me as it used to but I still like to go out with a woman and I'm still, I'll still be sexually active.

Similarly, Gary is concerned about how his body is currently experiencing changes that is affecting his sexual performance and his reprioritizing sexual expression and intimacy saying, The only thing I could change, if there would be any kind of physical change within my body, any kind of as the body gets older it has a tendency not to perform as it did in earlier years. So that's the only thing that I could think of would probably be a problem is just not being able to perform. But as far as I can see where it's not going to be that much of a priority of having sex at that age to be honest with you. It's probably because of the body illnesses and things like that, diseases and things like that, that I'll have because I'm already a diabetic so I already got some physical illness that's going to probably, and high blood pressure as well, and those things have a tendency to have an adverse effect upon the body as well as sexual...

Dave's concerns about intimacy in present and future time was the realization of how its level of importance had increased since his youth. He also has realized that more was required from a potential partner to invite such a depth of intimacy saying, I think my intimacy, I think I'm a lot wiser than I was in my youth. I think as far as, like a lot of men again, I think it takes more to get me going now. Ed expressed his concerns about intimacy his confidence that it would grow and that sex would become less important saying, 
I think the intimacy part will grow. Like I said, I think that's going to be more important in the future. The sexual expressions, I know there are people that are in their 80s that are still having intercourse, that are still having sex and probably very sexually satisfying lives. I don't view that as a top priority. I think the intimacy part is going to be more important.

Sarah also indicated that in the present and the future time that she expected sexual expression to decline and intimacy to become more important citing declining health and physical changes, especially weight gain, saying I think at this point in our lives, my biggest concern is more of the health issues and my inner fear with us being able to be independent. My husband is 6 1/2 years older than I am. I worry, I think the physical concerns are probably more of an issue more so than the intimacy. I think that that part, the sexual part doesn't bother me so much because I figure I can take care of my own needs. I think the intimacy becomes more important when you're older because the sex goes down. I also am concerned about the physical concerns about being overweight, about heart disease, about other things. I think we kind of put a big cloud over this.

Karen discussed the her concerns related to intimacy in the present and future time saying, "So, I think more things will become more important than intercourse. Even though it's not a sexually charged relationship like with the other, like with David or Clarence, it's still so safe and so loving in so many different ways rather than just intercourse. Lisa describes the present and future time with some frustration about the effects dementia is having on her husband and how it affects their sexual expression, more importantly, how it impacts their intimacy. She feels that intimacy is more important than ever yet is having much difficulty reading his expressions and 
understanding his wants, needs, and desires as they both attempt to navigate the

degenerative nature of the disease saying,

He has moved into the last stage of his life and he is very much, not just the dementia, but he is very much talking about the old days. Oh my God, it just about kills me. It just drives me nuts, honestly. I hate it. It's just part of where he is but it doesn't do a thing for me as far as intimacy, it's like an anti-intimacy in that if I hear one more story about when you were in seminary or when he taught in high school 50 years ago or the people he went to grade school with 70 years ago. You know, oh my God. I feel like I'm 2 generations apart now as opposed to 1. The time we married he was timeless. He just, not anymore. Not at home anyway ... It would be really helpful for me to know something about intimacy needs for my husband. He can't seem to articulate them. I don't know. I only know when it's violated ... I only recognize when we violated his things but I don't know what he needs. I wish I knew some way and I'm thinking about this senior tsunami happens what are the tenants to address the needs of someone who's not very articulate about their own needs? I don't know what to do with that. I'm trying to learn but it's baby steps kind of trial and error.

\section{Sexual Expression Continues to be Important}

Frank shared his concern how his health might affect his ability to engage in sexual expression saying, Bad health is one of the things that cause that to go away is what I always understood. Right now, I'm still fine but another year down the road or whatever, I guess if I can't do it anymore, I guess it's over. Dave stated, I want to stay healthy and to be able to medically continue. In the same way, Andrew passionately expressed his concern saying, I sure want to have sex. As passionately as Andrew expressed his concern he immediately followed that declaration saying,

Well, I feel like I'm going to put that in God's hands. My wife has some female problems to where it's very hard for her to have sex and she has no sex drive whatsoever. I love her. I'm afraid at times that I might be tempted but we've not had any kind of sexual contact probably in over 10 years. It's very frustrating to me but I would hope there's sex in the future.

Richard expressed a concern to continue to be sexually active both in the present and future time period of his life saying, Certain weeks of the month I get horny but the rest of the time I'm wrapped up in other stuff and don't even think about it. That could be my 
age. [I]Masturbate occasionally. That's about it. Michael also shared his concern about maintaining his ability to engage in sexual expression activities in the present as well as in the future saying,

For me, I do masturbate. I do that for health reasons, to tell you the truth, more than anything but also to keep myself still, I still want to be sexually active and involved in my life. But, for me I have to make a choice, like it's like balancing my life right now. Just the way it is and it doesn't mean as I get older that won't change.

Gary's was concerned about erectile dysfunction in the present and also for the future so that he could continue to engage in sexual expression and querying whether pharmaceutical solutions will continue to help saying, The main thing that I have is will I be able to maintain an erection at age 65. It's a little difficult at 63, so at 65 I'm still trying to wonder am I going to be able to maintain that level of being able to maintain an erection to have sex at 65 . Will the little blue pill still be working? Lila's concern involved having an active sex life citing that her sexual desire has not diminished much and her openness to any type of sexual expression and that might occur regardless of gender or sexual orientation as she has indicated in other statements saying,

I mean, my sexual desire has not backed off much. I don't really know if that's because I haven't had any sex for so long and so it's still there or what that's about. I can get aroused pretty easily so I'm hoping for an active sex life which doesn't necessarily have to mean, you know, it could mean what it means. I mean, I'm open to, you know, how could sex work for two people as they get old. I don't know how that works.

Sarah's concern involved continuing to engage in sexual expression activities in the present an $\mathrm{d}$ the future that fulfill both she and her husband's needs saying,

I had to really work on myself and say okay what's acceptable to me? In probably the course of the last, it's probably evolved into that, I would think it's probably due to lack of desire on his part to please me. It's just, I decided for myself that I'll take care of him and I'll take care of me and I'm okay with that ... 
Adding, I've always had that, you should be able to self-serve. I think that that part, the sexual part doesn't bother me so much because I figure I can take care of my own needs. Karen's concern for the present and future was the ability to sexually express herself, citing a slowdown in the present saying, I want to be able to have, and of course, still be sexually active. I don't want that to ever go away. I don't expect that to ever go away. It might slow down, but it's already slowed down a little bit. Lisa didn't express concern as much as self-confidence regarding sexual expression in the present and future saying, I think they'll be there until my mind is gone. Frankly. I can't imagine that. You know the show Golden Girls and the old lady that's always in bed with somebody? I could kind of see myself that way at 90 or something. I'm still kicking because you know, I haven't seriously as far as how I manage my life, there's many other elements besides sex. I pray, I do meditation, I have friends, I have many dynamics but it hasn't gone away.

\section{Dynamic and Expanding Conceptualizations of Intimacy}

Michael shared his concerns regarding how intimacy is compared to how he viewed it in the past and what he envisions it to look like in the future saying, I'll always have my friend as long as she's alive. We'll always be together and I guess in my mind, I think to myself, maybe someday we'll move in together, but I don't think that we'll ever have sex together. I don't think that that's, that's not part of that relationship. He then added,

It's interesting because that friend probably, I've been able to discuss more about intimacy than anybody in my whole life. We have an intimate relationship, yet have never had sex. So she's someone that I call every day. She calls me or I call her and we talk about spiritual matters. We talk about life. We talk about the kids. Our daughters were best friends. They went through grade school and high school together, so we became friends. She divorced her husband and I divorced my first wife and then she never married but then I married. No sexual attraction between us. She may have a sexual attraction towards me but I don't really have a sexual attraction towards her nor do I want to have a sexual attraction because then I think it would mess up this friendship that we've developed. This deep, deep friendship. It's interesting because now intimacy is switched from the sexual act to more of a heart connection. So, it would be nice if 
there was something who I could have both, but since I don't, this heart connection that I have with my friend seems to fulfill me. It is very intimate. She's someone that I can call and complain to and I can tell I had a miserable day and she won't try and fix me. She'll just listen to me. What I consider more of an adult intimacy.

Following his explanation of his dynamic friendship, he seemed more passionate and became more engaged. He sat forward in his chair and leaning in towards the researcher saying,

I think that they'll [desires for intimacy] grow from now. I think that they'll mature more and that they'll be something that I'm going to want, not only from another person, but from a lot of people. A larger group. So that intimacy maybe in the beginning was on a one-to-one basis but now I'm finding the older I get, is that I'm getting that intimacy energy from groups of people. From different friends and different things that I do, from a book that I read. It's morphing. It's interesting to watch it. It's morphing from, I think back to when I was a kid, where screwing was my intimacy to now, I'm like wow. If I take a meditation class or something with five people in the room, that can be as intimate as anything that I could want. So, I see myself pursuing that and growing into that as I get older.

Richard expressed his concerns about his lack of intimacy and how he presently engaged in ways to expand opportunities for intimacy by being inclusive of others, even those of whom he knows little saying,

I am, intimacy that's a tough one because I'm a listener, I listen to everybody and I'm friendly with everybody but I'm not asking much for myself. Does that make sense? I think I'm pretty popular when out just listening to people. Then again, I don't get to share much of my thoughts, some things I told you today I would love to be able to talk to somebody else about. Somebody I could be intimate with but I don't. I'm a good listener and listen to other people and listen to their problems and what's going on with their lives and that's good for me. I feel good that they have an opening that they can share with. I'm nonjudgmental.

Sarah expressed concerns about the ability to expand intimate relationships or if it were

possible within her relationship saying,

His idea of getting out and doing something would be to go to the shooting range with his working buddies to shoot like once a month or so. He made the comment driving up here that your plate is too full. I told him, I sprang this on him and he's like, you know. I try. I'm going out to dinner with so and so. I'm going out to lunch with so and so or we're 
going to drive over here and do this. It kind of drives him nuts but at the same time, if I'm sitting at home with him, what are we doing?

Lisa expressed that she had no concerns about intimacy and sexual expression in the present or the future saying, Whatever happens in the rest of my life, I think I will try to take care of my needs and put myself in situations where I can be with people, meet people. I'm actually probably more of an introvert than an extrovert.

\section{A Desire for Companionship}

Richard expressed his concern about being alone and his desire for a fulltime livein relationship with a female partner as well as frustration with his attempts to develop intimate relationships saying, I'm a little bit concerned that I would have like to have somebody on a permanent full time basis [to live] with. If sex comes out of that, that would be fine. That's not a priority. As he began describing his experiences in attempting to meet women, he spoke softly and quietly as he looked down toward at his kitchen tabl- top saying,

Like I said, I know [women] but you can't really talk to them like you can some people because they have that bubble around them. They've been intimate with this man for 40 years and now he's gone or I lived with him for 40 years and I've got the kids raised and I hated his guts the whole 40 years and I'll never get that close to anybody again, that kind of thing. I'm reflecting on older ladies that, I'm [over] older ladies and that's not fair to them but that's the way I see it. It's depressing on my part in a way because I don't get out more but I know it's my fault and it's not their fault and in a way it is their fault.

Dave spoke about his concerns as he is legally separated and strongly anticipates his that his marriage will be ending in divorce. He was very concerned about being alone now and in the future. He was currently living on the couch in one of his children's basements and felt demoralized. He was animated saying,

I want a future. I want a partner. I don't like loneliness. I want to have someone to talk to when I come in from work or during the day. One of these days I'll be retired and maybe going to a coffee shop but there's going to be times I want to have a conversation 
with someone of the opposite sex. I want that person that I love that loves me back. That I care for that person and hopefully [they] feel the same way.

Ed expressed his own concerns about the thought of being alone or being without his

wife saying,

It's hard to be alone. I don't want to be old and alone either. So, I figure a lot of times we'll grow old together and when one goes the other goes pretty quickly ... I think being able to weather future storms[together] is important. Know that I got a partner with me if there's a health issue or it's for the kids or those kinds of things.

Michael's expressed his present and future concerns saying,

I guess the only concern that I have is if I wasn't in this marriage relationship that I'm in that I would be able to have any intimacy, sexual intimacy, or this more emotional intimacy that I share now with my wife. So that would be a concern because I'm an outgoing person and again, to tell you the truth, I think that if I were in another situation, I think that I would find somebody or be in a space to have that intimacy with somebody. Maybe there will be a relationship that I'll be able to express my sexual self within the relationship, but for now it's just not there. Nor do I want it to be there.

Lila talked about her status as a single female and a desire to develop a committed relationships, primarily with a male, though from other responses she was also open to the possibility of a female companion since it was not something she had experienced saying,

I, somebody that doesn't have to live with me and I don't have to live with them and we can maintain households. As long as that can be made to work. That wants to spend some of their free time with me. That enjoys spending some of their free time with me. Who's going to be there if I need him and who knows that I'll be there.

Lisa discussed her intimacy and sexual expression concerns as being less important than

her ongoing need for physical touch and relationships saying,

I think whether I have sexual intimacy or not, I need physical, I need relational intimacy. I need to be able to talk honestly with people. To open up. Sometimes I find myself leaking. Just like who do I tell, no one will listen [?]. That's just, needy. So, I want to build supports. I have a lot of friends that are men. Some of them are attractive in a maybe potential sex partner kind of way but I don't think about it like that. I just like to be open to relationships as they arise. I hope I will continue to be. I consider myself a rather whole person in that it's kind of they're all woven together, you know? [Next 
sentence is indecipherable]. My physical, emotional, intellectual, spiritual, sexual intimate needs are all kind of together and I don't think I'm going to be driving myself towards a sexual or intimacy target but to be open because there are relationships that could really evolve.

Margaret discussed her concern about her present state as a single female as well for the future and her need to be with someone saying,

I have friends and we give each other hugs and kisses when we greet but it's and that meets some of my intimacy needs but it doesn't meet the way I would like for them to be met. I don't know, I really don't know how to go back to get that back in my life. I'm going to have to meet somebody that...

Karen described her concern about being alone or imagining being alone in the future saying,

That part was hard for me. How can you put events down in the future when you don't know what's going to happen? I just want to be able to, when I'm not able to take care of myself or when Ed is not able to take care of me, or he needs taken care of beyond what I can do, that we can still be together someplace.

\section{Summary}

Intimacy and sexual expression concerns in the present and of the future held by heterosexual Baby Boomers primarily involve four areas. Embedded within the responses of the participants of the study were four themes that included,

1) Importance of Intimacy Exceeds Sexual Expression.

2) Sexual Expression Continues to be Important (including masturbation)

3) Dynamic and Expanding Conceptualizations of Intimacy (more often to include friends, family, and others.

4) A Desire for Companionship (even if not the ideal situation).

The descriptions of the heterosexual Baby Boomer participants in the study regarding their concerns about intimacy and sexual expression in the present and future time of life have identified intimacy as being more important than sexual expression. Yet, 
they also identify sexual expression as an important concern in these same phases of time. Additionally, their concerns about having intimate relationships and life experiences have influenced how they view relationships and have resulted in the expansion of how they define intimacy and with whom they may have intimacy. Finally, there is a strong desire for companionship in the present and future time phases of life. Baby Boomers do not want to be alone. Their responses suggest their strong desire for companionship could cause them to accept less compatible companions resulting in a poor fit for their lives.

\section{Question 5:}

What major concerns do older adults share related to the intimacy and sexual expression issues surrounding their aging including long-term care needs in the future, and the thoughts that aging men and women have about solutions that address their major concerns?

Lastly, we examined the interview responses that identified concerns about the intimacy and sexual expression issues in part one of this question within the context of aging as well as their expectations on meeting their individual intimacy and sexual expression needs should they become residents of a long-term care facility. Those results will be followed by the answers to the second part of the question identifying their thoughts and ideas on how to address their major concerns. The responses and themes are divided into two parts, o better organize the results for this question

Part one will address the major intimacy and sexual expression concerns surrounding aging as well as the expectations. Part two, will address the participants' thoughts and ideas to address their concerns. In the course of 
reviewing the participant responses to part one of question five, the following themes emerged. 1) Sexual Expression Has/Will Diminish: Baby Boomers are concerned about the effects of aging and declining health. Study participants indicated that they expect their ability to engage in various forms of sexual expression will diminish due to health and physical difficulties due to aging. At the same time, despite this diminished ability, the Baby Boomers in this study also expect to continue to engage in sexual expression should they become residents of a long-term care facility. 2) Lack of Privacy: Many Baby Boomers view sex as impossible or nearly impossible for residents. While there is an expectation for intimacy and sexual expression as residents of long-term care, there exists much concern about the ability to have privacy in such a facility. Some participants believe that there is no way to have the privacy to engage in any form of intimacy or sexual expression, while others imagine intimacy limited only to touch. 3) Emotional Intimacy: Baby Boomers are concerned about meeting their need for emotional intimacy with friends, family and significant others. These study participants strongly desire emotional intimacy and they anticipate that desire will grow stronger as their aging continues and they become long-term care residents. They have identified their family, friends (both old and new), and especially a significant other as being the source of emotional intimacy. In addition to these themes, there was concern about erectile dysfunction by one male. Dave shared, Well, like a lot of men I want to be able to continue performing. 


\section{Part 1}

\section{Sexual Expression Has/Will Diminish}

Gary expects that sexual expression will diminish as a priority as he ages and experiences health conditions saying,

But as far as I can see where it's not going to be that much of a priority of having sex at that age to be honest with you. It's probably because of the body illnesses and things like that, diseases and things like that, that I'll have because I'm already a diabetic so I already got some physical illness that's going to probably, and high blood pressure as well, and those things have a tendency to have an adverse effect upon the body as well as sexual...

Andrew expressed no that he had zero expectation for intimacy or sexual expression as he aged or as a resident of long-term care saying, When you say "long term care" I'm assuming a nursing home or assisted living place. I would say it's zero.

Richard informed the researcher that he was familiar with long-term care facilities and couldn't imagine engaging in any sexual expression as a resident saying,

I'm kind of familiar with it. There again, the intimacy I hooked up on with several, like I said I'm a good listener and there again, I'm still not sharing a lot but I've made pretty close friends with certain staff members because I listen to them. That's what made my stays tolerable. Sexually, there wasn't, I don't see how you could possibly be sexual in a place like that.

Sarah indicated that she wasn't concerned about sexual expression as she aged or within long-term care saying,

I think sexual expression, like I said, I have no problems with taking care of my own needs. I don't think that will be an issue. I don't see myself running around wanting to have sex with the older men walking down the hallways or whatever. I don't see that at this point. That's not to say that if I were actually in that situation, my views might change. I think even just thinking about it, I would want to have a relationship. I think those would weigh more heavily than the sexual aspect.

Margaret shared her concerns on intimacy and sexual expression and the possibility of being a resident in a long-term care facility saying, 
Long-term care beliefs are not really, they're not real comfortable with sexual expression amongst the senior, or amongst anybody that's in a long-term care but especially seniors because seniors aren't supposed to be sexual beings. That's just sort of the prevalent mindset. I think it's a bunch of crap. Yes, I'm concerned that if I end up in a long-term residential facility that I will be, it will be much harder to have a sexual relationship.

\section{Lack of Privacy}

Richard shared his own personal experience as both a visitor and a resident of a longterm care facility saying, I don't see how you could possibly be sexual in a place like that.

Ed spoke about witnessing his mother as a resident of long-term care saying, $M y$ mother's in a nursing home right now. There is no privacy. It's bad man. I mean, I'm just thinking in that environment... Sam's response seemed more of a statement than a concern saying, There probably would be no sexual [activity]. Similarly, Andrew had little hope of any intimacy or sexual expression as a resident of Long-term care based on his personal observations saying, Even though I worked in a nursing home at one time and there was a guy in his 80s that they had to watch like a hawk because he would sneak the girls in his room and they caught him at the time having sex with more than three or four women. My hats off to him. Dave shared his concern that there would be little opportunity for sexual expression with partner and that he would have to masturbate saying, Not to say that you wouldn't have sexual expression urges and needs but the opportunity, there may not be as much opportunity unless you're taking care of yourself. When asked what he would do if he was attracted to another resident and she was attracted to him, he responded saying, I'd do what I could to introduce myself to her and try to develop some kind of friendship with her. If it ever became a deeper friendship, people are people and their sexual expression is a part of love and caring for someone at times. It doesn't have to be but at times it is. It's part of that extension of that intimacy 
and if I had intimacy with another individual at a long term care facility, I'm going to be trying to seek private moments with her. Michael could not imagine intimacy or sexual expression as a resident of a long-term care facility saying, I don't see any ability to express sexual identity at all within a nursing home.

Gary's expression was one of shock and surprise at the idea that someone could be intimate or have any kind of intimacy or sexual expression as a long-term care resident. He stumbled as he began to speak saying,

Would I be able to, how would I be able to go about fulfilling those desires? In other words, would I be able to find somebody? Would I be able to carry that out being in a long-term care facility? Would I be able to have the means to lock a door, make that happen, and do so because I'm still able to do it?

Margaret expressed concern over her privacy and ways she envisioned meeting sexual needs within the context of long-term care saying, They will probably have to pry the vibrator out of my hand but they can try to take it away from me. I will beat them over the head with it. Karen expressed her concerns when asked about her expectations for sexual expression as a resident of long-term care saying, Scares me to death. I think any time, I mean like maybe an apartment assisted living where you could still live as a family, that would be okay. I don't want to end up in some kind of long-term nursing home with Ed on one end of the, in the men's wing so to speak, and me in the other wing.

\section{Emotional Intimacy}

Richard shared an observation that he made of his parents. He looked across the room and she began to smile, saying,

I never saw my parents touch until they, you would go in there and they would be sitting in the chairs watching TV, holding hands or they would be in the, they had a little twin 
bed, but they would be in the bed together and they said they were all the time having to get my mom out of his bed.

Sam expressed his concern around emotional intimacy as he and his wife age and as a resident of long-term care saying, Loving each other. That will always be there. Dave discussed the importance family and other people other than one's significant other saying, Long-term care. I think intimacy potentially grows and that intimacy may include other people than just your wife. Maybe your family and your children, I would include in that intimacy. I would think that intimacy might become a little more important and maybe sexual expression a little less important.

Karen shared that regardless of the context, whether in assisted living or long-term care she needed the emotional intimacy with her husband saying, I just want to be able to, when I'm not able to take care of myself or when Ed is not able to take care of me, or he needs taken care of beyond what I can do, that we can still be together someplace. I still want to have that same intimacy that we have now. Margaret shared her expectations of intimacy and sexual expression based on her past observations of long-term care residents saying, The intimacy part, I don't know that that is going to be as difficult because in my head it's like, 'Oh, look at those two!

They're so cute!' You know when they're holding hands with the cane in one hand and the holding your sweeties hand or sitting on the sofa together or hugging. Sarah shared her expectations on intimacy and sexual expression within the context of long-term care residency saying,

It's not about the sexual act itself. It's the intimacy. Being able to hold hands or that pat on the back. I think those things you become more aware of because your body isn't what it used to be when you're 20. You can't stay up half the night and have sex 50 different ways. I think as you get older those things become prime. 


\section{Part 2}

This section will address the participants' thoughts and ideas that could be used to address their intimacy and sexual expression concerns as they related to aging and being a resident in long-term care. In the course of reviewing the participant responses to part two of question five, three themes emerged 1) Education and activism: Education to enlighten healthcare professionals and the general public regarding the intimacy and sexual expression needs and expectations of aging boomers. 2) Aging Rights Awareness: Aging individuals need to be educated about their rights. 3) Baby Boomer Accommodations: Long-term care providers need to develop protocols to facilitate meeting the intimacy and sexual expression needs of their residents.

\section{Education and Activism}

Andrew's idea to address his intimacy and sexual expression is to leave the outcome in the hands of his deity saying, I'll leave that up to God. Michael waxes philosophically regarding society's imposition of a certain way of being and the difficulties involved to address these problems saying,

It troubles me that society still has a vision of the way we should be. The other part that troubles me is that we're not allowed to talk about it. It's still very much taboo. It's still very much a taboo subject that we can't talk about sex. We just can't talk about it. It's difficult to talk about. It's a difficult conversation.

Ed offered his solution to address these concerns saying, There should be a rule or a law or something. You should be given that opportunity. What sex does to your body when you're old. I don't know. I don't know how it will work. Lila became very expressive, with the volume level of her voice raised in tone, she presented herself as a solution to 
address concerns that baby boomers have being residents of long-term care and meeting their intimacy and sexual expression needs saying,

So, it's a cultural thing. I, one source of specific change, it's got to start in the education of the people who, healthcare education. This idea that old people are just husks, that they're not people, that you don't have to listen to them. That, oh they're demented. They don't know what they're talking about or the common assumption, and I think that this has always been an assumption, you reach a certain age and you don't have sex anymore. You're not interested in sex anymore. You're not a sexual being anymore. That's partially American culture. We don't like to think of anybody as sexual beings. Yeah, so I don't know. It has to start with the education of those people that are the care providers and it has to, it also has to start with each and every one of us. I think it's my job and my duty at this point to be a loud mouthed broad and I'm real fucking good at it. My daughter's friends know from being around me, my daughter is 29, they know from being around me and I've had several of them tell me this, I didn't think people your age were this lively. Well, most of their parents are younger. I didn't have a child until I was 33. I'm like, fucking-A, you know. This is, I'm still alive. I'm still here. I've had a heart attack and I'm still here. I've lived through alcoholism and lots of other stuff and I'm still here and by God, I am tired of saying yes sir and no sir and can I and will you.

Lisa expressed her solution as taking action to ensure that her intimacy needs and sexual expression needs would be met saying, I would probably be calling the ombudsmen myself or something like that. Making a lot of noise or checking with something. Who knows what I'll be doing. But I can see me, if I go into a residence and of a sound mind then I might be organizing or something. Karen was greatly concerned about the possibility of being separated from her husband saying, I don't want to end up in some kind of long-term nursing home with Ed on one end of the, in the men's wing so to speak, and me in the other wing.

\section{Aging Rights Awareness}

The responses of many of the participants suggest that the awareness of their rights as a long-term care resident are limited as illustrated by Andrew as he recalls his experience working at a long-term care facility when he was in his $30 \mathrm{~s}$, I was there with 
husbands and wives, and they couldn't hold hands. Richard talked about his experience as a resident of a long-term care facility in the past saying, I'm kind of familiar with it. There again, the intimacy I hooked up on with several, like I said I'm a good listener and there again, I'm still not sharing a lot but I've made pretty close friends with certain staff members because I listen to them. That's what made my stays tolerable. Dave was at a loss about his rights as a long-term care resident saying, If I was a single person in long term care and I had a sexual urge, do what I have to do. Whether that was picking up a magazine or I don't know how you get a magazine? He sat up in his chair and seemed to become agitated as he spoke rhetorically, Someone that you are in a relationship [with] when you get to that long term care facility. Not knowing how that partner would be welcome inside that room. Whether or not you could close that door and have some private time. I'm not sure how that works out. Gary continued with his expression of shock and surprise as he tried to wrap his thoughts around the idea of his being a long-term care resident saying,

I can think, I can visualize that, maybe thinking about down road and how I would be able to do it. That would be something that I would think about you know. If I could find one that would get me stirred up to where I would [indecipherable] and would be able to have sex. Right now, by being in a nursing home, it just by being there so much and seeing what all goes on there, it just wow, sex is just, I don't think I would be able to, that would be on my mind being in a long term care facility like that.

Michael's solution toward addressing the intimacy and sexual expression needs of longterm care residents was final when he said, Death would be a better alternative. Lisa expressed her solutions to her intimacy and sexual expression concerns about aging and within the context of being a resident of long-term care saying, I don't know. I mean, as long as my brain is working I tend to be a squeaky wheel with things like that. I'm very; 
social worker is a good match for me because I've always been a justice advocate.

Something like that feels really unjust.

\section{Baby Boomer Accommodations}

Karen expressed her solution for helping her meet her intimacy and sexual

expression needs saying,

I think that everybody should get to stay together if they choose to. I think the people in the nursing homes now, if they want to hook up should be able to hook up. I mean, my gosh they're the people they are around every day. You need to build relationships with people or you kind of just die on the inside, I think.

Margaret offered her ideas as a solution to address baby concerns about intimacy and

sexual expression as residents of long-term care saying,

I think that long-term residential facilities need to allow their residents to have freedom to have sexual encounters, to have intimate encounters. I think they should they should do the same for two residents. I mean, we need to be able to have that part of your life. I mean, you may be old, you may not be able to stay at home but if you want to have sex, you ought to be able to have sex. There are many different ways of having sex as well. It doesn't have to be the traditional man and woman missionary position. There are lots of different positions, there's lots of different ways to have sex.

Margaret then paused for several seconds, tilting her head back and closing her eyes. She then looked toward the office door and said,

I'm thinking of college dorms where you tie the hanky on the doorknob or whatever. But, I mean there should be some way to signal that you do not want to be disturbed and it doesn't have to be because you're having sex. It could just be because you want to spend some intimate time with somebody.

\section{Summary}

The aging concerns and expectations for intimacy and sexual expression needs to be met as residents of long-term care held by heterosexual Baby Boomers primarily involve three areas. Embedded within the responses of the, the participants of the study were three themes that included, 
1) Sexual Expression Has/Will Diminish

2) Lack of Privacy

3) Emotional Intimacy

While the intimacy and sexual expression concerns of the heterosexual Baby Boomer participants in the study magnify the reality that sexual expression is and will diminish as they age, they still identify themselves as sexual beings. This realization that their sexual expression will diminish eventually appears to be accepted without exhibiting any sense of loss. As they maintain an identity of being sexual beings, privacy, and the lack of it is of great concern to these participants. They recognize the importance privacy plays to facilitate their ability to engage in sexual expression as they continue aging and within the context of being a resident of long-term care. Baby Boomers have also placed much more importance on emotional intimacy as they have aged and they desire to increase their level of intimacy with family, friends, and their significant others. Thus, the Baby Boomers participants in this study share these three identified themes as major concerns intimacy and sexual expression issues surrounding their aging including long-term care needs in the future.

With regard to the thoughts aging Baby Boomers have about solutions to address these major concerns, embedded within the responses from the study participants were three themes

1) Education and Activism

2) Aging Rights Awareness

3) Baby Boomer Accommodations 
The thoughts and solutions offered by the study participants reveal a sense of "fighting back" and "taking a stand" around the idea that their intimacy and sexual expression needs could be ignored as they age or as residents of long-term care. They object to being identified in American society as no longer intimate or sexual beings. The researcher sensed that 10 of the 13 participants appeared to share a common thread of taking a stance in the face of adversity that reminded him of the attitudes and internal drive he witnessed growing up in the 60 s and 70 s. The responses by each participant as they considered their intimacy and sexual expression needs as aging adults and how they would be met as future long-term care residents, fueled a sense of injustice in them. They bucked at the very idea that an institution such as long-term care, one in which is supposed to be their home, might prevent them from meeting their identified intimacy and sexual expression needs, or any needs in form. There was talk of marching, reaching out for regulatory assistance, and creating a movement working to ensure that their right to intimacy and sexual expression would not be obstructed by institutional administrators and staff. These Baby Boomer participants also offered solutions for long-term care providers to consider so they can accommodate the intimacy and sexual expression needs of the Baby Boomer generation. These participants revealed that having the opportunity to be intimate and express their sexuality is important to them if they were to become residents of LTC. Lastly, they indicated that they would like assistance have their needs facilitated through education and perhaps assistance from staff to be together (e.g. assistance getting in and out of bed, and other needs as they emerge). 


\section{CHAPTER 5}

\section{DISCUSSION}

The focus of this final chapter of the dissertation is to answer the research questions that guided this study. A brief summary of the study will be provided, followed by conclusions that have been drawn from the data in relation to the specific research questions and implications for policy, practice and advocacy. The third part of this section discusses the limitations of this study. Finally, recommendations for further research will be suggested.

\section{Summary}

The purpose of this study was to understand the phenomenon of how heterosexual Baby Boomer men and women define and understand intimacy, sexual expression, expectations and desires relating to their respective expressions across the life course through their individual experiences and reflections. Specifically, they were asked to think about their future considering long-term care, and common concerns and issues relating to these two areas facing heterosexual men and women as they age. In order to address these issues, this study examined the influences, experiences, and reflections of heterosexual Baby Boomers. As a result of these foci, guiding research questions were developed. These questions were:

1. How do aging heterosexual Baby Boomers define intimacy and sexual expression?

2. How are Baby Boomer definitions and expressions of intimacy influenced by experiences across the life course?

3. How do Baby Boomers envision defining/expressing intimacy in the future? 
4. What are the intimacy and sexual expression concerns of Baby Boomer males and females in the present and the future?

5. How do older adults share major concerns related to the intimacy and sexual expression issues surrounding their aging including long-term care needs in the future, and have the aging men and women developed thoughts regarding solutions that address their major concerns?

In order to collect this data, thirteen participants completed a demographic questionnaire, their Rappaport Time Line focused on key events regarding intimacy and sexual expression, a lengthy, semi-structured interview based on their individual timeline, and follow-up interviews for clarification of previous answers to ensure clarity of understanding.

\section{Hermeneutic Phenomenology}

The hermeneutic phenomenological research approach attempts to acquire comprehensive descriptions from research participants and provide a foundation for a reflective structural analysis that illustrates the essence of the experience (Moustakas, 1994). The experiences of planning, expectation, and concern are subjective in nature, and difficult to quantify. This

phenomenological study approach allows aging heterosexual male and female Baby Boomers to discuss topics in relative privacy. The intimate setting of the study design allowed for confidentiality and open flow of thoughts, lived experiences, concerns, and ideas to form and be articulated. As repetitive themes and ideas emerged from several research participants, a description of the collective experiences and concerns were developed that embodied the collective data from the participants.

\section{Literature}

The literature review for this study sought to find various perspectives on the phenomenon of what it was like to grow up as a heterosexual Baby Boomer male and 
female and how that might affect their definitions and understandings of intimacy and sexual expression. The current literature addressing intimacy and sexual expression in longterm care includes research related to barriers that effect residents' intimacy and sexual expression, barriers that effect providers from supporting and facilitating residents' intimacy and sexual expression.

There was a clear lack of information concerning the views of heterosexual Baby Boomers concerning their definitions and understandings of intimacy and sexual expression across the life course or their intimacy and sexual expression expectations as potential residents of long-term care. This study, therefore, sought to provide the insights of a diverse group of heterosexual Baby Boomers from a number of different backgrounds, across the different phases of the life course, and different ages within the span of their generation.

\section{Participants}

Participants for this study were obtained through advertisements on social media, discussion forums, public flyers, and Craig's List. Some of these participants were known by the researcher prior to the study. Others were recommended by study participants, ultimately resulting in 13 diverse, heterosexual Baby Boomers . They came from a variety of educational and professional backgrounds, including business, healthcare, social services, academia, and government. All had a desire to have relationships that were intimate and to continue sexual expression, now and within the context of being residents of long-term care. More importantly, these Baby Boomers reflected the major social changes in the structure of close relationships over the course of the past 50 years, which was likely to shape their perspectives about intimacy and sexual expression (Appendix H). Whereas, most of the members of the Traditionalist generation grew up in an era of emphasis on marriage and childbearing leading to over $90 \%$ of that cohort experiencing at least one marriage and few 
experiencing divorce (Shiono \& Quinn, 1994) the Baby Boomer generation grew up in an era of emphasis on individual achievement and personal happiness. More Baby Boomers attended and graduated from college than in the previous generation, more believed in the importance of self-expression including in the area of sexuality, and more believed in the importance of being happy. While Traditionalists focused on the duties associated with marriage and parenthood, Baby Boomers were more focused on how the partnership made them feel. As a result, over the course of the adult lives of the Baby Boomer generation, society saw a slight decrease in the number of individuals entering into marriage (Shiono \& Quinn, 1994). the rise in the divorce rate to almost 50\% of marriages (United States Census, 2011), and the rise in the number of older adults cohabitating or entering into second and third marriages after both divorce and widowhood (Kennedy \& Ruggles, 2014), the Baby Boomers also have a longer life span that Traditionalists). In this context, all of the participants engaged in pre-marital sex, $85 \%$ of the participants in this dissertation $(\mathrm{N}=11)$ have been married and divorced, $77 \%(\mathrm{~N}=10)$ of them have been married more than once, $31 \%(\mathrm{~N}=4)$ of them have been divorced more than once and $46 \%(\mathrm{~N}=6)$ admitted to having extramarital affairs. Of the two that have not been divorced, one is still married to their first and only spouse and another is remarried after the death of his first spouse. This high number of divorces and sexual partners is evident, even among a group with a disproportionate number of Roman Catholics (54\%), a faith tradition that frowns upon divorce and sex outside of the confines of marriage. Therefore, while the sample may be a small one, it does include individuals who more than reflect the trends of this generation. These statistics give additional validity to the generalizability of the findings in the study.

\section{Collection of Data}

Data for this study was collected in three ways. Study participants were asked to 
complete The Rappaport Time Line prepared specifically to gather data across four phases of the life course, including childhood through adolescent, early adulthood, middle adulthood, and future time. Participants were then interviewed guided by a semi-structured interview schedule that remained flexible to allow for an interactive process that was used to describe the lived and anticipated experience of each participant. The interviews lasted approximately one hour; with data being time stamped for accuracy, and was audio taped using a digital tape recorder. Once initial data analysis was completed, participants were contacted via email to perform a 'validity check' to verify that the essence of the interviews was captured correctly and possibly to ask additional questions based on the responses of participants to the initial questions.

\section{Theoretical Grounding}

This study drew upon the life course perspective as the basis for its philosophical underpinning. Within the life course paradigm, aging is viewed as a developmental process of changing events and socio-cultural meanings that move across time but within the historical and cultural context of the cohort (Giele \& Elder, 1998). The life course paradigm incorporates four distinct areas of social life that when brought together tell a story of aging. Elder, (1994, 1995) includes these four distinct areas of social life as follows: 1) Lives in time and place, 2) Human agency; 3) The timing of lives; 4) Linked lives. These elements, which are based upon the premises of symbolic interactionism, combine to form the life course view of aging. Symbolic interactionism (Blumer, 1969) is based on three premises that include:

1) People act based upon the meaning objects and events have for them.

2) The meaning that is assigned is based upon their interaction with other people

3) People select objects and events out of their environment, and they process them through time to make meaning. 
When a person is asked about an event in their childhood, they tell a story that may appear random, but because it was selected, it holds meaning to that person who has processed it over time. This indicates their story is not extraneous. It tells about their interaction with other people within a specified time and place. Those interactions are interpreted and conveyed through their stories, which provide information about their sense of human agency, how the timing of events affects them, and what the time and place they lived was like. The stories about how they chose to act or not to act throughout life provide a series of events and associated meanings that tell about aging.

The life course paradigm enables the researcher to understand the developmental changes Baby Boomers experience and provides the researcher a useful tool for understanding the meaning of intimacy and sexual expression from the perspective of heterosexual Baby Boomer men and women.

Understanding the life course paradigm is important in the effort to understand how heterosexual Baby Boomers define, understand, and form expectations of intimacy and sexual expression across the life course by time, place, people, relationships, and events that influence them. After all, aging occurs with time, and time is the horizon in which all interpretation is made (Heidegger, 1962).

\section{Major Findings}

The participants in this study mentioned several ingredients in the formula for an intimate relationship, several aspects of sexual expression that were important to them, a number of interpersonal relationship types and experiences that influenced their definitions and understandings of intimacy and sexual expression across their lives and a number of hopes and fears regarding intimacy and sexual expression into the future. All participants described at 
least one of three ways they defined and understood the linkage between intimacy and sexual expression. These include: 1) No differentiation between intimacy and sexual expression (only one participant has maintained this definition and understanding to date). 2) Change in views about intimacy and sexual expression over time. Some of the study participants definitions and understandings of intimacy and sexual expression changed over time. Some of the participants originally defined and understood intimacy and sexual expression as two terms that hold the same meaning, (having sex) new definitions and understandings were developed. Some participants separated intimacy from sexual expression in their $20 \mathrm{~s}$, in the early adulthood, while others did not separate the terms until their 40s in middle adulthood. 3) Consistently viewed intimacy and sexual expression as different. A majority of the participants steadily saw intimacy as listening, sharing everything, being supportive, being committed, being authentic, being emotionally safe and protected, affection, expressing love, being connected, being supportive, and being reassuring with their level of commitment to the other person across the lifespan.

Women described intimacy in a way that was similar to men, but tended to be more descriptive and to quickly move beyond showing affection to more personal forms of intimacy such as sharing feelings and engaging in mutual social support. What was even more interesting was that those study participants that differentiated between intimacy and sexual expression earlier in life had more rich descriptions of intimacy than those who came to appreciate the differences between intimacy and sex at a later point in time. It is as if time to practice intimacy with other human beings helps one to be a kind of expert in the art of intimacy understanding. 


\section{Intimacy}

Four types of intimacy were described by the study participants. One form of intimacy described by three participants, who changed their views of intimacy across time, was closest to sexual expression. Their definition of intimacy was that of expressing love verbally and physical. While this definition exhibits some growth in their understanding of intimacy, it remains mostly physical in nature with some expressions of love thrown in. The participants, who differentiated their notion of intimacy and sexual expression the longest, described three additional intimacy types. Subsequently, four major themes materialized that provided Baby Boomer's their understanding of what is intimacy. The four themes include:

Expressions: verbal (e.g., saying, "I love you") and physical expressions of affection and love (such as holding hands, hugging, cuddling, kissing, staring into each other's eyes).

Connection: having an authentic connection with the other person which can include honest disclosure about personal details of one's life as well as disclosure of values, hopes, dreams and who you are as a person. When intimacy is present, both types of disclosure (or communication) are met with acceptance and lead to feelings of closeness. Connection also includes sharing interests, spending time together, being friends and being "in tune" with each other.

Caring and Social Support: expressions of caring by listening, being there for the other person and giving emotional support when the other is in distress, giving tangible support such as advice, fixing a problem, doing things for the other person, and sharing possessions with the other person all make the couple feel cared for and supported.

Commitment: having a commitment to each other which is the basis of trust, emotional and physical safety.

These findings supported previous research identifying verbal expressions of emotion and physical affection (Greeff, \& Malherbe, 2001; Hazan, Zeifman, \& Middleton, 1994; Helgeson, Shaver, and Dyer, 1987; Lerner, 1990; Monsour, 1992; McCabe, 1999; Reis, \& Shaver, 1988; Tolstedt \& Stokes, 1983). However, they were limited primarily to college age participants. 
The connections theme supports previous research previous research by (Morelli,; Lee, Arnn, \& Zaki, 2015) of the positive relational affects emotional support and instrumental support (fixing, doing), also, emotional expressive-ness, unconditional support, shared activities, physical contact, and sexual contact (Monsur, 1992; Parks,1996).

Cutrona, (1996) and Pasch \& Bradbury, (1998) see individuals helping one another cope with personal problems and provide every day support to each other, and as key by (Bradbury, Fincham,\& Beach, 2000; Bradbury \& Karney, 2004) in marital well-being and maintaining relationships. Lastly, findings support previous research that maintenance acts are associated with couple well-being, (Murray et al., 1996; Rusbult, Bissonnette, Arriaga, \& Cox, 1998; Van Lange et al., 1997). Those on commitment were supported by studies of the benefits of mutual commitment (Drigotas, Rusbult, \& Verette, 1999). Lastly, the need and importance of trust toward commitment is supported by studies that include, (Holmes, 1989; Rempel, Holmes, \& Zanna, 1985; Sorrentino, Holmes, Hanna, \& Sharp, 1995; Wieselquist, Rusbult, Foster, \& Agnew, 1999).

\section{Sexual Expression}

Participants described sexual expression sometimes as being the same thing as intimacy and sometimes as a contrast with intimacy. Some participants had difficulty, particularly some of the female participants defining sexual expression without relating the concept to intimacy. Participants also discussed how their understanding of sexual expression occurred over the life span along with the differences between men and women regarding sexual expression. These understandings also materialized into four major themes that underscored how these Baby Boomers understood the meaning of sexual expression. The four themes included:

1) Sexual Intercourse: (vaginal penetrative sex), 
2) Oral Sex: Four of the women mentioned oral sex as a way that they express sexuality

3) Other types of touch included holding, caressing, kissing and cuddling and sometimes was a precursor to intercourse

4) Masturbation in-between relationships, as part of sex play within a relationship, or anytime.

One of the more interesting aspects of the discussion was how the purpose of sexual expression was viewed by the participants. Most of them saw at least one purpose of sex was to give (and/or) receive pleasure. Some participants also described other purposes including using sex as a way to achieve intimacy, closeness and bonding with their partner, and using sex to control their partner. Others held a meaning of sexual expression to include respect, kindness, holding and bonding. None of the participants talked about the procreative purpose of sex, which again is very interesting given their self-declared affiliation with the Roman Catholic Church, which teaches that the only purpose of sex is to procreate and the fact that most of them had children.

Study participants described their definition of sexual expression as being sexual intercourse (vaginal penetrative sex). Their descriptions align the common dictionary definition, "sexual activity between two people; especially: sexual activity in which a man puts his penis into the vagina of a woman" (Sexual Intercourse, n.d.). They also support research regarding defining sexual intercourse (Hite, 2004; Lerner \& Steinberg, 2004). Participants also described their definition of sexual expression as being oral sex. Their descriptions align with common dictionary definition, "sexual activity that involves stimulating someone's genitals with the tongue or mouth" (Oral Sex, n.d.). These definitions support previous research defining oral sex (Hite, 2004; Lerner \& Steinberg, 2004). In addition, participants described their definition of sexual expression as being other types of touch. These descriptions support previous research identify and discuss these forms of touch as sexual expression including (Masters \& Johnson, 1970; De Villers, 1997, 2012). Lastly, study participants described their 
definition of sexual expression as being masturbation. Their descriptions align the common dictionary definition, “erotic stimulation especially of one's own genital organs commonly resulting in orgasm and achieved by manual or other bodily contact exclusive of sexual intercourse, by instrumental manipulation, occasionally by sexual fantasies, or by various combinations of these agencies" (Masturbation, n.d.). The descriptions of their purpose and practice support previous research about masturbation (Kinsey, 1948, 1953; Janus \& Janus,

1994; Michael, Gagnon, Laumann, \& Kolata, 1994) as sexual expression.

\section{Baby Boomers' Definition of Intimacy}

From the information provided by the study participants, the researcher constructed the heterosexual Baby Boomer's definition of intimacy:

A relationship with a partner of the opposite sex that includes expressions of being inlove, verbal declarations of love, cuddling, hugging, touching, kissing, and caressing, having a connection through shared interests, spending time together, being a friend and receiving complete acceptance after sharing ones intellect and emotions, and being authentic, caring and being supportive through listening, kindness, and giving both emotional and tangible support and being committed as a foundation for trust, faith, and both emotional and physical safety.

\section{Baby Boomers’ Definition of Sexual Expression}

Similarly, the researcher also constructed the heterosexual Baby Boomer's

definition of sexual expression:

A physical relationship with one's self or between one or more partners, individually or inclusive of more than one partner at a time. These interactions may include sexual intercourse (vaginal penetrative sex), oral sex, other forms of touching and affection and masturbation by one's self and mutual masturbation with one's partner(s). It includes treating partners with kindness and respect recognizing that both genders can have such desire, is for the purpose of pleasure and/or bonding but sometimes is used negatively to control a partner's behavior. It is enjoyed either in the confines of one relationship and in the context of an open relationship so that sexual expression is allowed with other partners besides one's spouse/significant other. Finally, desire for sexual expression in both genders is on a continuum ranging from a voracious appetite to low sexual desire across the life span and may move periodically across time. 
Love, sexuality, and intimacy are important human features across the lifespan

(Hatfield, Rapson, \& Martel, 2007) While love, sex, and intimacy are important to people of all ages, the vast majority of research on relationships have targeted college students and their responses regarding sex (Marston, Hecht, Manke, McDaniel, \& Reeder, 1998; Gonzaga et al, 2006) until the past few years, (Reeder, 1996; Kessel, 2001). As the participants in this study have shared, sex is being experienced differently by people in their 50s and older than those in their 20s. Moreover, research shows that many people continue to have sex well into their later years (Levy, 1994), although the amount of people participating in sexual activity diminishes with age both for men and women (Mathias, Lubben, Atchison \& Schweitzer, 1997).

\section{Baby Boomer definitions of intimacy and sexual expressions influenced by}

\section{experiences across the lifespan?}

Study participants also revealed how experiences across the life course influenced Baby Boomer definitions of intimacy and sexual expressions. They revealed how they came to understand intimacy across the lifespan. Nine themes emerged from the three phases of the life course as identified through the RTL that include childhood through adolescence (0-20), early adulthood (21-40), and middle adulthood (40-60).

Childhood-Adolescent

1) Parents: mother, father, together as married couples and as single-parents provided both positive role models for paradigms of intimacy or disrupted their ability to bond with romantic partners due to sexual abuse.

2) Peer Relationships: Peers at school, church, athletics,

3) Girl-Friend Relationships: Non-romantic friends, dating partners,

Early and Middle Adulthood:

4) Marital Relationships: Husbands/Wives provided both positive and negative experiences that served as influences for how participants defined intimacy. Abuse, 
domestic violence, substance abuse, affairs and divorces often undermined healthy views of self, intimacy or sexual expression.

5) Casual Relationships: Casual relationships with the opposite sex that were not longterm friendships, and could include one-night stands, friends with benefits, etc. Most of these accounts included relationships of mutual sharing of heart and soul along with sexual bonding. .

6) Friend Relationships: Deep, sometimes long-term friendships, both same-sex and opposite sex influenced how participants defined intimacy during the adult years.

The responses in the study of their understanding of intimacy in each of phase of the participant's life span suggest that the Baby Boomers' understanding of intimacy was influenced greatly by their relational experiences. Close relationships with marital partners and friends were the predominant experiences within the early adulthood and middle adulthood life span phases that influenced their understanding of intimacy the most.

In looking at each phase separately and by gender, the researcher observed that males were influenced most by their peers and young girls were more influenced by their parents during childhood and adolescence. These findings support past research regarding the development of intimacy and sexual expression during childhood and adolescence such as McAdams, (1989) who found that the parental attachment bond provides the earliest pattern for warm and close relationships. Moreover, Furman \& Wehner, (1994) argue that these understandings tied largely to experiences children have with parents, while others are tied mostly to peers. Others include (Bleakley, Hennessy, Fishbein, Coles, \& Jordan, 2009; Furman, \& Buhrmester, 1992; Shulman, Laursen, Kalman, \& Karpovsky, S. 1997; Sullivan 1953). Lastly, Gordon et al (2013) completed a study about masculine norms across race of young teenage men and found that they sought intimacy above all other masculine norms and wanted sex to mean something with their girlfriends. At the same time no research was found that discussed how people define and understand intimacy and sexual expression during childhood and adolescence. 
In the early and middle adulthood phases, male understanding of intimacy was more influenced by their marital relationships, while casual relationships influenced females understanding more. Their descriptions of intimacy in these marital relationships supports previous research regarding how adults experience intimacy with relationship interactions and their influences (Reis \& Patrick,_1996; Reis \& Shaver, 1988). In addition, study participants' comments supported the research on couple's interactions regarding the importance of give and take responsiveness regarding self-disclosure (Laurenceau, Barrett, \& Pietromonaco, 1998; Laurenceau, Barrett, \& Rovine, 2005). In the middle adulthood phase of life span, both males' and females' understanding of intimacy was most influenced by their marital relationships (Reis \& Patrick,_1996; Reis \& Shaver, 1988). Friend relationships were identified in these phases as well. Their descriptions supported research about friendship and intimacy identifying the elements involved such as self-disclosure, expressed appreciation of the friendship, and support and shared interests (Parks \& Floyd, 1996) as well as trust, commitment, and respect supporting Felmlee \& Muraco's, (2009) work that targeted participants in the old age stage of the lifespan.. However, no previous research related to how people define and understand intimacy during these phases of their lives.

\section{Baby Boomers Future Definition of Intimacy and Sexual Expression}

The researcher learned from these study participants that Baby Boomers envision their future definitions of intimacy to be composed of three themes.

1) Mutual Support

2) Friendship

3) Multiple Forms of Physical Connection

This information suggests that heterosexual Baby Boomers anticipate placing greater emphasis on mutual support, deeper friendships, and multiple forms of physical touch than in the current and previous phases of the lifespan. 
Participants in the study provided their definition of intimacy and sexual expression as they consider the future time in the old age phase of the lifespan. Their descriptions of how they expected their understanding of intimacy and sexual expression to include 1) Mutual Support, 2) Friendship, and 3), Multiple Forms of Physical Connection.

\section{Mutual Support}

Study participants described their future definition of intimacy and sexual expression that included being considerate of the health and involvement of a spouse, being present and involved with their spouse, and to locate a partner/spouse with whom they can talk, touch one another, sleep together, share their lives, emotionally and physically supportive, and being together. These comments supported prior research about mutual support and its role in intimacy and sexual expression (Alexander, Sipski \& Findley, 1993; Barrett, 1982; Basson, 1998; Courtois, Charvier, Leriche \& Raymond, 1993; deMey, 1998; Sipski \& Alexander, 1997a; Sipski, Alexander, Rosen \& Raymond, 1995; Morelli; Lee, Arnn, \& Zaki, 2015).

\section{Friendship}

Study participants described their future definition of intimacy and sexual expression that included having friendly relationships, investing time with other people in a variety of contexts, whether one-one-one, within social, recreational, or educational groups, as a means of service to others who are alone or lonely and in need of friends. They also expressed having "friends with benefits" situations that include casual sex, seeking out others with opposing world views for challenging conversations, and being open to any type of friendship regardless of gender or context. These comments supported research on friendship its role in intimacy 
and sexual expression and a desire in long-term care (Parks \& Floyd, 1996; Felmlee \& Muraco's, 2009; Walker \& Ross, 1999).

\section{Multiple Forms of Physical Connection}

Study participants described their future definition of intimacy and sexual expression expression that included being to involve physical touch (sexual and nonsexual), including hugs, holding hands, holding another person, cuddling, and sitting closely to others. All of them placed a great deal of emphasis on their need and desire to touch and to be touched by others. These responses support previous research about aging and a desire for physical connection. Lindau et al (2007) found in their study that over half of those ages 65-75 were still sexually active. Moreover, the responses support the previous research regarding the need and benefits of physical connection (Frankowski \& Clark, 2009; Walker \& Ross, 1999; Willis \& Briggs, 1992)

\section{Baby Boomer Intimacy and Sexual Expression Concerns: Present and Future}

The researcher observed from the participant responses regarding intimacy and sexual expression concerns in the present and for the future held by heterosexual Baby Boomers primarily involve four areas that include:

1) Importance of Intimacy Exceeds Sexual Expression.

2) Sexual Expression Continues to be Important (including masturbation)

3) Dynamic and Expanding Conceptualizations of Intimacy (more often to include friends, family, and others)

4) A Desire for Companionship (even if not the ideal situation)

\section{Importance of Intimacy Exceeds Sexual Expression.}

These findings support the several studies that have revealed that education and support can help in aiding adults to benefit from successful and fulfilling sexual lives (Alexander, Sipski \& Findley, 1993; Barrett, 1982; Basson, 1998; Courtois, Charvier, Leriche \& Raymond, 1993; 
deMey, 1998; Sipski \& Alexander, 1997a; Sipski, Alexander, Rosen \& Raymond, 1995). Ten of the participants in the study shared their experiences and perspective regarding an increasing need for intimacy recognizing that their sexual behavior diminishes as they age. These findings support a similar study by Frankowski \& Clark, (2009) that found intimacy and sexuality are expressed in a variety of ways, including intercourse. However, intimate touch, handholding and other kinds of physical touch were more common.

They talked about a need for more interaction with family, friends, significant others, expanding their of intimacy and becoming more inclusive of others. They talked openly about their diminishing sexual capacity and the increasing importance of intimate relationships to their lives. Further, the comments from these study participants also correlate with research outcomes revealing that age and physical limitations might increase the need for intimacy (Dressel \& Avant, 1983; Reinisch \& Beaseley, 1990; Starr \& Weiner, 1981).

\section{Sexual Expression Continues to be Important (including masturbation)}

The participants in the current study believe that sexual expression should always be a part of their lives, even if only a small part. A supporting study of sexual development and behavior of individuals with disabilities found that most disabilities do not reduce interest in sex or the capacity for sexual function (Reinisch \& Beasley, 1990). Five participants talked about their experiences and perspectives regarding sexual behavior and their concerns related to long-term care. Their comments support research on aging adults that the appetite for human

touch and sexual expression does not disappear with age. Lindau et al (2007) found that 53\% of participants age 65 to 74 years and $26 \%$ of participants age 75 to 85 reported being sexually active with such activities kissing, fondling, or intercourse. Fifty-four percent of sexually active 
persons reported in the oldest group reported having sex at least two to three times per month. and $23 \%$ of those reported having sex once a week or more.

Two males discussed concerns regarding sexual expression and the effects of aging on such things as erectile dysfunction, early or lack of ejaculation, anorgasmia, impaired lubrication, dyspareunia, declining physical stamina and strength, negative self-image and body image, as well as communication challenges. As noted above, both residents and staff at LTC facilities are in need of education in the plethora of research studies finding that physical and psychological sexual dysfunctions or impairments such as erectile dysfunction, early or lack of ejaculation, anorgasmia, impaired lubrication, dyspareunia, negative self-image and body image, and communication challenges between partners can be improved through psychological counseling and physiological treatments and therapies (e.g., Elliott, 2002a, 2002b; Hennessey, Robertson, Swingler \& Compston, 1999; Roe, 1999; Zorzon et al., 1999).

Another issue related to sexuality in aging includes a lack of opportunity (Wasow \& Loeb, 1979). McCracken (1980) found that when older adults stopped sexual interactions, it is typically not because of incapacity or lack of interest. Frequently, sexual interactions cease because of the loss of sexual partners. Regardless of the lack of opportunity, some research studies have documented that a significant percentage of long-term care residents have an interest in sexual expression. White (1982) found that 17 percent of sexually inactive residents indicated a desire to have sexual lives in study of United States nursing home residents. In a study conducted by Fielden, (1997) 70 percent of males and 60 percent of females age 65 or more reported that they enjoyed sexual intercourse on a regular basis. Mulligan and Palguta (1991) found that institutionalized geriatric males remain especially interested in sexual intercourse. Lastly, Bretschneider \& McCoy (1988) found that 60 percent of males and 30 percent of females had sexual intercourse at least sometimes and 26 percent of the males and 
ten percent of the females were reported to have intercourse several times a week to several times a month in their study of sexual interest in healthy 80 to 102 - year-olds. Five participants also talked about sexual behavior and lack of opportunity in their concerns related to long-term care residency. Two single participants described the difficulties they experience meeting their intimacy and sexual expression needs without access to a partner. While three married participants discussed the how their partner's declining health or lack of interest created a lack of opportunity to meet their intimacy and sexual expression needs.

The four themes that emerged from the participant responses suggest that heterosexual Baby Boomers are primarily concerned about the ability to have intimacy more so than sex in both the present and in the future. Yet, they are also concerned about sexual expression being accessible in both phases of time. Having intimate relationships, expanding how they define intimacy, and with whom they may have intimacy is a major concern. Finally, they are concerned about companionship. Baby Boomers do not want to be alone; so much that they would rather have a bad companion than no companion. This is a very interesting outcome for a generation that tended to "live in the moment." The consequences of this philosophy are starting to catch up with this group of Baby Boomers, many of whom face old age without a close partner with whom to share their fears and their joys.

\section{Baby Boomer LTC Intimacy and Sexual Expression Concerns}

The responses of the participants about their intimacy and sexual expression concerns as they age and being a resident of long-term care suggest that Baby Boomers are not shy about expressing their needs. Their responses resulted in the emergence of three themes that heterosexual Baby Boomers want met if they become residents of long-term care include

1) Sexual Expression Has/Will Diminish 
2) Lack of Privacy

3) Emotional Intimacy

The results suggest that Baby Boomers accept the reality that sexual expression is already and will continue to diminish as they age. However, despite this fact, they still see themselves as sexual beings, and hope to continue to have this outlet for their wants and needs even as their bodies fade. They seemed to accept this inevitable occurrence and exhibited little sense of loss. As sexual beings, the inability to have enough privacy in long-term care facilities was of great concern to these participants. Baby Boomers place much importance on their privacy and how the lack of it could negatively affect their sexual and intimacy expressions as they continue aging, particularly in long-term care facilities. Emotional intimacy concerns and their opportunity to access them are also strong. They desire to increase their intensity and amount of intimacy with family, friends, and their significant others. As a group, these are the greatest concerns.

\section{Baby Boomer LTC Solutions}

Along with their concerns about intimacy and sexual expression as long-term care residents, Baby Boomers have offered solutions to address these major concerns involving three areas including:

1) Education and Activism

2) Aging Rights Awareness

3) Baby Boomer Accommodations

The participants in the study suggest to this researcher that they are not interested in sitting idly by the mythical river Styx for their boat to carry them to another realm. Many exuded a strong sense of injustice at the thought of the loss of privacy and revealed an interest in "fighting back" and "taking a stand" at the possibility of their intimacy and sexual expression needs being ignored as long-term care residents. They did not like being identified 
as being no longer intimate or sexual beings. They pushed back at the idea that a long-term care facility, a place that is to be their home, would define what they can or cannot do with regard to intimacy or sexual expression. The researcher may have experienced some of the fire, activism, and outrage that might have been part of the driving force motivating their contemporaries during the $60 \mathrm{~s}$ and $70 \mathrm{~s}$. These participants were fiery individuals and together could potentially be the beginning of a force to be reckoned with should their access to intimacy and sexual expression be denied. These participants also suggested that Baby Boomers are not shy about offering solutions to long-term care providers to consider accommodating their intimacy and sexual expression needs.

\section{Education and Activism}

Study participants talked about the negative attitudes and beliefs held in society at-large that continue to undergird myths and misconceptions about sexual desires and behaviors of aging Americans. These experiences and perspectives reported by this study's participants support findings of past research as well. Societal myths and misconceptions regarding the sexual desires and behaviors of the older people abound. One such myth is that older people are or should be asexual, along with a false assumption that physical attractiveness is dependent on youthful good looks (Henry \& McNab, 2003). A 2005 study about college student perceptions regarding old people and aging found," Students who had worked with older people were significantly more likely to believe that older people have little interest in sex and little capacity for having sex than those who had lived with grandparents" (Kimuna, Knox, \& Zusaman, 2005, p.566). Moreover, they found that students self-identified as uppermiddle class more likely to believe that older people have little interest in sex and consequently, no longer engage in sexual behavior (Kimuna, Knox, \& Zusaman, 2005). 
In a study about nursing student perceptions of older people, Moyle, (2003) asked, "Do you believe a 'love story' movie featuring older people, as the main stars would be a hit movie? She reported that the responses were divided in half. The reasons for the no responses included that society is not interested in older people and society encourages the belief that older people are 'asexual' (p. 18). That study quotes two participants, a 34-year-old female who said, "Modern day society is interested in seeing sexy and vibrant people. The aged would not fit this description," followed by an 18 year-old female who stated, "People would say it's disgusting seeing old people in these roles" (p. 19). Three participants in the current study shared about their experiences and perspective regarding the negative attitudes held about aging adults by younger generations and society at-large. One felt troubled that society at-large was imposing a vision of the way aging adults should be. Another became emboldened and discussing obtaining outside assistance to compel a change in the way providers and society atlarge view aging adults in regard to intimacy and sexual expression, while another offered a solution to address societal myths and misconceptions that aging adults are no longer viable, sexual beings who have intimacy and sexual expression needs. The study participant comments support research outcomes revealing similar findings regarding negative attitudes and myths promoted in society at-large about aging adults and their sexuality, including sexual behavior as long-term care residents Falk \& Falk, (1980).

\section{Lack of Education}

\section{Negative Attitudes and Stereotypes}

Research about staff at LTC facilities has found a lack of education and knowledge about sex and sexuality which results in their trying to curtail residents' sexual activity (Dupras \& Poissant, 1987). Some studies suggest that nurses, who have strong negative attitudes toward, or inadequate knowledge about, sex and sexuality, are unlikely to provide support for 
residents' intimacy or sexual expression needs (Gamel, Davis \& Hengeveld, 1993; Garrett, 1994; Lewis \& Bor, 1994; Payne, 1976; Webb, 1988). Four participants' comments correlated with research outcomes revealing similar findings regarding lack of education within long-term care administrators and staff. Participants talked about sexual expression in long-term care as being a taboo subject. Another participant believed these facilities should be legally compelled to accommodate the intimacy and sexual expression needs of aging adults. Another supported educating administrators and staff about the rights of the residents in their care. Another participant expressed a plea directed toward educating administrators and staff with the comment that if residents want to hook up, they should be able to hook up. Studies have shown that staff education programs are quite effective in eliciting support for residents' sexual lives, related to the intimacy and sexual expression needs of residents (Doyle et al., 1999; Lewis \& Bor, 1994; Mayers \& McBride, 1988; Steinke, 1997; Turnstull \& Henry, 1996; White \& Catania, 1982). These participant comments support research outcomes about the effectiveness of educating long-term care administrators and staff.

In addition to educating administrators and staff about the intimacy and sexual expression needs of aging adults in long-term care, not one of the participants were aware of their rights or how long-term care facilities currently address the intimacy and sexual expression needs of their residents. Consequently, aging adults need education about long-term care facilities and how to navigate them with regard to their intimacy and sexual expression needs as illustrated in these participant comments.

\section{Aging Rights Awareness}

The responses of many of the participants suggest that the awareness of their rights as a long-term care resident is limited. Ten of the 13 participants appeared to share a common thread of taking a stance in the face of adversity, reminding the researcher of the attitudes and 
internal drive he witnessed growing up in the 60 s and 70 s. The responses by each participant as they considered their intimacy and sexual expression needs as aging adults and how they would be met as future long-term care residents fueled a sense of injustice in them. They bristled at the fact that facilities would consider keeping them from meeting their identified intimacy and sexual expression needs. There was talk of marching, reaching out for regulatory assistance, and creating a movement working to ensure that their right to intimacy and sexual expression would not be obstructed by institutional administrators and staff.

\section{Baby Boomer Accommodations}

These study participants revealed that having the opportunity to be intimate and express their sexuality is important to them in the context of LTC residency. They desire privacy and procedures to ensure privacy such as signage to let visitors and staff know that they are unavailable and request privacy. Lastly, they indicated that they would like assistance to have their needs facilitated through education and perhaps assistance from staff to be together (e.g. assistance getting in and out of bed, and other needs as they emerge). when they have the urge to merge. These findings support previous studies that have found that LTC residents have a need for privacy and a means for privacy, (McDougall; 2008; Altman, 1975; Bauer, 1999; Bermann, 2003; Depres, 1991; McCann, 2000, Kass, 1978; Spector \& Fremeth, 1996, Walker \& Ross, 1999; Murray’s, 2011; Mroczek et al, 2013). At the same time, the request of personal assistance from staff to assist residents into and out of bed or into positions that were most comfortable for them to engage in sexual activities has not been found in any accessible previous research. It is possible that this need was identified in a book on supporting the sexual needs of LTC residents (Doll, 2013). An extensive study conducted in Poland by (Mroczek et al, 2013) is supported by these findings with the exception of the resident's desire for physical assistance when needed. 


\section{Participant Recommendations for Change}

Study participants generated 10 recommendations for possible solutions to the problems LTC facilities may create for themselves and others. 1) National Conversation: There is a need for a national conversation that addresses the intimacy and sexual expression needs as residents of LTC, The other part that troubles me is that we're not allowed to talk about it. It's still very much taboo. It's still very much a taboo subject that we can't talk about sex. We just can't talk about it. It's difficult to talk about. It's a difficult conversation. 2) Regulatory Enforcement: There is a need for the creation of an enforceable law to assure that LTC residents are able to exercise their right to intimacy and sexual expression, There should be a rule or a law or something. You should be given that opportunity. 3) Establish Policy \& Procedures: Someone should develop a universal practice to protect the privacy of LTC residents to signal those who approach their residential space o they privacy is not invaded, (do not disturb signs, hanky on the door handle, a privacy light, etc.).

I'm thinking of college dorms where you tie the hanky on the doorknob or whatever. But, I mean there should be some way to signal that you do not want to be disturbed and it doesn't have to be because you're having sex. It could just be because you want to spend some intimate time with somebody.

4) National Aging Education Campaign: Educating society at-large with facts to counter past generational myths that aging adults, especially those who are LTC residents, are "asexual" or no longer sexual beings is a critical next step. In addition, someone needs to educate healthcare workers about the intimacy and sexual expression needs and desires of LTC residents and how to facilitate those needs and desires. Moreover, there is a need to educate the LTC industry at-large about the LTC needs and desires of Baby Boomers and the benefits of making accommodations to fulfill them.

This idea that old people are just husks, that they're not people, that you don't have to listen to them. That, oh they're demented. They don't know what they're talking about 
or the common assumption, and I think that this has always been an assumption, you reach a certain age and you don't have sex anymore. You're not interested in sex anymore. You're not a sexual being anymore. That's partially American culture.

I can think, I can visualize that, maybe thinking about down road and how I would be able to do it. That would be something that I would think about you know. If I could find one that would get me stirred up to where I would [indecipherable] and would be able to have sex. Right now, by being in a nursing home, it just by being there so much and seeing what all goes on there, it just wow, sex is just,

5) A related idea is to Educate and Train LTC Staff: LTC staffs need education and training on methods to facilitate the intimacy and sexual expression needs of their residents as well as instructing them on safer ways to meet those intimacy and sexual needs. These approaches include educating and instructing residents about positions that accommodate their individual physical health issues, safer sex practices, providing residents with condoms, lubricants, dental dams, sex toys, and sexually oriented materials, (adult video, magazines, books, etc.) and teaching them how to utilize these items. 6) Establish Resident Advocacy Groups: They see a need for the establishment of resident oversight and advocacy groups in each LTC Facility. These groups could initiate an advocacy movement composed of LTC residents to maintain oversight over how their LTC facility s accommodates the intimacy and sexual expression needs of their residents. When LTC providers dismiss or fail to honor the residents' rights to intimacy and sexual expression in their facility, this group can take action. This group would act on behalf of residents by contacting their state's ombudsmen, state and federal legislative representatives, and organizing residents and others to effect change to address any civil or legal rights violations, including residents' rights to intimacy and sexual expression. I would probably be calling the ombudsmen myself or something like that. Making a lot of noise or checking with something. Who knows what I'll be doing. But I can see me, if I go into a residence and of a sound mind then I might be organizing or something. 7) Accommodate Room Sharing for all Couples: LTC facilities should maintain couples 
who desire to be together in the same room desire to reside in the same room. These couples should be permitted to share a bed whenever possible, and not separate them by assigning partnered residents to gender-specific residential space or in separate rooms in mixed residential space. I don't want to end up in some kind of long-term nursing home with Ed on one end of the, in the men's wing so to speak, and me in the other wing. 8) National Elder Rights Social Justice Campaign: A national social justice effort is needed to reduce ageism and educate older adults and their families about their rights as LTC residents. Such a movement should emphasize the rights to privacy, intimacy, and sexual expression needs and desires according to The Omnibus Budget Reconciliation Act (OBRA), also known as the Nursing Home Reform Act of 1987 ,

I was there with husbands and wives, and they couldn't hold hands, If I was a single person in long-term care and I had a sexual urge, do what I have to do. Whether that was picking up a magazine or I don't know how you get a magazine? Someone that you are in a relationship [with] when you get to that long-term care facility. Not knowing how that partner would be welcome inside that room. Whether or not you could close that door and have some private time. I'm not sure how that works out.

9) Right to Die or Dying with Dignity: Having the choice to die rather than enter LTC as a means to eliminate all of issues related to LTC residency, Death would be a better alternative. The topic on the right to die or dying with dignity has been in progress publicly since a Karen Ann Quinlan, a 21 year-old female, who lay in a coma for months in a vegetative state. Her parents request for life support to be removed 1976, (NA, 2015) sparked the debate on the controversial topic of right to die leading to more right to die legislation of the past 39 years. 10) Implications for LTCs That Do Not Change: LTC facilities that fail to address the intimacy and sexual expression requirements of Baby Boomers may be placing their economic viability at risk. This generation was involved in locating and selecting long-term care options for their parents. A great many shop online using the internet. This is a consumer generation, 
they are paying attention to the various amenities, policies, and services offered as they visit with their parents. These experiences are likely to shape their attitude about long-term care for themselves as was evidenced by the empirical observations of some of this study's participants. It is likely that Baby Boomers will choose the type of care and facility that provides the best return on their investment and for good reason. They have been known as the, "What's in it for me?" or as Tom Wolfe, (1976) labeled them, “The 'Me' Generation" as he described their focus on self-fulfillment and self-realization. While he did not identify the entire generation as acting on this focus, he does believe that the entire generation and their descendants will be victims of it (Wolfe, 2015). As members of the "Me Generation," there is likely to be much emphasis placed on person-centered care. The Heritage Foundation reported that $70 \%$ of more than 74 million Baby Boomers are likely to need LTC (Calmus, 2013). Should long-term care facilities continue to ignore the intimacy and sexual expression needs of their residents now and in the future, they are risking economic failure and encouraging Baby Boomers opting to age in place where they can maintain control and ensure that their intimacy and privacy needs are addressed of possibly live with their children.

\section{Policy Implications}

The policy implications are several. First, there needs to be a formal recognition that intimacy and sexual expression are inherent needs in residents of LTC along with definitions that incorporate the concepts identified by the participants. Second, policy makers need to create a federal policy establishing a universal standard of care for all LTC facilities in order to more easily identify the violation of those rights when they occur. In order to accomplish these tasks, conversations within and across stakeholders involved in the LTC system initiated. These types of policies would ensure that residents' rights to intimacy and sexual expression are

protected. With the establishment of these universal standards, regulations should require states 
to inspect all LTC facilities within their jurisdiction to assure that the rights of all long-term care residents including their right to intimacy and sexual expression are protected. Further, states need to investigate reports of incidents in which the rights of LTC residents may have been violated. LTC facilities that are found to be violating their resident's rights could be penalized by major fines and penalties, including owners and administrators, to establish personal accountability and increase the likelihood for compliance.

In addition to establishing universal standards and putting teeth into those standards to ensure compliance, policymakers should examine the possibility of federally mandating resident rights that are specific to intimacy and sexual expression, including the addition of cohabitation rights for unmarried individuals. Under the existing law, unmarried individuals have no guaranteed rights to cohabitation in LTC facilities,

Finally, the development and implementation of a national public service campaign that is two-fold. One part of such a campaign would be to educate Baby Boomers and existing LTC residents of their rights under OBRA (1987). A second part would be to educate society atlarge about aging adults and dispel the myths that have organized the culture and thinking of both LTC staff and the larger society.

\section{Practice Implications}

Based on the findings of this study, several recommendations for practice have arisen.

1. The importance of intimacy to Baby Boomers now and in the future is clear. Baby Boomers are primarily concerned about the ability to have intimacy more so than sex in both the present and in the future. From the findings, participants desire intimacy comprised of mutual support, deeper friendships, and multiple forms of physical touch now and in the future with family, friends, and significant others, both expressing and the ability

to receive. Therefore, an environment that allows Baby Boomers to both express and 
receive intimacy is important to health and aging as it is affecting their sexual expression in the present and the future.

2. The importance of sexual expression to Baby Boomers now and in the future is clear. Baby Boomers, while rating intimacy as important, still have a strong desire for sexual expression both now and in the future. From these findings, these participants' have a desire to engage in expressing their sexuality in a variety of ways with privacy.

Participants discussed how sexual performance, erectile dysfunction, and sexual desire effects physical and mental health. Therefore, an environment that allows for privacy is important to Baby Boomers to express themselves sexually as well as help maintain their sexual functionality.

3. The importance of companionship was also highlighted from the findings; participants do not want to be alone. The need for companionship is so strong; they would rather have a bad companion than no companion. Therefore, an environment that fosters opportunities to build close relationships will be beneficial in helping Baby Boomers establish relationships and have partner to share their fears and their joys as they age.

4. It appears from these findings that privacy is important to Baby Boomers now and in the future. From the findings, participants have an expectation for intimacy and sexual expression as residents of long-term care and yet view sex as impossible or nearly impossible for residents in that environment. Therefore, steps to provide an environment where privacy can occur is imperative to assisting Baby Boomers to maintain their identity as sexual beings.

5. The importance of knowledge of rights arose from the findings revealing that Baby Boomers are unware of their rights as residents of long-term care. Participants were unaware that they had a right to intimacy, to express themselves sexually, to privacy, to 
visitors. Many were under the impression they had no control or rights over their lives.

Therefore, educating society at-large and aging Americans about their aging rights would be helpful in assisting Baby Boomers to aware of and advocate for themselves regarding their right to intimacy and sexual expression.

\section{Advocacy Implications}

Social workers should be advocating for a universal national policy to address the intimacy and sexual expression rights of residents in LTC facilities. In addition to a universal policy, social workers should be advocating for onsite sex education and safer sex practices workshops for LTC residents. As a generation, Baby Boomers are experiencing a soaring rate of sexually transmitted diseases (CDC, 2013). This generation, along with the Traditionalists were not included in the population that was being targeted for safer sex education and practice following the outbreak of HIV/AIDS in the 1980s. Social workers should also be advocating for the coverage of erectile dysfunction drugs and hormones by Medicare and Medicaid along with medications that are being released to address with libido and sexual functioning disorders in females. Further, social workers should be advocating that LTC facilities obtain and provide sexually explicit materials and sexual aids to assist residents to meet their sexual expression needs. Finally, advocating for residents' privacy measures should be undertaken. These should include advocating for building design planners and architects consider privacy measures in new LTC design and as well as incorporating cost effective enhancements to existing facilities to create more physical privacy for residents to facilitate intimacy and sexual expression for residents of LTC facilities. 


\section{Ethical Implications}

There are a number of ethical areas that must be considered and navigated to arrive at the best possible policies and practices to meet the needs of all of the stakeholders. Beginning with LTC residents the following questions arise: How do residents navigate the mire/myriad challenges created by the competing values within the LTC industry to maintain and exercise their civil and legal rights? How will they freely follow and apply their personal morals and values within the framework of the LTC facility's duty to provide a safe environment for all residents, staff, and visitors? How will they continue to meet their intimacy and sexual expression needs when they begin to experience diminished mental capacity or can no longer speak for themselves? How will they continue to remain autonomous and participate in decision-making about their intimacy and sexual expression needs? What legal instrument is available or could be developed to address the intimacy and sexual expression needs for residents with diminished capacity. How can they maintain their privacy while having intimate relationships with others or privacy when they have sexual interactions with a spouse, friend, or significant other? Also, while not directly related to intimacy and sexual expression, do we or how do we honor an individual's autonomy should they choose to avoid LTC completely and desire to invoke their "right to die"?

Another stakeholder is the resident's family or conservator. What role does or should have either regarding their parents' or clients' intimacy and sexual expression needs? What authority do they have or should they have to facilitate or interfere in how their parent's or clients' meet their intimacy and sexual expression needs? If such authority exists, who gives them that power? How is that authority given and how is it removed? What liability does the resident's family or conservator carry with regard to their parents' or clients' behavior as they seek to meet their individual intimacy and sexual expression needs? Additionally, what role or 
authority would family or a conservator play around an aging adult who prefers to avoid LTC and would rather die instead?

Healthcare professionals, administrators, and direct service staff represent another stakeholder group. Questions arise about resident autonomy and decision-making. How do these group members balance their personal morals and values and honor the civil legal rights of the individuals they serve? Is it ethical for members of this group to impose their individual or collectively held morals and values on the residents they serve? What role do physicians, allied healthcare professionals, and direct care staff have in decision-making process of residents regarding their intimacy and sexual expression needs? Should they have any role in that process?

Individual and corporate owners of LTC represent another group of stakeholders who have to find a way to navigate a myriad of challenges to honor the residents' civil and legal rights above all. They must maintain a positive relationship with the families or conservators of the residents in their care. They also must find a way to balance their businesses responsibilities with federal regulations, criminal and civil liability, and navigate the ethical and moral values held implications that can be foreseen. It is likely that many more will emerge as the conversation continues of intimacy and sexual expression rights of LTC residents continues.

\section{Next Steps for the Field for Research}

The next steps for research are to repeat this study with LGTB Baby Boomers. That research would be followed by a national survey created from the data collected in the two qualitative studies. Additionally, research regarding SW ethics, intimacy and sexual expression rights in long-term care and the role of social workers to facilitate the 
intimacy and sexual expression rights of LTC candidates. Finally, explore advance directives to address consent issues for residents with diminished capacity

\section{Limitations}

There were several limitations to this study, as a qualitative study the participation numbers were small and as such, the findings could not be generalized. This limitation can be remedied by creating a survey to gather data nationally using online internet technology. Another limitation was that none of the participants was in LTC and as such, no information was generated in this study to be compared. Another limitation is the inability to compare Traditionalists or Gen Xers so consequently there is no information available to identify what is unique to Baby Boomers and what is simply growing older (e.g. is desire for intimacy as one ages normative or more so for this generation that has less stable partnerships?). Further, there is no data to conclude whether their children are going to support them in ways that some in their generation did not support their own parents. Thus, a study that includes both older adults and their children needs to be developed to examine that question. While I consider the second coder who is a Baby Boomer, female, with a more conservative upbringing and lifestyle that brought a different perspective to the research a strength, her participation in that role may be too close to the topic. Lastly, a limitation of the study is the lack of consideration in how abuse (physical, verbal, emotional, and sexual) may have affected how Baby Boomers define intimacy and sexual expression across the life course.

\section{Summary}

This hermeneutic phenomenological, qualitative study examined the meaning, interpretations, and individual experiences. Thirteen participants from diverse backgrounds were interviewed. This study provided new insight into how heterosexual Baby Boomers define intimacy and sexual expression across the life course. The 32 
themes that emerged allowed the researcher to gain a better understanding of how heterosexual Baby Boomer men and women define and understand intimacy, sexual expression, expectations and desires relating to their respective expressions across the life course and their current future considering long-term care, and common concerns and issues relating to these two areas facing heterosexual men and women as they age. In conclusion, based on the findings of the present study, the experiences heterosexual Baby Boomers described were both dynamic and ongoing. The participants in this study mentioned several ingredients in the formula for an intimate relationship, several aspects of sexual expression that were important to them, a number of interpersonal relationship types and experiences that influenced their definitions and understandings of intimacy and sexual expression and a number of hopes and fears regarding intimacy and sexual expression into the future. Lastly, these Baby Boomers, AKA the "Me Generation" emphasized doing what they wanted and what made them happy along the way. At the same time, once they reached middle and old age, the consequences of their choices and lifestyles, (multiple broken relationships, some alone or feared being alone) have become all too real and in some cases, the results suggest a sense of desperation for any type of human companionship, even if it is a bad relationship. As social workers and clinicians, we must understand the intimacy and sexual expression needs of the Baby Boomers and serve as advocates to assist them toward meeting their needs as they enter old age. 


\section{REFERENCES}

Abramson, P., Parker, T. \& Weisberg, S. (1988). Sexual expression of mentally retarded people: Education and legal implications. American Journal on Mental Retardation. 93(3), 328-334.

Adler, J., Wingert, P., Springen, K., Reno, J., Samuels, A., Raymond, J., \& Adams, W. L. (2005, November 14). The boomer files: Hitting 60. Newsweek. Retrieved May 5, 2010, from www.agewave.com Web site: http://www.agewave.com/media_files/ newsweek111405.html

Alexander, C.J., Sipski, M.L. \& Findley, T.W. (1993). Sexual activities, desire, and satisfaction in males pre- and post-spinal cord injury. Archives of Sexual Behavior. 22(3), 217-228.

Altman, I. (1975). The environment and social behavior: privacy, personal space, territory, crowding. Monterey, CA.: Brooks/Cole Publishing Company. American College of Health Care Administrators. (2010). Code of ethics [Brochure]. Retrieved July 1, 2010, from American College of Health Care Administrators Web site: http://achca.org/joomla/index.php/membership/code-of-ethics

American Medical Directors Association. (2010). AMDA code of ethics [Brochure]. Retrieved July 1, 2010, from AMDA Web site: http://www.amda.com/about/ $\underline{\text { ethics.cfm }}$

American Nurses Association. (2001). Code of ethics for nurses with interpretive statements [Brochure]. Retrieved July 1, 2010, from www.nursingworld.org Web site: http://nursingworld.org/ethics/code/protected_nwcoe629.htm 
Arno, P. S. (2002, February). The economic value of informal caregiving, U.S., 2000. Annual Meeting presented at the American Association for Geriatric Psychiatry, Florida.

Ary, D., Jacobs, L. C., Razavieh, A., \& Sorenson, C. K. (2006). Introduction to research in education (7th ed.). Belmont, CA: Thomson Wadsworth.

B.C. Coalition of the Disabled. "No sex, please. we're disabled." Transition. (Special Issue) July/August, 1990.-

Babbie, E. (1995). The practice of social research (7th ed.). Belmont, CA: Wadsworth.

Bailey, C.A. (1996). A guide to field research. Thousand Oaks, CA: Pine Forge.

Barnes, I. (2001) Sexuality and cognitive impairment in long-term care. Canadian Nursing Home. 72(3), 5-14.

Barrett, M. (1982). Sexuality and multiple sclerosis, (booklet). Toronto: Multiple Sclerosis Society of Canada.

Barrett, M. (1991). Sexuality and multiple sclerosis. (Information booklet). ( $3^{\text {rd }}$ ed.). Toronto: Multiple Sclerosis Society of Canada.

Basson, R (1998). Sexual health of women with disabilities. Canadian Medical Association Journal. 159(4), 359-362.

Bauer, M. (1999). Their only privacy is between their sheets. Privacy and the sexuality of elderly nursing home residents. Journal of Gerontological Nursing, 25(8), 37-41.

Becker, F. (1984). Sexuality and the spinal cord injured woman. In M. Tallmer, G. Buillard, M. Roberts, P. DeSanctus, A. Kutcher \& P. Patterson (Eds.) Sexuality and Life-Threatening Illness (pp. 174-185). Springfield, 111.: Charles C. Thomas Publisher. 
Bennett, J.B., (2000) Time and intimacy: A new science of personal relationships. Lawrence Erlbaum.

Berger, P. L. and T. Luckmann (1966), The Social Construction of Reality: A Treatise in the Sociology of Knowledge, Garden City, NY: Anchor Books.

Berkman LF. (1995). The role of social relations in health promotion. Psychosomatic Medicine, 57, 245-254.

Bermarm, K. (2003). Love and space in the nursing home. Theoretical Medicine. $24,511-523$

Bleakley, A., Hennessy, M., Fishbein, M., \& Jordan, A. (2009). How Sources of Sexual Information Relate to Adolescents' Beliefs about Sex. American Journal of Health Behavior, 33(1), 37-48.

Blumer, H. (1969). Symbolic interactionism: Perspective and method. Englewood Cliffs, N.J: Prentice-Hall.

Bretschneider, J.G. \& McCoy, N.C. (1988). Sexual interest and behavior in healthy 80- to 102 - year-olds. Archives of Sexual Behavior. 17, 109-129.

Brown G.T., Carney, P., Cortis, J.M., Metz, L. L., \& Petrie, A. M. (1994) Human sexuality handbook. Springfield, MA: The Association of Community Living.

Brown, L. (1989). Is there sexual freedom for our aging population in long-term care institutions? Journal of Gerontological Social Work, 13(3-4), 75-93.

Bullard-Poe, L., Powell, C., \& Mulligan, T. (1994). The importance of intimacy to men living in nursing homes. Archives of Sexual Behavior, 23(2), 231-236.

Cameron, P. (1970). The generation gap: beliefs about sexuality and self-reported sexuality. Developmental Psychology, 3, 272. 
CDC. (2013). HIV Surveillance Report, 2011 (Vol. 23).

Center for Practical Bioethics. (2006, August). Considerations regarding the needs of long term care residents for intimate relationships and sexual activity (Intimacy Guidelines). Kansas City, MO: Center for Practical Bioethics.

Code of Ethics of the National Association of Social Workers (Rev. ed.). (2002).

Washington, DC: Author. (Original work published Approved 1996).

Congressional Research Service. (2008). Prescription Drug Coverage

UnderMedicaid (RL30726). Washington, DC: U.S. Government Printing Office.

Cort, E. (1998). Nurses' attitudes to sexuality in caring for cancer patients. Nursing Times. 94, 54-57.

Courtois, F., Charvier, K., Leriche, A., \& Raymond, D. (1993). Sexual function in spinal cord injury men: I. Assessing sexual capability. Paraplegia, 31(12), 771-784.

Creswell, J. W. (1994). Research design: qualitative and quantitative approaches. Thousand Oaks, CA: Sage.

Creswell, J. W. (2007). Qualitative inquiry \& research design: Choosing among five approaches. Thousand Oaks, CA: Sage Publications.

Creswell, J. W., \& Plano Clark, V. (2004, July 15). Principles of qualitative research: Designing a qualitative study. Retrieved May 1, 2015, from Andrews.edu Web site: http://www.andrews.edu/leaderpart/RoundTable/2004/workshops/2b/AUQual-071504-jwc-vpc.pdf

Crabtree, B. F., \& Miller, W. L. (Eds.). (1992). Doing qualitative research: Research methods for primary care (Vol. 3). Newbury Park, CA: Sage.

Daniels, S., Cornelius, D., Makas, E. \& Chipouras, S. (1981). Sexuality and 
disability: The need for services. Annual Review of Rehabilitation. 2, 83-112.

Davidson, K. (2001). Late life widowhood, selfishness, and new partnership choices: A gendered perspective. Ageing \& Society, 21, 297-317.

d'Ardenne. P. (1986). Sex therapy education in a medical college. Sex and Marital Therapy. 1(2), 215-220.

de Mey, C. (1998). Opportunities for the treatment of erectile dysfunction by modulation of the NO axis - alternatives to sildenafil citrate. Current Medical Research and Opinion. 14(4), 187-202.

Denial of residents' sexuality is tantamount to institutional conspiracy. (1995, June). Brown University Long-Term Care Quality Letter, 7(12), 6 - 9.

Depres, C. (1991). The meaning of home: Literature review and directions for future research and theoretical development. The Journal of Architectural and Planning Research. 5(2), 96-114.

Dianko, A.C., Brown, M.B., Herzog, A.R. (1990). Sexual function in the elderly. Archives of Internal Medicine. 150, 197-200.

Dowrick, S. (2002). Intimacy \& solitude: Balancing closeness and independence. Milsons Point, N.S.W: Random House Australia.

Doyle, D., Bisson, D., Janes, N., Lynch, H. \& Martin, C. (1999). Human sexuality in long-term care. The Canadian Nurse. Jan., 26-29.

Drigotas, S. M., Rusbult, C. E., \& Verette, J. (1999). Level of commitment, mutuality of commitment, and couple wellbeing. Personal Relationships, 6, 389-409.

Dressel, P. \& Avant, W. (1983). Range of alternatives. In R. Weg (Ed.) Sexuality in later years: Roles and behavior (pp. 185-207). New York: Academic Press. 
Ducharme, S.H., \& Gill, K.M. (1997). Sexuality After Spinal Cord Injury: Answers to Your Questions. Baltimore, MD: Paul H. Brookes Publishing Co., Inc

Dupras, A., \& Poissant, M. S. (1987). The fear of sexuality in residents of a long-term care hospital. Sexuality and Disability, 8(4), 203-215.

Drugovich M.L. \& Friedlob, A. S. (1990). Designing the national resident assessment instrument for nursing homes. The Gerontologist, 30(3), 293-307.

Earle, S. (2001). Disability, facilitated sex and the role of the nurse. Journal of Advanced Nursing. 36(3), 433-440.

Edwards, D. J. (2003). Sex and intimacy in the nursing home. Nursing Homes: LongTerm Care Management, 52(2), 18-20.

Ehrenfeld, M., Tabak, N., \& Bergman, R. (1997). Ethical dilemmas concerning sexuality of elderly patients suffering from dementia. International Journal of Nursing Practice, 3(4), 255 - 259.

Ekland, M., Griffin, S., Copeland, J., Elliott, S., \& Nigro, M. (1998). Exploring male fertility options after spinal cord injury: The role of the nurse clinician. SCI Nursing 15(4), 95-98.

Elder, G. H., Jr. (1994). Time, human agency, and social change: Perspectives on the life course. Social Psychology Quarterly, 57, 4-15.

Elder, G. H., Jr. 1996. "Human Lives in Changing Societies: Life Course and Developmental Insights.” Pp. 31-62 in Developmental Science, edited by Robert B. Cairns, Glen H. Elder, Jr., and E. Jane Costello. Cambridge Studies in Social and Emotional Development. New York: Cambridge University Press. 
Elliott, S. (1998). A guide to the technique of erection enhancement. Vancouver:

G.F. Strong Rehab. Centre.

Elliott, S. (2002a). Ejaculation and orgasm: Sexuality in men with SCI. Topics in Spinal Cord Injury Rehabilitation. 5(1), 1-15.

Elliott, S. (2002b). Sexual dysfunction and infertility in men with spinal cord disorders. In Lin Vernon (Ed.) Spinal Cord Medicine: Principles and Practice (pp. 349365). New York: Demos Medical Publishing.

Elliott, S. (1999). Assessment and treatment of erection dysfunction in men with chronic illness. Vancouver: G.F. Strong Rehab. Centre.

Elliott S, and Krassioukov A. (2006). Malignant autonomic dysreflexia in spinal cord injured men. Spinal Cord, 44, 386-392.

Erber, R., \& Erber, M. W. (2001). Intimate relationships: Issues, theories, and research. Boston: Allyn and Bacon.

Evans, G. (1999). Sexuality in old age: Why it must not be ignored by nurses. Nursing Times. P5(20), 46-48.

Falk, G., \& Falk, U. S. (1980). U. S. Sexuality and the aged. Nursing Outlook, 28(January), 51-55.

Family Caregiver Alliance. (2001). Selected Caregiver Statistics (Fact Sheet). San Francisco: Author.

Felmlee, D., \& Muraco, A. (2009). Gender and friendship norms among older adults. Research On Aging, 31(3), 318-344.

Fielden, K.I. (1997). Sex in resident care facilities. The Lamp. 54(9), 24-25.

Feinberg, J. (1973). Social Philosophy. Englewood Cliffs, NJ: Prentice-Hall, Inc. 
Fontana, A. and Frey. J., (1994). The Art of Science." Pp. 361-76 in The Handbook of Qualitative Research, edited by N. a. Y. L. Denzin. Thousand Oaks: Sage Publications..

Ford, E., Rosenberg, M., Holsten, M., \& Boudreaux T. (2003). Managing sexual behavior on adult acute care inpatient psychiatric patients. Psychiatric Services, 54(3), 346350.

Forman, R., Gilmour- White, S. \& Forman, N. (1996). Drug-induced infertility and sexual dysfunction. Cambridge: Cambridge University Press.

Fowler, C. (Ed.) (1999). Neurology of bladder, bowel, and sexual dysfunction. New York: Butterworth-Heinemann.

Frank, A. (1996). Intimacy and individuation. In S. Akhtar \& S. Kramer (Eds.), Intimacy and infidelity: Separation-individuation perspectives (pp. 71-89). Northvale, NJ: Jason Aronson Inc.

Frankowski, A. C., \& Clark, L. J. (2009). Sexuality and Intimacy in Assisted Living: Residents' Perspectives and Experiences. Sexuality Research \& Social Policy: Journal of NSRC : SR \& SP, 6(4), 25-37. doi:10.1525/srsp.2009.6.4.25

Freedberg, S. (1989). Self-Determination: Historical perspectives and effects on current practice. Social Work, 34, 33 - 38.

Furman, W., \& Buhrmester, D. (1992). Age and sex differences in perceptions of networks of personal relationships. Child Development, 63, 103-115

Furman, W., \& Wehner, E. (1994). Romantic views: Toward a theory of adolescent romantic relationships. In R. Montemayor, G. R. Adams, \& T. P. Gullotta (Eds.), Advances in adolescent development: Volume 6, Personal relationships during 
adolescence (pp. 168-195). Thousand Oaks, CA: Sage.

Gabrel, C. S. (2000). Characteristics of elderly nursing home residents and discharges. In 1997 National Nursing Home Survey (Advance data from vital and health statistics; No. 312). Hyattsville, U.S: National Center for Health Statistics.

Gamel, C., Davis, B., \& Hengeveld, M. (1993). Nurses' provision of teaching and counselling on sexuality: review of the literature. Journal of Advanced Nursing, 18(8), 1219-1227.

Gamel, C., Hengeveld, M., Davis, B. Van Der Tweel, I. (1995). Factors that influence the provision of sexual health care by Dutch cancer nurses. International Journal of Nursing Studies. 32 (3), 301-314.

Garrett, G. (1994). Sexuality in later life. Elderly Care, 6(4), 23-28.

Giele, J. Z., and Elder, G. H., Jr. (1998). Methods of Life Course Research: Qualitative and Quantitative Approaches. Thousand Oaks, CA: Sage.

Geoffrey Fisher. (1959, March 17). Archbishop of Canterbury. Look.

Giles, L. C., Glonek, G. V. F., Luszcz, M. A., \& Andrews, G. R. (2005). Effect of social networks on 10 year survival in very old Australians: the Australian longitudinal study of aging. Journal of Epidemiology Community Health, 59, 574-579.

Gillon, S. (2004). Boomer Nation: the largest and richest generation ever and how it changed America (1st ed.). New York: Free Press.

Giorgi, A. (1997). The theory, practice, and evaluation of the phenomenological method as a qualitative research procedure. Journal of Phenomenological Psychology, $28(2), 235-251$.

Giorgi, A. (2009). The phenomenological movement and research in the human 
sciences. Nursing Science Quarterly, 18(1), 75-82.

Gledhill, Susan E. and Abbey, Jennifer A. and Schweitzer, Robert (2008) Sampling methods: methodological issues involved in the recruitment of older people into a study of sexuality. The Australian Journal of Advanced Nursing 26(1), 84-94.

Golde, P., \& Kogan, N. (1959). A sentence completion procedure for assessing attitudes toward old people. Journal of Gerontology, 14, 355 - 363.

Goodson, A. (1991). Therapy Nudity and Joy: The Therapeutic Use of Nudity Through the Ages from Ancient Ritual to Modern Psychology (1st ed.). Los Angeles, CA: Elysium Growth Press.

Gordon, D. M., Hawes, S. W., Reid, A. E., Callands, T. A., Magriples, U., Divney, A., Kershaw, T. (2013). The Many Faces of Manhood: Examining Masculine Norms and Health Behaviors of Young Fathers Across Race.American Journal of Men's Health, 7(5), 394-401.

Georgakopoulou, A., \& Goutsos, D. (2000). Revisiting discourse boundaries: The narrative and non-narrative modes. Text, 20, 63-82.

Greeff, A. P., \& Malherbe,H.L. (2001). Intimacy and marital satisfaction in spouses. Journal of Sex and Marital Therapy, 27, 247-257.

Grewen, K. M., Girdler, S. S., Amico, J., \& Light K.C. (2005). Effects of partner support on resting oxytocin, cortisol, norepinephrine, and blood pressure before and after warm partner contact. Psychosomatic Medicine, 67(4), 531-538.

Griffiths, E. (1988) No sex please, we're over 60. Nursing Times, 84, 34-35

Gripton, J. \& Valentich, M. (1983). Assessing sexual concerns of clients with health problems. Journal of Social Work \& Human Sexuality. 2 (1), 53-66. 
Hazan, C., Zeifman, D., \& Middleton, K. (1994). Adult romantic attachment, affection and sex. Paper presented at the International Conference on Personal Relationships, Groningen, NL.

Heidegger, M. (1962). Being and Time. New York, NY: Harper \& Row.

Helgeson, V. S., Shaver, P., \& Dyer, M. (1987). Prototypes of Intimacy and Distance in Same-Sex and Opposite-Sex Relationships. Journal Of Social And Personal Relationships, 4(2), 195-233.

Hosmer, R. (2008). Discussing the dead: Patterns of family interaction regarding lost family members (Master's thesis, University of Denver). Masters Abstracts.

Kennedy, S., \& Ruggles, S. (2014). Breaking up is hard to count: The rise of divorce in the united states, 1980-2010. Demography, 51(2), 587-598. Retrieved from University of Minnesota Web site: http://www.hist.umn.edu/ ruggles/Articles/ breaking_up.pdf

Hennessey, A., Robertson, N., Swingler, R., Compston, D. (1999). Urinacy, faecal and sexual dysfunction in patients with multiple sclerosis. Journal of Neurology. 246(1), 1027-1032.

Henry, J., \& McNab, W. (2003). Forever young: A health promotion focus on sexuality and aging. Gerontology \& Geriatrics Education, 23(4), 57-74.

Hillman, J. L., \& Stricker, G. (1994). A linkage of knowledge and attitudes toward elderly sexuality: Not necessarily a uniform relationship. The Gerontologist, $34(2), 256-260$.

Hobbs, F. B., \& Damon, B. L. (2015, May 22). Sixty-five plus in the United States. Retrieved from U. S. Census Web site: 
https://www.census.gov/prod/1/pop/p23-190/p23-190.pdf

Hodge, A.L. (1995). Addressing issues of sexuality with spinal cord injured persons. Orthopaedic Nursing. 14(3), 21-24.

Holloway, I. (1997). Basic concepts for qualitative research. Oxford: Blackwell Science.

Holmes, D., \& Fairchild, S. (1995). Policies and Procedures Concerning Sexual Expression at the Hebrew Home for the Aged at Riverdale. Unpublished manuscript, Riverdale, NY.

Holmes, D., Reingold, J., \& Teresi, J. (1977). Sexual expression and dementia. View of caregivers. International Journal of Geriatric Psychiatry, 12, 695 - 701.

Hugman, R. (2003). Professional ethics in social work: Living with the legacy. Australian Social Work, 56(1), 5 - 15.

Husserl, E. (1999). The Essential Husserl: Basic Writings in Transcendental Phenomenology (D. Weldon, Ed.). Bloomington, IN: Indiana University Press.

Hycner, R. H. (1999). Some guidelines for the phenomenological analysis of interview data. In A. Bryman \& R.G. Burgess (Eds.), Qualitative research (Vol. 3, pp. 143164). London: Sage.

Joseph, R. (1991). A case analysis in human sexuality: Counselling to a man with severe cerebral palsy. Sexuality and Disability. 9(2), 149-159.

Kaas, M. J. (1978). Sexual Expression of the Elderly in Nursing Homes. The Gerontologist, 18(4), 372-378.

Kahn, D .L. (1999). Making the best of it: adapting to the ambivalence of a nursing home environment. Qualitative health research, 9 (1), 119-132.

Kaiser, F. (2003). Sexual function and the older woman. Clinical Geriatric Medicine, 19, 
463-472.

Kane, R. A., \& Cutler, L. J. (2007, July-August). Comparing nursing home rules yields 10 lessons from 50 states. Aging Today, 28(4), 7-8.

Kamel, H. K., \& Hajjar, R. H. (2004). Sexuality in the nursing home, part 2: Managing abnormal behavior--legal and ethical issues. Journal of the American Medical Directors Association, 5(2 Supplement), S49 - S52.

Kamel, H. K., \& Hajjar, R. R. (2004). Sexuality in the nursing home pt. 1: Managing abnormal behavior. Journal of the American Medical Directors Association, 5, 548-552.

Karlen, A., \& Moglia, R. (1995). Sexuality, aging, and the education of health professionals. Sex Disability, 13(3), 191-199.

Kassel, V. (1983). Sexuality in the later years. In R. B. Weg (Ed.), Long-term care institutions (pp. 167 - 184). New York: Academic Press.

Katz, E. (1988). The History of Birth Control in the United States. Trends in History, 4(23), 81-101.

Kempton, W. \& Kah, E. (1991). Sexuality and people with intellectual disabilities: A historical perspective. Sexuality and Disability. 9 (2), 93-111.

Kessel, B. (2001). Sexuality in the older person. Age and Aging, 30, 121-124.

Kirkland, M. A., \& Seal, C. a. (2008). Intimacy in the elder law setting. Probate \& Property Magazine, 22(5), 34-39. Retrieved July 5, 2010, from www.abanet.org Web site: http://www.abanet.org/rpte/publications/magazine/2008/nd/kirtlandseal.html

Kuhn, D. (2002). Intimacy, sexuality, and residents with dementia. Alzheimer's Quarterly 
Care, 3(3), 165-176.

Langer, N. (2009). Late Life Love and Intimacy. Educational Gerontology, 35(8), 752764.

Latimer, A.M. (1981). Accountability for the sexual awareness of the spinal cord injured patient. Rehabilitation Nursing. 6(4), 8-11.

Laurenceau J.P., Barrett L.F., Pietromonaco P.R.,(1998). Intimacy as an interpersonal process: The importance of self-disclosure, partner disclosure, and perceived partner responsiveness in interpersonal exchanges.Journal of Personality and Social Psychology. 1998;74:1238-1251. [PubMed]

Laurenceau J.P., Barrett LF, Rovine M.J., (2005). The interpersonal process model of intimacy in marriage: A daily-diary and multilevel modeling approach. Journal of Family Psychology. 19:314-323.

Leiblum, S. R. (Ed.). (2006). Principles and Practice of Sex Therapy (4th ed.). New York: The Guilford Press. (Original work published 1980)

Lerner, H. G. (1990). The dance of intimacy: A woman's guide to courageous acts of change in key relationships. New York: Harper \& Row.

Lewis, S. \& Bor, R. (1994). Nurses' knowledge of and attitudes towards sexuality and the relationship of these with nursing practice. The Journal of Advanced Nursing. 20(2), 251-259.

Lichtenberg, P. A., \& Strzepek, D. M. (1990). Assessments of institutionalized dementia patients' competencies to participate in intimate relationships. Gerontologist, $30(1), 117-120$.

Lofland, J. and L. H. Lofland (1995). Analyzing Social Settings: a guide to qualitative 
observation and analysis. Belmont, CA, Wadsworth Publishing Company.

Lindau, S. T., Schumm, L. P., Laumann, E. O., Levinson, W., O'Muircheataigh, C. A., \& Waite, L. J. (2007). A study of sexuality and health among older adults in the United States. The New England Journal of Medicine, 357(8), 762-774.

Low, L. P. L., Lui, M. H. L., Diana T.F. Lee, D. T. F., Thompson, D. R., \& Chau, J. P. C. (2005). Promoting awareness of sexuality of older people in residential care. Electronic Journal of Human Sexuality, 8. Retrieved July 5, 2010, from www.ejhs.org Web site: http://www.ejhs.org/volume8/ sexuality_of_older_people.htm

Ludeman, K. (1981). Sexuality of the older person: Review of the literature. Gerontologist, 21(2), 203-208.

Marchant, R., \& Page, M. (1993). Bridging the gap: Child protection work with children with disabilities. London: National Society for the Prevention of Cruelty to Children. Marshall, N. (1974). Dimensions of privacy. Multivariate Behavioural Research, 9(3), 225-271.

Maurice, W.L. (1999). Sexual medicine in primary care. St. Louis: Mosby, Inc.

Masters, W.H., \& Johnson, V.E. (1970). Human sexual inadequacy. Boston, MA: Little, Brown and Company.

Maxwell, J. A. (2005). Qualitative Research Design: An Interactive Approach: An Interactive Approach. Thousand Oaks, CA: Sage Publications.

Mayer, K. S., \& McBride, D. (1998). Sexuality training for caretakers of geriatric residents in long term care facilities. Sexuality and Disability, 16(3), 227-236.

McAdams, D. D. (1989). Intimacy: The need to be close. New York: Doubleday. 
McCabe, M. P. (1999). The interrelationship between intimacy, relationship functioning, and sexuality among men and women in committed relationships. The Canadian Journal of Human Sexuality, 8, 31-40.

McCann, E. (2000). The expression of sexuality in people with psychosis: breaking the taboos. Journal of Advanced Nursing. 32(1), 132-138.

McCartney, J. R., Izeman, H., Rogers, D., \& Cohen N. (1987). Sexuality and the institutionalized elderly. Journal of the American Geriatric Society, 35(4), 331333.

McAuliffe, L., Bauer, M., \& Nay, R. (2007). Barriers to the expression of sexuality in the older person: The role of the health professional. International Journal of Older People Nursing, 2(1), 69-75.

McCracken, A. (1980). Sexual practices by elders: The forgotten aspect of functional health. Journal of Gerontological Nursing. 14(10), 21-25.

McKinley, H., \& Drew, B. (1977). The nursing home: Death of sexual expression. Health and Social Work, 2(3), 180 - 187.McSherry, B. \& Somerville, M. A. (1998). Sexual activity among persons in need of institutionalized care. Windsor Yearbook of Access to Justice, 16, $90-131$.

McSherry, B. \& Somerville, M. A. (1998). Sexual activity among persons in need of institutionalized care. Windsor Yearbook of Access to Justice, 16, 90 - 131.

Metz, L. (1998). Multiple sclerosis: symptomatic therapies. Seminal Neurology, 18, 389 $-395$

Miles, S. H., \& Parker, K. (1999). Sexuality in the nursing home: Iatrogenic loneliness. Generations, 23(9), $36-43$. 
Miller, R. S., \& Lefcourt, H. M. (1983). Social intimacy: An important moderator of stressful life events. American Journal of Community Psychology, 11(2), 127-139.

Monsour, M. (1992), 'Meanings of Intimacy in Cross- and Same-Sex

Friendships', Journal of Social and Personal Relationships, Vol. 9, 277-295.

Morley, J. E., \& Kaiser, F. E. (1989). Sexual function with advancing age. Medical Clinics of North America, 73(6), 1483-1495.

Morely, J. E., \& Tariq, S. H. (2003). Sexuality and disease. Clinical Geriatric Medicine, $19,563-573$.

Morelli, S. A., Lee, I. A., Arnn, M. E., \& Zaki, J. (2015). Emotional and instrumental support provision interact to predict well-being. Emotion, 15(4), 484-493.

Morris, J. N., Hawes, C., Fries, B. E., Phillips, C. D., Mor.,V., Katz., S., Murphy.,K., Morse, Janice, M. (2000). Determining sample size. Qualitative Health Research, 10(1), 3-5

Mossmann, D., Perlin, M. L., \& Dorman, D. A. (1997). Sex on the wards: Conundra for clinicians. Journal American Academy of Psychiatry and the Law, 25(4), 441-460.

Moustakas, C. (1994). Phenomenological research methods. Thousand Oaks, CA: Sage Publications, Inc.

Mulligan, T., \& Palguta, R. (1991). Sexual interest, activity, and satisfaction among male nursing home residents. Archives of Sexual Behavior, 20, 199 - 204.

Murray, S. L., Holmes, J. G., \& Griffin, D. W. (1996). The benefits of positive illusions: Idealization and the construction of satisfaction in close relationships. Journal of Personality and Social Psychology, 70, 79-98.

NA. (2015, August 3). National Center for Life and Liberty. Retrieved from NCLL Web 
site: http://www.ncll.org/liberty-centers/center-for-life-defense/cld-articles/57-

how-the-right-to-die-came-to-america

National Alliance for Caregiving, \& AARP. (1997). Family caregiving in the U.S.:

Findings from a national survey. Washington, DC: Author.

National Association of Social Workers. (2008). Code of ethics of the national

association of social workers (Rev. ed.) [Brochure]. Retrieved June 15, 2010, from National Association of Social Workers Web site: http://

www.socialworkers.org/pubs/code/code.asp

National Center for Health Statistics. (2007). Health, United States, 2007 with chart book on trends in the health of Americans (Health 2007). Hyattsville, MD: U.S.

Government Printing Office.

National Federation of Licensed Practical Nurses, Inc. (1979). Nursing practice standards for the licensed practical/vocational nurse (Rev. ed.) [Brochure]. Retrieved July 1, 2010, from www.nflpn.org Web site: http://www.nflpn.org/ practice-standards 4 web.pdf

NH Regulations Plus. (Ed.). (2009, December 22). Resident rights for the state of rhode island. Retrieved June 27, 2010, from NH Regulations Plus Web site: http:// www.sph.umn.edu/hpm/nhregsplus/resident_rights/ resident_rights_rhode_island.htm

Omnibus Budget Reconciliation Act of 1987. Section 4201, 42 U.S.C.A. Section $1396 r(c)(3)$.

Pangman, V. C., \& Sequire, M. (2000). Sexuality and the chronically ill adult: A social justice issue. Sexuality and Disability, 18(1), 49-59. 
Parks, M. R., \& Floyd, K. (1996). Meanings for closeness and intimacy in friendship. Journal Of Social And Personal Relationships, 13(1), 85-107

Parker, S. (2006). What barriers to sexual expression are experienced by older people in 24-hour care facilities? Reviews in Clinical Gerontology, 16(4), 275-279.

Patton, M. Q. (2002). Qualitative research \& evaluation methods (3rd ed.). Thousand Oaks, CA: Sage Publications, Inc. Payne, T. (1976). Sexuality of nurses: Correlations of knowledge, attitudes and behaviour. Nursing Research. 25 (4), 286-292.

Pederson, L. (1993). Sexuality after 70: Fact and fiction. Symposium conducted by Gerontological Nurses Group of B.C. Vancouver, Canada.

Penner, I. E. (1991, April). Sexual rights of long-term care residents: Balancing institutional responsibility against individual liberties. Health Care \& Law News Letter, 11-15.

Pfeiffer, E., \& Wang, H. (1968). Sexual behavior in aged men and women. Archives of General Psychiatry, 19, 756-758.

Piorkowski, G. K. (1994). Too close for comfort: Exploring the risks of intimacy. New York: Plenum Press.

Pollard, M. \& Barker, B. (1985). Straight talk on sex for the older patient. RN. 48(2), 1718.

Public Health (Vol. 42 CFR) [The Patient's Bill of Rights]. (1991). Retrieved October 10, 2008, from University of Minnesota: Health and Policy Management Web site: http://www.hpm.umn.edu/nhregsplus/federal_regulations/ Title\%2042 part 483 subpart_b requirements for_long term care facilities.pdf 
Rappaport, H. (1990). Marking Time. New York, NY: Simon and Schuster.

Reinisch, J. \& Beasley, R. (1990). The Kinsey Institute new report on sex. New York: St. Martens Press.

Reis H.T, Patrick BC. (1996).Attachment and intimacy: Component processes. In: Higgins ET, Kruglanski AW, editors. Social psychology: Handbook of basic principles. New York: $\quad$ Guilford Press. pp. 523-563.

Reis H.T, Shaver P. (1998). Intimacy as an interpersonal process. In: Duck S, editor. Handbook of personal relationships. Chichester, England: Wiley. pp. 367389

Riessman, C. K. (1993). Narrative Analysis ( Vol. 30). Newbury Park, CA: Sage Publications.

Rheaume, C., \& Mitty, E. (2008). Sexuality and Intimacy in Older Adults. Geriatric Nursing, 29(5), 342-349.

Rines, B. \& Breen, S. (1991a). Talking about sexual issues and SCI: A guide for professional caregivers. Vancouver: B.C. Rehabilitation Society.

Rines, B. \& Breen, S. (1991b). Talking about sexual issues and spinal cord injury. (Videotape). Vancouver: B.C. Rehabilitation Society \& Production Magic Limited.

Roach, S. M. (2004). Sexual behaviour of nursing home residents: Staff perceptions and responses. Journal of Advanced Nursing, 48(4), 371 - 379.

Roe, B. (1999). Incontinence \& sexuality: findings from a qualitative perspective. Journal of Advanced Nursing. 30 (3), 573-579.

Rubin, J. R., \& Rubin, I. S. (1995). Qualitative interviewing: The art of hearing data. 
Thousand Oaks, CA.: Sage Publications.

Rusbult, C. E., Bissonnette, V. I., Arriaga, X. B., \& Cox, C. L. (1998). Accommodation processes during the early years of marriage. In T. N. Bradbury (Ed.), The developmental course of marital dysfunction (pp. 74-113). New York: Cambridge.

Sanders, P. (1982). Phenomenology: A new way of viewing organizational research. Academy of Management Review, 7(3), 353-360.

Sant Angelo, D. (2000) Learning disability community nursing: Addressing emotional and sexual health needsin: R. Astor \& K. Jeffreys (Eds) Positive initiatives for people with learning difficulties (pp. 52-68) London: Macmillan,

Saretsky, K. (1987). The right to be human: How one facility cares. Provider. 73(20), $22-$ 23.

Schrover, L.R. \& Jensen, S.B. (1988). Sexuality and chronic illness. A comprehensive approach. New York: The Guilford Press.

Schuler, M. (1982). Sexual counselling for the spinal cord injured: A review of five programs. Journal of Sex \& Marital Therapy. 5(3), 241-252.

Shulman, S., Laursen, B., Kalman, Z., \& Karpovsky, S. (1997). Adolescent Intimacy Revisited. Journal of Youth and Adolescence, 26(5), 597-617.

Schuman, H., \& Scott, J. (1989). Generations and collective memories. American Psychological Review, 54(1), 359-381.

Shakespeare, T., Gillespie-Sells, K. \& Davies, D. (1996). The sexual politics of disability. Untold desires. London: Cassell Wellington House.

Siegal, J. (May 31, 1996). Aging into the 21st Century (National Aging Information 
Center, Administration on Aging). Retrieved June 22, 2010, from Administration on Aging: http://www.aoa.gov/AoARoot/Aging_Statistics/future_growth/ aging21/aging_21.aspx

Silverstone, B., \& Wynter, L. (1975). The effects of introducing a heterosexual living space. Gerontologist, 15(1), 83 - 87.

Sipski, M, L., Alexander, C.J. \& Rosen, R.C. (1995). Physiological parameters associated with psychogenic sexual arousal in women with complete spinal cord injuries. Archives of Physical Medicine and Rehabilitation. 76(9), 811-818.

Sipski, M.L. \& Alexander, C.J. (1997a). Sexual function in people with disability and chronic illness: A health professional's guide. Gaithersburg, MD.: Aspen Publishers Inc.

Sisk, J. (2009). Sexuality in Nursing Homes: Preserving Rights, Promoting Wellbeing. Aging Well Magazine. Retrieved June 5, 2010, from www.agingwellmag.com Web site: http://www.agingwellmag.com/news/

Shiono, P. H., \& Quinn, L. S. (1994). Epidemiology of divorce. Children and Divorce, 4(1). Retrieved from The Future of Children Web site: https://www.princeton.edu/ futureofchildren/publications/journals/article/ index.xml? journalid $=63 \&$ articleid $=408 \&$ sectionid $=2781$ septstory3.shtml

Slater, L. (1999). Viagra: Does it work with spinal cord injury? New Mobility. 10(65), 45-47.

Sloan, P. D. (1993). Sexual behavior in residents with dementia. Contemporary Long Term Care, October, 66-69. 
Spector, I. \& Fremeth, S. (1996). Sexual behaviors and attitudes of geriatric residents in long-term care facilities. Journal of Sex and Marital Therapy. 22(4), 235-246.

Speziale, H.J. and Carpenter, D.R. (2007). Qualitative Research in Nursing:

Advancing the Humanistic Imperative, ( $4^{\text {th }}$ ed. $)$. Philadelphia. Lippincott, Williams and Wilkins.

Staff should accept, respect the sexuality of residents. (1995, June). Brown University Long-Term Care Quality Letter, 7(12), 1 - 3.

Stake, R. E. (2005). Qualitative case studies. In N. K. Denzin \& Y. S. Lincoln (Eds.), Handbook of Qualitative Research (pp. 443 - 466). Thousand Oaks, CA: Author.

Starr, B. D., \& Weiner, M. B. (1981). The Starr-Weiner report on sexuality in the mature years. New York: Stein and Day.

Steinke, E.E. (1997). Sexuality in aging: Implications for nursing facility staff The Journal of Continuing Education in Nursing. 26(2), 59-63.

Sternberg, R. (1987). The triangle of love: Intimacy, passion, commitment. New York: Basic Books.

Stills, S. (1966). For What It's Worth [Recorded by R. Furay]. On Buffalo Springfield [CD]. Los Angeles, CA: Columbia Recording Studio. (1966)

Sullivan, H.S. (1953). The Interpersonal Theory of Psychiatry. Norton; New York:

Szasz, G. (1983). Sexual incidents in an extended care unit for aged men. Journal of the American Geriatrics Society, 31, 407 - 11.

Tabak, N., \& Shemesh-Kigli, R. (2006). Sexuality and Alzheimer's disease: Can the two go together? Nursing Forum, 41(4), 158 - 166.

Tepper, M. (1999). Letting go of restrictive notions of manhood: male 
sexuality, disability and chronic illness. Sexuality and Disability. 17(1), 37-52.

Thomas, D. (1971). Collected Poems of Dylan Thomas 1934-1952 (10th ed.). New York: New Directions Publishing Corporation.

Tilley, C. (1996). Sexuality in women with physical disabilities: A social justice or health issue? Sex Disability, 14(2), 139-151.

Tolstedt, B. E., \& Stokes, J. P. (1983). Relation of verbal, affective, and physical intimacy to marital satisfaction. Journal of Counseling Psychology, 30(4), 573580.

Turnstull, P. \& Henry, M. (1996). Approaches to resident sexuality. Journal of Gerontologial Nursing. 22(6), 37-42.

U.S. Census Bureau. (2005b). In H. Wan, M. Sengupta, V. A. Velkoff, \& K. A. DeBarros (Eds.), 65+ in the united states: 2005 (Current Populations

Report, pp. 23-209). Retrieved June 1, 2010, from www.census.gov Web site: http://www.census.gov/ prod/2006pubs/p23-209.pdf

United States Census Bureau. (2011). Statistical abstract of the United States: 2011 (131 Edition, pp. 63 -96). Retrieved from U.S. Census Web site: http:// www.census.gov/prod/2011pubs/11statab/vitstat.pdf

U. S. Department of Health, \& Human Services. (2009). Your Guide to Medicare Prescription Drug Coverage (CMS Publication No. 11109). Washington, DC: U.S. Government Printing Office. United States General Accounting Office. (2002). Aging baby boom generation will 
increase demand and burden on federal and state budgets. In Long Term

Care (GAO-02-544T). Washington, DC: U.S. Government Printing Office. USA. University of Louisville Institutional Review Board. (2015, August 1). Retrieved from U of L IRB Web site: http://louisville.edu/research/humansubjects ("University of," 2015) Adler, J., Wingert, P., Springen, K., Reno, J., Samuels, A., Raymond, J., \& Adams, W. L. 2005, November 14). The boomer files: Hitting 60. Newsweek. Retrieved May 5, 2010, from www.agewave.com Web site: http://www.agewave.com/media_files/ newsweek111405.html van Manen, M. (1997). Researching lived experience: Human science for an action sensitive pedagogy $\left(2^{\text {nd }}\right.$ ed.). London, Ontario: The Althouse Press. Voight, J. (2000, Spring). Mary furlong-interview. Adweek, 21(48), Q22-28. Wasow, M., \& Loeb, M. (1979). Sexuality in Nursing homes. Journal of the American Geriatrics Society, 27, 73 - 79.

Wattenberg, H. (Host). (2007). Daniel Yankelovich Interview [New River Media Interview with: Daniel Yankelovich transcript]. The First Measured Century. Audio March 26, 2010, posted to Broadcasting Service PBS.org Web site: : $\underline{\text { http:// }}$ www.pbs.org/fmc/interviews/yankelovich.html.

Webb, C. (1988). A study of nurses' knowledge and attitudes about sexuality in healthcare. International Journal of Nursing Studies. 25(3), 235-244.

Weingarten, K. (1992). A consideration of intimate and non-intimate interactions in therapy. Family Process, 30, 285-305.

Weiss, W. M., \& Bolton, P. (2000). Training in qualitative research methods for PVOs $\& N G O s$ (\& counterparts). A trainer's guide to strengthen program planning 
and evaluation. Center for Refugee and Disaster Studies. Johns Hopkins University.

Westcott, H.L . (1994) The memorandum of good practice and children with disabilities. Journal of Law and Practice, 3, 21-32.

Westgren, N., Hulting, C., Levi, R., Seiger, A. \& Westgren, M. (1997). Sexuality in women with traumatic spinal cord injury. Acta Obstetricia Et Gynecologica Scandanavica. 7(5(10), 977-983.

White, C. B. (1881). Interest, attitudes, knowledge, and sexual history in relation to sexual behavior in the institutionalized aged. Archives of Sexual Behavior, 11, 11 $-21$.

White, C. B. (1982). A scale for the assessment of attitudes and knowledge regarding sexuality in the aged. Archives of Sexual Behavior, 11(6), 491 - 502.

White, C. B., \& Catania, J. A. (1982). Psychoeducational intervention for sexuality with the aged, family members of the aged, and people who work with the aged. International Journal of Aging and Human Development, 15, 121 - 138.

Williams, S. (1999). Let's talk about sex. In search of the skills to talk about sexual issues. Nursing Times. 95(26), 58-62.

Wilner, W. (1982). Philosophical approaches to interpersonal intimacy. In M. Fisher \& G. Stricker (Eds.), Intimacy (pp. 21-38). New York: Plenum Press.

Wincze, J. P., \& Carey, M. P. (2001). Sexual dysfunction: A guide for assessment and treatment (2nd ed.). New York: The Guilford Press.

Wolf, R. (2007, October 9). Social security hits first wave of boomers. USA Today. 
Retrieved October 19, 2008, from USA Today Web site: http:// www.usatoday.com/news/washington/2007-10-08-boomers_N.htm.

Wolfe, T. (2015, August 3). The "me" decade and the third great awakening. Retrieved from NYMAG Web site: http://nymag.com/news/features/45938/

Woodard, W. S., \& Rollin, S. A. (1981). Sexuality and the elderly. Journal of Rehabilitation, October/November/December, 64-68.

Zeis, A. M., \& Kasl-Godley, J. (2001). Sexuality in older adults' relationships. Generations, Summer, 18-25.

Zorzon, M., Zivadinov, R., Bosco, A., Monti Bragadin, L., Moretti, R., Bonfigli, L., Morassi, P., lona, L. \& Cazzato, G. (1999). Sexual dysfunction in multiple sclerosis: a case-control study. 1. Frequency and comparison of groups. Multiple Sclerosis. 5(6), 418-427. 


\title{
APPENDIX A
}

\section{University of Louisville Institutional Review Board \\ Approval Letter}

\section{UNIVERSITY OF LOUISVILLE}

\author{
Human Subjects Protection Program Office \\ MedCenter One - suite 200 \\ $501 \mathrm{E}$. Broadway \\ Louisville, KY 40202-1798 \\ Office: 502.852 .5188 Fax: 502.852 .2164
}

\author{
DATE: \\ January 13,2015 \\ To: \\ Anita P Barbee, Ph.D. \\ FROM: \\ The University of Louisville Institutional Review Board \\ IRB NUMBER: \\ 13.0632 \\ STUDY TIT LE: \\ A PHENOMENOLOGICAL ST UDY OF ANTICIPATED INTIMACY AND SEXUAL \\ REFERENCE \#: \\ EXPRESSION NEEDS OF AGING MALE AND FEMALE BABY B OOMERS \\ 342070 \\ DATE OF REVIEW: \\ $01 / 12 / 2015$ \\ IRB STAFF CONTACT: \\ Name: Jacquelines. Powell \\ Phone: $852-4101$ \\ Email: jspowe01@Louisville.edu
}

The continuation request for this study was reviewed by the Chair of the Institutional Review Board (IRB) through the expedited review procedure, according to 45 CFR 46.110 and 21 CFR 56.110 since this study falls under Category 7 : Research on individual or group characteristics or behavior (including, but not limited to, research on perception, cognition, motivation, identity, language, communication, cultural beliefs or practices, and social behavior) or research employing survey, interview, oral history, focus group, program evaluation, human factors evaluation, or quality assurance methodologies.

The study now has continued committee approval from $01 / 02 / 2015$ through $01 / 01 / 2016$.

The following items were reviewed and approved:

\begin{tabular}{|l|l|l|l|}
\hline \multicolumn{4}{|l|}{ Submission Components } \\
\hline Protocol & Version 2.0 & $04 / 14 / 2014$ & Approved \\
\hline Recruitment Flyer & Version 5.2 & $04 / 14 / 2014$ & Approved \\
\hline Revised Consent dean & Version 6.1 & $04 / 21 / 2014$ & Approved \\
\hline
\end{tabular}

Continuation Review Requirements

You are responsible for submitting a continuation review 30 days prior to the expiration date of your research study. Investigators who allow their study approval to expire have committed significant non-compliance with federal regulations. Such lapses may require reporting to federal agencies, a program audit by compliance auditors to ensure that subjects were not enrolled during the expired period, and may lead to findings of serious and continuing noncompliance if expiration were to occur a second time.

Please begin using your newly approved documents 
This action will be reported promptly to the IRB at a scheduled full Board meeting.

If you have any questions, please contact the HSPPO at (502) 852-5188 or hsppofc@louisville.edu

Thank you for your submission.

Sincerely,

Pat 13 dursadh

Peter M. Quesada, Ph.D., Chair

Social/Behavioral/Educational Institutional Review Board

PMO/jsp 
APPENDIX B

Recruitment Flyer

Uofl Institutional Review Boards

IRB NUMBER: 13.0632

IRB APPROVAL DATE: 04/23/2014

\section{Kent School of Social Work University of Louisville
PARTICIPANTS NEEDED FOR RESEARCH IN INTIMACY AND SEXUAL EXPRESSION

Born between January 1, 1946 and December 31, 1964

Heterosexual

We are looking for volunteers to take part in a study to identify and describe the attitudes, concerns, values, and expectations around intimacy and sexuality of the Baby Boomers at various stages across the life course, including, past, present and as they consider their future long-term care needs.

As a participant in this study, you would be asked to: complete a time line, participate in an interview, and participate in a follow-up interview to verify that the essence of the interview has been accurately captured.

Your participation would involve three (3) sessions, each of which is approximately 60 minutes. At the completion of the third segment, you will receive a gift card valued at $\$ 25.00$

For more information about this study, or to volunteer for this study, please contact: Shawn Oak

Kent School of Social Work

202 Julius John Oppenheimer Hall, 2217 S 3rd Street, University of Louisville

Louisville, KY 40292

at

502-594-2829 or

Email: shawn.oak@louisville.edu

This study has been reviewed by, and received clearance through the University of Louisville Institutional Review Board 


\section{APPENDIX C \\ Subject Informed Consent}

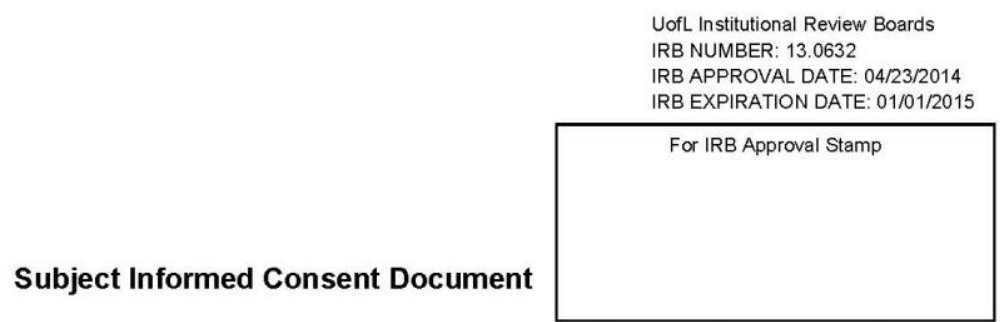

A Phenomenological Study to Explore How Heterosexual Baby Boomer Men and Women Define Intimacy, Sexual expression, Expectations and Desires as They Consider Their Current Future in Long Term Care.

IRB assigned number:

Investigator(s) name \& address:

Anita P. Barbee, Kent School of Social Work. 202 Julius John Oppenheimer Hall, 2217 S 3rd

Street, University of Louisville. Louisville, KY 40292.

Charles Shawn Oak, 8401 Shelbyville Rd, Suite 205, Louisville, KY 40222

Site(s) where study is to be conducted: Participant's Homes or other locations at the participant's convenience.

Phone number for subjects to call for questions: (502) 594-2829

\section{Introduction and Background Information}

You are invited to participate in a research study. The study is being conducted by Anita $\mathbf{P}$. Barbee, Ph.D. M.S.S.W. and Charles Shawn Oak, MSSW, Ph.D student. The study is sponsored by the University of Louisville, Department of Kent School of Social Work. The study will take place at various locations including the participant's residence or other locations at the convenience of the participants. Approximately 15 to 20 subjects will be invited to participate.

\section{Purpose}

The purpose of this study is to explore and describe the attitudes, concerns, values, and expectations around intimacy and sexuality of the Baby Boomers at various stages across the life course, including, past, present and as they consider their future long-term care needs.

\section{Procedures}

In this study, you will be asked to participate in three separate stages. In the first stage, you are asked to complete the Rappaport Time Line. The timeline will be marked from childhood through adolescence, early adulthood, middle adulthood, present time, and future time. The information provided on the completed timeline will inform the second stage of this study, the individual interview. The second stage will include an interview lasting from approximately 2 hours. This interview will be guided by an interview schedule developed from the information provided by each participant on their completed Rappaport Time Line. The final stage of the study includes a validity check to verify that the essence of the interviews have been captured correctly and possibility to ask additional questions based on the responses of participants to the initial interview. Participants may decline to answer any questions that may make them uncomfortable.

$$
\text { Page } 1 \text { of } 3
$$




\section{Potential Risks}

There are no foreseeable risks, although there may be unforeseen risks.

\section{Benefits}

The possible benefits of this study include a description of shared concerns and understanding of expectations as it relates to the intimacy and sexual expression needs and desires involved in phenomenon of aging. The information collected may not benefit you directly. The information learned in this study may be helpful to others.

\section{Compensation}

Because you will be paid $\$ 25.00$ to be in this study, the University of Louisville must collect your name, address, social security number, ask you to sign a W-9 form, and keep records of how much you are paid. You may or may not be sent a Form 1099 by the University. This will only happen if you are paid $\$ 600$ or more in one year by the University. We are required by the Internal Revenue Service to collect this information and you may need to report the payment as income on your taxes.

This information will be protected and kept secure in the same way that we protect your other private information. If you do not agree to give us this information, we can't pay you for being in this study. You can still be in the study even if you don't want to be paid.

This information will be protected and kept secure in the same way that we protect your other private information.

\section{Confidentiality}

Total privacy cannot be guaranteed. Your privacy will be protected to the extent permitted by law. If the results from this study are published, your name will not be made public. While unlikely, the following may look at the study records:

The University of Louisville Institutional Review Board and Human Subjects Protection Program Office.

Office for Human Research Protections (OHRP),

The data collected is kept in a secured area or kept in a password protected computer.

\section{Conflict of Interest}

This study involves a conflict of interest because the investigator may be compensated for your participation in it. Please ask the investigator how the investigator will benefit by your participation in the study.

Page 2 of 3 8/26/2012 


\section{Voluntary Participation}

Taking part in this study is voluntary. You may choose not to take part at all. If you decide to be in this study you may stop taking part at any time. If you decide not to be in this study or if you stop taking part at any time, you will not lose any benefits for which you may qualify.

You will be told about any changes that may affect your decision to continue in the study.

\section{Research Subject's Rights, Questions, Concerns, and Complaints}

If you have any concerns or complaints about the study or the study staff, you have three options.

You may contact the principal investigator at (502) 594-2829

If you have any questions about your rights as a study subject, questions, concerns or complaints, you may call the Human Subjects Protection Program Office (HSPPO) (502) 852-5188. You may discuss any questions about your rights as a subject, in secret, with a member of the Institutional Review Board (IRB) or the HSPPO staff. The IRB is an independent committee composed of members of the University community, staff of the institutions, as well as lay members of the community not connected with these institutions. The IRB has reviewed this study.

If you want to speak to a person outside the University, you may call 1-877-852-1167. You will be given the chance to talk about any questions, concerns or complaints in secret. This is a 24 hour hot line answered by people who do not work at the University of Louisville.

This paper tells you what will happen during the study if you choose to take part. Your signature means that this study has been discussed with you, that your questions have been answered, and that you will take part in the study. This informed consent document is not a contract. You are not giving up any legal rights by signing this informed consent document. You will be given a signed copy of this paper to keep for your records.

Signature of Subject/Legal Representative Date Signed

Signature of Person Explaining the Consent Form $\quad$ Date Signed

(if other than the Investigator)

Signature of Investigator

Date Signed

LIST OF INVESTIGATORS

Charles Shawn Oak

Anita P. Barbee
PHONE NUMBERS

(502) 594-2829

(502) 852-0416

Page 3 of $38 / 26 / 2012$ 
APPENDIX D

Multiple Consents Form

\section{CONSENT FORM}

By signing this consent form, you are not waiving your legal rights or releasing the investigator(s) or involved institution(s) from their legal and professional responsibilities.

I have read the information presented in the information letter about a study being conducted by Charles Shawn Oak of the Kent School of Social Work at the University of Louisville. I have had the opportunity to ask any questions related to this study, to receive satisfactory answers to my questions, and any additional details I wanted.

I am aware that I have the option of allowing my interview to be audio recorded to ensure an accurate recording of my responses.

I am also aware that excerpts from the interview may be included in the dissertation and/or publications to come from this research, with the understanding that the quotations will be anonymous.

I was informed that I may withdraw my consent at any time without penalty by advising the researcher

This project has been reviewed by, and received ethics clearance through a University of Louisville Institutional Review Board. I was informed that If you have concerns or complaints about the research or research staff and you do not wish to give your name, you may call toll free at $1-877-852-1167$. This is a 24 hour hot line answered by people who do not work at the University of Louisville. With full knowledge of all foregoing, I agree, of my own free will, to participate in this study.

\section{$\square$ YES $\square$ NO}

I agree to have my interview audio recorded.

$\square$ YES $\square$ NO

I agree to the use of anonymous quotations in any dissertation or publication that comes of this research.

YES $\square$ NO

Participant Name (Please print)

Participant Signature

Witness Name: (Please print)

Witness Signature:

Date:

This study has been reviewed by, and received clearance through the University of Louisville Institutional Review Board 
APPENDIX E

Rappaport Time Line

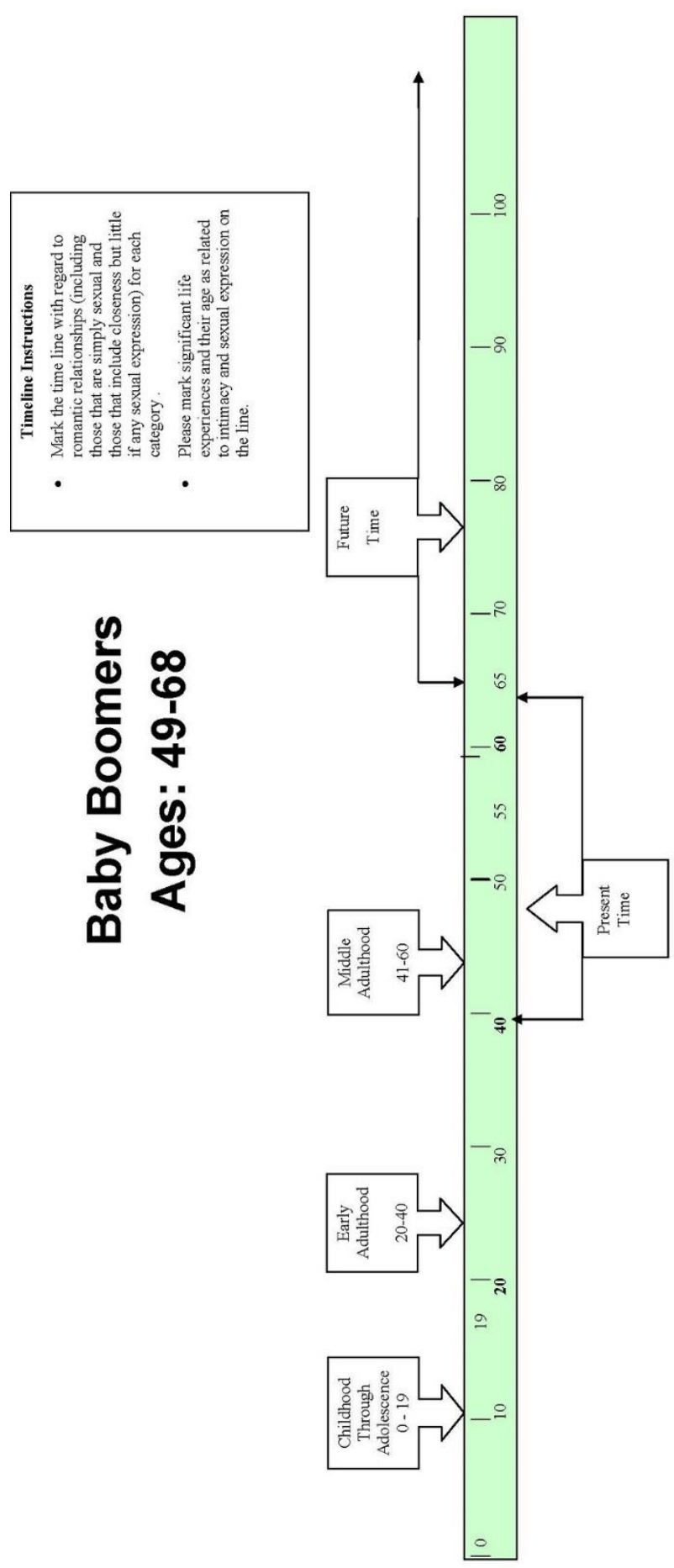




\section{APPENDIX F}

\section{Demographic Information}

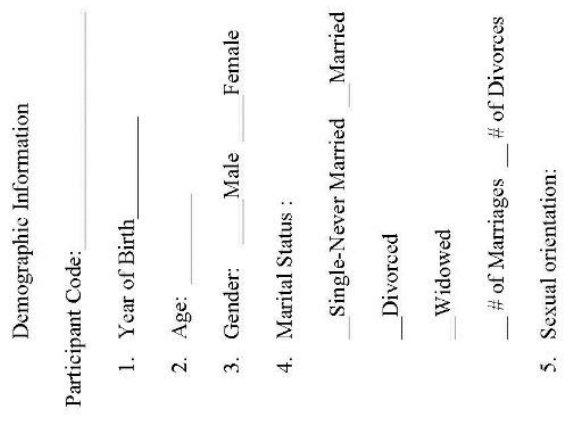




\section{APENDIX G}

\section{Study Interviews}

\section{Michael}

Interviewer: Okay. On your timeline, you indicate that at age 14 you had your first girlfriend and that included sexual petting and kissing. At age 16, you had your second girlfriend who became your wife later. At that age, you indicated that you were kissing and petting.

\section{Participant: Right.}

I: There was no intercourse.

P: That's correct.

I: At age 19, you indicated you had sexual intercourse for the first time with a friend.

P: Yes.

I: What was your understanding of intimacy during this first 19 year period of your life?

P: I would say that it was immature at that point in my life. I didn't really understand what intimacy meant. I didn't really understand sexual intercourse. I learned everything from watching pornography at that point in my life. So, to me, it was not about intimacy, it was more about the sexual act and orgasm.

I: Okay. So, that was the meaning of intimacy for you at that time period. Okay. How did you identify intimacy in yourself and your partners in that timeframe?

P: I don't really think I thought about it. I really didn't. I don't think it was on the agenda at all. 
I: Now, with the partners you were with, did they share the same meaning or did they have different meanings of intimacy with you?

P: I would think that with some of them it had different meanings, but at that young age intimacy was not involved. Then as I got married, since I married my high school sweetheart, I think she had a different understanding of intimacy. It wasn't mature either, I don't think. She just wanted a partner, more of a partner, more of a buddy, instead of a partner. I wanted a sexual partner and I wanted a life partner.

I: What was your understanding of sexual expression during this same period?

P: Sexual expression probably was tied to orgasm.

I: Was there any, just whatever would make that happen?

P: Yeah. Whatever would make that happen and considering that I was trained on pornography, like that was my training that I had. No one ever talked to me so I didn't know, no father or anybody talking to me about what it really means to be intimate with somebody, even what sex is about. It was all about this, you know, what I saw in the movies that I duplicated or tried to duplicate.

I: Okay. All right. What did sexual expression mean to you within that time?

P: It meant having a good feeling inside and that if someone was willing to be sexual with me, that they cared about me.

I: Okay. So, it kind of in way answers my next question but I want to go ahead and ask anyway. What meanings and understandings of sexual expression did you share with your partners? 
P: I think I equated that connection to love. So, for me, it was I had the feeling that I loved that person. Not really knowing what I meant by it at that age, but it was like that I loved that person. That that was what love was.

I: Okay. Were there ways that the meaning and understanding of sexual expression differed between you and your partners?

P: Yeah. I think for some of them, looking back on my younger years especially, it was not that deep. It was more about sex than anything and as time went by it probably increased more to deeper meaning. A shared journey versus just a sexual connection. I: Okay. We're going to step into the second phase, your early adulthood period. At age 20, you indicated on your timeline that you had your second sexual intercourse experience with a friend. Same friend or different friend?

P: It was the same friend.

I: Okay. You also indicated that you married the girlfriend that you had had at age 16 when you were age 21 .

P: Yes, that's correct.

I: Okay. Then at age 25 and at age 30 , you indicated you had extramarital sexual relationships. What was your understanding of intimacy during this time of your early adulthood?

P: I would say it was still very much focused on orgasm. It was still very much focused on the act of sex.

I: With regard to intimacy, in what ways did these experiences impact your understanding of intimacy? 
P: One of the people that I had an affair with, I really did fall in love with her and it was the first time that I felt that I really wanted to be with somebody and share a life with somebody, but I was already married and it was complicated. She was younger than me and I thought to myself that I needed to suck it up and go back to my wife and not hurt this person anymore. So, yeah, I stopped that. I didn't pursue it.

I: Considering those same experiences, in what ways did they impact your understanding and expectations of sexual...[Participant interrupts].

P: Well, I think that that one experience that I had with the one person, it gave me a feeling that there was something more than just meeting and having sex. That there was this deeper meaning that was starting to develop within me, that I wanted, that I desired. I: In what ways did partners share this kind of growth, this intimacy? P: It was interesting. Out of the two partners, the wife and one other partner, didn't share anything, but the one partner I was really connected to really shared with me that she wanted a deeper relationship. She was younger than me but she was more mature than me, at the time. I was pretty sexually immature.

I: Okay. You're really doing good here because you're answering questions already. In what ways did your meaning and understanding of intimacy differ from your partners? P: Well, I think, take my wife for example, to me the sexual act and being sexual was part of what I was thinking at the time was intimacy and for her, it was this duty that she had to do. It was never something where she said I really want to be with you. She said, “Oh, we haven't had sex in three weeks so I'll have sex with you." So, it was always a 
one way energy sort of thing. I never felt like it was two ways. It was always felt like it was one way. But, that one person that wanted to have sex with me, the one that I let go of, that was the first time in my life really that I felt that two way energy going back and forth. To me, that was what intimacy was about, sexually intimacy anyway.

I: Okay. Now, going into this next phase, on your timeline at around age 41, you indicated that you met your second wife and married about three years later?

P: Yes, that's correct.

I: When did your previous marriage end?

P: It ended after 17 years and it was in, I want to say 1993.

I: Okay. Now, also on your timeline you indicated at age 55 and forward that there is no sex and that there is intimacy. What do you mean when you say no sex?

P: My wife and I have not had sex for 7 years, 8 years. I sleep in a separate room, she sleeps in a separate room and we do share intimacy in raising a child and during the daily activities but there's no sexual expression of that intimacy. At this moment in time, I really don't want it. I'm just done.

I: Okay. Also, you indicated that around age 41 until the age of 61, that you have intimacy with a friend and it is with no sex involved. How did these experiences affect your understanding of intimacy and expectations?

P: It's interesting because that friend probably, I've been able to discuss more about intimacy than anybody in my whole life. We have an intimate relationship, yet have never had sex. So she's someone that I call every day. She calls me or I call her and we talk about spiritual matters. We talk about life. We talk about the kids. Our daughters 
were best friends. They went through grade school and high school together, so we became friends. She divorced her husband and I divorced my first wife and then she never married but then I married. No sexual attraction between us. She may have a sexual attraction towards me but I don't really have a sexual attraction towards her nor do I want to have a sexual attraction because then I think it would mess up this friendship that we've developed. This deep, deep friendship. It's interesting because now intimacy is switched from the sexual act to more of a heart connection. So, it would be nice if there was something who I could have both, but since I don't, this heart connection that I have with my friend seems to fulfill me. It is very intimate. She's someone that I can call and complain to and I can tell I had a miserable day and she won't try and fix me. She'll just listen to me. What I consider more of an adult intimacy.

I: So, at some point then you've completely separated sexual expression from intimacy as being mutually exclusive?

P: Unfortunately, and I say unfortunately in my life I have, now in my head, no. I think that it would be really great. I do think that intimacy is both. That if someone would have intimacy you got to have the sexual intimacy but you also have that heart intimacy where you both are on the same page and if you can get those two together, you're lucky. You hit the jackpot.

I: Okay. Fantastic. Now, what was your understanding of sexual expression during this period?

P: For me, I do masturbate. I do that for health reasons, to tell you the truth, more than anything but also to keep myself still, I still want to be sexually active and involved in my 
life. But, for me I have to make a choice, like it's like balancing my life right now. Just the way it is and it doesn't mean as I get older that won't change. Maybe there will be a relationship that I'll be able to express my sexual self within the relationship, but for now it's just not there. Nor do I want it to be there.

I: Okay. All right. That's good. Good. Okay. Now, I'm thinking about the [indecipherable]. You didn't indicate any age or information on the timeline. So as you consider your future, what concerns do you have about your intimacy and sexual expression needs?

P: I guess the only concern that I have is if I wasn't in this marriage relationship that I'm in that I would be able to have any intimacy, sexual intimacy, or this more emotional intimacy that I share now with my wife. So that would be a concern because I'm an outgoing person and again, to tell you the truth, I think that if I were in another situation, I think that I would find somebody or be in a space to have that intimacy with somebody. I'll always have my friend as long as she's alive. We'll always be together and I guess in my mind, I think to myself, maybe someday we'll move in together, but I don't think that we'll ever have sex together. I don't think that that's, that's not part of that relationship. I: Okay. As you look into the future, what do you anticipate your intimacy and sexual expression needs and expectations will be?

P: I think that they'll grow from now. I think that they'll mature more and that they'll be something that I'm going to want, not only from another person, but from a lot of people. A larger group. So that intimacy maybe in the beginning was on a one-to-one basis but 
now I'm finding the older I get, is that I'm getting that intimacy energy from groups of people. From different friends and different things that I do, from a book that I read. It's morphing. It's interesting to watch it. It's morphing from, I think back to when I was a kid, where screwing was my intimacy to now, I'm like wow. If I take a meditation class or something with five people in the room, that can be as intimate as anything that I could want. So, I see myself pursuing that and growing into that as I get older.

I: So, shared experiences start creating a sense of intimacy for you?

P: Absolutely. Shared experiences are now creating the intimacy that I didn't see before or didn't value maybe.

I: In what ways, if any, do you expect your definition of intimacy or sexual expression changing?

P: I think it's going to continue to grow. I think, it seems like it is growing. So that where it was really limited back when I was a kid, now intimacy to me could be you calling me saying, "Joe, let's go for a beer." That could be, that I look at wow that's pretty intimate in sharing life with somebody. Whatever, a marriage and family therapy discussion, whatever it is. It's not focused on the sexual act anymore. I guess maybe that's what it is.

I: Okay. What are your expectations for intimacy and sexual expression when you think about potentially being a resident in long term care?

P: That's interesting because I know too much and I know that that's really difficult to do, but that's, I would rather die than to go into long term care, number one. That's 
number one. Death would be a better alternative. Number two is I don't see any ability to express sexual identity at all within a nursing home.

I: What gave you that idea?

P: In my experience of working with nursing homes and going into nursing homes and viewing nursing homes and looking at how they separate husbands and wives even in nursing homes.

I: Okay. Now, those are all my specific questions. What information would you like to share that you feel would be important?

P: Well Shawn, I think for me, what I'm learning too in life is that when you're older, once you reach 60, it's like people don't think you have sex anymore. So, it becomes problematic because we're programmed to be a certain way. So you have a whole world out there that's looking at youth and they're not looking at older adults as being able to have traversed this path from this sexual act to what real intimacy is, this knowledge that we have and it saddens me that people think we're going to stop having sex. I mean, I have had people, clients, who have been 80 -years-old and they're still having sex. Better sex than they were having when they were 20 -years-old. It troubles me that society still has a vision of the way we should be. The other part that troubles me is that we're not allowed to talk about it. It's still very much taboo. It's still very much a taboo subject that we can't talk about sex. We just can't talk about it. It's difficult to talk about. It's a difficult conversation.

I: Thank you very much. I appreciate it. 
P: You're welcome.

\section{Gary}

Interviewer: On your timeline, you indicate at age 13 that thoughts and desires were very obvious. What did you mean by that statement?

Participant: That I had sexual thoughts. That's what you're talking about right?

I: I was just going by what you said so I wanted to make sure that I understood what you meant.

P: That's what I thought it means about sexual thoughts and ideas [were prevalent?]. I mean, they were on my bad [?]. I was well aware that, you know, my hormones were starting to kick in.

I: All right. You then indicated at age 15 that you had your first sexual encounter. What was your understanding of intimacy at that time?

P: Intimacy to me at that time was actual intercourse. The actual act.

I: Where, or from whom, did you obtain that understanding?

P: I don't know. I don't know if it's innate or where that come from. I mean, I didn't, I don't know. It just all of a sudden was there and I had a desire for it.

I: It didn't come from family or friends, or school, or maybe church, or something like that? 
P: It might have been, you know, no, to be honest with you I think it was just from self, you know, from myself. Of course, you know, when you get around your peers and stuff like that you talk about them, but I think a lot of it I had that drive early on and I identified that early like I said, around 13. I knew it was prevalent with me and I was attracted to the females and everything in school and I wanted to, it was just something, there was a drive there.

I: How did you identify intimacy in yourself and in your partner?

P: How did I?

I: You sort of mentioned that you felt like it was an innate aspect of you at that point in time. How did you identify that in a partner?

P: Well, it was a partner/female that I was attracted to in school. Like, I had a physical attraction to this female. We started off being friends and then it turned into a physical attraction. There, it just developed into intimacy. I wanted to touch her and I wanted to have intercourse with her so that intimacy not only just from a kiss to a, but, my thing was in intimacy was to be sexual intercourse.

I: Okay. Now, what meanings of intimacy did you share with your partner? What did you share together, did she have the same view?

P: She did have the, I'm pretty sure she did, because when we started out, like I would start on the phone talking about it and when I started talking about it the conversations would go there to that, to being intimate. That's where they would end at, you know we would talk about it on the telephone. She was kind of, at first she was not wanting to engage in any intimacy whether it was a kiss or whatever, but we just started kissing and 
started playing around and touching and then we went on to have intercourse. Now, I guess, my thought about when I was that young, the reason I said intercourse was because that was what I felt intimacy was, was the actual act of intimacy was intercourse. I: Now, can you identify, or do you identify any meanings or understandings of intimacy that differ from your partner?

P: No, not really. We're talking about, I'm going back in time quite a bit. I'm 63 now. We're talking about going back and I was 15-years-old at that period of time so that's a long period of that time to kind of relate. As far as any differences, because we talked about it and shared it on the telephone, I don't think there was much difference, you know, any differences that we disagreed upon on the intimacy part of it.

I: Okay. Now, this may seem redundant but this is the second aspect of this section of this timeframe. What was your understanding of sexual expression at that time of your life?

P: Expression was intercourse.

I: Okay and what did it mean to you? Did sexual expression have any particular meanings to you?

P: Not really a meaning. It was a desire. It was a relief from desire, not a relief, but sort of like even a goal to have that relief from having intercourse. Sexual gratification.

I: Okay. You and your partner shared the same understanding of sexual expression at that time too?

P: Oh yeah. Yes.

I: Did either of you have any differences in your understanding of that? 
P: No. I wouldn't say we did.

I: Okay. Moving into the next section of your life between 20 and age 40, what was your understanding of intimacy?

P: Oh, intimacy was a totally whole different picture from that timeframe until 40. I understood what being intimate was versus sexual gratification. Being intimate could be just a kiss. It could be a touch. Holding someone. It didn't have to be all the way to having sexual intercourse. It was, I was very much more, I guess in tune or understanding of what intimacy meant versus sexual gratification. I guess it appeared at a young age.

I: Okay. Now where, or from whom, did you obtain this new understanding?

P: Knowledge applied I guess from reading, watching television.

I: Okay. Were there any different ways that you were able to identify this intimacy in yourself or in your partners in this timeframe?

P: Was I able? Repeat that again.

I: In what ways were you able to identify intimacy in yourself or in your partners during that timeframe?

P: In myself, it was a lot more different. I wasn't really too much concerned about the intimacy that was going on with my partner. It was pretty much, I was concerned about my intimacy aspect on myself. So, I wasn't in tune to worry about what the intimacy level was with my partner. I felt like it was my job to initiate and to make that intimacy happen. So, I was kind of the driving force of making the intimacy happen. 
I: Okay. Now, during this timeframe between age 20 and 40 , what was your understanding of sexual expression then?

P: Being able to have as much sex as I wanted. Being able to achieve that climax. Being able to live out my sexual fantasies and desires. That's what my sexual expression was.

I: Okay. How would you describe or define your sexual expression? What sexual expression meant.

P: What sexual expression meant to me is being intimate, having sexual intercourse. That's how I defined sexual expression.

I: Was there any particular person or source for you to obtain this understanding of sexual expression at that time?

P: No, because most of my sexual partners had always been younger. I've always desired younger ladies and they were much younger so I was always the, always initiated, controlled. I guess I was always attracted to someone that I could have my way with sexually.

I: What meanings and understandings of sexual expression might have differed between you and your partners in that timeframe?

P: I can't think of anything that was different because, like I say, I was the one that was initiating and it was always like it was my idea, my responsibility and it was always on me to be able to control that. I really didn't, wasn't worried or paying any attention to what type of level or what, as long as they were willing to do it I was ready. No problem. 
I: Okay. Moving between 41 and age 60. On your timeline you stated that you still exhibit a strong desire and are very active. During this phase between 41 and 60 , what was your understanding of intimacy?

P: Intimacy, I understand intimacy more so now as it's more about a personal relationship, being more into a relationship versus just sex, the touch, it's just more of a relationship now between the male and female viewpoint. I'm more so now in that age frame that you're talking about.

I: When you talk about the relationship aspect of it, can you give me a little more detail about what that looks like?

P: That means that I don't get to, while I was being married during that timeframe, is that I'm not able to really use my sexual expression more with my wife as I had in prior years. Meaning, I'm more in tune to whether she wants to or not and I'm more conscious of her desires more so than mine. I guess I'm more in tune now. I'm more, not so much more trying to engage as much.

I: So, if I'm understanding correctly, it's a greater emphasis on the relationship and the needs and desires of your partner versus just yourself.

P: Yeah, less self-gratification and more in tune with my partner.

I: Where, or from whom, did this new understanding of intimacy come from?

P: It pretty much well come from, I guess, with age and also with her, with my wife, with my partner.

I: Okay. In what ways, what meanings of intimacy do you share with your partner and in what ways are you different? 
P: I'm a little bit more touchier, hugging, touching, feely person than my wife is. I guess that might have something to do with it.

I: Any other differences that you identify?

P: I guess I'm more, my sexual hyper than she is.

I: Okay. In this timeframe between 41 and 60 , what was your understanding of sexual expression and had it changed any from the past?

P: It really hasn't changed much from the past. It's just that I'm more in tune with my partner. I kind of, just more in tune with what she wants more so than what I want. Of course, my desires are not like they used to be either. The older I get the more, you know, it's not as important. I still like to have sex. Are we talking about sex or just intimacy?

I: Sex.

P: At this point, it's not as higher a priority as it had been in past years.

I: Okay. Thinking about age 65 , or the future period, and older. I noticed you didn't indicate any age or information on the timeline for the future period past age 65 . So, as you consider your future, what concerns do you have about your intimacy and sexual expression needs?

P: The main thing that I have is will I be able to maintain an erection at age 65. It's a little difficult at 63 , so at 65 I'm still trying to wonder am I going to be able to maintain that level of being able to maintain an erection to have sex at 65 . Will the little blue pill still be working? 
I: Now, as you look into the future, can you define and describe your intimacy and sexual expression needs and expectations?

P: At 65 or beyond?

I: Beyond.

P: Wow. I don't know. I never have given any thought to 65 and beyond. I never have even thought about that. I don't even know if I'll be here at 65 and beyond, so I haven't really given any thought to that.

I: Okay. Well how about this, in what ways, if any, do you expect your definition of intimacy or sexual expression changing in the future?

P: The only thing I could change, if there would be any kind of physical change within my body, any kind of as the body gets older it has a tendency not to perform as it did in earlier years. So that's the only thing that I could think of would probably be a problem is just not being able to perform. But as far as I can see where it's not going to be that much of a priority of having sex at that age to be honest with you. It's probably because of the body illnesses and things like that, diseases and things like that, that I'll have because I'm already a diabetic so I already got some physical illness that's going to probably, and high blood pressure as well, and those things have a tendency to have an adverse effect upon the body as well as sexual...

I: Now, with the idea in mind that you are still able to perform in some way as you age, as you look into the future and including the possible of being a resident in long term care, can you define and describe your intimacy and sexual expression needs and 
expectations for that time? I know that's looking way off but what do you anticipate your expectations around those things?

P: I really don't have any expectations. I've visited nursing homes quite a bit and I see a lot of people that are there and I guess by going to nursing homes quite frequently and seeing persons there in that capacity that they're in, I'm not even able to comprehend what that might be for me because persons that I've seen in nursing homes and long care facilities are not able to hardly take care of themselves let alone try to have any type of sexual activity. Of course, I don't know, if I'm up in shape of body and everything, I guess if I have my physical health and some young, very attractive lady come through and gave me a rouse I think I might be able to think about it. I'll just probably lay there and think about wow, back in the day, if I was just a little bit younger what I would do or as someone my age, I don't think I'd be attracted to someone my age that's really along themselves, you know.

\section{I: Okay.}

P: Who knows? I never really gave any thought to that.

I: The last question I really have for you is, if you can kind of again picture yourself in that possible position of being a resident in long term care and you were able to still perform in a variety of ways, what concerns would you have about your intimacy and sexual expression needs?

P: Would I be able to, how would I be able to go about fulfilling those desires? In other words, would I be able to find somebody? Would I be able to carry that out being in a long term care facility? Would I be able to have the means to lock a door, make that 
happen, and [indecipherable] so because I'm still able to do it. I can think, I can visualize that, maybe thinking about down road and how I would be able to do it. That would be something that I would think about you know. If I could find one that would get me stirred up to where I would [indecipherable] and would be able to have sex. Right now, by being in a nursing home, it just by being there so much and seeing what all goes on there, it just wow, sex is just, I don't think I would be able to, that would be on my mind being in a long term care facility like that.

I: Is there anything else that you feel like would be important for me to know that might be helpful in thinking about intimacy and sexual expression?

P: No. Just by talking with you and just kind of give me an understanding of how throughout the years what intimacy versus sexual relations has changed. At first, my thought was to have sexual intercourse. That was being intimate to me. Then later on in life, I got to the point where I understood what just being intimate was, touching, hugging, holding, or even just a conversation of one, to get into a good conversation could be an intimate relationship. So, I guess throughout the years my understanding of and perspective of intimacy versus sex is. I'm able to do that now versus when I was much younger.

I: Fantastic. Thank you very much.

\section{Richard}

Interviewer: Alright, so we can get started. The first sections, I'm going to just read what I was able to understand from your timeline. If I need to correct something, or you need to correct something, please feel free to do that. On your timeline, you indicated 
that from age 7 to age 17 you had several girlfriends that involved kissing, holding hands, heavy petting, passion, without any sexual intercourse. Then at age 17, you indicated that you or stated that you lost your virginity with a new girlfriend but then went back to a past girlfriend sometime after. You also indicated that you then, around that time, you went away to college and had lots of dates your freshman year without any sexual intercourse. Then dated an older girl in the summer of 67. Between age 19 and 20, you indicated you began dating a girl, [Her name. Can't understand], involving lots of sex and that you had become engaged at age 20 as well. What was your understanding of intimacy at that time?

Participant: At that time, probably sex.

I: Okay. What kind of meanings did that have for you?

P: What kind of meanings?

I: Around intimacy.

P: Well, that's a difficult question because I feel like now that I was very immature. It was more of a, I really didn't understand intimacy at the time. To me, sex was the goal and that was how I defined intimacy.

I: Okay.

P: Do you want me to retrospect it?

I: No, that's okay. Where and from whom did you obtain that understanding and that meaning of intimacy? 
P: Probably, I hadn't learned much from my parents because they weren't intimate. I think, okay that's why. That's why I didn't understand intimacy. I never saw my parents touch each other until they were really old.

I: What did you see from your parents?

P: Well, we thought, my brothers and sisters and I thought everybody's dad got home 5:30 and left 6:30 because he had two jobs. He was a $* * *$ in the day and musician at night. So, that's the way we grew up. That was normal. You didn't bother him on weekends because he has to sleep in because he played jobs on Friday and Saturday night. Then my mom was a control freak. The funny thing about my mother is she wanted to keep us all separate. She raised all six of us like we were individual children. Really up until the last 10 or 20 years, my brothers and sisters weren't that close. Then we started, when mom started getting older and less involved because of her mental state, she had Alzheimer's, then we kind of grown back together. So there wasn't any intimacy at all really. So there's nothing for me to go by.

I: If there's anything, you didn't learn anything or see anything from your parents, did you pick these things up, your understanding of intimacy and how your needs from other people [Participant speaking over Interviewer]?

P: I guess just other people. Just, that was the mid-60s and the sexual revolution was starting and that kind of thing.

I: Okay. How did you identify intimacy in yourself and your partner(s)?

P: I know how I would define intimacy now, I'm not sure how I would have defined it then. I don't think I did. It wasn't a term or an adjective that comes to mind back then. 
I: What are the, based on what you said before, were intimacy and sex pretty much interchangeable at that point in time?

P: At the time. Now, reflecting now that I understand it more, the one girl that I said I dated and then dated again, we were more intimate than the girls I was having sex with. She had gone to Western and I went to Eastern [indecipherable]. We may have ended up together but it was a distance thing that didn't work out. Because we shared things. We shared thoughts and we shared activities that weren't ${ }^{* * *}$ it wasn't like sex was even necessary. We liked to make out. So I would define that relationship as intimate. More so than the steady girls I dated for the sex. At the time, I didn't know that.

I: You were doing those things with didn't have that label put on it. Okay. What meanings of intimacy did you share with your partner? What understandings or meanings did you share?

P: I would just say we were on the same wavelength on values, actions towards others, we weren't afraid to share our thoughts with each other. There's been women that even at that time, you had to watch what you said because you didn't want to get, you were enjoying the sex so much that you didn't want to stop it. But with Barbara, that was her name, it was more of a just natural and that's how I would define intimacy today.

I: Let's see. In what ways did your meaning and understanding of intimacy differ from your partner(s)?

P: My partners wanted to change me. 
I: Okay. In what ways?

P: Well, at the time I was borderline shy and they wanted me to be more outgoing. They wanted me to do things that they wanted to do regardless of whether I really wanted to do it or not. Which I think is a big deal even today with marriages that don't work.

I: What did that mean to you when that was going on?

P: It meant that I was just arm candy. I was just an object because I was kind of cute back then.

I: How is that different with the girl you mentioned earlier that you just connected with that she was, it was natural with?

P: She just wanted me to be me. We didn't even think along those lines because we were on the same wavelength so to speak.

I: Let's see here. Now, the next section is, what was your understanding of sexual expression during that phase of your life?

P: Sexual expression? I'm not sure I understand what [indecipherable].

I: Well, how did you understand or expect your, how did you express yourself sexually and how did you understand it? What were your definitions of sex or what wasn't?

P: I was probably, maybe moderately more attractive than some because I was always more or less concerned with the girl being satisfied. More than just slam, bam, thank you. I guess I was more of a, I wasn't self-centered.

I: How would you define sexual expression as far as action? 
P: Sexual expression [indecipherable]. What do you think [indecipherable]. Actions, actions, actions. There again I'm not really sure what you're talking about, like holding hands, that kind of thing?

I: Anything that you identified as being sexual in nature that you involved yourself with with a partner.

P: Okay, I wouldn't call holding hands sexual in nature. You know, making out, the girl dressing in a provocative manner and [indecipherable].

I: Were there any particular things that you and/or your partners enjoyed sexually?

P: [Starts at 10 minutes, 30 seconds on recording. Talking over interviewer, unable to understand participant]. [Unable to understand next sentence or so.] Again, I didn't have a lot of imagination, but then again there were things that would always run through my mind. I forgot about that. Really crazy things.

I: Like what?

P: Well, my roommate he got married and moved out so [indecipherable]. We did stupid stuff like get undressed in the car and go running into the girls ***. You know, like you go out and get a pizza and then come back. Things like that. *** back then. Get drunk and get a hotel room or a couple of occasions between girlfriends there was a lot of what we call 'one night, no last name' affairs. I don't know if kids still do that or not. I: Probably. When I ask you about how you're defining sexual expression, sometimes there's confusion anymore especially after Bill Clinton because he doesn't define oral sex as being sex or sexual expression. So, I'm kind of curious how you looked at it. 
P: Well, back then there wasn't a whole lot of oral sex. It just wasn't something we did back then. I think there's a lot of, because we didn't have cohabitation like kids do now, separate male and female dorms and all that. We ${ }^{* * *}$ a lot in cars and it was mostly in, because cars are not exactly the most comfortable place ${ }^{* * *}$. There's a lot of mutual masturbation more than actual sex. Sex was such an effort that, you know, going to dinner and then going to make out ended up with some mutual masturbation more so than actual sex. The sex was for special occasions, you get a motel room for stuff like that. I: Oh, okay. That's interesting. Where or from whom did you obtain your understanding and meaning of sexual expression that phase?

P: I don't know. It definitely wasn't my wife [Not sure this is what is being said.]. I guess, I don't know, it would have to be peer group discussions and just the experience. [Indecipherable] more so than any [indecipherable]. It was more of a one-on-one learning experience than $* * * *$.

I: Okay. So, nothing in school or nothing really from friends or videos, maybe not videos, but films or French or anything.

P: We didn't have any of that back then.

I: Okay.

P: [Indecipherable except for the word 'Playboy']

I: Okay. Kind of along the same lines as intimacy, what meanings and understandings of sexual expression did you share with your partners? Did you guys kind of have, be on the same wavelength about? 
P: It's funny because you didn't really talk about it, you just let it happen. The biggest thing, like I just said, was a lot of mutual masturbation. The first couple, like I said when I lost my virginity that was a girl that I think she just wanted to have sex because she didn't live in my neighborhood. [Indecipherable] and I was somebody that wouldn't get *** to her school. That kind of sexual expression. Then later girls were mostly just making out and if they got fired up *** masturbation then sex and very rarely was girls, girls weren't aggressive but they didn't fight back either. Not fight back, but they weren't resistant. It wasn't like I had to seduce them.

I: How did you know that you weren't in agreement about something sexually with your partners?

P: Well, let's see, I can't think of too many times that happened. One girl said don't do that. That was, but it wasn't sex it was something like that.

I: Okay. We can move into your early adulthood period between age 20 and 40 . At age 21 through 25 , you indicated you were in a marriage that had included lots of sex but no love and no closeness.

P: I was, she was rich. I think that was just pure sex. We loved to have sex. I was from the other side of the tracks and a whole other class. I never understood [indecipherable]. There was never booze in my house when I was growing up even though my father drank and played in bands. If we had a family picnic or something there would be some beers but they drank all the time.

I: When you say no love and no closeness, what do you mean? 
P: I didn't really actually say I don't feel anything. The only thing that hurt when she left was my pride. There's no love broken heart.

I: How did you guys end up together and being married?

P: I was dating her next door neighbor who was a really nice girl but that would have never worked because she's a Baptist and I'm a Catholic. She ended up a doctor of Theology [indecipherable]. That's how Baptist she was. She asked me to give the next door neighbor a ride home to Louisville and before we got all the way to Louisville we were making out at a rest stop along the way. Pure sex.

I: How'd you end up getting married?

P: It just kind of snowballed. God as my witness, my Best Man and I sat outside the church and he said you don't have to do this and I said I don't want to do this but I kind of have to, there's 300 people in there. It's just one of those things where you lose control and you're not sure what happened. It's like, somehow we were all of a sudden getting married and she was making all these big plans and all this kind of crap and I'm just kind of rolling with the punches because the sex was good.

I: Interesting. Okay. Thinking about intimacy during this relationship, in what ways did it impact your understanding of intimacy?

P: I think one of the ways that is, is because I really wasn't intimate with this person. You know, it was just kind of a sex thing because I had met a couple of other young ladies. I didn't cheat physically but emotionally I did. I'm thinking, I can talk to these 
people. The values are the same as mine. So I really don't think the marriage would have lasted much longer on my part. I mean, she just walked out first.

I: When you say you emotionally, you didn't cheat physically, but you felt like emotionally, what do you mean emotionally? What [participant starts speaking over interviewer]

P: Well, I wasn't, like you said, I wasn't intimate with her. I didn't tell her how I felt about stuff. I was the strong, silent person. There again, what I said a while ago is true. I didn't say anything because I didn't want to mess things up. Does that make sense? I: Sure. So, in the marriage you didn't really talk about anything because you thought it would affect the sex [participant talking at the same time] even though you weren't really in love with her or, it sounds like you cared about her. The bigger concern of it was if the sex would hold up or not.

P: Yeah and then the fact that we went on exotic vacations and stuff with her parents. They had money and they had a private lake up in Wisconsin and we went every summer and things like that. That's just pure immature greed on my part.

I: Okay. Well, thinking about that same marital relationship, in what ways did it impact your understanding as expectations of sexual expression or for sexual expression?

P: I think I learned that sex and love are two different things.

I: Okay. What do you mean?

P: That if you're in love, sex is an expression of that love. It's, you're doing it differently. If you just want sex, that's back to the one night, no last name affair and if you date the girl several months, if it's just sex it's just you're just doing it for that and 
nothing else. There's no intimacy, there's no *** mutual attraction. That's a word we're not using, attraction. There's a difference between love and intimacy and attraction. I think I was attracted to a lot of women but I was only in love with 2 or 3 .

I: Okay. How did you identify intimacy in yourself and in your partner at that time?

P: I wasn't a very intimate person, I'll have to admit it. I kept to myself. I withheld my feelings. In that first marriage, I definitely did it then. Withheld my feelings and kept to myself. Just as you grow older you learn. It took me a long time.

I: How did your partner express intimacy or show intimacy during that time?

P: Are we talking about the first marriage?

I: Yes.

P: That's a tough one too because she was kind of sexually oriented too. I really never knew what she was thinking. I'm just trying to think of one moment that she was actually emotional, sharing, that kind of thing. I really can't think of, it was all just fun. It was more of a trip to the amusement park than it was a marriage.

I: Okay. Interesting. Now, according to your timeline at age 25 that marriage ended by divorce. At that age, you indicated that you had lots of dates and lots of sex. How did those experiences affect your understanding of intimacy and your expectations of sexual expression?

P: I learned that sex and intimacy was two different things. As in, very few cases was I intimate and I learned that in order to have a real relationship you have to be intimate. 
You have to share your feelings, not just your body. I was a little bit manipulative, it was you know, a keeping score kind of thing. Then again, that was the 70s.

I: When you say 'keeping score kind of thing' what are you talking about?

P: [indecipherable]. Lot of bar hopping back then. You could actually pick up girls at bars. A lot of parties. People, driving after a few drinks wasn't a big taboo back then. It was still dangerous and we shouldn't have done it. You get pulled and they let you go back then. There's only a couple of instances where I had a girlfriend that I actually shared my life with, what I liked, what I didn't like, that kind of thing. For the most part it was just *** a couple months and then move on.

I: Those relationships where you shared about yourself, what other things did you do besides talk?

P: Family things. Visit her family and Christmas's together, things like that. One girl I would probably still be with except that she got me, we met just right after I got divorced and I wasn't ready but she was and she was putting too much pressure on me. I don't know if I mentioned that one in there or not.

\section{I: You did.}

P: She's on metro council now. So I had some good influences on these girls. [Laughs] I: Yeah, it sounds that way. Now, on your timeline from age 26 you had a steady girlfriend. You wrote love, close, and sex and you let this one get away. That's the one you're referring to? Then at age 27, you wrote lots of dating and much sex. At age 28, you had a steady girlfriend that you stated, 'She dumped me,' with an exclamation point. What did that mean to you? 
P: That one hurt and you know what? In retrospect, still angry with that ***. It was my fault because she was married when I started dating her and she got a divorce and then we started dating. She moved in with me for a little while and then I went away, I had to go away for a week. It was a, I had already planned this vacation before I even met this girl and me and a buddy had already paid for it. So, we went ahead and went and she was going to watch my house because I had a cat and dog at the time. Then, she had a boyfriend stay with her in my house. I should have known. What was it? The joke about, not a joke, the story about the frog giving the [indecipherable] and he $* * * *$ him at the end and the frog says what did you do that for, serves you right. [Indecipherable]. Well, if she's going to fool around with me while she's married, she's not a very stable person.

I: Okay. P: So, [indecipherable] even though I was really crazy about it. There again the values was the same, sort of, obviously not intimate, intimacy wasn't the same for both of us. I showed a lot with her but she wasn't intimate with me.

I: Okay. Then at 29, you indicated you had two girlfriends and were in love with both and were having sex with both. How'd you know you were in love with both of them? P: I just couldn't make up my mind. There again, we were both family oriented. I did things with [indecipherable] dated both of them at the exact same time. I wasn't shy around them. I was shy around their families. We shared things. We shared our lives. You get involved with family and everything it's and expressing yourself and what you're thinking actually comes out, it a lot different than trying to be polite. I actually at 
one point broke up with both of them because I couldn't make up my mind. Of course, they didn't know about each other until one night. It was tough on my part. I could have settled down with either one of them but in hindsight I settled down with the wrong one.

I: That takes me to the next one. At age 30, you wrote that you chose the wrong one and regret it to this day.

P: Yeah, see, we're still buddies. She's the mother of my child. We're probably better friends now than when we were married. She's actually been married to her second husband longer than she was ever married to me. Still, she's just not, there's one *** that we didn't share that I think that would have shared with the other girl and that is once she had the one kid that was it. She didn't want another one. She got spaded. I wanted more. But, I just went along with it because I wanted to make her happy.

[Indecipherable] As far as intimacy, I wanted to make the other person happy. If you're not intimate, you don't give a shit. If you're intimate, you want the other person to be happy. But then, if you sacrifice yourself to do that then you're not being honest.

I: How do you know that the other person is being intimate with you? How do you know they want you to be happy?

P: Well, time would tell that. [Indecipherable] married girl. I wanted her to be happy but obviously she didn't give a shit what I ***. Tina, she's the one I ended up marrying because she was pregnant. We're buddies [?] but I was real disappointed that she was *** and I ain't going to put her through college to get a degree ***. I: What was it you said about that you were disappointed she was what? 
P: [Indecipherable] which is there's four sisters and the other ones have several children and Tina's the only one with just one child. She's the only one with a college degree and a good job. She didn't really [indecipherable]. My mother said she was *** but the other girl, Debbie, was kind of strange.

I: That was how you made your choice somewhat? How your mom described [participant speaking over interviewer]. I'm just kind of curious.

P: Well, not really. Mostly because she was pregnant.

I: Okay. You indicated in that marriage that there was love and sex but not a lot of time together. How did that experience, that marriage, affect your understanding of intimacy and sexual expression?

P: Well, it let me know how important communication was to intimacy.

I: Communication how? In what ways?

P: With each other because she would tell her feelings and emotions to her sisters or her, she had several older males that were friends, she'd talk to them on the phone for hours while my son and I watched TV or played games or something. She never talked to me. Now she talks to me. Too late now. It's like, I don't know what her deal was but I always wanted to be intimate and I always wanted to share with her but she was always just out of reach. I don't know why she was like that. Told me once that it was late and she said I just wanted to be on my own because I live with my daddy and then I married you. I've never been on my own. Okay, that was reasonable. I thought, and like I just said, I wanted to make her happy. I said okay, stay on your own for a while. Then, nine months later she married somebody else. That's not really staying on your own because 
she moved from my house, I don't even say our house, my house. She moved from my house to her daddy's house and then to the other guy's house. Actually, it was her house. But you'd need to talk to her about that.

I: Okay. Well, on the timeline, you indicated that this marriage ended in divorce when you were age 42 .

P: I'm guessing, I can't really, it really ended about mid-80s I think. But then we finally got, like you say intimacy, as far as being intimate I was all wrapped up in our son and she was all wrapped up in talking to other people. It was 91 or 92 , somewhere in there. I can't even remember that we were divorced.

I: What were your expectations around, for and around sexual expression during that relationship?

P: I wanted to make her happy and I wanted to have fun because I think that's part, if it's not fun it's just doing it because you have to then no joy for either partner. She was kind of moody, still is but we didn't have sex all the time but when we did it was, we had fun. It wasn't like, I don't know if this is true, but some married couples they just go to bed and the husband just wants to have sex so they have sex and go to sleep. It was never like that. So it wasn't real often but when we did have it, it was more of a fun thing. It was more, not so much in the bedroom kind of thing. [Indecipherable] just talking about this girl [indecipherable]. [Name of store?] they had a lingerie department. They would have sexy outfits so I'd buy her sexy outfits but I never them on her. She'd go in the bathroom and try them on, come out and say it was uncomfortable or I don't know why you'd like something like that. That was, then she did like cat suits. It's like a body 
stocking. Sometimes they're lacy. She loved to wear those. When we did have sex, it was a lot of fun but it wasn't often.

I: You were a single parent until you were age 51?

P: About. Somewhere in there because I wanted to be there for him because he was so crushed with his mother leaving. I think I said in an email that she never asked for visitation rights. She just said well I know you'll let me have him anytime I want to which, when she first left, when he really needed her is when she saw him less. When he got older, especially when he met the girl he ended up marrying, then she started back with him but now he's an adult. He needed her when he was 11, 12, 13-years-old. He was out of high school before she, he was 22,23 -years-old before she really took a fulltime interest in him. She was all wrapped up with her new husband and he had smaller kids.

I: You say then from age 51 to the present, you had occasional dates without sexual intercourse.

P: Yeah, this leads us to today because I'm tired and I found out women my age, or say 10 years or 55 and up, their husbands have either passed away or they got a divorce and they just moved out or they never married and they want to be romanced and I just don't have the energy. I have a good friend now and we like to go out and be with each other but she's still working and she's at a real high pressure job where she has to, runs a charity. She has to go out and gather funds and she's got a lot of business meetings so we don't see each other very often. Then, since I broke my hip and been in this wheelchair for a while now, that makes it inconvenient too. I'm sure there's a lot of ladies that 
would go out with me if I asked, there was another one at church that I dated for a little while too, but sometimes it's just that I can just tell that they want to be romanced and I just haven't got the energy anymore.

I: So, how would you define your understanding of intimacy at this point in your life and when you think about those things?

P: I still think intimacy is sharing yourself, heart and soul, not necessarily physical sex or anything. Letting the walls come down. That kind of thing. In order to that, you have to get to know somebody. Like I said, ladies my age they have this bubble around them that some of them have had husbands who passed away they had to take care of them and stuff and now they want to be out and about without that burden. So, they want to deal with somebody like me. That kind of thing. I don't know, they want to be taken to dinner and flowers and all that kind of stuff. I used to do that and I know what to do, I just don't feel like doing it.

\section{I: Okay.}

P: It's not my fault I don't have a lot of dates. It's like I said, I know [indecipherable] but you can't really talk to them like you can some people because they have that bubble around them. They've been intimate with this man for 40 years and now he's gone or I lived with him for 40 years and I've got the kids raised and I hated his guts the whole 40 years and I'll never get that close to anybody again, that kind of thing. I'm reflecting on older ladies that, I'm *** older ladies and that's not fair to them but that's the way I see it. It's depressing on my part in a way because I don't get out more but I know it's my fault and it's not their fault and in a way it is their fault. 
I: What, how do you meet your needs? Your personal needs for intimacy and sexual expression at this point or circumstance now?

P: I am, intimacy that's a tough one because I'm a listener, I listen to everybody and I'm friendly with everybody but I'm not asking much for myself. Does that make sense? I think I'm pretty popular when [indecipherable] but just listening to people. Then again I don't get to share [indecipherable] thoughts, some things I told you today I would love to be able to talk to somebody else about. Somebody I could be intimate with but I don't. I'm a good listener and listen to other people and listen to their *** and what's going on with their lives and that's good for me. I feel good that they have an opening that they can share with. I'm nonjudgmental. [Indecipherable]

I: Good.

P: [Indecipherable] An official befriender [?]. Do you know what that is?

I: Not sure, no.

P: Okay. A minister, years ago, $* * *$ Catholic started this $* * *$ people in hospitals and nursing homes and life in general that just want to be listened to, especially women. They don't want you to solve their problems. They just want somebody to listen to them.

I: Like they're craving intimacy.

P: Yeah, So, we have a group at church that are befrienders and we went through extensive training to learn how to be listeners.

I: Wow.

P: [Indecipherable]

I: How are you addressing your sexual expression needs? 
P: Oh, I got this funny. I'm like a woman. Certain weeks of the month I get horny but the rest of the time I'm wrapped up in other stuff and don't even think about it. That could be my age. Masturbate occasionally. That's about it. It could be because I'm older and losing my testosterone.

I: Now, you didn't indicate any age or information on a timeline for a future period past 65. So, without that, I'm going to go ahead and ask you some additional questions. As you consider your future, what concerns do you have about your intimacy and sexual expression needs?

P: I'm a little bit concerned that I would have like to have somebody on a permanent full time basis *** with. If sex comes out of that, that would be fine. That's not a priority. I'm more intimate with my ex-wife than I used to be but then she's married to somebody else. Really, there again, I don't do that much talking, listening to her. Come to think of it, I don't do that much sharing of myself with many people. Trying to think of somebody I knew that, I think one thing that's hurt me, in 1986 my best friend, a male, got murdered. He and I, if he was still alive I would definitely be sharing things with him. The future, as far as that goes, I'd like to have somebody but I'm not super concerned. It would be nice but as I've gotten older I've sort of gotten wrapped up in church. I've always got God. That's satisfying because I let him slip for all those years. Grandmother was a good Catholic and he passed away when I was, and that kind of ended my religious background.

I: One last question I want to ask you about and none of us really want to think about it. It's a strong potential for that. Similarly, as you think about the future and you consider 
possibly being a resident of a long term care facility, what concerns might you have about your intimacy and sexual expression needs in that context?

P: I've been in a long term care facility twice now with broken bones, but still it was what they call $* * * *$ care. You're right down the hall from assisted living and the nursing care and then having dealt with my parents being in a nursing home for 3 years. I'm kind of familiar with it. There again, the intimacy I hooked up on with several, like I said I'm a good listener and there again, I'm still not sharing a lot but I've made pretty close friends with certain staff members because I listen to them. That's what made my stays tolerable. Sexually, there wasn't, I don't see how you could possibly be sexual in a place like that. Although, my mom and dad, they would catch them. I finally got them in a room together. My mom had Alzheimer's and my dad couldn't walk because his arthritis in his knees, they just didn't work anymore. We had to have him, back then the doctor fudged his record to say he had dementia so we could put him in memory care with my mom. Like I said, I never saw my parents touch until they, you would go in there and they would be sitting in the chairs watching TV, holding hands or they would be in the, they had a little twin bed, but they would be in the bed together and they said they were all the time having to get my mom out of his bed.

I: I wonder what would have happened if they gave them a double bed.

P: It probably would have been fine. They probably would have made out or something, I don't know but they can't do that in a nursing home.

I: You'd be surprised that as a resident that's your right.

P: Is it? 
I: Yes.

P: I didn't know that.

I: It is your right.

I: Before we end, is there anything that you feel would be important and clear that you would like to include around this topic of intimacy and sexual expression?

P: Well, I think I've learned a lot just talking to you just now. Realize that I've always known the difference between intimacy and sexual expression and the intimate part of sexual expression is trying to please the other person. I had never thought of that before. I really learned something that has motivated me a little bit. [Indecipherable]

I: Fantastic. I'm glad it was useful for you too.

\section{H., J.B., 1957.54}

Interviewer: On your timeline, you indicate at age 12 that a boyhood friend introduced you to masturbation. At age 13, you indicated that you were molested by a church deacon. At age 15, you indicated that you had a short relationship with a girl of the same age without any sexual interactions and that you were introduced to pornographic print material around the age of 15. At 19, you indicated that you had sex for the first time with a girlfriend and later became engaged. What was your understanding of intimacy throughout this?

Participant: My understanding of intimacy throughout this. Wow, good question. I don't think I really understood much about intimacy until I was probably during that age of 16-17. Me and some friends that I lived close to, close friends with, we started going up to a town skating rink and we were introduced to a lot of girls. Some of my friends 
started dating at that time. That's, they started getting into deeper relationships and that's probably when I would really perceive the notion of having a long term relationship with someone of the opposite sex. The relationship meant that you were a couple and you were sharing things. You know, that kind of an intimacy. It's a tough question.

I: Sharing things, how?

P: Baring your dreams, your what you wanted to do once you graduated from high school, where you're going to go to college, were you going to go directly into the workforce somewhere, what were you going to do, what was she going to do. It was just a gradual introduction to having a deeper relationship. Not me per se, but seeing my friends do this. They were meeting their girlfriend's parents. This one particular friend of mine, a girl that he was dating had a sister so I would sometimes tag along and go over there like on a Sunday afternoon and I'd see their family and what they were doing and it was just a sense of watching how families interact with each other. Watching how a young person is accepted by the parents. Just that interaction.

I: You indicated you learned some of that from your friends. Were there any other people that you learned from or obtained your understanding and meaning of intimacy?

P: Personally, I probably should have gotten a lot of that from my own parents but they didn't have a lot of intimacy. Now, I will say my older sister, I watched her and she began dating as a teenager and she had one serious relationship and she eventually married that guy. You know, they're married today with a child that's grown now. Me being around my sister, I would hear all of her stories about the good and the bad of her 
relationship with her boyfriend. They might have breakups and get back together. They would plan certain events and go do those events whether it was go to a concert or go to the state fair, visit each other because he actually lived in a small town 70 miles away. We lived down in that area of the state at one time. He had to travel to Louisville to see her, to visit her. So, that was always a topic of discussion. Was she going to see him that weekend or was he coming up. If he did come up, what kind of plans they were making. That probably also gave me some instructions, some expectations on how to have a relationship.

I: How did you identify intimacy in yourself and in your partners?

P: How did I identify intimacy? Intimacy, first I have to have an understanding of what intimacy is. For me, personally it means commitment to that one person, a closeness, a person that you can share your thoughts and feelings to, a person that eventually leads to sexual relations more than likely, a person that you can share your deepest thoughts with. So the question again. The follow-up question?

I: Is how did you identify intimacy in yourself and your partner?

P: My first serious girlfriend who I later was engaged to for a short while as I was attending technical school, I met her and she demonstrated caring for me on a deeper level and concern. I remember at the time I used to go out drinking a little bit with my buddies on weekends. Friday and Saturday night. I can remember the thing that impacted me the most during the early stages of our relationship, I can remember her telling me one day, this is shortly after we started our relationship, she says you're drinking with your buddies and everything and I'm just concerned about that a little bit. 
Why you need to do that and what that means to you? That immediately had an effect on me that this person cared enough about me to question me going out drinking on weekends. It's not like I was going out just totally abusing alcohol and everything. She knew enough about me to know that that's what I did. Of course, she came from a Baptist family so she may not have been around people drinking that much at all. Period. The fact that she said that left an impression on me. That this girl might be worth knowing a little bit more. Our relationship grew and we did have sex together for the first time, the two of us. We thought we were made for each other but we were still very young and that changed.

I: What ways did your meanings and understandings of intimacy differ from your partner?

P: In what way was my meaning of intimacy different than my partners? How can I answer that? I mean, if I don't know what their thoughts of intimacy were versus my own?

I: I guess, the question is how did you recognize it in them? How was it different from yours? Did you see something that differed from their perspective of intimacy than yours?

P: I don't think a whole lot, to be honest. I mean, again I developed a relationship with Patsy was her name and we had common interest and we would make plans together and do things together. It might be a trip up to Kings Island, it might be a trip up to a little picnic or something, or it might be going to the store or going to a restaurant. Maybe 
going to the park, having a little cookout just the two of us. She seemed to enjoy spending time with me and I enjoyed likewise spending time with her as well as her family. She had a younger brother who I liked hanging around and she had an older sister that she wasn't there much. Her older sister was married to a guy that I developed a friendship with and he was talented playing the guitar. I'd go over there, even at that age, I'd go over there and take my guitar and we would play guitar together. Again, it introduced me to a normal family. What I would consider a normal family and how they interacted with each other. Her being my first serious girlfriend, we did a lot of holding and hugging and kissing and fondling if you want to call it that until at one point, I think it was one night, we discussed having sex with each other. We, by then, we both acknowledged that we were both virgins and I recall we actually made a planned date for that occasion. That's what happened.

I: Those things that you just described, the kissing and touching, would you include those as forms of sexual expression?

P: Yes. Sexual expression and probably a form of love and caring for the other individual. Wanting to please someone.

I: What was your understanding of sexual expression during that phase of your life?

P: It was fun! That it was exciting, passionate. Still trying to learn as much as I could. It's like an awakening because you go through puberty and you have some idea of what this thing is called sex then you discover it and then you want that. You want more. The hormones kick in and it drives you to become the person that you eventually become I 
think in ways. As a young man I wanted to have a girlfriend. I wanted to have a wife. I wanted to be a productive employee somewhere and have a good job and hopefully have children someday and raise those children. A sexual relationship was a big part of that. It's one of the payoffs.

I: Okay. What did sexual expression mean to you at that period of time?

P: We're talking about 16 to 19 -years-old?

I: 0 to 19 .

P: What did it mean to me? Well, for me it was something that was private between me and one other person. At the time, someone that I was in love with. There was like certain things that had to be met in order to have that sexual encounter. I don't know.

I: Where, or from whom, did you obtain this understanding and meaning?

P: I figured it out. I had an introduction to a porn magazine one day. Believe it or not, I was walking home from school one day. I walked to and from school. One afternoon I'm walking down the road and there's a magazine laying out in the street and the pages are flipped open. I glanced down and looked at that and picked it up. It was a magazine. Porn. It was a porn magazine and it was very explicit. I was like the little kid you see in the movie, what was it? The one that John Belushi is in. The girl flies through the window and he's like, “Oh yeah!" That's like, I got this magazine here and I've never seen one before and I'm looking at the pictures and actually reading along with it because I've always read. Then that stoked something a little bit, you know? Then I can remember, I don't know when I saw my first Playboy or Penthouse or whatever, but I did sometime after that and I would actually read sometimes the columns where they would 
have a person, a columnist, write about her sexual experiences or something. Sometimes people would write in with their sexual experiences. So, I would read that. Not only would it help me a little bit, it was a way of learning a little bit too. Here's what people do. Their experiences. It drove my curiosity a little bit and it also, I stored it away. Some of the knowledge. When I developed real relationships with women, no matter what you read or what you look at, it's going to be different. You naturally just do what comes naturally and you get better as time goes on, hopefully.

I: Okay. What meanings and understandings of sexual expression did you share with your partners and how might they have been different from your partner or partners? P: I can remember my first serious girlfriend, the sexual expression that we had was pretty common. Nothing way out there or anything. At that time, to me, sexual expression was something pretty pure and something that you shared deeply with one person. It was just exciting and fulfilling but there wasn't much experimentation or anything. The lady that, the next lady that I had a serious relationship with that I do to this day somewhat, when we started dating we started trying different things. She would tell me what she liked. I would express for her what I liked. She had one other experience before me. I had one other experience. Neither one of us had a lot underneath our belts but I guess we both wanted to experiment a little bit. Experience some of the other means of satisfying each other. I can remember the first time I had oral sex was with her. I was driving a car. She was in the passenger seat. That was pretty exciting. Did a lot of massaging of each other. I guess you'd call it petting maybe, is the word. She was probably the first woman that wanted to be on top instead of just the 
traditional missionary style. I enjoyed it. She did too. So, the sexual expression was at a higher level. It stayed there for many years.

I: Differences as far as what she might have [Participant says "Yes" and word that interviewer says cannot be understood] as well?

P: She didn't care for oral sex very much. You know with me return the favor to her. Not that we never did, but by and large she didn't enjoy that a whole lot or at least she claimed she didn't. I can remember the first time, of course any male probably wants, you read and hear so much you think you're failing unless your partner is climaxing. So, I think I gauged myself on whether or not I could bring my partner to an orgasm. That was one of my goals, to be able to get there to do that and eventually I was and I learned there's many different ways to reach that. It's just not always intercourse. There's other ways and other means to get there. Sexual expression, I mean she knew that I like to have my nipples sucked on and she would do that. We had lots of little things that we both liked to do that we enjoyed and things we did for each other.

I: Going into your early adulthood, age $20-40$. This is broken down a little bit as I go through instead of all together like the last time.

P: Okay.

I: At age 20, you indicated on your timeline that you began having frequent sex with your future wife. Additionally, you indicated that around 21 or 22 you had a one night stand. In regard to intimacy, in what ways did these experiences impact your understanding? 
P: Well, the one night stand was pretty much as stated. Pretty much a one night stand. It was a girl I had met, and was attractive, invited me to her house. She lived with her parents. I think her mother and dad may have been divorced because they weren't around. We, it was kind of strange because here I am pretty much a complete stranger to her and we're in her mom and dad's den having sex. Going at it and there's no really closeness with each other. We were just two kids going at it and it was just for the sole purpose of having sex with each other is all it was. There was no intimacy to it. Now, there was, as opposed to the intimacy that was growing my future wife where I loved her parents. I got along with her sisters. That intimacy grew.

I: During that same experiences, in what ways did it impact your understanding and expectations?

P: How did it impact my understanding of sexual expression? Well, the one night stand convinced me that sex could be very exciting. Which I knew that, but as I recall I felt it taught me more than anything that the woman wants it as bad as a guy does. That's what it taught me because we had sex more than once that night and I just knew she had a voracious appetite. Sex. It taught me that women were no different than I was really when it came to sex. XXXX, who I was having a relationship an actual relationship with, she had some of those same traits but the relationship was there with it.

I: Looking at your timeline, at age 35 you and your wife developed a close relationship with another couple. On several occasions you had sex in the same area together, some light swapping on a couple of occasions and one serious. You also indicated that you and your wife visited a nudist resort with that couple and that over the course of that 
relationship you and the female from the other couple had one failed attempt at sexual intercourse. I want to get some clarification before we go into it. What do you mean that you had sex in the same area together?

P: One evening we went out to a park and had a cookout. We left the area we were in looking for a quiet, private spot which we found. We laid, probably on blankets I'm certain, but it was in a field. It was a field and we were all four within a 10' x 10' area. Joe and Susie had sex and XXXX and I had sex. That wasn't, there were several occasions when we had sex in the vicinity of each other. Even when we sometimes travelled and we would stay at hotels, we usually registered one room and there were times when there was sex going on in one bed while there was sex going on in the bed next to it.

I: What do you mean when you use the phrase "light swapping"?

P: Light swapping. We always played strip poker a lot, often. That was always fun but because the relationship was so comfortable, we were all so comfortable together, we started playing silly games like I think it's called Twister. Where you got the colored dots on the mat and you put this hand down, this knee, and that foot. We started doing that. Now, I can't remember whether we were naked or not. My guess is we probably were. You wouldn't necessarily be on the mat with your partner. It might be the other spouse. We actually played another game where some kind of board game. I can't remember if it was dice or you spin the thing but you land on a square and you pick up a card and the card might say, "You've been a good boy. The person to the left of you needs to give you a kiss on the mouth." Now, none of this was boy to boy contact or 
female to female. It was all opposite genders. It might be your wife that was sitting to the left of you. It might be the other spouse sitting to the left of you. That was some of what I would call light swinging.

I: Okay. What do you mean when you use the phrase "one serious"?

P: Together. The four of us. It occurred during one evening when we were playing this little game. Things evolved. I wound up laying next to Susie and Joe wound up laying next to Cindy. There was fondling going on and Susie was the more aggressor and she had actually been doing a little oral sex with me. I remember laying on top of her and Susie whispering in my ear more or less, "Do it. Do it." I think she, it was loud enough that Joe heard it. He's like on the other side, just feet away. I looked over at Joe and of course Joey and Cindy were together. They weren't doing anything to the extent that Susie and I were. I looked at Joe and he kind of just shook his head, nodded in a negative way a little bit. That's all it took. That put a stop to that. Joe and I were always, we always communicated very well with each other and Cindy and Susie did too. I used to think they had ESP. They knew what each other were thinking. That ended that. What did happen though, I think it was the same night. We reunited with our partners and had, well XXXX and I had sex. I'm not sure XXXX and XXXX did but XXXX and I had sex. $\mathrm{XXXX}$ was on top. $\mathrm{XXXX}$ and $\mathrm{XXXX}$ were right there. $\mathrm{XXXX}$ came over as we were having sex. Now, I orgasmed. Climaxed and all of a sudden I remember XXXX being there between our legs with her hands and she said, "Hey Dave, you know what this is?" I don't know that, that was high moments of my sexual encounters. 
I: Okay. All right. How did these experiences affect your understanding of intimacy and expectations for sexual expression?

P: Intimacy and sexual expression to me are two different things. Intimacy again is someone you share, things you share deeply with your partner. Sexual expression is something different. It can be with your partner or it could be with someone else. It could be in a group setting, possibly. That's about it.

I: Now, on your timeline from age 40 until age 54, you indicated that the relationship that you and your wife had with this other couple continued including some of the things you discussed. Then, from age 43 to 54, you indicated you had a romantic interest in a female neighbor across the street that included hugging and kissing. That you would fix things for her at her house. You also indicated that there was never any real sex and that you and she had phone sex once. What do you mean by the phrase "real sex"?

P: Both partners, I mean obviously you can have sex with your clothes on. You don't have to have clothes off to have sex. In my case, having sex with a person means that you're probably going to have clothes off and probably one of you is going to have an orgasm. That's how I would generally define having sex.

I: With intercourse or not without intercourse, either way?

P: Either way.

I: Okay. What do you mean when you say "phone sex"?

P: I was out of town on business and we talked to each other a lot. I called her up on the cell phone and we just had phone sex. 
I: In that situation, how did that experience affect your understanding of intimacy?

P: Well, again they're two different things.

I: Okay. There wasn't a change or any differences at all?

P: No.

I: Okay. During that time, what expectations of sexual expression did you have?

P: When I was with?

I: Period. Throughout that phase.

P: During that age. I felt that I was still learning and growing as far as sexual expression. I had explored a little bit and wanted to continue to explore. I enjoyed sharing sexual expression with my wife. [Indecipherable] also. You know, when we were with the other couple all the parties always seemed to enjoy each other's company and enjoyed having that sexual expression. Other than that, I'm not sure that, I don't know if that answers the question.

I: I think you're fine. In what ways did your meaning and understanding of intimacy differ from your partners?

P: Well, I think my wife has always been dedicated to me, committed to me. We enjoyed being on the fringes a little bit. I don't think she ever did anything that she regretted later. It was just who she was. That was her expression and that's who she was. Another tough question. These aren't easy! 
I: [I don't know] or [Got to know]. You didn't indicate any age or information on the timeline for the future period. As you consider your future, what concerns do you have about your intimacy and sexual expression needs?

P: Well, like a lot of men I want to be able to continue performing. I want to stay healthy and to be able to medically continue. I think my intimacy, I think I'm a lot wiser than I was in my youth. I think as far as, like a lot of mean again, I think it takes more to get me going now.

I: You say "wiser" around intimacy. What do you mean?

P: Well, I hope I learned something over the years but the relationship I've had with my wife, at times it's been a struggle and a challenge. Right now, we're going through a particular rough spell. You got to listen to your wife. You have to, both of you, communicate very well. Sometimes, she'll say one thing and I hear it different and I think she's guilty of that too. So, clarity and some kind of confirmation on what you just said is important. To achieve that intimacy, you got to have trust and faith and commitment. You don't want to do anything to break that.

I: As you look into the future, what do you anticipate your intimacy and sexual expression needs and explain [Participant begins speaking so the end of the sentence is not clear].

P: Well, I'm at the point in my life where my wife and I may not never have a sexual expression with each other ever again. So, this is a new, this is new to me. I don't know what the next phase will be. I would hope that, to meet an interesting lady eventually and 
hope I find someone who's a match that I can feel intimacy with and lead to sexual expressions. I want a future. I want a partner. I don't like loneliness. I want to have someone to talk to when I come in from work or during the day. One of these days I'll be retired and maybe going to a coffee shop but there's going to be times I want to have a conversation with someone of the opposite sex. I want that person that I love that loves me back. That I care for and $* * *$ that person and hopefully feel the same way.

I: In what ways, if any, do you expect your definition of intimacy or sexual expression changing in the future?

P: I don't see it changing. They may not always necessarily be together. There may be some intimacy without a lot of sex or there may be some sex going on without intimacy. But as far as how I perceive the two, I don't think I see that changing a whole lot. I: All right. Well, that's a question I have for you. What are your expectations for intimacy and sexual expression when you think about potentially being a resident in long term care?

P: Long term care. I think intimacy potentially grows and that intimacy may include other people than just your wife. Maybe your family and your children, I would include in that intimacy. I would think that intimacy might become a little more important and maybe sexual expression a little less important. Not to say that you wouldn't have sexual expression urges and needs but the opportunity, there may not be as much opportunity unless you're taking care of yourself. You may not always have the advantage of having an intimate partner with you. 
I: What leads you to have that idea that you have a partner in that environment?

P: Someone that you are in a relationship when you get to that long term care facility. Not knowing how that partner would be welcome inside that room. Whether or not you could close that door and have some private time. I'm not sure how that works out.

I: For a single person, in that same situation [Participant begins speaking].

P: If I was a single person in long term care and I had a sexual urge, do what I have to do. Whether that was picking up a magazine or I don't know how you get a magazine [Interviewer begins speaking].

I: What if you saw $\mathrm{XXXX}$ down the hall and thought she was really sweet and she liked you too?

P: New thought. I'd do what I could to introduce myself to her and try to develop some kind of friendship with her. If it ever became a deeper friendship, people are people and their sexual expression is a part of love and caring for someone at times. It doesn't have to be but at times it is. It's part of that extension of that intimacy and if I had intimacy with another individual at a long term care facility, I'm going to be trying to seek private moments with her.

I: That's all of my questions. Is there anything you feel [Participant begins speaking]. P: No. The only thing I would suggest is just a little discussion beforehand on intimacy versus sexual expression. Those seem to be the two key points here. Intimacy is one of those words, when you first threw it out there, I'm like, "What does intimacy mean?" It was kind of a shock at first. What are we doing talking about intimacy? What is intimacy? So, it took me by surprise a little bit. 


\section{Sam}

Interviewer: You can use names if you want, just don't use last names. Nobody knows who they are really, but I just want to make that available to you to ensure you're keeping that information private, if you choose to. Now, on your timeline, up through, you don't really have much marked except around maybe 18 in your childhood and adolescence section.

Participant: Well, actually I got it, what, 14, the age is actually 14 or 15 to 18 .

I: Okay. Can you tell me about that timeframe? About those experiences or relationships and your understanding of intimacy at that time?

P: That's when a girl, a year younger than I was, was paying a lot of attention to me. Beautiful looking girl and I'm a shy guy, so I kind of somewhat ignored her. It was on Broadway, which first thing in the morning I used to go to work at that age before I went to school because school was 6 blocks away from where I was right there on Broadway at my dad's business and I'd walk a block down to go to work. She was with her mother in a store next door. Of course, every morning I'd walk by, nothing but smiles. You know, I'd smile back and keep on walking. I'm shy and went to work. Well, this one morning she had me pinned down at the bus stop waiting to catch a bus to go to her school. "Hi!" It started and we just hooked up.

I: How did, in that relationship, how would you describe your understanding of intimacy?

P: I was scared to death. I guess I was 15, but scared. 
I: In what ways? In what ways were you scared?

P: I don't know nothing about it.

I: Okay, okay.

P: I don't know nothing about it.

I: So, you'd gathered no information or understanding of intimacy at all at that age.

P: Not really. You hear it. You hear a lot of things when you're young. For instance, just like talking about gay people. You always heard, the word always went around. “Ah, he's gay. He's gay.” You know? Today, they use that word in a nice way sometimes with people, but I didn't know what it was about. Love, never heard about love. Felt it. Never heard the word.

I: Okay. How did you in this [new way?] express yourself, your intimacy with $* * *$ ?

P: After we started seeing each other, after that her mother would go to work early during the week, early in the morning as she changed jobs. On my way to school, I'd always stop and see her in the morning because she, I guess she went to school later. I don't know. In another city since they had moved there this [year?] which was 4 blocks away from dad's business, which was 2 blocks away from my school. I used to walk. Always go see her and she always used to tease me and yeah, we kissed and it was something. Actually, she, I found out later years she was raped by a step-father and by a guy so she knew what sex was about. I don't know, maybe she just liked it. I don't know. She always teased me.

I: When you say 'tease you', what do you mean? 
P: She used to take, I don't remember what I had, something of mine and she'd set it down on top of her bra and go, "Oh, get it. Go, get it."

I: Okay. I see.

P: Then I'd go deeper and deeper and deeper.

I: Did you ever act on those teases?

P: I just went after my item.

I: Okay. You had to get it back.

P: Yeah.

I: Okay.

P: That's all I was interested in was my item and I knew what she was doing. I thought, "You don't go there."

I: Okay.

P: You just don't go there.

I: Okay.

P: But, within the year, evidently I went there.

I: Okay, okay.

P: Within the year, I don't, that's a long time back.

I: So, you $* * *$ maybe there was some kind of a, there was a difference in your meaning and understanding of intimacy and hers.

P: Right. Completely different.

I: So, how would you describe hers? 
P: I think she liked it. After years of knowing afterwards, yeah she did.

I: Okay. Now, what was your understanding of sexual expression during that phase?

P: Understand. Expression.

I: Sexual activity. How you behaved or interacted at that time frame. Or did you put the two together? Was intimacy and sexual expression connected?

P: Connected. Both the same.

I: Where, or from whom, did you obtain your understanding of intimacy and [Participant speaks over interviewer].

P: From her.

I: From her. So, nothing from parents or family members or anything like that?

P: No.

I: Okay. Any particular spiritual faith tradition you're involved with that shared any kind of influence on that as well?

P: No.

I: Okay.

P: I had a girl that I, we used to sit together in church that was my age, but nothing happened. It was just church.

I: Okay. So, church didn't give you any kind of ideas about what intimacy and sexual expression should look like?

P: No, no. I know I like girls, but if they smiled at me, I'd pretty much run from them.

I: Okay. Got ya. 
P: You know? When I was in school, the guys you run around with they always talk all kinds of trash or whatever you want to call it. You know? It just goes in one ear and out the other because I always felt they ain't nobody after me, you know? Every time, I'm lucky I got to sit with [loud noise, can't understand].

I: Well, now on your timeline, you have a period of time between 19 and 20 [Participant speaks over interviewer]

P: Okay, that was in 17, actually 17 when I left home. Went into the military, lots of sex from 17 on.

I: Okay.

P: And how did I get involved in that?

I: Yeah.

P: My first cruise overseas in Japan, guys I worked with and all that used to tease me about it. We'd go ashore, they'd get drunk. I wouldn't mess with women and they wanted to know why. Because I just didn't know nothing about it. I had one guy that was over me. We had left that port and went to another port and right off the bat he says, "Come on, you're coming with me today." He took me out and I guess it was a whorehouse. I don't remember what the heck it was, but he went and paid for all that and said, "Now, you got this girl. Take them and do the works." So, I learned a lot.

I: Awesome.

P: But, a friend of mine paid for it all. I was paranoid, somewhat. You know? Wow, wow. Stuff I knew nothing about. Live and learn. 
I: Now, in those experiences, how did your understanding of intimacy change if at all?

P: I enjoyed it.

I: Okay.

P: It was just sex.

I: Okay.

P: That's it. Just sex.

I: Okay.

P: Military life.

I: And that period was until what age?

P: I got out when I was...

I: You have a period between...

P: Oh, 21 up. That's when I met my wife.

\section{I: Okay.}

P: Which was, that's all that was, was sex.

I: Okay. Did you both share the same understanding of intimacy and sexual expression and/or did you have different understandings?

P: No, I think we shared it at that time. She was 4 years older than I was. She had 5 kids. She knew what it was about. And to me, I was only after one thing.

I: Okay. All right. Now, in that time frame between the time you got married and age 40 for example, did your understanding of intimacy and sexual expression change at all or did it remain the same? 
P: I'd say it remained the same. I had got her pregnant and I ended up marrying her. I: Are there other things that you guys, that you did, around intimacy? That you and your wife may have done? That maybe didn't involve sex?

P: Understand now. All I know is that I didn't really love her. I married her because she was carrying and I, that you take care of her, you do what your [Interviewer speaks over participant]

I: Okay. All right. Now [Participant speaks over interviewer]

P: Had a good, bad 15 year first years. Okay. Difference of, okay she felt all men were equal. All men are equal, all they care about is sex, sex, sex. They'll screw off on their wife, girlfriend, whatever. I didn't do that.

I: Okay.

P: So, if I was getting home late from work whatever. 2, 3, 4 minutes, whatever. I was screwing around on her. So, we fought a lot. I always got upset because all men are not alike.

I: I understand why you would be upset.

P: Yeah. I get blamed for it every time something would come up. I'd look at women. [Participant and Interviewer speak at the same time. Can't understand either]. I looked but I never touched.

I: Okay.

P: But I always got blamed for it. Yeah, real hard.

I: After the first 15 years? 
P: I had an opportunity and I took it. What I'd do? I went and told her, shove it in your face.

I: Okay. Well, you're getting blamed for it. Might as well.

P: Yeah. That's the way I felt.

I: It's not uncommon.

P: That's what I explained to her. That was it. After that, I didn't hear no more about it. I: Interesting. So, speaking of that experience, did that have an effect on your understanding of intimacy and sexual expression?

P: No, because I stayed married. You know? Like I say, stayed married for 39 years until she passed away. Until death do us part, that's what it was all about.

I: Did your wife just have the idea that all men were the same? They were cheaters and run around and probably made it very difficult for you to feel close to each other?

P: Yeah. It did for me. Getting close to her. I got close to her because if I wanted sex, I got my sex.

I: Right.

P: Other than that, you know?

I: Did she try to be close to you?

P: Well, more, no not really. No, we were equal when it comes to that.

I: Okay. All right. Looking at them from, how old are you now?

P: I'm 69. 
I: After that time frame, to the present time, what would your understanding of sexual expression be now?

P: Today? I don't even think about it today. I'm married. Got a woman that, actually I think, I've only had two. This one's the best one out of the two. Even though I had kids with the other one. We were two different worlds. We really wasn't interested in the same thing. My first marriage. Except the kids, the kids. That's all I did. I took her 5

kids and had my 2 and raise them. Her baby was a year old when I met her [and the 5?]. Then my kids. Their dad [interviewer speaks]

I: Took off?

P: Yeah. Even though they seen them. I allowed them. Never paid child support, nothing. Never did nothing for them.

I: Currently, in your marriage, how are you two, what do you share as far as your understanding of intimacy and sexual expression?

P: I don't think we both differ.

\section{I: Okay.}

P: Both of us realize we're up in the years.

I: How would you express intimacy? Are you close to one another? Do you, what do you do? Describe that.

P: Well, kiss on a goodbye. Kiss on a hello. Anytime we talk to each other, "Okay, I love you. I love you a whole lot."

I: Okay. 
P: Anytime you turn around, "I love you." I wasn't brought up with that. There we go. Let's go back to my first marriage. I never told her I loved her. She said, "You got a problem with it?" Problem with what? "You can't say the word?" No, I [stutters the word love] you. It just wouldn't come out. I just didn't know how to say it. That could go way back. Where's that come from? Comes from childhood. Never heard it. Never heard it. Seen it. Never heard it.

I: Now, we're kind of stepping into thinking about the future. Heaven forbid that anything happen to us to where we end up in a situation where we would be in a longterm care facility, but if we are, what would be your concerns around the intimacy and sexual expression in that environment? For you.

P: There probably would be no sexual. Loving each other? That will always be there. I: What would not, why wouldn't there be any sexual? I'm just curious why you would think that.

P: Hence [It's?] the condition we're in, you know? Talk about hospitals, a patient or you know? I don't know. That's hard to explain about the future.

\section{I: Okay.}

P: Yeah, that's hard. You don't know.

I: Do you have any, say you're both physically able and healthy, and wanted to engage in that?

P: We'd both jump at the moment. No problem. 
I: Do you expect the opportunity to be there, ${ }^{* * *}$ to be there, would you picture yourself being able to be sharing the same space together?

P: Oh yeah.

I: Okay. Around those things is there anything that you feel would be important for me to know or to include?

P: You ask questions, I can give you answers.

I: That's pretty much all of it. The things I want to ask you based on your timeline. So, I'll stop with that.

\section{Ed}

Interviewer: Okay. We're going to begin with childhood up through age 19.

Participant: Okay.

I: On your timeline, you indicate that at age 10 you had your first crush.

P: Yeah.

I: What do you mean by the word 'crush'?

P: That's when I realized that girls were pretty and this particular young lady was, she lived close to me and naturally [?], I mean, I don't know I just liked walking with her and holding her hand. We'd walk home from school and carry her books and you know, be sweet to her.

I: Okay.

P: That's when I realized that girls were okay. Some girls, you know?

I: So at age 16, you indicated that you had your first real girlfriend. That relationship included dating, kissing, and exploring your bodies. At age 17, you indicated that you 
had your first experience with sexual intercourse and you were nervous and awkward. At 18 , you indicated that you had sex with the sister of the lady you had sex with when you were 17.

P: Yeah.

I: You wrote, "I cared deeply about her and that she was a better lady than you deserve. Didn't know how to commit to something so beautiful." What was your understanding of intimacy in these relationships?

P: It was just, I don’t know, just nervous. Not sure what ***. My father passed away when I was a little boy, just a few days after I turned 7, a week after I turned 7. I didn't really have a father figure per se and I had to just kind of *** my way through. Mom never had the talk and it was just awkward for me for a while. I was kind of shy and bashful per se. These were very beautiful, nice ladies. A lot more experienced than I was at that time, as it turns out. Hindsight being 20/20. It was a real growing experience to say the least. The first lady, the sister that I really fell for, we split up and I wasn't a basketcase or nothing but it was time to move on. Hell, her sister $* * * * * * * * *$, her sister was calling to check on me. "How are you doing? I missed you. Why don't we get together and do something sometime because I miss you." You know what that turned into. Exactly. Which is fine, it ran its course. Later, after that, things started, maybe I took it too serious. That I tried to make it more meaningful or not just a cheap thrill or you know, I tried to genuinely care about somebody before I *** myself like that.

I: Okay. What did intimacy mean to you? 
P: Probably not just sex and stuff, but being a good listener. I tried to be like friend. Sharing anything and everything. I like talking and more than just a piece of flesh, like not soulmates or whatever either but just like who wants to interact with their families and get along with everybody and feel like it was pleasant.

I: Okay.

P: Pleasant with people and if it wasn't worth being pleasant, kind, and get that in return than it wasn't worth being around, you know?

I: Where, or from whom, did you obtain these understandings?

P: My mother had a big influence on my life because my father passed. She had 5 kids and that was a lot of baggage for anybody else to want to get involved with her. Taking on 5. A lot of the good in my heart, I got from my mother. How I raised my kids. I was divorced after 7 years. That was in 90 . Getting married [?]. It was nothing I didn't work through, I just never [indecipherable]. Yeah, I was a single dad for $* * * * * *$ put all I had into those kids. Put them first. They were my number one priority and everything and then when they got big and gone, I forgot how to do for me. You know what I mean?

I: When you think back into this childhood adolescence, what was your understanding of sexual expression during that time?

P: I don't know. I don't know how to put that. Let me reflect a minute. I'm going to guess you mean more than just self-gratification. I tried to make my ladies that I was with feel fulfilled, but then I loved the after, us holding or bonding with her. You know, instead of just getting up like I'm done and go get a sandwich.

\section{I: Okay.}


P: You know what I'm saying?

I: Yeah.

P: You have somebody give themselves to you like that, I've always tried to let them know how [beautiful?] it was and I appreciated her.

I: What did sexual expression [participant speaks over interviewer]...

P: I'm not sure I understand where you're going.

I: What meaning did you attribute to that sexual expression that you had?

P: I just because my mother and my grandmother, I was raised by women. I was taught to respect women. $* * *$ respect women. I just, I was trying to go out of my way to treat a lady with kindness and not a piece of meat or whatever. When I was younger, *** it profoundly moved me how somebody ended up getting hurt. I hated that. The lady would get really quick serious. Then, I would freak out. I didn't know what to do with that. I guess, I always hated hurting people and I mean, I hated being hurt. The first one, I had an affair, my gut feeling I mean, I knew but I was, it's not that it happened to other people. That just killed [?] me.

I: Since you brought that up, we'll move into your early adulthood phase. Age 20, you indicated on your timeline that you had sex with [recording skip? Can't understand.]. Additionally, you indicated around $* * * * * *$ felt wonderful for [4 years?]. At age 30, you indicated that your beautiful children that you $* * * * * *$ pursued [?] many people. Age 31, you indicated that sexual relationship after your divorce. You wrote that she was a wonderful woman but you *** for your ex-wife. At age 35, your third [?] sexual 
relationship $*^{* *}$. At about 48 , according to your timeline, you *** relationship better but a part of your heart still ached for your ex-wife.

P: Always did. A piece of it belonged to her for way too long. We were friends the whole time. It was just like a [blessing?]. I really just can’t do a lady justice with half a heart or ***. I mean, in retrospect, I should have went to counseling. Long ago [indecipherable] went through a whole range of emotions and years and years to ***. It did a number on my self-esteem. I hated that I allowed her to make me feel that way. [It *** our friendship ended?]. I haven't spoke [indecipherable]. She's a shitty person that I allowed, I allowed her to make me feel that way about myself. Care about what somebody like her thought.

I: With regard to intimacy, in what ways did the experiences *** impact your understanding of intimacy?

P: Well, made me really selective of who I gave myself to or who I allowed in my life. [Indecipherable]. I'm not scared to death to get involved or take a chance or give your heart to somebody *** cautious, you know. [Methodical?] but don't just jump into something. Yeah, I liked to spend a lot of time getting to know what I was getting into and it was kind of fascinating to me how a particular ticked or how different $* * * * * *$ about their emotional needs or depending on what their life experience had been or how that molded them. It's kind of fascinating. You know, listening to their life stories and what molded them and how that kind of entwined with mine and what got me where I am today [in life?]. It's kind of remarkable how life has a way of [kicking?] people sometimes. If it doesn't kill you, it makes you stronger. You know? 
I: *** your intimacy $* * *$ [your own?] intimacy $* * * ?$

P: It was compassion or tender-hearted to these ladies and how *** appreciated or treated [indecipherable]. [Indecipherable] been hit or abused. I had a lady like that once. I didn't get involved with her but from talking to her man, that's all she knew. [Pathetic?]. Broke my heart for her. Yeah, I'm tender-hearted. I care about people. I treat people the way I like to be treated. [Indecipherable]. I like to do for people, like the intimacy thing. I like $* * *$ my time to $* * *$ anything I can do to help them like $* * *$ good or I'll *** the house or mowing grass or something. I do things like that for [indecipherable] in the Army. I was in the military for a while and before that my grandmother taught me how to make my bed and pick up after myself. $* * * * * *$ in the Army [indecipherable]. It carried over into my life so I was pretty good at picking up after myself and being kind of neat and stuff. You know, ladies let me into their life, I tried to be not just physically available or whatever but I like to give my time and my ***, if you will for helping to fix their house or working really hard or making things nice. I'm real considerate of their families and families are important and bonding with their families. In retrospect, if I had one thing to do over again, there was a lady that was, I loved her. It was [Karen?]. Sweetest, sweetest, angelic and *** I didn't know how to appreciate that gift then. Beautiful [in every way?]. I think about her a lot still to this day. She deserved better than anything [indecipherable]. [That woman?] touched me. Deeply. [Even up until now?] I've been so blessed. What a blessing she is. Now, *** *** past experiences that $* * *$ how to appreciate a gift. 
I: When you consider those same experiences, in what ways did it impact your [participant speaks over interviewer].

P: I enjoyed *** now. I have always put a greater emphasis on [love?]. I, meaning putting my lady first and meeting their needs. The more I was in tune with that, the more my needs were met and fulfilled beyond my expectations. [Indecipherable] and considerate of what they needed opened up, I mean I received pleasures more that way. They were $* * *$ so appreciate $* * *$. I don't know but they were more [giving?] to me. I've always got more enjoyment out of my partner being happy than [indecipherable]. I like my***, you know what I mean? For the most part, I think I've always tried to [indecipherable] consideration into their needs then mine are always met.

[Indecipherable] selfish prick and just in it for me.

I: Unfortunately, there's a lot of that out there, isn't there?

P: I think so.

I: You hear the stories. You know. That brings us up to your present time. On your timeline, at age 40, you indicated that you had sex with the sister of a good friend that you had known since school. At age 42, you indicated you had sex with your bank teller that led to a nice romance. At around age 44 , you wrote that $* * *$ resulted in an unexpected pregnancy and that your son was born from that ***. At around age 48, you indicated a lady at work and identified a brief romance that just, and wrote a mistake. Then at age 54, you wrote, "Met the sweetest lady that *** married." And you wrote, 
"Totally committed to loving." [Recording skip?] 56, your current age, what do you mean when you say...[participant speaks over interviewer].

P: No baggage, if you will. ${ }^{* * *}$ myself, like the thing of a piece of my heart belonged to my ex-wife for years. I mean, yeah, that hole has growed up. It's been a blessing. It's completely mesh with somebody you know. She's my best friend. She's my soul mate. She's my very good lover. She's very giving. [Indecipherable] she has a hard time. I tell her I love her all the time, but she doesn't have to. I don't expect her to. ${ }^{* * *}$ she lets her guard down and she lets herself ${ }^{* * *}$ she'll tell me things. [Indecipherable]. She says, I'll always feel that way about you but I'm just not good at telling you. I'm not good at telling you the way that you do. I'm not good at doing things for you. You don't have to say it all the time. But, I do. It's easy for me to tell her. Show her. It makes me happy to do for her. She appreciates it. I know she does. It's good to completely, I mean, I'm hers, she's mine. You know? She's my heart's desire. She makes me happy. [Indecipherable] not that I'm not a fool, but I've done foolish things. *** had to get older to get a little wiser. I appreciate that gift and I know what to do with it.

I: Great segue into my next question. How did these experiences from 40 through now affect your understanding of intimacy and [participant speaks over interviewer].

P: As a result of those brief moments, I still felt lonely, or empty, or unfulfilled. I began to question if I was just destined to be alone. Why had I never remarried or what was I looking for? What was my, I mean, you know I never had any answers. I prayed a lot about it. I just wondered what the deal was. I didn't expect God to just dump somebody 
sweet in my life and say, "There she is." [I saw it?] in the scripture anyway that God helps those that helps themselves. I believe that, but it's not in there anywhere.

[Indecipherable]. I tried and I failed but I didn't feel like a failure. [Indecipherable]. I was even okay with the I'm better off alone than just being with the wrong person.

[Indecipherable]. It was everything. I never dreamed or prayed about *** more. It's like *** breath away. It was like we'd known each other forever it seemed like. It was just, it was so easy. I guess it was supposed to be like that with your perfect one. I never thought, you hear people say that a relationship takes work. You have to work at it. I never thought with the right person that it would resemble anything like work. It ought to be pleasant. Anyhow, I just, I love that she told me her past a long time ago. [This?] shit could be that way for me. Sometimes, but she's changed. She doesn't feel good about herself right now in a lot of ways. Her letting me in takes a bit. For her to want to give herself. I remember $* * *$ that $* * *$ the sex is just a bonus. The $* * *$ being by her side and talking to her, listening to her, she $* * * * * *$ good for her soul. A real calming effect on her that she used to be very tempestuous and temperamental but I'm satisfied that *** *** with made her that way. Didn't know how to tap into good that's in there. I like finding that happy spot with her. I get a kick out of it when she brags on me or she tells me things and *** she's come as far as she says she used to yell at people 5 times a day or something. Now that she's, she's [indecipherable] raise my voice to you or *** me. Not even 5 times in a year. She's the same for me. I couldn't imagine my life without her. I mean, she's a gift from the good Lord. I know she is. I honor her like that. Honor what the gift come from. 
I: What meanings of intimacy [participant speaks over interviewer].

P: We're pretty open. I don't think we differ on anything, if anything. I desire her more she desires me, the way it is. I know how sexually active she used to be so I thought maybe she just had to like me because I was sweet to her. [Indecipherable] the way that she always wished she'd been treated. Maybe I just didn't float her boat. Then, she said no that's not it. That's how I used to feel. She would [indecipherable] shitty, real shitty. Ignored her and deprived her. I wouldn't do that to you for nothing because that's been done to me. She says it's me. [It's sick?]. It's just, $* * * * * *$ feel good about herself but she's still [stunning?] to me. She's very desirable, but she's a little more ***. Go above and beyond, I mean, I like, I do everything I can to make her special that she is. I don't know. I mean.

I: You got it.

P: She's my everything now. You know what I mean? I'll never hurt her. The few times she has [bit?] at me, I never [bit?] back or $* * *$ her or say anything derogatory to her. I love her.

I: Stepping into the future period, $* * * * * *$ you wrote, "Be with my wife and cherishing each day as a gift from God *** He made her just for me, [Indecipherable]". As you consider your future, [recording seems to skip badly during this section]. P: My intimacy is being there for her. Holding her hand and comforting her and *** her. I just, I just want to be by her side. Be there for her and not [indecipherable] appreciated or, it makes me feel like a million bucks when she hugs me and kisses me. I don't want to miss out on that. I don't [indecipherable] I kind of hope I die first so I 
don't know what it's like to be without her. It's hard to be alone. I don't want to be old and alone either. So, I figure a lot of times we'll grow old together and when one goes the other goes pretty quickly. I don't think it will be that way with us, maybe. The good Lord blessed us with good health and we can dress ourselves and feed ourselves and all that, we'll be all right.

I: In what ways, if any do you expect your definition of intimacy or sexual expression to [participant speaks over interviewer].

P: I don't expect it to. I hope it doesn't.

I: What are your expectations for intimacy and sexual expression about [sentence ends? Participant begins speaking].

P: My mother's in a nursing home right now. There is no privacy. [It's bad man?]. I mean, I'm just thinking in that environment...

I: [Complete picture? Bleak picture?]

P: [Indecipherable] a rule or a law or [indecipherable]. You should be given that opportunity. [Indecipherable] does to your body is when you're old. I don't know. I don't know how it will work.

I: Okay. I understand.

P: It's kind of a scary thought.

I: Is there, that question is there anything [participant begins speaking].

P: [I want to] be with her until I take my last breath.

\section{Frank}


Interviewer: I got your timeline here. On your timeline you indicated at age 15 you had your first girlfriend. Then at age 16, your first sexual encounter and at age 18, you married your first wife. What was your understanding of intimacy during that time of your life?

Participant: I didn't really know for sure, but I knew after the first time that I was damn sure going to like that.

I: Okay. All right.

P: And I wanted more of it.

I: What did intimacy mean to you?

P: I don't know. It happened, you know.

I: Okay. Good. Where, or from whom, did you obtain your understanding and meaning of intimacy?

P: It come natural [?].

I: How did you identify intimacy in yourself and in your partner? Do you have any, I know you said you didn't have a meaning, but what kinds of meanings of intimacy did you share with your partner?

P: [indecipherable]. [Sounds like a one word response.]

I: Did your, were there any ways that your meaning and understanding differed from your partner?

P: She didn't say anything so I don't know. If she didn't like it, she would have told me and she didn't say anything so I assumed she thought the same as I did. 
I: Okay. What was your understanding of sexual expression at this time? Were there any particular things you learned or knew about as far as your sexual expression? What did sexual expression mean to you? Were there any meanings or understanding of sexual expression that your partner had? Now we're going to slip into early adulthood. You wrote at age 20, you indicated that your first marriage ended in divorce. At age 23, a child was born [indecipherable] [out of wedlock?]. Did I read that correctly? What was your understanding of intimacy at that time? What differences might there be if there were any?

P: I made mistake on that, out of that wedlock and I probably [either the recording skips or the participant stops abruptly midsentence].

I: What meanings of intimacy did you share with your partners during that time? How about beyond that between age 23 and 40? Did you have other partners during that timeframe?

P: No meaning to it. Just a one shot deal.

I: What changes, if any, around your understanding and meaning of intimacy between you and your wife?

P: Good relationship. [indecipherable].

I: Okay. Did you both, did you share the same meaning and understanding of intimacy with you and your wife? Was there any differences as far as those meanings go? Now, on your timeline, and this is the middle adulthood between [recording skips?]. You stated that at age 57, your wife died. You began online dating and being fixed up. What do you mean by 'fixed up'? 
P: *** (with?) a woman. (Got?) through the internet.

I: Okay. All right. At age 60 you wrote that you met Billie. Right?

P: Correct.

I: And at age 61, she moved in with you. What did intimacy mean to you at that time in your life?

P: I don't know. Just something I got used to. I like it and I wanted to continue it.

I: How did you identify the intimacy in your partner?

P: First, we both had the same feelings about it. Later on in the relationship, she [indecipherable. Skip again?] the middle of fights or arguments over it.

I: There was a shift in your understanding... [participant interrupts].

P: She started taking a lot of medicine and stuff and it [again, either a recording skip or participant abruptly stops speaking].

I: Did your understanding or meaning of sexual expression change in any ways in that timeframe?

P: She said it did. I didn't think it did.

I: In what ways would you say?

P: She said I was taking her for granted and I wasn't near as comforting as I had been and blah, blah, blah.

I: Okay. We're getting into this future time. You indicated on your timeline that at age 68 you became single and started dating again. What did intimacy mean at this point for you? 
P: It don't mean as much to me as it used to but I still like to go out with a woman and I'm still, I'll still be sexually active.

I: How would you define intimacy now for you?

P: I still think it's gratifying. It's far and in between, I still enjoy it when it happens.

I: Okay and as far as sexual expression is concerned, is there any difference in how you experience it or think about it or practice those things at this point?

P: I think about it a lot but as far as actual, right now I'm not with anybody. But, I think about it a lot.

I: Okay. So here we are in the latter part of it. You didn't indicate any age or information on the timeline for the future period. As you consider your future, what concerns do you have about your intimacy and sexual expression needs?

P: [indecipherable]. I always heard the expression 'if you don't use it, you lose it' and I'm afraid I might lose it and I really don't want to do that, but if it happens, it happens. I: Okay. As you look into the future, how would you define and describe your intimacy and sexual expression needs and expectations?

P: My sexual needs now, at this age, are not as great as they have been because of my age. I really, when I went out with a couple three women that I don't even think about it. The feeling is not that the relationship is going any place or what, but I just kind of, we went out on a dinner date. Fine. I didn't push the issue on anything else.

I: In what ways, if any, do you expect your definition of intimacy or sexual expression changing in the future? 
P: The only way I would say that my definition would change if I [indecipherable].

Right now, I'm still fine but another year down the road or whatever, I guess if I can't do it anymore, I guess it's over.

I: Okay. What are your expectations for intimacy and sexual expression when you think of the potential of being a resident in a long term care [participant interrupts].

P: [indecipherable] I don't [indecipherable] but that.

I: What is it that makes you have that belief?

P: [indecipherable] you're probably getting in pretty bad health. Bad health is one of the things that cause that to go away is what I always understood.

I: What do you know of anything about, is there anything you feel would be important for me to know or that you would like to share that would be important for me to know as part of our research [indecipherable] sexual expression?

P: Men are men and women are women, you know. Men like it more than women, my experience. But, women are more [indecipherable].

I: Okay. All right.

\section{Andrew}

Interviewer: On your timeline, you indicated that you had sex for the first time at age 17 with a girlfriend and you were very much in love. How old were you when you married? Participant: 21 .

I: What was your understanding of intimacy at that time?

P: Hugging, kissing. Basically that was all it was.

I: What did intimacy mean to you? How did you understand it as far as its meaning? 
P: I think it came down to two people being in love. You really couldn't be intimate with anybody other than someone you loved.

I: Where, or from whom, did you obtain that understanding?

P: Probably church.

I: Was it just the church's teachings or people in church?

P: I believe it was the church's teachings. I was raised Catholic so that's not a very, how do I want to say it, you know shaking hands is about all that goes on at any church, Catholic church, I was ever involved with.

I: Okay. What meanings of intimacy did you share with your partners?

P: What means?

I: What meanings.

P: Kissing, holding, telling them you love them. I don't know what else to say.

I: In what ways did your meaning and understanding of intimacy differ from your partners, if at all?

P: I think it was kind of, she was looking for commitment. I don't do this unless it's somebody I'm committed to and being a young boy, I was more or less interested in sex and to me that was intimacy.

I: Okay. What was your understanding of sexual expression at that time?

P: At that time, it was probably just getting what I wanted. Not so much, I figured that if I was happy with sex then my partner should be happy with sex. 
I: Okay. Where, or from whom, did you obtain your understanding of sexual expression?

P: Well, I didn't have a very good role model from my father. He was a truck driver and he didn't, he never really showed my mom any kind of affection or anything unless you knew he wanted something. It was more yelling and screaming than anything. So there really wasn't much intimacy around my house between my parents. He kept a lot of pornography in there in his room and when he was gone we would look at it and things, so we really didn't have a good example. Myself and my brothers.

I: What meanings and understandings of sexual expression did you share with your partners and where did you may have differed?

P: I believe it's, I looked for sex all the time. It was kind of a reward for doing something nice for your partner. My partner believed, or my wife because the girl I was with first was my wife who I was faithful to until I was in my middle to late 30s. I don't remember exactly what I put down. Her understanding was different than mine because of different raising. She was an only child and grew up very faithful in the church and I grew up from a more or less broken home, fighting and screaming all the time. Sex was just something you snuck around and did. There really wasn't much sexual intimacy at really any age until I was probably in my older years.

I: Okay. Going into early adulthood, at age 35, you indicated on your timeline that it was the first time you were unfaithful to your wife. At age 38, you indicated that you had numerous sexual partners, maybe 10 , and that you had given up on your marriage. With 
regard to intimacy, in what ways did these experiences impact your understanding of intimacy?

P: Well, I kind of gave up on thinking love and intimacy was something I was ever going to find. I wasn't looking for it at that time, I should say. Because I tried so hard for years and years. I used to tell my wife, I would say, "I want you and only you and what can I do to make you want me so we can be happy? I would love for you and I to be able to sit down, talk about things and be just each other's soul mate and be very close." But she told me that the only way she knew to get even with me was through sex. To keep it from me. That kind of hurt me very deeply and caused me to have a different opinion to women because even though I didn't share that with other people, you could tell that was kind of a common theme among a lot of my friends. It felt like sex was something their wives or girlfriends, usually wives, used against them. I didn't want to go out on my wife and become involved with an affair with any other woman. I just kept praying that things would get better at home and they just seemed to get worse instead of better.

I: Considering those same experiences, in what ways did it impact your understanding and expectations of sexual expression?

P: Well, everybody I think wants to be pleased and everybody wants to have a good sex life. It was just different when I got into my 30 s, late 30 s, that instead of hearing how bad a guy I was, it was what a good guy I was and how any woman would be glad to have me and that caused me to stray from my marriage and go out with women that was really trying to please me and love me for who I was. It wasn't, there was no reward for doing 
this or that. They wanted to do what I wanted to do, as much as them. I've never been any kind of pervert or nothing like that. All I wanted was just to be able to hold and kiss and love a woman.

I: On your timeline, from the time you turned 40 until age 49 , you had had several partners. At age 42, you indicated that you got a girl pregnant, divorced your wife, and just wanted to have fun. At age 50, you indicated you had a light stroke and that sex became unimportant. How have those experiences affected your understanding of intimacy and your expectations for sexual expression?

P: Well, I went through a time of depression after I had my stroke. I think that was the main thing. You go to thinking of where you're going to live forever to where you realize your mortality. I pictured myself as having another stroke any time and another and another and they told me that could very well happen with my blood pressure as high as it was. So, I started looking at cleaning up my life and straightening up things in my life. I was divorced at the time. For a while, until they got my medicines regulated, I didn't care a whole lot about sex. After I got my medicine straightened up and everything then I started to want sex again and be sexually active. After I turned, probably my late 40s, when I met the woman I'm married to now, I've been faithful to her ever since. Probably for several reasons. I'm older and uglier and don't feel like I'm very attractive anymore. I just feel it's the right thing to do also. That's what God would have me to do.

I: What meanings of intimacy did you share with your partners in that time? 
P: It was probably, basically, I feel like I never went around bars or got out and run around with a bunch of buddies drinking and things like that. I kind of felt like I was the guy in the bar that was always trying to figure out what to say to a woman to be able to get her alone to have a good time with her. There was one or two women, the woman that I got pregnant. I thought that that's what she wanted. I didn't think she wanted to get pregnant but I thought that she was in a very unhappy marriage and she told me that her husband had beat her and this and that, which later I found out to be false. He loved her very much and she was, he'd had a vasectomy and she was wanting another child. Her plans were to get pregnant and tell him that his vasectomy must have not worked or something. She ended up, when she found out she was pregnant, she pretty much told me that she didn't want anything to do with me anymore. So, it was really tough on me for a day or a few days but then I've always been one that if somebody doesn't want you, or rejects you, to just turn the other way and go. Move on. That's what I did and I haven't talked to her since.

I: What was your understanding of sexual expression during that period?

P: I think at that time, like I say I wasn't one of these in all kinds of sex things. I just wanted a woman that I could be intimate with even though really, I wanted to please her and I wanted her to please me. That was basically what went on. It was a kind of mutual understanding of, I'll be good to you and you'll be good to me. After I got to thinking, when I wrote that timeline down, I would have to probably cut that down to about 6 or 7 is what I would have to put it down. It wasn't 10. I kind of hurried and filled that out. 
Even that's, maybe that's less, maybe that's more than other men. For a few years I was wild during that time and that was the extent of it during that time until I met the woman that I'm with now.

I: On your timeline, you didn't indicate any age or information for the future period past age 60. As you consider your future, what concerns do you have about your intimacy and sexual expression needs?

P: Well, I feel like I'm going to put that in God's hands. My wife has some female problems to where it's very hard for her to have sex and she has no sex drive whatsoever. I love her. I'm afraid at times that I might be tempted but we've not had any kind of sexual contact probably in over 10 years. It's very frustrating to me but I would hope there's sex in the future. I'll leave that up to God.

I: A little bit further as you look into the future, what do you anticipate your intimacy and sexual expression needs and expectations will be?

P: Well, I feel like my needs and expectations are the same. I sure want to have sex. My wife is a pretty lady and I don't know what to do. I feel like I'm not in the same boat because there was nothing physically wrong with my first wife. This wife, there is something wrong so I don't want to feel like, I feel like I would be very selfish to only want what I want. I think if I only think of myself then I'm not being fair to the marriage. I: In what ways, if any, do you expect your definition of intimacy or sexual expression changing in the future?

P: Read that again. 
I: In what ways, if any, do you expect your definition of intimacy or sexual expression to change in the future?

P: Well, health wise I'm not the guy I used to be but that doesn't mean I still don't want to, really it's been, it's not too long after my stroke. Possibly, I think that could be part of her problem is that she thinks sex would be hard on me. I do get winded very easy and where I could use to be able to perform for a long time, I don't know about now. I don't want to endanger myself. I know health wise it will be different if something would happen where I would start having sex. I think that's very common in guys over 60 . I: One last question for you. What are your expectations for intimacy and sexual expression when you think about potentially being a resident in long term care?

P: I would say it's zero. When you say "long term care" I'm assuming a nursing home or assisted living place. Even though I worked in a nursing home at one time and there was a guy in his 80 s that they had to watch like a hawk because he would sneak the girls in his room and they caught him at the time having sex with more than 3 or 4 women. My hats off to him. Even though I don't think I would ever try something like that because I'm very modest in things like that. I don't think I could even attempt something like that in a nursing home or care facility.

I: Okay. Thank you. Now, would you believe that, when was that when you worked in the nursing home?

P: Probably in the middle 70s.

I: Well, it wasn't wrong then. It just hadn't had some legal protections. In 95 there was the Resident's Rights Act for seniors. It's your right. It's your home. That's where you 
live. To privacy to have relationships with other people to whatever level that would be. The problem is the facilities don't do what they're supposed to do. Privacy in one of those places is, you're supposed to knock and wait for, "Come in." They don't wait. They just knock as the door is opening. If they knock. One of the big problems that is going on is a lot of males specifically because of that practice, they walk in and there's a male who's pleasuring themselves. Now suddenly he's acting out and needs to go. That's not what's happening. Their privacy is being violated. The only time they have that issue is with a stage of dementia or Alzheimer's. That's really not them acting out as much as they don't even really know where they are or what they're doing. P: I talked to a lady that worked at Muscatatuck one time, she worked with a rough bunch. She was in the very worst bunch. It was as long as nobody was hurting each other, they could do whatever they wanted to in front of whoever they wanted to. She always said I don't care what's missing up here, they know what that's for down there. I: You're right. Unfortunately, nursing homes are scared to death. There's different levels. There's liability concerns around capacity, which we understand that. The ability to make yes or no decisions. One of the things we've talked about is a way to deal with that or like advanced directives we have for our healthcare. If you are going into that facility, you have advanced, you're starting into dementia or some form of dementia, an advanced directive basically is if I'm smiling leave me alone, if I'm frowning there might be something [?]. That's not happening yet. The other piece is staff there. They want to impose their own views, moral views, whether people are married or single. Whether 
they should be doing this or not. The sad thing is, you know when couples are in the same facility?

P: I was there with husbands and wives and they couldn't hold hands.

I: They try to keep them apart even. By law, if they're a couple in there and they have a double room together, they are supposed to let them be together. Even if they're Medicaid. If they have the space and a room becomes available, they are to put them together. They won't because they're afraid that something might happen. By law, if their family knows this, see that's the thing. People don't know. Then they can require them to do it. There's a case in, one of many, but this stuck out, in Kentucky. Where a man's wife has had dementia and she was in the nursing home. He couldn't take care of her by himself at home. He put her in there. She would cry for him every night. He would see her every day and they'd make him leave. He couldn't stand it. Finally, he said, "Look, I'm paying for it. I'm going to move in here with her and stay with her." They told him no, he couldn't that. He said yes I can. He went to the states Ombudsman's office in the state of Kentucky and he said, "Yes, you will." They made them, they allowed them to put a double bed in and he stayed there. He lived there. He paid his own way for everything. They tried to tell him he couldn't do that and didn't want him to do that.

P: I think they want to create, I don't care how healthy they are, some people are in a nursing home simply because nobody wants them.

I: I know. 
P: They can drive. They can do anything they want to but yet when they go in them doors, they babysit them like little 5-year-olds. You can't do anything without asking. I: There's a Jewish nursing home in New York that is kind of leading the way. They have created spaces that can be used for anything. You book it. There's televisions, there's couches, there's chairs, there's tables. You can play cards, you can sit on the couch, you can watch TV. There's a bed too. So whatever you book it for is between you and whoever you're with. Nobody knows. It's just locked down so that's taken care of. So there is some movement, but as a program overall there's a lot of people that are just, there's just no way to make sure people have their rights protected because they don't know. What I'm hoping to do is this information will lead to some policy changes where even though we have resident rights, it gets cleared. Specified that you can't do this anymore. For the long term care providers. There's 78 million Boomers coming into that system at some point and they didn't take too well to a lot of the stuff in the 60s, being told no. I don't think they'll take too well [Participant begins speaking over interviewer].

P: I believe they'll try $100 \%$ because you know when I was in my 20 s, I pictured in your 30s sex wasn't very important and in your 40s it was just almost unheard of and in your 50s, well you're just too old to do anything.

I: But it's not true, is it?

P: No.

I: People are active well into their 90 s sometimes. 
P: I look at girls now and I still have the same thoughts I had. What I'm looking at now is the same young beautiful girl but what they're looking at is not a thoroughbred anymore but an old nag. Something ready for the glue factory. It's surprising to me that girls my age, that I thought was beautiful then, I think are beautiful now.

I: I know. Isn't that interesting?

P: It is interesting.

I: Some even are actually prettier than they were.

P: And you don't just look at physical things.

I: No.

P: Where as a kid that's what you think of.

I: Well, I really appreciate you doing this. It will help me a lot. I've still got to get some more men. I've only gotten four so far. I think two got conscripted by their wives for me on Friday because the wives are going to do it but they're affiliated with the university and they're going to make their husbands. Yes! I'm so glad! I need the help.

P: You know XXXX and I went through, it was a Christian counseling. There was a place down there if you know where the Goodwill store is off Lewis and Clark.

I: Yes.

P: If you went the back way behind the Sportsdrome on the right. We went there for a while and then we went somewhere else for a while. XXXX would say, "Well, I don't understand this. He's the one that's been going out on me and you guys are making me think I'm the bad guy here." And all I was saying was why I felt like I felt. Then it was, 
“Well, why XXXX do you think he feels like that?" "Well, I don't know! He's wrong!" You know? It was, she wouldn't accept any responsibility.

I: Using sex as a weapon is not a good idea. It doesn't work well. Well, I do really appreciate it. I know you're tired.

\section{Margaret}

Interviewer: Okay. You had a very interesting timeline. It was fascinating to read through and to formulate my current questions. My first question, some of my questions are going to be long, so if you need me to repeat it just let me know. The first one is really long, starting right off the bat. On your timeline, you indicate that from age 2 to 12 you were raped, sexually abused by your father. Raped twice when you were age 15 . At age 16 , you indicated that you had had a sexual relationship with a boy you liked and from age 16 to 20 that you had had many sexual partners, most acquaintances and some friends, and that you had also met your future husband at age 18 during that time. What was your understanding of intimacy during this phase of your life?

Participant: Intimacy was how I expressed that I loved somebody and that's because having been molested by my dad for so long and at such a young age, that's just how I equated love.

I: And how would you express that intimacy and how would you expect it to be expressed back?

P: Well, I would, I was very sexually active from 15 or 16 until I got married. To me, having sex, one thing that I just never really enjoyed were blowjobs and that's because that's what my dad did to me. So that's just, I mean, I would try but it was just not fun. 
Then, I would think that the guys that I was sexually active with really liked me and that they were showing love to me but I really didn't know, I mean it wasn't the romantic kind of love. It was just love.

I: I'm not sure, you might have answered this somewhat. What did intimacy mean to you?

P: Intimacy. So you're differentiating between sexual and intimacy. I didn't know what intimacy was.

I: Okay. Where did you get your information, well we'll go on to that later on. This question may be sensitive, if you don't want to answer it then don't answer it.

P: That's fine.

I: How did your experience of being a victim of sexual molestation and rape impact your understanding of intimacy?

P: The guy that raped me, I really didn't realize that he had raped me until years later when I sort of started working on the molestation from my dad and then it was like, 'Oh." I mean, I didn't say no but I had no idea what was going on when this guy raped me. I had no clue. I guess it was until, until I guess when I was in my, I can't remember all the exact ages that I put on my timeline because they were sort of approximations but when I met the woman who I had my first bisexual encounter with, that is when I learned what intimacy was. I know that's sort of going where you don't want to go but...

I: We'll get to that phase of your life a little bit later, but I'm really curious if you have any idea about this time as a child? 
P: I don't think I really knew what intimacy was. I mean, I don't think I knew what intimacy was. My parents were very distant. My dad was very overpowering and dictatorial in the house. I guess the easiest way to explain that is, I was raised as a Victorian child rather than a child of the 50 s or 60 s. I mean, his viewpoint on childrearing was Victorian. He was the head of the household and what he said went. I went to my mom, I would see them kiss on the cheek but never, never have a real intimate kiss. I never really saw intimacy of my parents so I don't know that I knew, really knew what intimacy was.

I: How did the change [at all?] when you got married? You were married for that time period.

P: I don't think I really thought anything different. I mean, that's just how it was supposed to be. I believe I was intimate with my husband but I don't think I had *** the difference between sex and intimacy.

I: So, at that point they were still sort of meshed together?

P: Yes.

I: Okay. Thinking about that particular time, that relationship when you were married, what meanings and understandings of sexual expression and intimacy did you share with your partner?

P: I shared just about every type of sexual activity at some point. I mean, I would attempt to give him blowjobs but that, as I said, that just did not and to this day I'm finding more pleasure now than I ever have but at that point in time it was more of he really wanted me to do it so I would give him a blowjob. He would perform cunnilingus 
on me, which I really enjoyed. We had anal sex which was 'eh,' but not my favorite. We didn't, we sort of, we would try different positions and different things like that but it was mainly missionary position. I hate the word 'normal,' but normal sex.

I: Okay. Were there any other expressions of intimacy that you shared together?

P: Well, yes, we would cuddle and hold hands. You know, just kiss and make out and things like that.

I: Okay. In what ways did your meaning and understanding of intimacy and/or sexual expression differ from your partner? Were there any differences and what were they?

P: I don't know because we never talked about it.

I: Okay. Moving into early adulthood, at age 20. At age 20, you indicated on your timeline that your sexual activities lessened at age 21. Married the man you met at age 18 and $* * *$ as seen from your timeline that your marital relationship was monogamous from age 21 until you were age 27, where you indicated that you had a sexual relationship with a stranger then ended your marital relationship by divorce at age 33 . At age 37 into middle adulthood you indicated that you became celibate and your only sexual expression was masturbation with the aid of pornography. What was your understanding of intimacy during that time?

P: I had intimacy with my children in loving them and caring for them and nurturing them. I don't know that I really thought of it at that point as intimacy but that's, reflecting back that is very intimate and I really threw myself $100 \%$ into being a mom. Being a single mom, it was difficult although I was lucky enough where I didn't have to 
work. So, I was able to spend lots of time with my kids, focus on them and it was during this time that the abuse came up that I was working very hard on getting myself straightened out because I knew, my ex-husband was an alcoholic just like both of my parents were so again I didn't see that until, you know, the light bulb went off and he'd go down to the little store and get a quart of milk and a six pack of beer instead of a gallon of milk for the kids. It's like, something's not right here. I had a huge spiritual awakening at that same time. I just spent all of my energy either on working on me or nurturing and caring for my children.

I: Considering those experiences you just shared, in what ways did any of them impact your understanding $* * * *$ into your childhood and adolescence?

P: I don't know that I, I would not have said that I was being intimate with my children because to me, intimacy was sex and I would never be sexual with my children.

I: On your timeline from age 37 to 46 you indicated that you were celibate. How did that experience itself affect your understanding of intimacy and expectations of sexual expression?

P: I think it was, for me being celibate was just a way not to have extra things in my life. People distract me from what I was doing. I mean, I knew that I could not have a healthy sexual intimate relationship until I got myself to a point where I had gone through all of this funky, yucky, nasty garbage that I had been carrying around for so long.

I: [Indecipherable] Sorry, you're, don't be sorry. You're doing great. At age 47, you indicated that your friends, you had a friends with benefits relationship. What do you mean by the phrase 'friends with benefits?' 
P: Friends where, I had sex with them.

I: In what ways did this relationship meet your intimacy needs?

P: That relationship was very intimate. I never really had had a relationship quite like that relationship. I never really, I mean, when I was in high school and all that, I never really dated. We would go out as a group but I never really went out on a date with anyone. This person really wooed [?] me and took me out on dates. We'd go out to lunch together and I would pick up the tab. That was very different for me. That was like because we'd always gone Dutch, you know everybody had gone Dutch. We would just sort of stare into each other's eyes and I had never had as much feeling and intimacy from another person as I did with this person.

I: So that's, with, in paying the tab for your lunch or staring into each other's eyes, were there other things about the relationship that were [indecipherable]?

P: Well, yes. We would cuddle. Just sit and listen to music together with our arms around each other. We would hold hands. We did a lot, a lot of things that I never really thought of as being intimate.

I: So, was it in this relationship that you identified or discovered intimacy needs that you weren't really aware of or maybe hadn't been able to label?

P: Yes.

I: What ways did that relationship, in that relationship did it not meet your needs? Your intimacy needs. 
P: Well, this was a relationship that I knew would not be a long term relationship. I knew that I would enjoy it while it lasted. There wasn't that expectation that this would be a long term relationship. That this would be somebody that I would grow old with.

I: On your timeline again, from age 53 to age 59 you were in a relationship with a boyfriend and were very sexually active but before the relationship ended that you as a couple added another woman to the relationship for about 5 months before the end of that relationship. How would you define your intimacy, define intimacy and your expectations and sexual expression during that relationship?

P: My expectations of intimacy were very high. I really thought that that relationship was going to be my 'until I die' partner. We fit together very well even though he was like 18 years younger than I am. He's very wise for his age. He is the one that when I started exploring the BDSM side of me, helped me along. For the longest time, I never thought I would meet him because he lived in Indiana and I lived in North Carolina at the time. I thought we might meet but you know, we would not be in a relationship because of the distance.

Once I got up here it was like, 'Woah.' The sexual side was just incredible. It was very respectful of what I wanted to do and what I didn't want to do. He was very cuddly. I, we would touch a lot. We would hug a lot. Hugging was huge to me with intimacy. I'm a big hugger. He showed me a lot of different parts of myself in sexual terms and how it was to be treated like a lady. 
When we brought the other woman in, and this was something, he has known most of his life that he is not a monogamous person. I know that I have the ability to love more than one person. I've never really been in a sexual relationship with more than one person but I know I can love more than one. The fact that he would have other sexual partners, provided the ground rules, you will use a condom. Period. End of sentence. You know, you will practice safe sex and all of this. I didn't have a problem with him having other sexual relationships. When we brought this woman in, we did not do all of the work that we needed to do before we brought her in.

He and I have talked about this and because of the nature of power dynamics, he is the one that should have the preparations done. I had never been in a polyamorous relationship in this way. He had and he knew, he had had some that failed miserably because they didn't set ground rules and all of this. We all sort of got caught up in the new relationship and just didn't do that ground work. It, the relationship failed between he and I because she was so extremely needy that she needed to have him by her side all the time. It got to the point where his and my sex and intimacy went down to nothing. When I asked him to leave, he was basically and we were all living in the same house and I finally got to the point it's like, she's got to move. I cannot have her in our house. I don't want her here. Get her out. At that point, her and my relationship was over. Because of how he was treating me and favoring her, I started to act out and I started to get very angry and I would scream and I would yell and this is just not me at all. His way of to correct it was to just not have anything to do with me which just made me act out more. I just, I could not live like that and I deserved better than that. I told him that is 
why I want you to leave. I was trying to talk to him about what we could do to fix things and he started on this well, I just can't forget everything that's happened and that's not what I was asking. That's what he keeps coming back to, 'I just can't forget all of this.' Quite honestly, none of us were happy at this point and he moved in with her because he had no other place to go.

I: So, it started out meeting your intimacy needs in the beginning but then it didn't at all towards the end?

P: No. It was probably the last two months that it really got bad. Maybe, it would have been two months. She had been coming down to spend weekends and stuff with us almost for a year. It wasn't that we just *** I mean, we had. She and I would sit, she'd come down and spend a week at a time at some point and we'd sit and talk and pour our souls out to each other. I really, I liked her but the more I learned about her the more needy I saw her as being. I mean, I made mistakes. The one thing he had always said to me was that no matter who comes into our life, our bed is my bed and I will always come back to our bed. She said that, 'Well, I need to sleep with him all night." Well, you can do that every once in a while that's fine. Well, then it got to be she was working days and he was working nights and the only time that they could see each other was on the weekends. I didn't see a whole lot of him on the weekdays either because, it, then she became real clingy. I'm not really answering your question.

I: You did, you are answering the question. Sure, you were. When you think about that relationship experience, in what ways did it impact your understanding of intimacy? 
P: It made me crawl back into my shell. I don't, it's still really raw and still fairly new but I don't know that I could have another, I don't know that I will have another relationship. An intimate relationship that I'm looking for to be long term. It has hurt me that much. Yes, I will have sexual relationships that's not a problem but the intimate side, I don't know.

I: *** present age, you indicated on your timeline you are not opposed to *****. I'm sorry. When you think about this time of your life and these thoughts around your life defined, what is your definition of intimacy or what are your expectations of sexual expression at the present?

P: My definition of sexual expression would just purely be having sexual encounters. I would hope that I can get through this. A big part of it is, I trusted *** [name of the guy?] with my life. He broke that trust and trust is a big thing for me. I do not trust very easily. It took me 50 some years to get up, well not 50 , yeah 50 some years to get to the point where I could trust enough and move 3 or 4 states away to live with somebody in a house with somebody you really think of this being my the rest of my life partner. For me right now intimacy, I don't have a whole lot of intimacy in my life. I have friends and we give each other hugs and kisses when we greet but it's and that meets some of my intimacy needs but it doesn't meet the way I would like for them to be met. I don't know, I really don't know how to go back to get that back in my life. I'm going to have to meet somebody that... 
I: That you're able to develop that kind of a trust with to be able to be that vulnerable with. What, as you think about the future, what concerns might you have to your intimacy expectations or sexual expression especially when you think about that? P: Long term care beliefs are not really, they're not real comfortable with sexual expression amongst the senior, or amongst anybody that's in a long term care but especially seniors because seniors aren't supposed to be sexual beings. That's just sort of the prevalent mindset. I think it's a bunch of crap. Yes, I'm concerned that if I end up in a long term residential facility that I will be, it will be much harder to have a sexual relationship. The intimacy part, I don't know that that is going to be as difficult because in my head it's like, 'Oh, look at those two! They're so cute!' You know when they're holding hands with the cane in one hand and the holding your sweeties hand or sitting on the sofa together or hugging. I don't see that I would miss the cuddling. That for me is a pretty integral part of a sexual relationship is cuddling in bed. I am concerned about that. They will probably have to pry the vibrator out of my hand but they can try to take it away from me. I will beat them over the head with it.

I: What are the things that *** addressed?

P: I think that long term residential facilities need to allow their residents to have freedom to have sexual encounters, to have intimate encounters. When you first asked that, I'm going back to I was doing social work with adolescents and it was like, 'oh my gosh.' They go into [indecipherable, laughing while talking]. That's not the, I mean, you know but that sort of [indecipherable]. 
I: It kind of happens.

P: Yes.

I: In facilities.

P: But, now the facilities I have seen have been mixed sex. I don't have a whole lot of experience with the nursing home with all the nursing care. I am more familiar with more of the assisted living. It shouldn't be single sex. Life is not a single sex.

I: Okay.

P: You didn't have co-ed nursing homes and floors and all of that.

P: Well, number 1 they need to acknowledge that it's a fact of life. That seniors are sexual beings and are sexually active. You're thinking of college dorms where you tie the hanky on the doorknob or whatever. But, I mean there should be some way to signal that you do not want to be disturbed and it doesn't have to be because you're having sex. It could just be because you want to spend some intimate time with somebody.

I: Those are all of my specific questions. I wanted to ask what, if anything, are thoughts that you have that you feel important for me to know? *** expectations of *** as we look into the future.

P: Start fighting for it.

\section{I: Okay.}

P: I mean it's, it never was anything that I had thought that much about until, well I had thought about it but it wasn't a burning desire or anything until this relationship fell through. I just expected to be at home with him and you know, he was going to take care 
of me when I got to old and feeble to take care of me. We would just always be together. Now, it's a reality. I may end up having to go into some kind of a residential facility. I: This is just a question that kind of came up based upon what you said. That you were in another relationship at some point perhaps your health got to a place where you could not stay at home but you were still in that relationship, what accommodations do you feel should be made available to you or your partner who may not be a resident for you two to be able to meet your intimacy and sexual needs?

P: I think they should they should do the same for two residents. I mean, we need to be able to have that part of your life. I mean, you may be old, you may not be able to stay at home but if you want to have sex you ought to be able to have sex. There are many different ways of having sex as well. It doesn't have to be the traditional man and woman missionary position. There are lots of different positions, there's lots of different ways to have sex.

I: Thank you very much. I appreciate your time. I appreciate your willingness to participate.

\section{Lisa}

Interviewer: Feel free to say anything you want to say. I'm not going to ask you specific things at all but if you want to share something that's up to you because I want you to be comfortable. Some people [participant speaks over interviewer].

Participant: So the goal of this story is what?

I: I'm hoping, the goal is, I'm trying to affect policy in long-term care. Residents are strongly discouraged and told oftentimes prohibited from any kind of sexual interaction 
or intimacy. Even married couples. I mean, it's their right as residents but there's no privacy. There's supposed to be privacy. Knocking on the door and getting a "Come in," before you're knocking and just walk through the door. Then there's a real problem with predominantly males because of the privacy issue, they're walked in on and then they are told they are acting out and then they are put out. So there's issues that's been happening so that's kind of the overall purpose but I mostly wanted to look and see about intimacy and sexual expression and how it changes, if it changes, over time. Past, present, and future.

P: Okay.

I: Any other questions?

P: No.

I: At age 11, you indicated that you had your first crush. At age 14, you indicated that you had your first boyfriend. At age 16, you had your first kiss where you then dated from that age until you were married at age 19. Okay. What was your understanding of intimacy during this phase of your life?

P: What did intimacy mean?

I: Yes.

P: Okay, well. I grew up Roman Catholic. Big family. Very clear pre-Vatican[?] to black and white, no sex before marriage. Intimacy. Gosh, it's hard for me to imagine what it meant at 11, but it's different from sex. If that's what you mean. So, closeness, friendship. I had a very clear differentiation between boys who were friends and boyfriends. You know, that. I don't know what else to say about that. Intimacy, 
closeness, getting to know each other, caring about each other, being physically close, sitting next to each other in the car, holding hands, making out, that kind of stuff.

I: Okay. How did your experiences of dating and ultimately being married in that phase of your life affect your understanding of intimacy?

P: Well, the boy I met at 14 is the one I married at 19. So, we were boyfriend and girlfriend as freshman. We didn't go out, we weren't allowed to date yet. I wasn't. He was a year older than me but lived on the other side of town. We didn't have cars. We talked on the phone a lot. I got bored with him. I got rid of him. I dated a few guys the next two years and then I think, after my sophomore year, I went to visit some out of town relatives and sent him a postcard from Canada or someplace and he called me and we started dating again in junior year. We went to proms and stuff like that together. But, again we didn't see each other very often because we didn't have vehicles and we didn't have any way to get together really. He got a vehicle by the time I was a senior, so he would come to my house frequently. He was in college then and I was a senior and all that.

Then I moved, my parents moved to Lexington when I was a senior and I lived with a woman in our community that we knew. We continued to date. When I was a freshman in college, I moved home. That was kind of weird. It was kind of backward. We actually broke up from that summer before I went to college and I broke up with him again. He had already dropped out of college and that didn't seem like a good fit for me. However, when I went to college I didn't really date anybody. The guys that I was in school with, I was a music ed major, they were weird. I didn't like anybody so I didn't 
date anybody. Then, I ended up dating him again. He contacted me again and we got married by the time I was a sophomore. I quit college and got married. We were married 10 years and then I was done. I was done several times. Do you hear that theme? At that point, I was really done. After that, I can't, I never was very good at the dating ritual. The game, the dance, the whatever. I've always been kind of like what you see is what you get. That doesn't attract very many guys. Not heterosexual guys that I've noticed. So, I dated a couple guys but it wasn't anything serious.

I: How did you identify intimacy in yourself and your partners, dating or when you were married?

P: Well, I think closeness as in honesty, as in physical intimacy, physical/sexual intimacy, sexual expression, but a lot of it would be just closeness as in honesty, kindness, acceptance, those kind of things that were lacking in the marriage. Also, despite common beliefs, it was my husband who held out on me. He didn't like me, honestly. He would, he didn't have any interest in sex with me. I wondered if he was gay. I wondered if he was having an affair. I didn't know what was going on but he just didn't like me and he would publicly humiliate. It would start with this verbal abuse kind of stuff and threats and I decided that I'm done with that. I don't need to be hit before I figure out that this is not a good idea. I had many times, memories of laying in bed talking and he wanted to go to sleep and I was trying to have a conversation and he would put his fist in my face. I don't need this shit, you know? So, anyway I recognized what I didn't have and what I did have was growing abuse. 
I: What understandings or meanings did you share with the partner? That you had in common. Those things that you described?

P: Initially.

I: Okay.

P: You know, there was a lot of presents and affirmation and also, in retrospect, I think because we were young there was a lot of dynamics about the roles in the family. I was the oldest child. He was the oldest child. I was a music performer. He liked to watch. I liked to perform. That's not conducive to personal intimacy over time. That kind of somebody watching and somebody doing. That pattern kind of went into our marriage. It's like I was the activist and he was happy to just sit and watch TV or whatever. I wanted a life and he thought that was a problem. So, the dynamics of what make intimacy was problematic in that relationship.

I: Okay.

P: Unfortunately, we didn't have a child but we adopted a child. By the time she was 3, I realized I had two children and I was done with that. He stayed engaged peripherally, which is enough to kind of stir the pot over time.

I: Now, what was your understanding of sexual expression during this phase? From age birth to 19 .

P: Well, I was a very curious child. I was a very talkative child. I was very close to my mother. I would ask her all kinds of things. I pretty much knew the birds and the bees by the time I was about 8 or 9-years-old just because I asked and she would talk to me about things. My perspective was her perspective. That was things like once you're married 
anything goes, so to speak. In reality, when I got older that's not really what she meant. Anything goes according to what they do but whatever. My perspective was once you're married then you can do whatever the couple decides to do. So that could be intercourse, oral sex, nothing. Whatever the couple's comfortable with and I came deeply wedded to the idea that the couple has to define their sexual relationship and their intimacy relationship and when it is out of sync that is when problems begin. I think I've taken that, and this is long before I was trained as a social worker or an MFT or anything, into my therapeutic life as talking with couples that the correct answer is what you define.

I: What meanings and understandings about sexual expression did you share with your partner and how did they maybe have differed as well?

P: Well, sometimes we would just do things as young people. We weren't real articulate about what we were going to do. We weren't real talkative. But I also, I would be able to say if I was comfortable or uncomfortable and sometimes he wanted to do things that I was not comfortable with. So in that relationship, in my first marriage, I was much stronger as far as personality and assertiveness of what I wanted or didn't want than he was. He would say things sometimes that he would think would be arousing or fun and I wasn't into that. So, sometimes we would differ in that way.

I: Okay. Moving into early adulthood, 20 to 40 . On your timeline, at approximately age 27 , you indicated that you experienced your second crush and that it was not sexual. Then you indicated that around age 31, your first marriage ended in divorce. P: 30 . 
I: 30 , okay. That you then dated 3 or 4 individuals with having 3 sexual partners until you married at age 36. During this phase of your life, what was your understanding of intimacy?

P: Well, I think starting at age 26 or 27 when I met this guy that I had this big crush on, I was just needy. My husband was very standoffish. I don't know if he was depressed or just mean. I was very, very lonely and very, very needy and my crush had to do with this guy that I found fascinating that was energetic and smart and educated and I was like, hanging on to life. There was no relationship really. We sang in a chorus group together and made eyes at each other. Somehow I think, honestly more, at that point it was more fantasy than anything because it was something that kept from my doldrum life. I had this very deep-rooted Catholic belief that I should stay in the same marriage my whole life. I remember during this period of around '77, the Pope came to the United States and was on TV and talked about marriage being forever. I sat on the floor in front of the TV and just wept. Finally, I got to the point where I thought, "Screw this." All these people and all these priests and popes and I don't care what they say. It's my life by God and I'm getting out of this mess and I did. That was a really good thing for me. It was like I claimed my adulthood. I claimed the fact that people have a right to a healthy life, a healthy intimacy life, sex and all that.

I don't think I went crazy. Well, a little bit in that the first sexual encounter I had was very needy and very, he was married and that was like way out of my purview of supposedly moral values. Then, I kind of got through that with myself that this is not who I am. So I think some of that was trying things. In fact, I remember a term in 
psychology, something about foreclosure. Where you sort of shut down your own health and development and just adhere to your parents' way of being and I think I had done that about 14 . So, somewhere along in 30 , I start to, after my divorce started to kind of define who I was and who I wasn't. So, the intimacy had a lot to do with who I was with myself before I could be with another partner and I was really wedded to the idea that, I did a lot of reading and therapy and this kind of stuff during that time, that I wanted to be okay with myself before I went out and mated with somebody else and made another mistake. I was very selective about dating and going out with people. I had friends. I had a lot of friends. I got involved in divorce ministry and I met a lot of nice people. Women and men. I dated a little bit but it wasn't right.

The second guy I had a sexual encounter with was actually somebody I met at a conference while I was working in banking at the time. It was in the early ' 80 s and they were in the process of converting everything from paper to computer and I did that conversion. I ended up going to conferences about the online blah, blah, blah. I met people and just hooked up with this guy who I really liked and he was very nice and he was very cute and he was separated and I was divorced. We hooked up a couple times but he was also an alcoholic, very clearly. I also think I got something from him. Some sexually transmitted something. They told me I had herpes and I don't know that I actually do because I never had another recurrence and this was like ' 82 maybe. I called him and said, "What did you do?" He's like, "Why would you say that?" He's running off to the doctor and all that. That was my first experience with that fun stuff. Those things were way out of my purview as a young, innocent, Catholic guarded... Anyway, I 
realized after about the third conference that I went to that he's drinking those yards of beer starting at 10 am and I don't think so. I really kind of hung on to this crush on this guy with the chorus for quite a while and then it was in another city, I wasn't in

Louisville at the time and I just hung on to that. I think just to give myself some fantasy support. There wasn't any real relationship.

I: That's interesting that I wanted to ask you about the fantasy part of that. What was it that you fantasized about that person as far as [participant speaks over interviewer]. P: Well, there's something about his presence. His spirit, just I felt real connected. I don't know, like a soul mate kind of thing. Everything I saw of him, everything I heard from him. One time I went to a daylong retreat where we practiced all day for some choral and we were at the same table and in the same group and I was just very, very attracted to his style of talking and conversation and what he said and everything about him just clicked. I think, at that point, it was less about him and more about me but I felt hopeful that there was somebody out there that I would be able to relate to on an intimate, personal level that would respect me equally. That wouldn't be this like, ${ }^{* * *}$ down thing that is a real, from my perspective and I hear this constantly in therapy from women, it's like this is the curse of heterosexual men. They think they have to dominate and be in charge of and the women's movement kind of left them out. Part of my divorce might have been about the women's movement because I got married in '69 and divorced in '80. The women's movement happened in the '70s and I was ready for it. In fact, I think I was despite the conservative sexual stuff about marriage and so on, I felt like our family was rather liberated. We were a big family but we all learned to do everything. None of 
us were told women should be in the kitchen and men should be on the job. It just wasn't part of the way we were raised. My mother was a strong figure. My father was a strong figure but he worked and travelled and she was alone in the house and taking care of nine kids and a $\operatorname{dog}[?]$.

I: Quite a job, I can imagine.

P: So anyway, I've often thought that part of the problem might have been just the shift of roles and the shift of the way I looked at what I wanted. My first husband's take on that was I was selfish. I was so selfish. That's what I heard a lot because I wanted to have a say in my own life. That meant I was selfish. He didn't move that way and I did. I: How, if at all, did your understanding of intimacy change or what stayed the same with your partner(s)?

P: Well, I think I had, I've always had since a child, a high libido. Somehow thought that that wasn't, and at the same time taught, that women were supposed to satisfy their husbands. That's a job. It didn't make sense. I think that my own sexuality or my own sexual libido got in my way sometimes of intimacy because I was afraid of where it would go because I had all these rules about where it shouldn't go and couldn't go. Anyway, I think I kind of got that out of the way and began to risk. The issue with the guy in the chorus taught me some things about myself which was I regretted not having a better relationship with this guy but I was so afraid of myself and my feelings and my neediness that I didn't risk it and I ended up having nothing really. So, you know, I had other relationships and friendships with men some of which were flirtish and they would be married or we'd be in a group and their wife was there too. I had this one guy, I 
remember, and he was old enough to be my father but he was just a real flirtatious guy but I realized that I didn't have to do anything I didn't want to do. I could talk to people and they could say things and if they were inappropriate then I could say that was not where I wanted to go. I became clearer on me. In the process, I think that my ability to be intimate grew and to be sexual grew appropriate, what was appropriate for me. If that makes sense.

I: How did, did anything about your sexual expression, how was it the same or how might it had been different during this phase?

P: Oh heck. I learned to masturbate. That was a big no, no. As a kid, we'd hide under the covers but whatever. That was, they'd be killed[?] if we got caught. I think I got over myself about that and I really at that point. Part of it was hooking up with, I helped start this divorce group at my parish and I did it because there was a Catholic divorce group in Louisville and my ex-husband was going there. I don't want to do that. So, I helped start this group in the Hike's Point area and we consulted with somebody who had done that and a couple people were interested. We put information out at a whole lot of churches and this guy that was a priest who told us, who was kind of the head of a family ministry or some such thing, he said that if we get ten people to not be discourage because that's pretty normal. Well, we got like 45 people the first week. The issue was, I thought I was the only divorced Catholic person. Well, I found out, this is in 1980 so there's like 18,000 in Louisville. Okay. So, it's like my whole fantasy about what life is about versus reality check shifted. I met some women that I'm still friends with during this time that helped start this group. We talked a lot about all these things as friends. 
We talked about, now I went to therapy. They went to therapy. We did a lot of stuff that was helping us become better people, owning our own sexuality, owning our own intimacy, owning our ability to be in safe relationships, healthy relationships. So, all of those things shaped how I began to see that.

I: Going back to the time from your divorce until age 36 and your relationships with the three partners. How would you describe the different relationships in terms of intimacy and sexual expression?

P: Well, the first one was somebody that had the crush on me and really pursued me and was married and I was flattered and I was needy and that was it. That didn't work long range. The second one was a long distance thing. The third one was the person I ended up marrying. I really was in a relationship with this person for a long time before we were ever intimate. Again, it was kind of a taboo thing in that he wasn't married but he was clergy and he was supposedly not going to marry and all this. I think that originally I didn't want to be married again. Marriage was a terrible experience for me. I don't need some oppressive, pain in the ass, abusive person in my life so that's how I defined marriage. If that's it then I don't want it. Well, he was nothing like that. He was a lovely human being and still is. I knew that I was in love with him but I'm like, I didn't pursue that at all.

When I moved to Chicago and he pursued me and he came to every event that was held. Goodbye parties and made a lot of noise and kind of had a reputation for showing up late and leaving early, kind of dropping in like some people do. What's this about, you 
know? So, anyway I moved to Chicago and he came to visit me a few times. We had an affair and then I had to decide whether I wanted to do this or not. What I came to, honestly for a while, was another delusion I think. I was kind of like doing the church a favor. Delusion, big time. I didn't really want to be married so it didn't matter. I was out of town. Met a lot of nonphysical intimacy needs without having to deal with a long term commitment. Honestly, after a while I was in anyway. I was committed but without strings attached, so to speak. The longer that went on and I moved back to town after about two years and went back to school. The longer that went on the more uncomfortable I became with it because I was leading a double life and like I said, I'm kind of what you see is what you get and so it's like I'm not a sneaky person so if I would go out to dinner then there would be talk and it was like, I'm not happy. You're the one with the issue, you decide. Well, and of course there's a whole lot of pressure on women, any time a guy does anything wrong it's the woman's fault. At least that's the overarching, blaming thing that I got back. You know, the seductress, the this or that. I didn't pursue him, he pursued me. It's like, so I was struggling again with that and we broke up a couple times and finally I'm like, I'm done. I can't do this. So we broke up, didn't see each other for probably three months. I see him walking down the street one day and I'm ready to run him over with my car because he looked so happy and I'm struggling, I'm miserable and the very next day I get a letter he's left and he's wanting to come see me. We were engaged in about three months, married six months later, and we've been married 27 years.

I: Wow, that's quite a story. 
P: Yeah. He continued the ministry, just a different kind. Catholic priest, there's other things to do besides that. He worked for hospice for years and years and years as a chaplain. The big issue for us now is our age difference. He's nineteen years older than me and this is not good because in the last ten years his libido has gone down and mine has not so that's a struggle that way. He has been impotent for a long time and that's a struggle. I mean, I don't appreciate it but don't resent it but I do struggle with as he's aged and now he has dementia, the beginning stages of Alheimer's. He has no interest in even hugging or touching or nothing and I'm starving. It's very hard. Sometimes I talk about that with him and sometimes I don't.

In the meantime then I have, I have other friends who are men and I have another friend that I'm very close to but there's no sexual anything and I think that's my choice because he's in a committed relationship and I'm in a committed relationship and that's not who I am but sometimes we talk or we, we don't pursue each other like dating. He'll listen to me if I need to talk and honestly I don't call him much anymore because I just don't want to go there. So, I look for other ways to deal with my own stress and my own, I've got a really stressful life right now. I've been raising two grandchildren and we have been for eight years and they are 14 and 18, almost 15 and 18, they are 14 and 17 . The 17 year old is taking the SAT as we speak. She'll be a senior. He was diagnosed two years ago with dementia and has always been a real mild mannered, easy going kind of guy and has been madder than hell for two years about everything. Losing his independence, he's not driving anymore. He's not handling money anymore because those two things were a nightmare for a while. That's what led up to me, I couldn't not see it anymore and I went 
to a couple, [indecipherable, possibly a name] was one, a couple friends I had were dermatologists and said, "Help! What do I do?" They recommended an assessment and we did all of that. He's been kicking and screaming the whole way and I'm like, if we had kids that would be helpful. That would be one thing but I had an adopted daughter from our first marriage and she's a mess. She's 37, that's why I'm raising two of her kids. I mean, she's not going to help us and we don't have any other kids. It's like, I'm sorry it has to be me. If you had a son who was 40 saying, "Dad, you're in trouble." You might listen better but you don't. I'm the one. I say this.

He's got a lot of friends and a lot of support as far as he's a very likable soul. He always has been. Very dynamic. Very robust for his age. But behind the scenes, not much left. It's just like he's very personable but if you listen like I do, for more than five minutes, it's the same stories, the same stories, there's no live, very little, not no, but very rare to have a live conversation. So, what is intimacy at this point? Wow. To be where I am. To be supportive of him. To widen my circle of friends and activities to give me support. To just be myself, to be able to be, I don't have dementia. I'm not 80 -something. So, to try to be me and to be okay with that, I guess. I don't know what I'm supposed to say. I: When going into middle adulthood on your timeline, you said from 40 to your present age you had many male friends of varying degrees of intimacy but no sexual interactions outside of your spouse. On your timeline, at age 47 you had a close male friend for 3 years that didn't involve any sexual interaction. Would you describe that in [participant speaks over interviewer]. 
P: That was, again I've been a singer for most of my life. I stopped about almost 10 years ago singing in choral groups but I sang in choral groups from age 14 to 54 almost constantly except for 2 or 3 years that my daughter was in school about middle school or something. Too many places to go. This was somebody I met in the chorus and we sang next to each other and we talked a lot and he was fun and he was, I was attracted to him and I think vice versa. We had a lot of good conversations. Encouraging things. We didn't go out and date. We didn't do anything. He's happily married and I invited him and his wife over a couple of times. We had dinner together. He was flirtatious and I probably was too but other than that it was just a nice relationship. It wasn't anything beyond that. I think honestly he is very, very, very conservative Christian right-wing and I'm not. So that became an issue for me over time. I mean, I wasn't really interested in all that. My daughter was in the throes of her chaos in the late 90s and had a child and then had a second child. I think he and his wife really looked down their nose, "A second one?" I just that was the end of that for me. I just couldn't deal with the judgment and the, all that stuff.

I: Now, you also had another close relationship with a male friend from age 52 that lasted 12 years. Is that [participant speaks over interviewer].

P: That's the one. That's the one I said from time to time I'd talk to him and lean on him. I had been at different points in that period of time, I had been involved in things where he was involved. Groups or whatever. I was actually on a trip that he was on and that was a fun, delightful experience. He's just fun to be with, he's solid, he's smart, he's a lot of things that I appreciate. He's a very compassionate soul and he's also 
trustworthy. He is very clear on who he is so he doesn't go over his limits either. I respect that and I appreciate him. I think I've had a lot of fantasies about him and he's a wonderful hugger. God, he's a wonderful hugger and I'm sometimes very needy. I need to kind of stay away from that because it's just too much for me right now.

I: So, hugging would be a form of intimacy to you. It wouldn't be, you wouldn't classify it has a form of sexual expression?

P: Not usually but with him it feels like I'm starting something else because I'm so turned on to this guy it's like, that's why I said I probably need to put a limit up. I hug a lot, I'm a regular church goer in a pretty radical church and I hug a lot of people on a regular basis but I don't get turned on by it. I like hugging. I like women and men hugging and there are some people that when they hug you they, "Eh. Okay". So, but for the most part hugging is an expression of caring and sharing and touching and good stuff, but with this person I feel more than intimate so for my own boundaries sake I try to...

I: I understand. Now, on your timeline you indicated that from age 36 to your present age of $631 / 2$, is that correct? That you maintained your marriage for 27 years. You also indicated, congratulations by the way.

P: A gift.

I: That's still a milestone these days. You also indicated that over the course of those years that sexual activity diminished and that you're fidelity is still intact and you talked a little bit about that. Can you describe, in terms of intimacy, your relationship with your husband?

P: You mean from the beginning? 
I: Yeah.

P: Well, gosh in the beginning it was just pure joy. Just so happy to be together and regularly, in fact, when I said my libido is high he about wore me out in the beginning. He was, I guess, very needy and whatever. That was a good thing in a good kind of way. We both slept together. We had sex often, like two or three times a week in the beginning I think or maybe more. Then, the sexual part diminished but we still talked a lot. We went places together. We hugged. We had friends. We went out together. We belonged to a swimming pool for a long time and we would get in the water and just chat. We talked.

My daughter, that child was a mess. She had both mental illness and substance abuse from about 13 on. So that took a huge amount of energy and he was just rock solid. He really is a very dependable, smart, savvy, educated guy. He was like a rock, like an oak. I say that because one time my daughter was about 17 and she was in a substance abuse treatment and we went to some kind of art therapy. We had to draw a picture, some kind of symbol, for each member of the family. That's what I drew for him, a huge, solid oak. A solid foundation and I was more creative and much more flowery but more flexible in the wind, you know. Not really as solid and stable as he and my daughter was all over the place. She was like a butterfly. That was my images.

I think the difference is that over time he started having trouble with erectile dysfunction. God, after about 5 or 6 years and he had this intermittent problem. He went to treatment and we went to sex therapy and all this stuff and nothing worked. Nothing worked. 
What I ended up hearing was that he really does want people to be happy with him and he really presents a great front no matter where we are. No matter what's really happening at home. In front of the sex therapist he is just as pleasant, as if there's no problem and I'm furious. We're not dealing with anything! Finally, we did that for a year and I'm like, I'm done. Nothing is happening except we're coming in here and spending money and there's no difference. That kind of dynamic between us and I often think about this book Men are from Mars, Women are from Venus which feels like all poppycock to me for the most part but the issues of men going in their caves and try to go inside to solve problems, that is so him. He is an extreme extrovert unless he's got a problem and then he's completely withdrawn. He will not share. I struggle with that. So, he's had 2 hip replacements in our marriage and both times he became completely, he was in physical pain, and he just shut down. I'm not, I don't get in and the first time I tried. The second time I'm like, if you need me let me know. I'm not doing this. I'm not doing this dance where I have to dig[?]. I'm not doing that. So, you let me know.

So, the dynamics the sexual thing has dropped but I think the intimacy and the level of sharing, the level of talking, of all of that. He has moved into the last stage of his life and he is very much, not just the dementia, but he is very much talking about the old days. Oh my God, it just about kills me. It just drives me nuts, honestly. I hate it. It's just part of where he is but it doesn't do a thing for me as far as intimacy, it's like an anti-intimacy in that if I hear one more story about when you were in seminary or when he taught in high school 50 years ago or the people he went to grade school with 70 years ago. You 
know, oh my God. I feel like I'm 2 generations apart now as opposed to 1 . The time we married he was timeless. He just, not anymore. Not at home anyway.

I: On your timeline, on future times, you didn't identify any events or expectations regarding intimacy and sexual expression.

P: Future? I didn't? Okay, I missed that.

I: As you consider your future, what concerns do you have about your intimacy and sexual expression needs?

P: I think they'll be there until my mind is gone. Frankly. I can't imagine that. You know the show Golden Girls and the old lady that's always in bed with somebody? I could kind of see myself that way at 90 or something. I'm still kicking because you know, I haven't seriously as far as how I manage my life, there's many other elements besides sex. I pray, I do meditation, I have friends, I have many dynamics but it hasn't gone away.

I: How do you anticipate meeting those needs?

P: I think, probably, those things could shift as life shifts. One thing is, Tony lives, and he could easily live another 10 years. I see a lot of longevity in his family. He is very, very healthy physically. I try not to think about that because it just exhausts me. I think over time that's why I need to broaden my horizons. I think whether I have sexual intimacy or not, I need physical, I need relational intimacy. I need to be able to talk honestly with people. To open up. Sometimes I find myself leaking. Just like who do I tell, no one will listen [?]. That's just, needy. So, I want to build supports. I have a lot of friends that are men. Some of them are attractive in a maybe potential sex partner kind 
of way but I don't think about it like that. I just like to be open to relationships as they arise. I hope I will continue to be. I used to have this dream to join the Peace Corps when I retired. That's not going to happen. [Next sentence is indecipherable]. Whatever happens in the rest of my life, I think I will try to take care of my needs and put myself in situations where I can be with people, meet people. I'm actually probably more of an introvert than an extrovert. I'm talking now because it's my job but I really, really need quiet time and alone time especially with this chaotic life that I live between teaching, practice, and 2 kids, and a husband with growing dementia. I am being very intentional this summer about broadening my support systems. Doing things that give me life. That give me energy. I'm not draining, that kind of stuff. I think on this fear of sexual/intimacy bout[?] I see that the same way. All of those things, I consider myself a rather whole person in that it's kind of they're all woven together, you know? [Next sentence is indecipherable]. My physical, emotional, intellectual, spiritual, sexual intimate needs are all kind of together and I don't think I'm going to be driving myself towards a sexual or intimacy target but to be open because there are relationships that could really evolve.

I: I'm going to throw a little wrinkle in that. As you consider the future and the possibility of being a resident in long term care, what concerns do you have about your intimacy and sexual expression needs in that environment?

P: Well, see, what you told me at the beginning of this interview is news to me. I don't know much about this at all. If even your spouse isn't allowed to be with you then what the hell is that about? 
I: It's not that it isn't allowed but they make it very difficult. They make it very difficult. Even if you have one healthy, one healthy spouse who's able to take care of himself and the other is in long term care they make it very difficult. There's an old *** account here in Kentucky where that was the very case and because the spouse cried for him, she just cried for him every day, he couldn't stand it and he wanted to move in with her. They fought it and actually wouldn't allow it. He had to go through the **** office and force them to make room. Which is sad, they'd been married all their life.

P: I don't know. I mean, as long as my brain is working I tend to be a squeaky wheel with things like that. I'm very, social worker is a good match for me because I've always been a justice advocate. Something like that feels really unjust. I would probably be calling $* * * *$ myself or something like that. Making a lot of noise or checking with something. Who knows what I'll be doing. But I can see me, if I go into a residence and of a sound mind then I might be organizing or something.

I: It wouldn't surprise me at all.

P: Because, you know, we are just the cusp of the baby boomers. Wait until the majority of the people are in that situation. Where we're going to be. You know, I don't know when you were born but...

I: 61. So almost toward the end of that.

P: Okay, so you're yeah. You were born in 61. I thought you said you were 61.

I: No, I'm sorry. I was born in 61.

P: Yeah, my twin sisters are the same... 
I: The things you said because it's been sort of my belief as well. The members of the folks who did the protests, the fighting and arguing and advocacy for themselves.... P: I didn't because I was in this real conservative family that didn't do anything. I was just scared to death that my boyfriend was going to have to go to Vietnam and [indecipherable]. He got a low number but he flunked the physical. I was glad of that. So I wasn't a part of that Woodstock kind of thing because I wasn't, that's what I meant by the foreclosure. I didn't do that until my 30s.

I: That's really kind of the last question I have for you. If there's anything else you feel like would be important for me to know or that you would like to share that would be helpful...

P: I kind of just thought of this because of how our conversation has evolved. It would be really helpful for me to know something about intimacy needs for my husband. $\mathrm{He}$ can't seem to articulate them. I don't know. I only know when it's violated. One of our granddaughters, like yesterday, she wanted to get her belly button pierced. Well, I kind of have this, if you want to pierce or tattoo you do it on your own time. When you're 18 and I'm not signing for that stuff. So she wanted to get her belly button pierced and she had written this 2 page of why it could be okay and then she's talking to us and the more she talks the worse I feel and he's [making noises] and he probably couldn't stand the [indecipherable] and I'm like okay. I only recognize when we violated his things but I don't know what he needs. I wish I knew some way and I'm thinking about this senior tsunami happens what are the tenants of address the needs of someone who's not very 
articulate about their own needs? I don't know what to do with that. I'm trying to learn but it's baby steps kind of trial and error.

I: It's definitely going to be a problem. That's one of the things that's a concern and it's starting to be talked about now in the legal profession and [noise, recorder being moved?] trying to address $* * *$. Possibly thinking about ideas around intimacy and sexual expression as far as advanced directives for people who are in dementia.

P: Oh, for sexual expression?

I: Right. So kind of like, I say this jokingly, but kind of like if I'm smiling leave me alone, if I'm frowning maybe there's a problem.

P: That's kind of the way it is with my husband.

I: That's something I've kind of thrown around with $\mathrm{XXXX}^{* * *}$ a little bit to see if there's any kind of way to look into that but I've got to get this out of the way first before I start going that direction. That conversation is already starting to occur. There's all kinds of issues around this around liability and most of the facilities, they do everything they possibly can to discourage it. Actually, I'm trying to think of the name of a facility up around New York, or is in New York, it's a Hebrew long term care and they have [participant speaking over interviewer].

\section{Sarah}

Interviewer: On your timeline, you indicate that at age 12 you lost your virginity. From 12 to age 20, you indicated you had multiple partners. What was your understanding of intimacy in these relationships? 
Participant: I think at that time, to give you some background, my mother had married a man that was much older, like 28 years older. He had gotten ill and we were living overseas at the time and he came back to the States to have surgery done. During that time, my mother worked as a prostitute. She worked at a bar and she also worked as a prostitute. Now, this is probably when I was in second grade, probably second or third grade so I was probably 7 or 8 -years-old. So, I was sleeping in the same room as my mother and she would bring some of these clients home. I actually witnessed her having sex with men. My memories of my dad, he passed away when I was 9 . He came back and he was very sick and he eventually passed away. I saw some intimacy between them as far as the sexual act but as far as intimacy from what I can recall, was not what you would expect intimacy to be. It was more of she was a caregiver for him because he was so much older and he was sickly. One of the men that she had brought over several times started grooming me. I can look back and say that now. When mom wasn't there, he would show me pornography and showed me his penis. He didn't really do anything at that time to me other than just show me things. What ended up happening is my dad passed away when I was 9 and she married this man at age 11. I really fought that because I did not want this man. I didn't come out and say that this is what he did but I said I don't like this. She went ahead and married him because she thought by marrying him, he was a soldier, that she was giving me a better life.

She married him and of course what he did was he started working on me as far as, first it was looking and then it was touching. It started with oral sex. Probably when I was 11 
or 12 , I started hanging out at the skating rink and he was not the one that actually had sexual intercourse with me the first time. It was somebody else. Somebody I just randomly picked up. There was no intimacy. To me, it was just an act. This is something guys like, I have something that they want, so let them have it. Of course, when he found out he was very furious. From that point on, it became a relationship where the sex was involved with physical penetration. So, around all this time it got to where, okay if I give this man what he wants I can pretty much run the streets and do whatever I want. That's pretty much my thinking. There was no intimacy you know, involved. It was just basically, okay, you know?

A couple of different times I did try to tell my mom what was going on. She was either, didn't know what to do or she chose to ignore it or whatever but she was aware of it. Really and truly they *** [show?] what you know about intimacy. You don't have a concept of that especially if you grow up and you don't have the loving parents that show each other affection, that do those things that those $* * *$ [little?] things that you see that you really, that show they really care about each other. That was nonexistent. That's where my idea of sex came into being was like, this is a means to an end. I can get things if I do this. Throughout my teenage years, even after we moved to the States, we had no support system here. My father was, not only was he abusing me but he was a very bad alcoholic and an abusive alcoholic. He got very mean when he was drinking. What was interesting is, he would bring people home from work and he would have parties on weekends and beer. He would bring these other soldiers around and I got involved with a couple of them. It was almost like he did it on purpose to bring people home but at the 
same time it was like he got upset when they showed me attention. It was kind of a bizarre situation. It's like, why would he do this?

\section{I: Right.}

P: But then what happened is that I got into my later teens and he decided that he was in love with me. He had tried to have a baby with my mother. Supposedly, that was his rationale for taking advantage of me was my mother had gotten pregnant I guess a couple of times. She had aborted, I think, maybe a couple of babies. The last one, she carried only a few months and she lost it. Supposedly, that was his rationale for turning to me. The relationship, the sexual relationship, went on until I graduated school. I stayed at home. I was really worried about my mother at that time. I didn't want to leave her. In between, he was still taking advantage of me all this time.

I would have other relationships. I tended to date older guys when I was in high school. I went to the community college and I stayed home. I left for school. I went to Korea for a year. A sexual relationship didn't exist there but we all slept in the same room. He didn't have physical sex with me but we had, we slept in the same room. Me, my mother, and him. By this time, my mother was well aware of what was going on. So, he started the 'I'm in love with you, I want to marry you' kind of thing and I was like I don't think so. I was 21 , I think, when I left home for the first time and went to the University of Kentucky. We had spent a year in Korea and I came back to the community college for a semester and I had to go away to school. I went to UK and I got a summer job. I came back and forth at home but the physical relationship pretty much had stopped once we went to Korea and not resumed. He was still 'I love you, I want to marry you' kind of 
thing. As far as, from age 12 to 20 , I really didn't have a handle on what intimacy was. I'm basically looking for love, what I thought was love, I wanted to get out of that house. I think if somebody said to me let's get married I probably would have jumped at the chance.

I: That makes sense.

P: To get away from this but I still had that, I had a lot of anger towards my mom for a long time. I said, why did you let this continue? A lot of blame and at the same time. So really, as far as intimacy goes, during those years I really did not have a grasp of it.

I: Okay.

P: I have answered number 2, haven't I?

I: Yeah, you sure did. That's fine. Basically, you have answered all of these in this section. I want to make sure I understood you clearly, but I'm going to ask you this last one on here. What did sexual expression mean to you? Was it kind of a means to an end at that point?

P: Yes. It was part of a means to get what I want. Usually, like with my step dad, I got to stay out later or I got to go do whatever I wanted to do. Hang out with friends, whatever.

I: Now, outside of what had happened, with other people what meanings and understandings of sexual expression did you share with your partners? How did you differ? 
P: I think with, and I guess you could say a consistent partner at that time would have been my father. He was kind of a, an odd man. He grew up in poverty and bestiality was a big part of what he ${ }^{* * *}$, you know. He was very $* * *$ [fascinated?] with bestiality. He, from what I understand, he did it with my mother with dogs. But, that was that. I just put my foot down and said no. As far as you know, he was orally and physically into penetration. That was kind of his thing, as far as expressing himself. He was not, like I said, he tried to tie love into this and I just felt like, this is not love. I just never felt that way. So as far as sexual expression goes, really, and what I think I did with other people was basically I did what I was taught.

I: Did those partners differ, their views differ from yours?

P: When I was, I guess one of the things was when I was with my dad. It was like, oral sex is not having sex. That's kind of the mentality I carried.

I: Like President Clinton's definition.

P: Yes. It's okay. It's okay if I gave other men blowjobs. That's not really having sex. Of course, young guys they're like hey, you know? As long as you're not having intercourse, that's not sex so it's okay. That kind of thing. My views changed after I turned 20 or thereabouts. I thought I'd save that for the next section.

I: That's good. That takes us right into that. From age 20 to 26 , you indicated you continued to have multiple partners. They were sexual only. Then, you indicated that from age 23 to 25 , you had a long term sexual and romantic relationship with a man 28 years your senior?

P: Yes. 
I: Okay. Then, at age 26, you indicated that you were married to your current husband. P: Yes.

I: So, with regard to intimacy, in what ways did these experiences impact your understanding of intimacy?

P: I think what happened when I was in my early 20s was I said, you know, a lot of the sexual encounters I've had have kind of been one sided. All about the men's pleasure. There's something missing here because I should be getting some pleasure as well. So, it's kind of my turn. Instead of allowing men to abuse me, or take advantage of me, I said I'll turn the tables. My thinking was that I'm going to go out there and I'm going to rule the roost. I'm going to take charge of my sexual contacts and such. I think I kind of evolved from that mentality. Letting them use me. I think I became more confident too. I think. Going into my early 20s, I think what I did was, if I [indecipherable, 2 words] sex with a partner, I would probably stay with them a little bit longer but if I didn't, I kind of $* * *$. I was $* * *$ doing his doing or whatever versus... But also too, I think I started looking at the whole package. Not necessarily just okay, we're going to go meet at a hotel and have sex kind of thing. Okay. Do you have anything up here that, intellectually stimulating. Can I have a conversation with you? There has to be something a little bit more there than just sex. I think that's kind of when the intimacy and becoming a little more involved with the people I was encountering came into play. I was looking more for something else besides just the sexual contact. 
I: Did you have any kind of close friendships with people that you would describe as being intimate?

P: I think, let me think here. It's kind of interesting, I've got friends throughout different periods of my time that I still keep in contact with. In high school, I think I had a close friend who probably knew what was going on with me and my father but we never really talked about it. When I first started the community college, I had a group of friends that thought my dad was the greatest thing on Earth. He seemed to be the doting husband and washed cars, mowed grass, and all this kind of thing that a good husband on the surface would do. Really could not talk to them about him.

When I went away to college and one of the things was he had gone to Germany during that time, my step-father had. He got assigned to Germany and slept with a German woman. When he was getting ready to retire from the military, he came back because she had to $* * *$ process back here. I saw him and he said I hooked up with this person. She is pregnant with my child. I said well good for you. My concern was she had an 11 or 12year-old daughter. This is in another country. There was nothing I could do and this woman knew about me. On rare occasion, that comes into play. Just live a happy life and said you know, good luck to you. Sounds like this is what you need.

I didn't have a lot of male friends, per se. I had more female friends. It seems like, that even at that time, a lot of my intimacy started becoming tied into that sexual act. It was more of a ${ }^{* * *}$ for sex. Anybody that I just kind of hung out with and you know, that I would call good friends with. I will say that probably towards the, I guess when I was 
about 23 maybe, I did meet a fella that I would say that I could probably call him a friend. We just recently connected on Facebook. I never knew about him. I never knew if he was asexual, homosexual, or you know, he hung out with the girls a lot. He liked to talk dirty but you never saw him dating or hanging out with anybody in particular as far as a relationship goes. To this day, this man is still single. I don't know, like I said. He was kind of always the person that he liked to hang out with the girls. He liked to hear about what we were doing. He liked to hear about the sexual stories but never really like to, because there was a couple of girls that entered into a lesbian relationship over the summer and he was kind of fascinated with that. I would talk to him about some of my escapades so you know, it was kind of interesting in that way. Really, truly, to this day I still don't know what he is, where he's at or what he's doing sexually.

I: Interesting.

P: So, it's kind of a one sided thing but he comes to mind because he was kind of always there but in the background. In the same *** [fall?] too, I actually lived with him for a few months. My husband was stationed in North Carolina and I kept coming back to finish my degree. I left UK without finishing my studies and so I had spent probably about 3 months living with him. It was a waste of time. He never made a move. We cooked a couple of meals together or whatever. He was working so I kind of just went to school and did my thing.

I: Now, considering these same experiences, what ways did it impact your understanding and expectations? 
P: I think it kind of evolved me into, I was starting to have a better understanding of what a relationship consists of, or what it should consist of. What I wanted in a relationship. Sexual expression, I think was important. Like I said earlier, it wasn't the whole package. I still had not really been in any kind of long term relationship until I met this older fella. This older fella, he had 4 kids. The oldest one was 5 years younger than me. I can say what was unique about this fella was number one, he had the means to wine and dine me. He was a reservist. I was in ROTC and I was in the reserve unit and he was a reservist. He was a higher ranking officer and he's also a psychiatrist. I think he was the first person that, he gave me my first true orgasm. This is a man that was, if I were to rate him sexually he probably wasn't up at the top but he gave me my first real orgasm. He was kind of the guy that anything goes. He kind of, because of that I think there was an attachment there. It was like he [indecipherable, maybe 2 words] for a while. This is where I saw the bottle rockets and stars and things so I thought, okay. I think with him, my awareness of this now. I mean, I had given myself orgasms through masturbation but to have a partner give me one, a true orgasm. That was kind of like, wow this can happen. I think that kind of gave me a better understanding too. Okay, I can do this but some people, you have to teach men sometimes. It's not going to be an automatic kind of thing. I think the same holds true for both ways. You really need to have that communication. What you think might feel good to you or should feel good to that person may not be true. I think that that is where that aspect of my sexuality came into being. It was like, okay. 
I was with him for probably a good 10 years. I had another person in between that I, actually at one time I had 3 of them going. I was having sex with 3 different men. One was really a play toy. This guy was dumb as rocks but he was *** and I said okay. I'll have a play toy here on the side. Then, I met this older man and about 6 months after I started with the older man, I met my current husband. My husband knew about the older man. He didn't know about his other guy. My husband knew about the older man. My husband was very naïve. He had been married once before but he was very limited in his sexual experience. I told him he had to broaden his horizons. I knew, as far as a long term relationship went that this older man was not going to be a committed person. He'd already had his kids. He was just out for a good time. I think we were able to talk about different things. I felt comfortable talking to him about different things. I talked to him about my father and growing up being lost and such. He worked in a women's prison as one of his numerous jobs. We would share stories and things. Actually, I wish I could have that relationship with a man today because being in social work I'm in a lot more different, I could pick his brain in a lot of different areas than I did.

I think that kind of, that was a huge turning point in my life in view of sexual expression and what my expectations were of me and vice versa. I think I knew what I should be doing. There was intimacy there, but with my husband it was kind of like my trial project because he had just gotten divorced and he had a very bitter divorce so he was kind of turned off to women. He was all about here's a girl that's willing and ready and able and we had sex first on our first outing. Our first date, I guess you could say. I told him, I 
was giving him oral sex and I said if he was wanting intercourse it was going to change the relationship and it did but he was willing to take that risk.

\section{I: Interesting.}

P: Anyway, I don't know if that answered the question or not.

I: Now, how did you identify intimacy in yourself and in your partner?

P: I think, to me, intimacy is when you have that connection. Not only are you sexually connected to that person but I think on an intellectual level you are connected. You know, you kind of understand. I think also too, I think it's the little things that show affection. Before there wasn't a lot of affection involved. Affection was something that, I didn't see my mom having affection with other people or vice versa. At that time, there weren't a whole lot of people I knew that had been in long term relationships that were married for many years. A lot of parents of high school friends and such were going through divorce. So, I really didn't have a good example of what a good marriage should be or look like. Really, the day I got married, I thought oh my god can I be faithful to one person for any length of time before getting bored? I had this thought on the day I got married. When my husband and I first got together, I would say probably within about 6 months I was ready to get married and he, of course, was not. He had just gotten divorced and was paying alimony and child support and all that.

I think one summer he was working and we weren't together anyway and I was spending some time with my little boy toy, that's what I call him, and I knew my husband had suspicions but he didn't have confirmation. That was actually the summer before I actually moved in with him. We lived together for a little while. We was leaving 
Kentucky and going to North Carolina and so it was that summer before. Actually, even while we lived in North Carolina I had ***. In my mind, we weren't married so it was okay that I was living with him. Actually, the following summer is when I came back to UK to work on my degree *** supposed to be and we got married within a month or so later. When I was at UK, when I came back to UK, I had hooked up with this older man a few times from the area. He knew I had moved out there with him and came back. I hooked up with him a few times. It was primarily sexual. So, when I decided to marry my husband, and it was hard, there were probably about 3 or 4 times where I was actually tempted.

I: I'm curious. At what point in this phase of life, that you separated intimacy away from sex more so than it had been?

P: I think probably, it probably wasn't until later on. When you first get married and you're young and I think the sex is great. Everything is great. You have your battles over stupid things like the toilet seat up or down or toothpaste, all that kind of stuff. I think the intimacy being separate from the sex came later. Probably, I had my first child when I was 29 and it seemed like after kids came along the sex kind of drops off for various reasons. It drops off and the baby's up all night or whatever. I think with women undergoes so many changes that it's like wow. You lose that confidence. I wouldn't say all women. I would say for me it actually happened. Sex was not as big of a deal anymore. I think for men, they're like you had a baby but that doesn't mean I stopped wanting you. 
I really think it kind of evolved after I had kids I think the sex drops off. The intimacy is there but I think, at that time, my focus wasn't really on the intimacy. My husband probably took a backseat when I had my son. Of course, we had 2 more kids after that. I think the relationship kind of stagnated and I would say that we weren't having sex a lot but we also weren't connecting that much either. That kind of died down. The, I would say probably when, I'm trying to think of a timeline, I mean today our relationship is much more intimate than it was ever before and I think it's because we're at this phase in our lives where the kids are adults. We enjoy hanging out with each other. When did that actually start? I would say the intimacy was there during the beginning of the marriage. It kind of dropped off after the children came along. Along with the sex. Then, it probably started picking back up when the kids were maybe in middle school. Probably a period of maybe 10 years.

I: How would you describe intimacy?

P: The way I look at intimacy today is like we have a connection. It's almost like you can look at your partner and know what he's thinking or that telepathic kind of communication. I think it's the affection. That touch on the arm or that squeeze. He likes to come by and squeeze my butt. I think it's those subtle things that maybe before I didn't pay attention to that seem to mean more now.

I: Okay. So, those would be things that occurred when that started for you when you separated those. But you didn't really attach a connection to it until later.

P: Right. I think now because the kids are adults. We close the door and we can have sex and I don't worry about it. You're still conscience about it. You know, we're not 
going to run naked through the house and do those things in front of them. When the kids were younger, you got to wait until they go to bed. You got to make sure they're asleep. You don't want to make too much noise. Those kinds of things. I think because I grew up observing my mother. I didn't want my children to walk in and catch us in the act so I was even more conscience that my kids aren't going to see it.

I: Now, on your timeline, in the present period at age 40 and beyond, what other types of relationships have you had during your marriage that you would describe as intimate?

P: I think that's when my friendship with other women were important. I'm not saying sexually. I'm just saying to be able to talk to someone about intimate things. Maybe with your partner or with your kids. I think that became important to me. I've had different sets of friends that I do different things with. It's kind of interesting. I've had some that I see maybe once or twice a year but when we see each other, it's like we never, I have college friends that I see once or twice a year. I think around age 40 is when those kind of relationships become important. You know, outside of your partner. When you're in your 20s, because I started so late, when you're in your 30s its more about the kids. You're so and so's mom and when you get together with other people you're talking about kids.

I: Sure.

P: That's usually what it revolves around. I think when you start getting into your 40s and the kids are older and doesn't necessarily need you as much, rely on you as much, I think you start broadening this other horizon maybe. You try to find other women that 
share interests that you like to go shopping or go traveling with or go sightseeing with or whatever.

I: Okay. During this phase of your life, how did these experiences so far, how did they affect your understanding of sexual expression?

P: I think, my husband was because he's kind of a hermit, he doesn't really get out. His idea of getting out and doing something would be to go to the shooting range with his working buddies to shoot like once a month or so. He made the comment driving up here that your plate is too full. I told him, I sprang this on him and he's like, you know. I try. I'm going out to dinner with so and so. I'm going out to lunch with so and so or we're going to drive over here and do this. It kind of drives him nuts but at the same time, if I'm sitting at home with him, what are we doing? He likes to do the family thing but once in a while we'll sit down and watch TV or you know. To me, that's kind of an intimate moment. It's not something that we do a lot of.

I: Sure.

P: It's kind of like, last night he was giving me a hard time. He was watching TV so I let him watch TV but I lost interest in that show and rather than leave and go somewhere else I just sat there and I was on my phone. He looks up and is like what are you doing? I said well I'm just surfing Facebook for a few minutes. He was like, oh. I don't like what you're watching on TV but rather than leave the room and leave you here by yourself, I chose to sit here and do something that interests me. I think as far as sexual expression goes, I think that our expectations of sexual expression have really changed a lot in the sense that our sex lives have changed. We've both gotten older and heavier and 
he can't perform like he used to. My role has been, the last few years, has been that I take care of him and I take care of myself. That's kind of a wrong way to look at it but it works for us. I'm okay with that. I wasn't okay with it in the beginning when it started happening. When he started having difficulty performing. I kind of felt like this is not good for me and on the rare occasion it's good for you so there's something wrong here. I had to really work on myself and say okay what's acceptable to me? In probably the course of the last, it's probably evolved into that, I would think it's probably due to lack of desire on his part to please me. It's just, I decided for myself that I'll take care of him and I'll take care of me and I'm okay with that. I guess, in some ways, it's kind of irritating. It's kind of interesting because I listen to clients. It's kind of irritating at times because sometimes the grab your breasts or pat you on the ass gets annoying at times and I don't know why. What used to be kind of flattering is now kind of annoying at times. Don't wake me up in the middle of the night for anything because I'm a grouch. I'm not a morning person and don't wake me up, just let me sleep because I'm a grouch. I think that the level of sexual expression has gone down but I think in return the intimacy has kind of gone up in a different area. We're not as connected as we used to be. Once upon a time, they were very connected. Now they kind of coexist but they're not interrelated like they used to be.

I: Got it. Yes. Now, in the future period, you didn't mark anything and that's okay. You didn't identify any expectations of intimacy or sexual expression. As you consider your future, what concerns do you have about your intimacy and sexual expression needs? 
P: I think at this point in our lives, my biggest concern is more of the health issues and my inner fear with us being able to be independent. My husband is $61 / 2$ years older than I am. I worry, I think the physical concerns are probably more of an issue more so than the intimacy. I've always been a big proponent of self-serving. When I talk to teenagers, it's like you have got to self-serve rather than hump all these girls especially when you're riding bareback. You need to learn that if you've got to jack off 5 times a day, that's okay. That keeps you from going out and sleeping with 5 girls in one day because you're horny and you figure somebody else needs to. I've always had that, you should be able to self-serve. I think that that part, the sexual part doesn't bother me so much because I figure I can take care of my own needs. I think the intimacy becomes more important when you're older because the sex goes down. I also am concerned about the physical concerns about being overweight, about heart disease, about other things. I think we kind of put a big cloud over this.

I: In what ways, if any, do you expect your definition of intimacy or sexual expression changing in the future?

P: I think the intimacy part will grow. Like I said, I think that's going to be more important in the future. The sexual expressions, I know there are people that are in their 80s that are still having intercourse, that are still having sex and probably very sexually satisfying lives. I don't view that as a top priority. I think the intimacy part is going to be more important. I think being able to weather future storms is important. Know that I got a partner with me if there's a health issue or it's for the kids or those kinds of things. 
I: My last question. What are your expectations for intimacy and sexual expression when you think about potentially being a resident in long term care? Married or single. P: I think sexual expression, like I said, I have no problems with taking care of my own needs. I don't think that will be an issue. I think it would be important for me to be able to maintain friendships and to be able to interact with other residents. I think that will be more of a concern for me. I don't see myself running around wanting to have sex with the older men walking down the hallways or whatever. I don't see that at this point. That's not to say that if I were actually in that situation, my views might change. I think even just thinking about it, I would want to have a relationship. I think those would weigh more heavily than the sexual aspect.

I: Given everything that we've talked about, is there anything else that you feel like that might be important for me to know as far as these topics?

P: I don't think so. Is there any place that you feel like I didn't clarify enough or anything?

I: Not at all. I appreciate it.

P: Okay. I try to be open and honest and hopefully I answered all of your questions.

I: You answered them very well and knew what you were talking about. What we're finding though, what goes on is even though people may not be sexually active, they don't have any privacy. They're supposed to have privacy. I understand self-serving but the problem right now though is, especially for males, is the knock and the door opens and they are pleasuring themselves. They are acting out instead of being in the privacy of 
their own home. Then they are treated as if they have done something horrible. On top of that then is even married couples, if one or both are in a facility, by law if they are both in a facility they are supposed to put them in the same room together even if they are on Medicaid. However, they usually don't unless there's somebody right there to force it to happen.

In fact, I may have talked about that, a man put his wife in there by himself. He was wealthy enough that he was paying for everything. He came to see her, she wanted him to be there. He couldn't stand it so he said I want to move in here with her. They said no. Fortunately, he knew that they couldn't just say no. So, he had to go to the Ombudsman office and they said to let them do that. He wanted to put a double bed, all these things they kept saying no to and he just said I'm doing this and they had no choice. Unfortunately, most people don't have those resources, don't have that knowledge that this is your home. This is your right. People can't come in your house and tell you what you can and cannot do. Same situation. But even around intimacy, they don't want people getting close, holding hands or that kind because they're uncomfortable. Then you start imposing moral views by different staff members of what's right and what's not. Those people aren't married. How can they be together? They're adults. So, hopefully, I'm hoping what this will turn out to be at some point, is to make policy clearer. Regulations clearer so that it will help kind of alleviate some of the liability concerns. I understand about capacity and dementia and those pieces and there might even be an option, Joe and I have talked a little bit about advanced directives around dementia. It's kind of like if I'm smiling, leave me alone. If I'm not, maybe something 
is wrong. You know? The ironic part for me is when, I talked to some people who are aides or nurses and their like, "Putting them in bed together? I don't want to clean up that mess!" I looked at them and said really? You change diapers, you clean and that's a mess? Really? Don't want them to sleep together. The couple, even if they didn't have any kind of a sexual behavior, just holding each other. What is wrong with that? P: You're right. It shouldn't be that way. I really think, as you get older, that's important.

I: It is.

P: It's not about the sexual act itself. It's the intimacy. I think that's when, like I said, just being in the same room with my husband. I think, even though I wasn't engaged on what he was engaged, just being in the same room. Being able to hold hands or that pat on the back. I think those things you become more aware of because your body isn't what it used to be when you're 20. You can't stay up half the night and have sex 50 different ways. I think as you get older those things become prime.

I: I think touch is huge. I haven't looked. I haven't done any research, or even looked if there's any existing research but I think that touch at the end of our life is just as important, maybe if not more so, than it is in the beginning. We see what happens to babies when they don't have human touch.

P: I think, that's the thing, people start regressing as you get older.

I: It's like it turns full circle. 
P: I think you're absolutely right in that sense that people are starting to go back to infancy. They're heading that way and so I think you kind of have to start looking at well what did you do with these folks when they were babies? What was important at that time for stimulation?

I: My hypothesis is, as I've said I haven't even gone to look at it yet, that people who do not have human touch and contact die quicker.

P: And I think a lot of times, you can definitely tell in nursing homes and even hospitals, you can tell those people that are working there that truly care about the patient's versus those that are there for a paycheck.

I: Yes, you can. That's true.

P: You can see that in nursing homes as well. The ones that are about the human being as a whole are the ones that take the time to engage them in conversation, that will pat them, that will show them signs of affections.

I: Yes. I agree.

P: Those make a difference. A hell of a difference in a person's life.

I: I agree. That's going to be I think, further down but that's what I'm [participant speaks over interviewer]

P: Well and we're all living longer. Modern medicine.

I: Nursing homes are forcing you to become kind of like your seat by the River Styx and people tend to forget about you and unfortunately there are families who just put dad and 
mom in there and don't show up again until they call and say to come get the body. Which is horrible but it goes on.

P: Anyway, we're going to do a follow-up interview?

I: What I will do, it will be a phone call to make sure that I got everything accurately on the transcript and I understood everything and we'll go from there.

P: Okay.

\section{Lila}

Interviewer: [Indecipherable, muffled. Recorder being moved]...a little bit to see how you are.

Participant: I'm good.

I: Feel relaxed, comfortable?

P: Oh yeah.

I: I went through your timeline.

P: Okay.

I: And I developed some questions for it based upon it. I wanted to start off with your early childhood to age 19 .

P: Anytime.

I: At and during your first marriage, what was your understanding of intimacy?

P: I didn't really have an understanding of intimacy, to be honest with you. I think I believed it to be someone wanted you sexually. That meant you were intimate. I'm certain that's why I married that guy, he wanted me so okay, we'll get married. It was 
1970 and it was $* * * *$. So, I don't know, I mean, my parent's marriage was a little sick and twisted. My dad was an alcoholic and he obviously adored my mother, drunk or sober, and it wasn't like he was drunk all the time. And he did adore my mother, but he behaved very inappropriately in front of us. Fondling her in front of us. That's one thing. He didn't have much in the way of boundaries. So, I didn't really know what it meant to be. I mean not having examples outside of home, what it meant to be intimate with people, not sexually but just intimate. But I really didn't know for myself. It was basically if a boy wanted me, okay. I mean, I didn't, I wasn't promiscuous at all. I only actually dated the one guy and then I married him. That was it. I mean, I don't know $* * * * * * *$.

I: You might have alluded to this and I wanted to ask you specifically. What did intimacy mean to you during that time?

P: Not necessarily just sexual intimacy or are you talking specifically?

I: Anything.

P: I wanted to be wanted. I did not feel wanted in my family. Even though I was the oldest and I knew my dad loved me a great deal. My mother did. But again, daddy was inappropriate. Particularly when he was drinking. I felt a great deal of intimacy with him. There was nothing untoward sexually that happened. That I recall anyway. I'm pretty sure nothing did. I've been through years of therapy so I'm pretty sure where that would have come up. But, it was just wanting, somebody wanting to be around you. Somebody wanting you in their presence. Somebody who was, as we say to our own children, I'm so glad you are here with me. That was what I wanted. From family, from 
friends, from certainly boys. Not so much from girls. It was interesting, I was always very standoffish from girls. I did have girlfriends but not huge numbers of them. I don't know why that was but I just didn't really care if they wanted me around or not. It was more if boys wanted me around. I guess, that I'm getting all psychotherapy about it, I think it was, I felt like the love I got at home was from my dad, so I didn't, so I transferred it out into the world.

I: With your, from what you said, I understand you got your understanding and your meaning from your dad. Did anybody else have an influence on that?

P: Well, his mom. His mother I felt very close to. Just almost wishing I, I can remember wishing she was my mother. ${ }^{* * * *}$ I remember wishing she was my mother. That I could just live with her. I don't know that I cared if she was my mother or not, just I wanted to live with her and I felt close to her, but I didn't open up verbally to anybody really much. I wanted, I didn't have any trust that if I really told people what I really thought, or how I really felt, that they were still going to want me around. One of the best therapists that I had for years after several years, he finally said you do realize that you were depressed most of your childhood. And I said, oh that's what that was! So verbally opening up but I always wanted physical hugs, kisses, touch, and I guess I was fortunate that nothing bad ever did happen to me because I was so needy in that area as a kid. And even into high school, I was pretty fortunate that nothing bad really happened. I mean, I did see some guys but never dated guys. So, I was incredibly lucky that I did not end up with my overt need getting into a situation I wouldn't have known what to do with.

I: How did you identify intimacy in yourself and your partner? 
P: Well, sexually I was and continue to be very interested in sex. I can certainly live without it but I much prefer that I have frequent sex, good sex, but also if he would listen when I talked which he wasn't real interested in doing. At the time, I couldn't understand why and now I go well, of course, he wasn't ever. You just didn't pay any attention to what he was interested in but I did want and I was searching for friends after we married. I was on a constant search for other people too, that were interested in what I had to say. To me, that felt very intimate. Not necessarily emotional stuff, just that wanted me around because they liked what I had to say and how I did things and who I was. That was kind of, I mean I was frustrated in it partially because I wouldn't be emotionally authentic. I didn't know how to be emotionally authentic with people. I mean, I'm very clear on that now. Everybody's always thought, well up until the last 10 years or so that I was extremely self-sufficient and didn't need a whole lot because I never opened up. I wanted somebody to magically know what I wanted and particularly my husband, he was supposed to magically know what I needed and wanted. Now I don't think it was that, now that I look back on the times, I'm not sure that that was that rare. I think a lot of us were raised in that sort of Cinderella story where he shows up and he magically knows what you want and what you need and thinks you're wonderful for it.

I: Okay. When you think about your partner, what meanings of intimacy did you share? P: Meanings of intimacy? I'm not sure that we did share much. I really don't think so.

I: Know what ways they differed? 
P: I do know that he thought that I was oversexed. That I was way too interested in sex to be a good Catholic girl. Which probably I was. I do know that he began to feel very guilty after about a year of marriage when I kept saying, "No, I don't want another baby." Because in the Catholic Church, I do know that, this is mostly sex stuff. I do know that I was interested in trying things that he wasn't interested in trying. He was not interested in getting a blowjob or giving oral sex, he thought that was disgusting. I mean, you know, beyond that if you can't even go there you're not going to go anywhere else either. You know what I'm saying? Am I answering your question?

I: This is actually a great segue into the next question. What was your understanding of sexual expression?

P: Well, I think I believed and maybe still do, I don't know don't hold me to it, that it ranged from every kind of loving touch whether it's holding hands or the gesture on the face or just you know, putting the arm around you, just sort of you know, I want to touch you, I want to be close to you, I want to physically to be close to you. To me that was, it didn't have to lead to sex but that was sexual to me. That was sexual to me. It actually kind of still is. I can get very turned on very quickly by those sorts of things.

I: So, what does sexual expression mean to you?

P: I was wanted. Not necessary loved, I was wanted.

I: From him or from her? [Not clear on what is being asked/words used. Difficult to hear so this may be incorrect] 
P: You know? I don't think there was real life. I think it was movies and books and sort of a culture of acidity [?] that females were supposed to have sexual initiative. Maybe I'm struggling too hard. No, I don't think it was from reality because I certainly didn't learn it from home. I think it was just my ideal, maybe related to the "he's magically going to know me."

I: Any movies or books come to mind? [Participant speaking over interviewer] P: Oh God, all those black and white **** movies and Gone with the Wind is the pick me up, carry me up the stairs, and ravish me and I'm going to think it's the best thing since sliced bread. Yeah, I've always been a huge book reader and a huge movie, huge movie and you know, in those days and in those kinds of films, sex is implied. You don't see it and to this day a really well done scene that doesn't show you, I, porn does not do much for me. But implications, you know, touches, fingers, doing this whatever it is to me that's incredibly sexy. I think that I just maybe the world I was existing in wasn't very attractive to me and so that looked like a good bet. Not understanding, or maybe even caring, that it wasn't real. I didn't have that much insight when I was that age. I: What meanings or understandings of sexual expression did you and your partner share? I think you somewhat answered it before...[participant speaks over interviewer]. P: I'm trying to think if there's anything else I didn't lead to. I mean, I sort of understood his point of view and felt incredibly guilty that I didn't share it. I thought that's how it's supposed to be but, so perhaps that was a shared, maybe I wanted to be like that but something inside of me, something at my core just wasn't that good Catholic girl that only wants to have sex with, he wants to have sex and only wants to have sex 
more to have babies and babies are going to be the most wonderful, fulfilling thing in the world. Which is what both sets of parents kept $* * * *$.

I: Okay, now let's move into your early adulthood period when you ****. At age 22 and 23 on your timeline, you wrote that you experienced a sexual relationship with someone who you stated identified himself primarily as gay. At this time, what was your understanding of intimacy?

P: I was beginning to understand. I was still married to my husband and actually this gentleman and his partner were friends of his that he had introduced me to and I **** these guys. I thought they were fabulous and they were so unlike anybody else that I, that we, ran around with. I was beginning to understand and to have been able to observe even among friends but especially with these two men not, I was beginning to understand that intimacy was this desire for the other person and didn't always have to be about sex. I'll tell you the story of that and maybe that will help. I don't know. This was 1970 but the marriage was almost over. We'd been friends with and I was dropping something off at their apartment and I knew that John had been sick quite some time. And nobody knew about AIDS but it was around and nobody just knew and I walked into a situation where I knew he'd been sick and I knew he was feeling better physically. I'm very embarrassed by this story and I don't know why, maybe I've never told it to a gay man. They had had a terrible, terrible, terrible fight, terrible fight evidently and he was just beside himself. I mean, just mourning and just worrying you know, oh my god he's going to leave me. You know, it was that bad of a fight. I was, we were close enough that we hugged on occasion and it was pretty much our parting gesture and all that kind 
of stuff. We were sitting on their couch and I was just kind of, you know it's okay, letting him cry on my shoulder and talk and blah, blah, blah. It was literally one thing led to another and I was shocked, shocked. Not shocked in a bad way but just overwhelmed by “what do you mean this is moving along?" I mean, I didn't say it but in my mind I was like, this is going to go somewhere, you know? He kissed me and said oh thank you and the kiss became something else and blah, blah, blah. We ended up having sex. He didn't tell me a while back that he had been with women prior to coming out. We ended up having sex. I remember him insisting that he wear a condom. I was like, I'm on birth control pills and it's no, I need to wear a condom. I couldn't quite understand it but I was like whatever makes you comfortable is fine. The sex was so different, very different. There was a lot more appreciation of my body than I had felt from my husband. Kind of an awe of my body and a lot of talk and slowness. It was like something just opened up inside of me. I didn't know anything could be like this and I'm not in love with this guy. I mean, I loved him but I'm not in love with this guy. He has this partner and their going to work this out. I found out later that, in fact, he had what we would now call AIDS. And because he and his partner were both biochemists they sort of had an inkling that there was something that was going on.

But, that particular experience was a great leap forward for me in terms of understanding. If we had not even completed the act, it would have felt like the most intimate thing I had ever with anyone. Especially the emotional height of it because I was truly concerned for him. I mean, he really seemed like he was desperate because of this terrible, terrible fight which I never did completely understand what it was about to be honest. So, from that 
particular incident, that was the beginning of the end of that marriage. It was, I didn't know it was almost over, but it was in fact. I was like, why should I put up with this when that is available. Not with him, but that is out there. There's somebody that I can have that level of be completely myself and he's completely himself and we know each other's shit and it doesn't matter and he enjoys me and I enjoy him. There's a lightness as well as an intensity and that may have been because I knew he was a gay man and I was very curious about how he lived and how they had sex. I mean, I knew how they had sex but you know what I'm saying. I don't know, I'm kind of rambling here. I'm not sure I'm addressing what you want to know.

I: Actually, it's interesting that as you related this story, I'm wondering how or what impact that experience had on your meaning?

P: Oh, you know, I guess I understood for the first time that there could be intimacy. That having sex wasn't just sex. That there could actually be something called intimacy. Which I don't think I had even probably, I'd started to understand that it existed because I observed other people's relationships and saw that they had a way of communicating and a way of knowing each other and a way of looking at each other even in a room full of other people. It made me increasingly dissatisfied with what I had with my husband which didn't hold any of that. Our life was kind of day to day, to day, to day, and what did you do today? Oh great. What are we going to do now? There wasn't any talk of plans or future or what do you really want out of life or anything like that. I didn't know people could do that. So, I'd started to see it and then the time, and watching John and Steve and the whole time it was so interesting. 
I remember saying to him after this was over and we were getting dressed and I said, I have a feeling you love Steve. You guys were meant to be together. I mean, you guys are wonderful together and you adore him and he adores you. He said well, this is kind of, it's not time for that. It's just you and me. I remember crying. I want to cry right now. I remember sitting there crying and crying and crying. He said I'm sorry, did that bother you? I said no, you're just showing me something. I remember saying you're just showing me something and I didn't know what it was to be honest with you. I'm watery. So, I think it did. It just rocked my world in terms of there is something out there that's more important than just getting laid. It was a huge leap forward and it wasn't, whatever it was we got we split up in 1975 . So, that was late ' 74 or early ' 75 . When we split up, I just looked at him and said I don't want to do this anymore. I'm out of here. Wasn't very nice. But that was the kind of relationship we had sort of, in a way. In a way, it wasn't any point in trying to make my leaving an intimate act when there hadn't really been any intimacy in the relationship. I don't mean to sound like it was torture or terrible or, you know, it's just what did I know? I was 18-years-old and I had no examples before me growing up as to what a marriage was really, or even a good relationship really was. I: Now, at age, 20 from 23 to 28 on your timeline, you indicated you had multiple partners. Some [indecipherable] only once. How would you describe these different relationships in terms of intimacy and sexual expression?

P: I don't know if there was a whole lot of intimacy in some of those. Actually, most of those. I just was, I mean, I had left my husband. We were divorced and I was, I remember being very grateful that I hadn't dated around or been with a lot of different 
guys earlier because now I was older and I could do stuff. I was doing what some people do when their younger. It was mostly, I mean, there were bar pickups. I won't lie. There were pickups sometimes I just zeroed in on somebody and thought I'm going to go home with him. Sometimes, you know, for whatever reason he decided he was going home with me. Some of the people I knew from work, or whatever. Some bands. I had a lot of friends in bands. I don't know that there was a lot of intimacy. There was a lot of just free and joyous sex. Again, it's one of the things I look back on and oh God am I lucky? You know? But, everybody was doing that at that time. There were some drugs involved so sometimes it wasn't, you know, because there were a lot of drugs available in the midto-late 70s. I was into the, everything that I'd never done I was fixing to do it.

So, I'm not sure how much intimacy there was but I learned a lot about myself as a sexual being. I learned that there were men out there. I never considered women. I didn't know any lesbian women that I knew of. Come to find out, I did but I didn't know they were. They were very closeted. I did learn that there were an awful lot of men who just appreciated a really randy woman. Some of them, there were a couple of guys, that really wanted to further the relationship but I was already moving on. So, I don't know that there was a great deal of intimacy but I did learn that sexual appreciation. I did learn a lot of technique. I'll stop there and if you want to follow up you go right ahead.

I: Actually, I was wanting to move on to your second marriage.

P: Okay.

I: At 28, which is the second marriage, what was your understanding and meaning of intimacy during that relationship? 
P: I really believed I didn't like this guy at first. He was all about me and I was just not so much about him. I don't really remember now why. I didn't, perhaps it was the smarter part of me that didn't like him at first. As it turned out. But anyway, he was all about me and so, I, you know, he took me on dates. That's where we had sex, that didn't **** have sex with him. And that was really, from the beginning, that sex was really pretty remarkable in the level of openness. As time went on, and I was a little manipulated, not by him but by my roommate at the time that really thought he was great. He kept telling ****. So, I was really a little bit manipulated but I was okay with it. I was still open to whatever was happening. I think I left a guy off of there too. Early on, I was, I did. I left this person off of there. As I was seeing Robert, that's my second husband, as I was seeing Robert early on I was also seeing a guy from work. I met ${ }^{* * *}$ at work, who was married. That was awesome but it wasn't very intimate. It was kind of like, okay this is something bad that you're not supposed to do. Let's see what happens and it turned out okay. I mean, you know, it didn't last very long. But anyway, I was also seeing this other guy and I'm pretty sure Robert knew that I was seeing him because I'm not real great at hiding. Didn't see any need to. I wasn't married to anybody. Why would I have to hide shit from you? I think that made me the more attractive to him in some way. So, as it moved along and I stopped seeing, I think it was $\mathrm{C}^{* * * *}$. Anyway, I started getting more and more into Robert because it seemed like I would open my mouth and start a thought and he could finish it. I thought wow, this is great. We saw things the same and we were both very intellectually curious about the world and you know, he was introducing me to books and 
I was introducing him to books and we were going to different kinds of music things that I had never gone to and then I would take him to hear music that I liked and so it became very quickly after that, after that started happening where I felt like this person really saw who I was and enjoyed who I was and it wasn't just about the sex which was amazing. It wasn't just about the sex. It was an intimacy of the minds as well and I felt like in some ways this *** was my soul mate. It didn't last very long. It, for about a year and a half to two years, that was I felt like I had found this person who can appreciate me and really digs me and wants to be with me and I'm important to him. He's important to me and I also was very into him because he came from a family that was even more fucked up than mine. If you want to follow up, go ahead.

I: That experience, how did that experience effect your understanding and definition of intimacy and expectations for sexual expression at [indecipherable]?

P: Well, like I said, that once I started getting into him as much as he was into me, that year and a half to two years I felt like this is how life is, this is how life's supposed to be. This is a relationship that's going on this way. What's interesting is little by little after that there started to be cracks in it. I was devastated. It was, you now, it's one thing to not ever know you can have something and it's another thing to have it and adult children of alcoholics, which you may know, we're waiting for the other shoe to drop on our heads. So for an adult child like myself, to allow ourselves to believe that it can happen, incredibly difficult. It didn't seem difficult at the time, I was like oh yeah here it is. Open up to it. But, then for it to start going away, it, I hate to use the word again but it's devastating. Devastating. It started, little by little, cracks. He would be didn't give a shit 
what I had to say and then of course he'd come right back with oh I'm so sorry. That won't happen again. An adult child of an alcoholic that I was might not have ***. I didn't realize that I was looking for my daddy all over again. I had no clue! But, yeah, so I really had expectations now and I couldn't understand what was going wrong. I couldn't understand it. In some ways, dumb, the dumb things that people do to try and hold onto a relationship may turn out not to be so dumb but I decided in my 30 s, I was in grad school at UK and he was there with me. He had moved to Lexington with me which I took as a great sign. I mean, he stayed but you know it wasn't the good relationship. I kept looking for that first year and half to two years. I kept thinking that's going to come back. That's going to come back, like a dumbass. I knew I was you know, the biological clock was ticking. I knew I wanted to have a baby and I thought maybe that's the answer. She has turned out to be the most wonderful thing that's ever happened to me but it was a stupid move to be honest. I mean, because that guy's boat had serious leaks. I was coming to find out that he was the best practicing alcoholic I've ever seen. And then too, and just as I said his family was more fucked up than mine and of course that certainly doesn't leave you whole and able to walk down the street and whistle. So, you know, I mean he was a mess but I decided I was going to have a baby and I got pregnant. He was overtly fabulous about it and boy it went downhill from then even. I, one of the things that I don't know why I need to say this but I need to say this. That man never would have sex with me when I told him I was pregnant. And I was the horniest pregnant woman you've ever met in your life. He would never, I was throwing 
myself on him and he would not have sex with me. Anyway, so I don't even know if that answers the question. I keep going into my stories. Okay.

I: At approximately age 48 on your timeline, you indicated that there was nearly zero sexual expression or intimacy. What had changed [indecipherable]?

P: ${ }^{* * * * *}$. Oh, I was married to him. He was just, it was a nightmare. ${ }^{* * *}$, it was a nightmare. He'd been recovered with, well rehab twice. Waste of money. I wouldn't give up. I kept thinking there's something that I'm, I'm doing something. If I didn't do this and he was very quick to tell me it was all my fault. I thought I was better than him or whatever the hell he would say at the time. He was drunk all the time. So you don't have much sex when somebody's drunk all the time. I didn't want to have sex with him. I did not want to have sex with him at all. There were times when he would sort of grab at me and I would just, one time that I didn't stop him felt like rape during that time. I thought, never again. Not ever again. So, and I was hiding from everybody. I was so ashamed at how I was living and how I was allowing myself to be treated and I was aware that I was allowing myself to be treated this way. I mean, I knew I had two good legs that worked and a good job. I was in fact supporting him and had been for years. I knew I could walk. I knew I could take my daughter and book but I didn't do it. I don't know why. So, I was hiding literally from everybody. Family, friends, and I hid it. There were people I worked with that did not ever know I was married. This is in a small town.

I: At age 52, I wasn't clear but I presume the marriage ended?

P: Yeah, it took me that long. 
I: So, between age 40 and 52 nothing went on?

P: Nothing.

I: I wasn't sure I was clear.

P: No. Not a thing.

I: On your timeline, from age 55 to age 60 you had a relationship with one partner that you identified as being a self-professed bisexual. What was your understanding and meaning of intimacy during that time and within that relationship?

P: For the first year or so of that relationship we were just friends. There was nothing physical or sexual. Well, hugs but you know. Just friends. We described each other as separated at birth. I met him in a 12-step meeting. Both of us had a past, you know an adult child. His was an alcoholic. No difference. From just like the very beginning, he was younger than me. About nine years younger than me. Just from the very beginning I was just fascinated by what this guy ***.

There wasn't any I pushed it or he pushed it. It was just kind of a natural flow and we just became almost inseparable. We did everything together. I was never interested in this guy had to say and what he did. He was raised a Mormon which I found just horrific but I was very interested in how does this form a person? We were both very interested in emotional, psych emotional, soul aspects of both concurrently and adult child meetings as well as both doing psychotherapy with different people. So, you know everything was out in the open you know. Or so I believed. I was very drawn to him sexually but I was, no, I'm not going there. Then one day it just sort of happened. Turns out he had been 
doing the same thing. Thinking the same things. It was probably, it was better than that first year and a half to two years with Robert.

In some ways, partially because we were, I was at a stage where I was learning you have to be vulnerable. You have to let people in. He would just open his arms because I'm distraught. I was worrying a lot about myself. I was going through a lot of change. I had a fabulous therapist who was really helping me open up. So, I had just sort of learned it was still hard. But I had sort of learned that you have to open up, you have to let people know who you are even if you think they're going to run screaming with their hair on fire. He never did. I was just like wow, I love that guy probably more than I've ever loved any guy. He was just amazing in all those things for a long time and towards the end of that relationship. I was very accepting of his sexuality. He had been with men and I was just like that's cool, I don't know what it is about me that's attracted to gay men but that's okay. You know, that's cool, if you are interested in being with a man I'm fine with it. You know, even once we start having sex, the sex was awesome. Awesome. Partially, I don't know, I don't know why it was so awesome. Then, it was, I don't know. I went to, his mother died, when we were together and it wasn't unexpected. It was expected. So, his family was devoutly Mormon. He had been trained when he was, he was going to be the new Joe Smith. I mean, he was like a direct descendant of Brigham Young. I mean, almost literally on his mother's side. Yeah, I know. He had an awakening when he was on his mission which happens a lot, I understand. It scared him so badly that he fought and fought and fought against, I will not be gay, I will not be gay, I will not be gay, because you know you lose everything if that's your situation. Your 
family, your whole world. I was just in awe of the fact that he had finally made this break and had come to accept himself. What I found out, and I know this is convoluted. What I found out toward the end of the relationship was he made the break in lots of ways but emotionally he'd never made the break. So, he still saw the world through the Mormon eyes. He would, come to find out, he told me and I'll never know if this was actually true but he finally told me that I couldn't have, you know. Broke my heart. I mean, broke my fucking heart. What was funny is, this is a sideline, I was sitting in the bath this morning and I wasn't thinking about coming here or anything. I thought, and I thought this before but this time it really went deeper. If he hadn't ** me that way, if he hadn't done that to me, so many things in my life that have been just life altering would not have happened. I don't know if I'm unique as an adult child or not but I experience anger with a whole lot of energy.

So, anyway the intimacy was on every level. Physical intimacy, not just sexual physical but just you know, the want to touch, the need to touch, the need to be around each other. It was really, I mean, I look back on it and go wow that's really not healthy but at the time I was just happier than a hog in slop and believed he was too. For all I know, he was and he just got scared. I'll never know. I'll never know the answer to him. But, it was amazing and it was transformative for me. He appreciated my sexual need. He appreciated, by that time I had started to come to realize that occasionally, not very often but occasionally I would see a woman and go oh my god I think I've just come. I mean, literally. Of course we traveled. We would go around and sometimes we would go to 
gay bars and we'll pick somebody up *** and I wouldn't give a shit. Of course there would be woman there. There was a whole lot of that sort of energy in our lives. We did not live together but we lived five minutes from each other. We were there for each other constantly. I learned later that everybody else in my life went, "what the fuck were you doing” but I didn't care. I guess that answers the question.

I: Okay. Now, also on your timeline from age 59 to 61 , you said you had several nonsexual but very intimate relationships. What was your understanding of intimacy and expectations around sexual expression during that time?

P: All those relationships were outcomes of having had that relationship with Andy. I, when he finally said you're not good enough and I don't want to be with you anymore, you know after the grieving and the screaming and the shouting and the throwing shit and the crying, I did something I'd always wanted to do. There's a school in California that at the time was called Meridian University. It's in Petaluma, Northern California. Now it's called Institute of Imaginal Studies and they do a weekend extensive Masters or Doctoral program in Psychology and it's when I learned about it, and I learned about it from him. When I learned about it I knew I wanted to do something else. I wanted to have another challenge in my life.

I'd been working as a college librarian for ***years. I liked that work but I was kind of okay time to move on and when I learned about it and the way they do, they have a kind of a whole subfield of depth psychology called Imaginal Psychology that they transmit through, you just sort of go through it. So, I decided okay this is a bookend to that experience. He's, you know, I mean I still lived five minutes from him but you live five 
minutes from somebody and never seen them. So I moved back here, which is where I grew up and said I'm going to find some old job. I know I can live here cheaply. I'm going to find little job that will allow me to go attend this school.

I'm getting to the answer to your question. My mother had died a couple of years before and it took a couple years to probate everything. Each of the five of us got a good chunk of money which surprised the shit out of me because I wasn't quite sure how I was going to pay for the school. I was going to have to go to California once a month for at least two years. So, there's plane fare and blah, blah, blah. It was a residential school so you didn't have to stay in a hotel. They fed you and the whole nine yards. Still, you have to get there and get from San Francisco to Petaluma. [Indecipherable] and explored it and I was more than sure than ever that's what I wanted to do.

So, anyway, I did. I, number 1, it was the first thing that was good about it was able to see him for the first time and go fuck you and the horse you rode in on here. You don't have all your shit *** this stuff. Because he was at the school, which wasn't why I went. It's a hard experience to explain to somebody. You go through and cohort. I will never be closer to anybody than I am to those people in that cohort. Because the way we, the educational style, or the education practice that happens there is, of course you read the books and you write the papers and do the study and learn what has to be learned, but it's experiential as well. It's not like [indecipherable] weekend or anything, okay? For example, I know what class was that, classes had odd names. There was one on working with dreams and part of the final thing in working with dreams class was you were supposed to, you had a dream that you had worked on, your paper was around this dream 
and weaving theory and all the ways of working with dreams. Which were many and varied. We studied a lot of them and a lot of the study was you just studied it. It wasn't like a classroom where you repeated. They assumed that we were grownups. We were all different ages, we were all different backgrounds, and everybody was amazed and shocked that I came all the way from Kentucky until they got used to it. What we were supposed to do was the dream that you used as the center of this paper, then you were to come to school that weekend, the final weekend of that quarter and share in some embodied way with your cohort, this dream. People did all kinds of strange stuff. There was, everybody did their thing. I had totally forgotten about it. So, all of a sudden I was like oh shit we're supposed to do this. [Indecipherable]...I got nothing. Well, which turned out to be the best thing and those are sometimes the best thing. So, I had in working on this dream, you know Jeremy Taylor's work? Books on working through dreams? Very interesting. Jeremy had suggested, I did a work shop with him a couple of years before then. He's an amazing man, *** minister. That if you were having trouble dealing with some aspect of the dream, it would somatically and you know, gave some different ideas. So I put on some music and just sort of moved. It didn't help me, actually. So I decided, okay, I [indecipherable]. Those sorts of experiences are irreplaceable. Not just for you but for everybody else in the room. I mean, that was the kind of thing we did a lot. In doing those sorts of things and when you have a lot of time to when we had to do exercises outside of the weekend. Of course, me being in Kentucky, I've got to do them over the phone with people. But it never seemed like it was a problem. 
The intimacy of being with those people and the opening up that happens that is often so incredibly painful. I mean, just the boxes of Kleenex we would go through because you just start with something, you don't know where it's going to go even in just responding to a question maybe. The whole idea is how can you help somebody else in a therapeutic situation if you don't know how you feel on what's going on inside of you and why don't I feel comfortable with this person, happening within me. So, a lot of our training was to elicit and to come to an understanding of yourself, maybe the child that's still in you. You know, maybe the older person that you are not yet but you are, you know what I'm saying? You know? So that was the kind of training and I don't know. It was draining and terribly hard sometimes and there were people who wouldn't fully participate which was also part of the process. We were together, literally, from Friday morning to Sunday afternoon. We slept but other than that we were together. You come to know, it's kind of like being in a foxhole with someone. You come to know those people in a way, I don't know anything about your past life really. I don't know who you are. I've never met your husband or your kids. I've never seen your house. It doesn't matter. I know you and you know me. The most intimate. The most intimate without having any sexual anything. I mean, there's a lot of hugging and touching. It's California after all. There's a lot of $* * *$ work and hot springs and sitting nude in the tub after the weekend, but nothing sexual.

There was no, there was one guy I absolutely adored and to this day I love him to death. When I left, I decided to stop with the Masters and some of them were staying on for the $\mathrm{PhD}$ and when I left, I was the only one leaving at that time. The final hug was 
[indecipherable]. I've been lusting after you for two years. So there was that level of, and he was serious. The most intimate without having a thing to do with sex.

I: So I can clarify, discussing intimacy in that context was it open and raw or?

P: Not necessarily raw. There was a healing aspect.

I: Okay.

P: But, open definitely. Vulnerability was just sort of [never there?] I mean, you know, if you chose not to be vulnerable, I mean they weren't going to kick you out or anything. And, you know, we were all very, what was interesting is we did have a couple people in our group that were never able to become truly vulnerable. It just scared them so badly. You could see it. What was interesting is those were the people that everybody loved so much because we knew how hard it was. I mean, and I discovered about myself, I learned so much about myself. I'd been in therapy and I continue to go to therapy because one of the requirements of going to the school was you have to have a therapeutic relationship because shit comes up that you got to deal with. So, I was very fortunate to find a gentleman here who actually sees children and I convinced him to see me. When we ended our relationship, he said you know when you first came I didn't understand this but now I understand why you needed somebody that deals with *** because your child came in here every time. Yeah, so it was, yeah. I was so, I learned so much about myself. I finally accepted. I've been told all my life you're a leader. I would be like when I was kid, I don't want that responsibility. What the fuck is that about? I don't, go away from me with that shit. I finally came to an acceptance of the fact that it is truly my nature. It is not something I get to choose. Yeah, I mean, I never, 
after the first weekend I thought oh shit I'm not coming back here these people are nuts. But, I mean, there's something about them. I don't know if you've ever been there but there's something about being in California.

I: On your timeline, in the future time you wrote I hope to find an intimate partner. Could you describe what you mean by that statement?

P: I don't give a shit about *** anymore although I have no idea if I would be interested in having sex with a woman. I've never experienced it so how would I know? But I'm certainly open to it. I am hoping for somebody to come along or to fall into my life or for me to stumble over, or whatever, because I can't do the online thing. I've got to be [indecipherable], who finds me interesting and who I find interesting and who I want to touch and who wants to touch me. I don't care particularly what they look like. That's different. I mean, I guess if I saw somebody and I was repulsed by them then it would be different. But, I'm not particular about looks, age. I've never been particular about age. I, somebody that doesn't have to live with me and I don't have to live with them and we can maintain households. As long as that can be made to work. That wants to spend some of their free time with me. That enjoys spending some of their free time with me. Who's going to be there if I need him and who knows that I'll be there. To me, all that's intimate stuff. We don't even have to agree on things. I could deal with a Republican, it's fine. That would make life really interesting. An intelligent Republican, I'm fine with that. Yeah, that's what I'm kind of hoping for. I mean, my sexual desire has not backed off much. I don't really know if that's because I haven't had any sex for so long and so it's still there or what that's about. I can get aroused pretty easily so I'm hoping 
for an active sex life which doesn't necessarily have to mean, you know, it could mean what it means. I mean, I'm open to, you know, how could sex work for two people as they get old. I don't know how that works.

I: Well, Heaven forbid that it happened to you or anybody, I'm just curious when you think about the future and the possibility of at some point being a resident of a long term care facility, what concerns do you have about your intimacy and sexual expression needs?

P: Well, I know people whose parents, single parents, who have been thrown out of places for approaching people about, approaching people in a sexual fashion. I wouldn't be surprised if there's not a lot of that because I, those places are institutions. Institutions don't like that. Institutions want everybody to sit down and shut up and follow the rules. Well, that's my experience of institutions anyway. Could be wrong. I mean, the institution I went to school in California wouldn't be like that but even they would have frowned on us having sex while pretty much inside of the cohort. [Indecipherable]. So, I, you know, I'm more than a little worried. I truly, truly, truly, truly hope I never have to go to one of those places. I am open to the idea of perhaps going to a place that has apartments. Independent apartments. Even assisted living, but oh dear God, I mean, that just scares the bejesus out of me. It truly does. Partially because I don't, I have spent time in those places over the years and I've had all kinds of jobs and I used to work for hospice and I would occasionally be an eleventh hour volunteer, which is the person you know what that is? Okay. So often that's in a nursing home and the family can't get there and you just see these are not people, these are just these things. So, I really worry 
about that. I would probably be kicked out. I would probably be kicked out. I would probably be, my daughter would probably have to come and get me.

I: What things would, given your experience with that, what things would you want to see change or be different so that if it were a situation you found yourself in, you wouldn't be kicked out... [talking over interviewer]. P: It's a culture change that has to happen. Nursing homes, even in assisted living, even some of these independent apartments, they're corporate now. They're all corporate. One of my jobs since I help people with disabilities, I work and I'm working with two people right now who think they want to work in that sort of environment and I'm always having to remind them. This is a corporation. I didn't think nursing homes were quite ****. I said, 'hmmm'. So, it's a cultural thing and it's not just the culture of the, of that institution. It's the culture generally. Reach your 60s and the culture out there in the world, the young culture particularly, ignores you. You don't exist anymore. You're in the way, you're too slow, you don't know how to text, you still think you have to balance a checkbook. They haven't done that.

So, it's a cultural thing. I, one source of specific change, it's got to start in the education of the people who, healthcare education. My other job is working at the medical school training doctors, future doctors. It has to start there. This idea that old people are just husks, that they're not people, that you don't have to listen to them. That, oh they're demented. They don't know what they're talking about or the common assumption, and I think that this has always been an assumption, you reach a certain age and you don't have sex anymore. You're not interested in sex anymore. You're not a sexual being anymore. 
That's partially American culture. We don't like to think of anybody as sexual beings. Yeah, so I don't know. It has to start with the education of those people that are the care providers and it has to, it also has to start with each and every one of us. I think it's my job and my duty at this point to be a loud mouthed broad and I'm real fucking good at it. My daughter's friends know from being around me, my daughter is 29 , they know from being around me and I've had several of them tell me this, I didn't think people your age were this lively. Well, most of their parents are younger. I didn't have a child until I was 33. I'm like, fucking-A, you know. This is, I'm still alive. I'm still here. I've had a heart attack and I'm still here. I've lived through alcoholism and lots of other stuff and I'm still here and by God, I am tired of saying yes sir and no sir and can I and will you. I: Those are all my specific questions. I appreciate and thank you. Is there anything else you feel like would be important to know? What you shared was amazing...[talking over interviewer]

P: No, well no, I can't do any of this without telling a story. That's what I do. I tell stories. Not really. I mean, the only, I'm trying to think. I've pretty much told you all kinds of stuff that I never even thought I'd be saying and I'm okay with it. But, not off the top of my head. I mean, I hope you haven't been frustrated with my definition of the meaning of intimacy.

I: Not at all.

P: Okay.

I: I have no definition. 
P: You don't have an agenda.

I: Whatever you, whatever comes out, comes out. I do have, if you don't mind, this is not part of the study but there's something that I'm interested in knowing. P: Oh, absolutely.

I: What was this experience like for you? This type of an interview using these topics. P: Oh, it was good. It was [indecipherable]. It was revealing. Well, I mean the fact that I'd forgotten to put somebody on that timeline and remember them, it's neither here nor there. I mean, that speaks to the importance of that relationship. I, you know, a couple of times I remember saying I'm a little embarrassed by this and I didn't, I'd never felt that when talking about it but then I realized that you're like the third person, it never came up in therapy. No reason to really. Other than the fact that it was such a life altering relationship or situation for me. So that was interesting. So now I get to sit with that, well why would I even ****, let's be with that a while and see. I did know that I have had a few dreams that when I woke up, I sort of realized, as I was jotting down, I realized they were related to this. To this talking openly about your sexual. I think it's grand what you're doing. I'm just, I have told everybody I know to please contact this man. He needs subjects and this is great work that he's going to do here. I've had several people say oh my God he'd never be able, he'd have to get three timeline for me. I'm like, really? That's interesting! I don't think Shawn would care.

I: That's true. 
P: Yeah, so no it's been a very positive, I mean, and I think you're probably going to get that from most people. Most people wouldn't volunteer to do something like this if they weren't already pretty open.

I: I'm finding that out.

P: Yeah, well people that are funny about sex are not going to sign up, are not going to sign up for a study like this.

I: I know.

P: If they knew what it was oriented towards, in the future, you might get some people that you wouldn't get otherwise but I don't know how you could say that.

I: That's true. Well, again I really thank you. I appreciate it very much.

P: Sure.

I: ***very, very helpful.

P: Is this the end of it?

I: This is the end.

\section{Karen}

Interviewer: Okay. Now, at age 17, you indicated you had your first sexual experience besides kissing. At age 18, you indicated intercourse for the first time. Also, you indicated at the same age that your mother cut you off from all emotional and financial support.

Participant: Yeah.

I: What was your understanding of intimacy during this phase? 
P: Well, the way I was raised, they were really loving physically. We had hugs and I got to sleep with them when I was a little girl if I got scared and stuff like that. So, when I turned 18 and she just kind of like cut everything off, I didn't understand what I did wrong. It felt like I did something wrong. Her response was, "Well, you're 18. You're an adult now. You're on your own." But, she had never told me that before. It was, it was difficult and my dad didn’t cut off support but my mom did.

I: How did your experiences of dating and becoming married in this phase of your life affect your understanding of intimacy?

P: I thought I was supposed to get married. I thought that was my only option, but looking back on it now, I never realized that then, but that's what I thought. So, I kind of married the first person I thought I was in love with and it ended up being a nightmare.

I: Did it affect your understanding of intimacy?

P: I mean, he was incredibly abusive. The emotional abuse was worse than the physical abuse because that stays in your head. I had a pretty good understanding somehow of, I mean, I never thought anything was my fault or I never thought I should stay. My mom's response was you made your bed, you have to lie in it. I thought, like hell I do. She didn't even believe me that he was abusive until we actually got divorced. I divorced him as soon as I could. I got pregnant with XXXXn, we were married for 3 months and I got pregnant because everybody in his family said if he has a baby he'll settle down and I believed that. I believe them, you know? That only made it 10 times worse. Back then, in Indiana you couldn't get a divorce when you were pregnant. I had to wait until I had 
XXXX. He was good for about a month and then one time he shoved me while she was in my arms and I left that day and I never looked back.

I: Wow.

P: I worked with Turning Point a lot. The domestic violence shelter. I went to the shelter. I got all kinds of information on domestic violent and stuff and that's actually what got me in social services to begin with was that. I went back and volunteered a few years later and you know, evolved from there.

I: What did intimacy mean to you?

P: To me, it meant safety. Emotional and physical safety. That you could express yourself. That you could totally be yourself and the other person would be accepting. I definitely didn't experience that with him, but that's what I still thought it was. I still thought it was the same thing I grew up with.

I: Where, or from whom, did you obtain this understanding?

P: Mostly from my dad.

I: Okay.

P: But a lot from my mom, too. My mom had really good talks with me and they were very open with your body and stuff happening and sexuality and relationships and sex and all kinds of different things like that. We had all those conversations.

I: Now, how did you identify intimacy in yourself and in your partner?

P: With XXXX, that was abusive? There wasn't any.

I: Okay. Tough to identify if there wasn't any there. 
P: No, he was not, he was so high every day. The bong sat by the bed. First thing, last thing. If he didn't have pot, he drank. I don't know if he did anything else because I don't think he did, but I stayed completely out of that. So, he was never there. I knew he wasn't there.

I: Right.

P: So, there was no intimacy.

I: How did you identify it in yourself though?

P: I don't understand what you mean by that.

I: How would you present, how would you be intimate? Would you express your intimacy [participant begins speaking]...

P: No. I wasn't, after the first couple times of him hurting me, I withdrew.

I: Okay.

P: There was no trust. I just knew the whole thing was wrong. I just closed down.

I: Okay. That makes sense. What was your understanding of sexual expression during this phase of your [participant speaks over interviewer]...

P: What do you mean?

I: What was your understanding of how you would express yourself sexually [participant begins speaking]...

P: I mean, I just had to have sex whenever he wanted to have sex. There was no, I mean, technically I mean he raped me. Almost all the time. I don't know. Does that answer your question? 
I: Well, I, maybe we'll get there more as we go. What did sexual expression mean to you? Not just there, but I mean at that phase [participant speaks over interviewer]...

P: Well, I mean, it still meant the same thing as when I was a kid.

I: Okay.

P: That it was loving and the person who loved you would not hurt you. Physically or emotionally and that you could be safe. You worked as a team, together to do things. You know, you helped take care of each other when you needed it.

I: And that's how you understood sexual expression? Or do you put them together? Are you putting intimacy and sexual expression, sort of interchangeable?

P: I thought it was supposed to be interchangeable.

I: Okay.

P: But, it didn't end up that way. But, I still knew that what I was doing was okay until I could get out of there.

I: Okay. I got you. Where did you, did you get this same understanding about sexual expression from your parents?

P: Yes.

I: As well? Okay.

P: Well, my dad. And my friends.

I: Okay. Now, we're going to move into early adulthood, 20 to 40 . A lot of stuff in this section.

P: Oh, I'm sorry. 
I: Don't be sorry. I just wanted to prepare you because I'm going to go through it.

P: Okay.

I: On your timeline, at approximately age 20, you indicated that you had several sexual partners. Mostly friends, not boyfriends. One night stands, which you wrote, "loved it". Also, at 20, you indicated that you were married and that your husband was abusive indicating that he raped you several times. At age 21, you indicated your daughter was born and that your marriage ended in divorce.

P: Right.

I: Age 21 to 23, you indicated that you had more sexual partners and also at age 23, you wrote, "When my brother died, my parents were never the same, but dad was still emotionally supportive." Age 24, you wrote that you got cancer and that additionally your 24 and your 21-year-old brother died. Two brothers?

P: No, one brother.

I: Oh, you're at age 24 .

P: I was 24 when he died.

I: Okay, I wanted to make sure because I [participant speaks over interviewer]...

P: He was 21.

I: Okay. Age 25, you indicated that your son was born. At age 27, your marriage ended in divorce. Age 29, you indicated that you had lots of sexual partners and then married again at age 29 . Age 30 , you wrote or indicated that your father died and it was a $* * *$ event. Additionally, you wrote that when your father died, "My mom left the house and 
everything in it. Left the house and everything in it. Here, this is yours." That meaning you and your children?

P: Mmhmm. [Yes.]

I: Okay. Only saw her at Thanksgiving and Christmas after that. During this phase of your life, this timeframe, what was your understanding of intimacy then?

P: I kind of think that, well, I have to clarify something. Okay. I didn't have sex with lots of people until after my divorce. It's switched around. Okay.

I: That's fine. That's fine.

P: Because I didn't have affairs or anything. I think at that time in my life, sex was totally separate from intimacy.

I: Okay.

P: I was kind of how you would think, all my friends say that I think like a guy thinks about sex. I never thought of it, like, I had fuck buddies and I liked it. It was fun. You could date whoever you wanted to date and then, if you didn't have anything going on you hooked up.

I: Okay.

P: There was a degree of very good friendship with those people. There were four of them total, in my life. They were my friends and they kind of ended up being fuck buddies. They were not, I guess we had intimacy like in a friendship you would have. Like, support and they wouldn't let anything ever happen to me or anything like that. They would be a little protective in that kind of thing, but the sex was totally separate. 
They could have girlfriends. They could be doing whatever they wanted. I could be doing whatever I wanted. In my mind, it was completely different and I didn't attach love to that. It was just sex. It was just sex and I liked it and it was fun. They didn't seem to mind.

I: Now, were there any new sources or shifts in your understanding or definition of [sexual expression?] [Recording almost seems to skip at this point. Difficult to understand a word or two] during the time frame and if so, where did you pick that up or learn that?

P: Well, when I married the kids' dad, because the abusive guy, I mean, he got sent to jail and he didn't see XXXX so XXXX adopted her. That's her dad. The kids' dad kind of changed that. I had known him for several years and we just started dating and fell in love and then like, life was normal again. He went to work. He provided for us. He loved Jacklyn just like he loved XXXX. We had XXXX. It was, my family life then became like my childhood family. There was lots of love and lots of attention and hugging and lots of physical things. We were real open with the kids even though we got divorced. We had joint custody before joint custody was the definition of anything. He's still my best friend.

I: That's great. Now, what was your expectations for sexual expression during that period?

P: Well, he was all about having sex. It was really good. We had a really good sex life. That was the best part of the relationship. 
I: So, on top of that, I was going to ask what did sexual expression mean to you at this time?

P: So, then it went to being with one person who loves you and who protects you and who was safe emotionally and you had sex when you wanted to have sex and if you wanted to lay on the couch and cuddle, you did that. It went back to how I grew up.

I: Okay. Good. In what ways did your understanding of intimacy and/or sexual expression differ from you and your partner?

P: What do you mean?

I: Did you have different views of what those two things meant?

P: You mean me and XXXX?

I: Yes.

P: XXXX and I were pretty much on the same track on both of those things.

I: Okay. Now, into middle adulthood, you indicated on your timeline that at age 45 that marriage ended by divorce. I'm trying to figure out. Is that the one with XXXX?

P: No. XXXX and I got divorced when XXXX was 3. The long marriage was XXXX. XXXX, I was married to for 5 years. Jeff, I was married to for 15 . He's actually getting married today.

I: Oh wow. And you said, you wrote you went years without sex.

P: Yes, with XXXX.

I: He was emotionally abusive. There was no intimacy. 
P: No. He was total zero, always.

I: You said it was like 15 years of a black hole.

P: Yes.

I: He was emotionally closed off.

P: Yes.

I: You also indicated that you then moved in with a boyfriend and had cancer, which lasted for 5 years. Age 50, you indicated that you broke up and met a new boyfriend. Got married and didn't really want to have sex because you were very sick. At age 51, you indicated that you would want more sex and that you [recording skip?] during this time of your life, what is your understanding of intimacy?

P: I mean, it's still the same thing. It's still the love and the security and the protection and all of the other things. When I was with XXXX, he tried to make me feel like any emotion I had was wrong. You weren't supposed to be sad. I don't think that if my dad would have, if my dad would not have died, I wouldn't have married XXXX. XXXX and I had just started living together. We weren't getting along and, but when my dad died he was horrible. I didn't know what else to do because my mom literally packed a suitcase and said, “This is all yours. You deal with it. I'm going to my mom's. I'll see you. I'm going to grandma's." Mom literally packed a suitcase and left and her whole house was there. I know! I mean, it was crazy. Since I never talked to her, I didn't have anybody except for XXXX. I did still talk to XXXX a lot. One of the reasons why I 
think he continues to stay in my life. He was there when my brother died. He was there when my dad died.

My view of intimacy and what was supposed to happen sexually never changed. Jeff just tried to make me feel crazy. That I was wrong for wanting a hug and wanting a kiss. He actually couldn't even smile when I came home from work so he drew a smiley face on the garage door opener. We went to counseling probably 5 different times. His first wife said the same thing. If she would have stayed with him, she would have been, and I was totally a mess. You know, I leave XXXX and I'm still hoping that I'm going to find that. I thought I found that with the 5 year relationship guy. The only problem is he's an alcoholic. I don't like alcoholics. [Indecipherable]. Even when he quit drinking, he was like what they call white knuckling it. I was really hurt whenever he left. He left, *** and I went to Las Vegas on vacation. She lives in South Dakota so we met in Vegas. When I come home, he had texted me that everything was fine at the house. Then, at the airport when we were coming back, you know how your phone doesn't work and then you get your messages when you're off the plane, he said how much he loved me and he was at work and he was thinking about me. When XXXX picked me up at the airport, XXXX didn't take me or pick me up, and he came home about 3 hours after I had gotten home and said, "I bought a house." I said, "You did what?" He said, "I did a purchase order, or whatever that's called, and purchased a house." I said, "Get the fuck out. You don't have the balls to have a conversation about this? You just go and buy a house?" It wasn't for me to live in. I was devastated. I was completely devastated. Then, something was going on with XXXX and he, because him and XXXX were friends, and 
he was for some reason he could not be there for me during that breakup and I was so mad at him.

I didn't feel like I had anybody. Out of desperation, I went to my mom. Her husband was very supportive. Mom wasn't that supportive, but he was supportive. He kind of helped me figure out what do next financially and you know. I was scared financially, because I worked so hard to have this beautiful house and swimming pool and hot tub. I had saved and saved because the whole time XXXX and I was together, I was in charge of the money and I'm really good at that. When XXXX left, I couldn't afford to stay there by myself. I ended up here in the ghetto. I hated it and I hated him. We broke up and then almost a year later, I still wanted to be with him. It's, I'm sure you know that those kind of relationships where you have an alcoholic that those highs are really high and the lows are really low. I missed those highs. He couldn't do it. That didn't last very long. That second part of trying.

A few months after that, my friends were like you have to do something. My kids were worried about me. I was here. I tried to be here and I like being by myself and I can afford to live here. I like how low my house payment is. I really wanted to get married again. My friends talked me into going online. I had never even thought I would ever do, and on Christian Mingle, I met Alan who also wanted to get married. You put yourself in a category. We were both in the 'I want to get married' category. We talked all the time on the phone. I really had to lean on my faith to get through the whole thing with XXXX and stuff. I have situational depression anyway, so that was the worst it had 
ever been, except for maybe when my dad died. Ed just had all of that safety and wanted the same things that I wanted. [Indecipherable] and we have a wonderful, open, loving relationship and it just feels so good to have that again. How it [?] has changed for me. I think because I got older and smarter. I lived with XXXX before we got married. I lived with XXXX before we got married. I didn't want to do that again. I didn't want to have sex again right off the bat, which is what I had done with XXXX and XXXX.

I wanted to build a relationship, an emotional relationship. Luckily, that's the same thing that Ed wanted. We actually dated and talked on the phone for hours. Even though XXXX is really my best friend, I still feel safer emotionally with Ed than I do with XXXX. XXXX has been my safety net throughout most of my life. My adult life. Here I got a pretty good gig. I've changed a lot. When I got sick, when I got cancer I got fatter. I've probably always had little body issues and vanity issues, not that you can tell today because... [Laughing]. I just really lost my train of thought. Oh, the sex part with Ed. When I got sick, I got fatter and I didn't feel very good about my body. I was just getting to accept it when I first met him. This is from the cancer with the boyfriend. Body issues with the breast reconstruction and all of that. It's very hard to try and explain this to someone else and I thought I would stay with XXXX and it wouldn't matter. I would never have to explain it. You know what I mean?

I: Sure.

P: But, Ed understands all of those things that I'm able to tell him. You know, those things. So, I got sick again in October. Just this last October. In 3 weeks, gained 45 pounds. When you got somebody who already had a body issue because she gained 10 
pounds, you know what I mean? Now, I can't lose it because of the way my body is, it's not strong enough. They can't figure out what's wrong with me, but something's wrong with me. I can't do a lot of the same things that I used to do. I just got comfortable with Ed and this part of me whenever I got sick and got fatter and it's like, if you don't feel good about yourself then it's hard to you know? He's like, I love you and it doesn't matter. I still see you the way I saw you the first day. I'm sure he'll probably say something like that. He doesn't see that extra, well some of it did go away because it was fluid or whatever. He doesn't see the extra 35 pounds like I do. I did not have body issues until Jeff because I thought, he's not having sex with me so it must be me. I'm down to a size 2 , thumping on my treadmill every day, which is good for you anyway. My whole adult life, that's what I was until just a few years ago. It's really different. I was not one of those yo-yo people like most girls are. I just never was. I liked being like that. I liked being skinny and having a six-pack. I took pride in that. Not showing it off but to myself. It makes it more difficult now that I don't have that. I feel like he might not think I'm as attractive. Then of course, you got the whole freaking menopause crap. You know? That changes things.

I: That's true.

P: Because I had cancer in the beginning, they said my ovaries weren't going to last very long, which of course is the estrogen. Then, my cancer was estrogen driven. They give you medicine to stop that and it's like, I don't really feel like a woman anymore. That's hard, but he's very loving and supportive and stuff about that. Even though it's not a sexually charged relationship like with the other, like with XXXX or XXXX, it's still so 
safe and so loving in so many different ways rather than just intercourse. I guess that's how it's changed. It's went back to what I've always wanted. For someone to love me for who I am.

I: Now, I'm going to ask you a section. You didn't identify any events or expectations regarding intimacy and sexual expression for the future, but you did indicate that if you had to go into assisted living or a nursing home, you would have to have your husband with you. So, the question I have for you is, as you consider your future, what concerns do you have about your intimacy and sexual [participant speaks over interviewer].

P: That part was hard for me. How can you put events down in the future when you don't know what's going to happen? I just want to be able to, when I'm not able to take care of myself or when Ed is not able to take care of me, or he needs taken care of beyond what I can do, that we can still be together someplace. I still want to have that same intimacy that we have now. I want to be able to have, and of course, still be sexually active. I don't want that to ever go away. I don't expect that to ever go away. It might slow down, but it's already slowed down a little bit. You know what I mean? I: Sure.

P: So, I think more things will become more important than intercourse.

I: In what ways?

P: Just like I think him just being there and being emotionally safe and being able to have intimate conversation and other physical cuddling and sleeping together and being 
together like that will become more important and I don't ever want to lose that. Does that make sense?

I: Yes. In what ways, if any, do you expect your definition of intimacy changing in the future?

P: I think the way I think about it will evolve just like it has over my history. I think it will just be, intimacy will just be a deeper security and a deeper understanding of my husband and it will just get better that way. I'll just keep learning as we're together about him and feelings and things like that will be shared. Does that make sense? Did I answer that the way you...?

I: Whatever answer you provide is the answer.

P: But did I answer it?

I: I think you have. Yes.

P: Yes.

I: This is really the last question.

P: Okay.

I: I don't think it's redundant. It may seem like that. What are your expectations for sexual expression when you think about being a potential resident [participant speaks over interviewer].

P: Scares me to death [?]. I think any time, I mean like maybe an apartment assisted living where you could still live as a family, that would be okay. I don't want to end up in some kind of long-term nursing home with Ed on one end of the, in the men's wing so 
to speak, and me in the other wing. I think that everybody should get to stay together if they choose to. I think the people in the nursing homes now, if they want to hook up should be able to hook up. I mean, my gosh they're the people they are around every day. You need to build relationships with people or you kind of just die on the inside, I think.

I: You brought up having a men's, that doesn't exist anymore.

P: Oh, it doesn't?

I: No. Yet, married couples.

P: Like what kind?

I: *** [Sounds like the recorder is dropped. End of recording.] 


\section{TIMELINE: Baby Boomens 1946-1964,}

World War II Officially Ends, Benjamin Spock's influential The Common Sense Book of Baby and Child Care is published,

1947 Edwin Land, founder of the Polaroid Corporation, makes first "instant camera", the Polaroid Land Camera

Supreme Court rules that religious instruction in public schools is unconstitutional

President Truman establishes rocket test range at Cape Canaveral, Florida

President Truman orders development of the hydrogen bomb in response to detonation of Soviet Union's first atomic bomb in 1949. He sends U.S military advisors to Vietnam to aid French forces. The Mattachine Society, the first gay liberation organization, is founded in Los Angeles, California

Direct dial coast-to-coast telephone service begins in the U.S. First regularly scheduled transatlantic flights begin operation

A mechanical heart is used for first time in a human patient. Christine Jorgensen, a transsexual woman in Denmark, becomes the recipient of the first successful sexual reassignment operation.

68 percent of all television sets in the U.S. are tuned into I Love Lucy to watch the character Lucy (Lucille Ball) give birth. The CIA helps overthrow government of Mohammed Mossadegh in Iran; CIA Technical Services approves use of the synthetic drug LSD in a MKULTRA subproject (MKULTRA was a covert, illegal CIA human research program investigating mind control) schools in Brown v. Board of Education. Boomers are the first elementary school generation to attend integrated schools. The first shopping mall opens in Southfield, Michigan. The first mass vaccination of children against polio begins in Pittsburgh, Pennsylvania

1955 The FDA approves an oral contraceptive, Enovid (The Pill), for sale in the U.S. Racial segregation is forbidden on trains and buses in U.S. interstate commerce. The American Civil Liberties Union defends Allen Ginsberg's epic poem "Howl" against obscenity charges. The Pentagon announces plan to develop ICBMs (intercontinental ballistic missiles) armed with nuclear weapons. The first electric power generated from atomic energy is sold commercially

1956 Dick Clark appears as host of American Bandstand. Ninety-six U.S. Congressmen sign "Southern Manifesto," a protest against the $\mathbf{1 9 5 4}$ Supreme Court ruling desegregating public education. The first transatlantic telephone cable goes into operation. Videotape is used for the first time on television. The first pre-frontal lobotomy is performed. IBM introduces the first computer disk storage unit, the RAMAC 305 .

1957 President Eisenhower orders U.S. troops to desegregate schools in Little Rock, Arkansas. Georgia State Senate unanimously approves Sen Butts' bill barring blacks from playing baseball with whites New York City is first to legislate a Fair Housing Practices Law against racial or religious discrimination. The Ford Motor Company introduces the Edsel car. Toyota begins exporting vehicles to the U.S. The Gaither Report calls for more American missiles and fallout shelters. Elvis Presley is drafted into the U.S. Army 
The first successful American satellite, Explorer 1, is launched into orbit. A 7,600 -pound hydrogen bomb is lost in the waters off Savannah, Georgia. The U.S. Army launches the Explorer 3 satellite. CBS Labs announce stereophonic records. Actress Betsy Palmer joins The Today Show. Mao Tse Tung starts the "Great Leap Forward" movement in China. Nikita Khrushchev becomes Soviet Premier and First Secretary of the Communist Party in the Soviet Union.

Cuban Dictator Fulgencio Batista flees Cuba for the Dominican Republic. The Dalai Lama flees Tibet for India. A Vatican edict forbids Roman Catholics to vote for Communists. Nikita Khrushchev is denied access to Disneyland. The Barbie Doll debuts and begins domination of the toy market. Allen Ginsberg writes his poem "Lysergic Acid". Congress passes a bill authorizing food stamps for poor Americans. Pan Am begins regular passenger flights around the world. Soviet Luna 3, the first successful photographic spacecraft, impacts the Moon. NASA announces selection of seven military pilots to become the first U.S. astronaut.

U.S. announces 3,500 American soldiers will be sent to Vietnam. U.S. Senate passes the Civil Rights Bill. The first guided missile is launched from a nuclear powered submarine. The U.S. Court of Appeals rules that D. $\mathrm{H}$. Lawrence's novel Lady Chatterly's Lover (1928) is not obscene. The first contraceptive pill is made available on the market. John F. Kennedy becomes the 35th President of The United States

President Kennedy accepts "sole responsibility" for The Bay of Pigs invasion and declares national goal to reach the Moon. Astronaut Alan
Shepard becomes the first American in space. FCC Chairman Newton Minow criticizes TV as a "vast wasteland". TWA shows the first in-flight movie. A U.S. commercial plane is hijacked to Cuba. Construction of the Berlin Wall begins in East Germany.

President John F. Kennedy begins blockade of Cuba, introducing "duck and cover" into the vernacular. Astronaut John Glenn is first American to orbit Earth. First Lady Jacqueline Kennedy conducts tour of newly refurbished White House on TV. Actress Elizabeth Taylor is condemned by Vatican for "moral vagrancy," and is wildly cheered by thousands of Catholic extras during the filming of Cleopatra in Rome. The Beach Boys introduce a new musical style with their hit "Surfin". Folk singers Peter, Paul \& Mary release their premier hit "If I Had a Hammer". The first WalMart and K-Mart stores open.

1963 Betty Friedan publishes The Feminine Mystique, relaunching Women's Movement. Coca-Cola Company debuts Tab, its first diet drink. American Heart Association is first agency to campaign against cigarettes. Push-button telephones and Instant Replay are introduced. Cancellation of Mercury 10 effectively ends U.S. manned space flight. After signing a nuclear test ban treaty, John F. Kennedy proposes a joint U.S. Soviet voyage to the Moon. Reverend Martin Luther King Jr. delivers his "I Have a Dream" speech on the steps of the Lincoln Memorial in Washington, DC. President John F. Kennedy promises a Civil Rights Bill. President John F. Kennedy is assassinated in Dallas, Texas.

Beatles debut to mass 'tween "Beatlemania" on "The Ed Sullivan Show," launching pop "British Invasion" of America. Bob Dylan introduces The Beatles to cannabis for the first time. 
Twelve young men in New York City publicly burn their draft cards. Comedian Lenny Bruce is convicted of obscenity. China becomes fifth nuclear power. NASA launches its first Orbital Geophysical Observatory (OGO-1). U.S. report titled "Smoking \& Health" connects smoking to lung cancer. Federal Trade Commission rules health warnings must appear on all cigarette packages.

1964-1975 Vietnam War, the war boomers fought in and protested against. The average age of combat soldiers is 19 .

1967 The "Summer of Love" and the hippie counterculture of sex, drugs and rock $n$ roll.

1968 Women's Liberation and the feminist movement begins. The oldest boomers are 22.

1969 Woodstock, a music festival in Bethel, New York takes place, where more than $\mathbf{4 0 0 , 0 0 0}$ people attended and more than 30 acts perform.

1969 The first Selective Service lottery since 1942 is held. The lottery is for armed forces inductees for 1970 . Only males 18-26 are eligible.

1973 Roe v Wade makes abortion legal in the United States.

1974 U.S President Nixon resigns following the Watergate Scandal. Gerald Ford takes over.

1975 The last Selective Service lottery. The oldest boomers are 29. The system is suspended on April 1 and registration for the draft is suspended in January 1976.

'CNN Baby Boomer Fast Facts
1979 - The year the U.S. divorce rate peaks. There are 2,331,000 marriages and $1,181,000$ divorces, according to the U.S Census. Margaret Thatcher becomes first woman Prime Minister of Britain SALT II agreement signed by Jimmy Carter and the Soviet leaders.

1980 Selective Service registration is revived for all males born 1960 and later. The youngest of the boomers will be 16 by year's end.

1981 The reusable Space Shuttle Columbia launched.

1983 Legislation passes raising the retirement age, with full Social Security benefits, from 65 to 67 to begin in 2000 .

1993 Bill Clinton (August 19, 1946), is sworn in as the $42 \mathrm{nd}$ president of the United States, the first boomer in the White House.

1986 US Space Shuttle Challenger explodes after takeoff, killing seven astronaut. Soviet Union's Mir Space Station launched. Nuclear leak in Chernobyl power station.

1990 Unification of Germany. Formal end of Cold War.

1995 DNA code of living organisms deciphered.

2003 The space shuttle Columbia perished in space. Seven astronauts died. The USA and Britain jointly launch Operation Iraqi Freedom to liberate Iraq from Sadam Hussain, who build up weapons of mass destruction. 
APPENDIX I

\section{CHAPTER 4 QUESTION 1 SE $=$ SEXUAL EXPRESSION CODES}

COMBINED M-F-SEXUAL EXPRESSION

$\mathrm{SE}-\mathrm{IC}=\mathrm{INTERCOURSE}$

$\mathrm{SE}-\mathrm{ALT}=(\mathrm{ANY}$ FORM OF LOVING TOUCH, I.E. HAND HOLDING,

CARESSING OF THE FACE, PUTTING AN ARM AROUND SOMEONE, WANTING

TO BE CLOSE, AND TO TOUCH YOU.)

$\mathrm{SE}-\mathrm{EP}=\mathrm{EMOTIONAL} \mathrm{PROTECTION}$

$\mathrm{SE}-\mathrm{M}=$ MASTURBATION

\section{CHAPTER 4 QUESTION 1 INT - INTIMACY CODES}

COMBINED M-F INTIMACY

$\mathrm{I}=\mathrm{GTOT}=$ GROWING TOGETHER OVER TIME

$\mathrm{I}=\mathrm{IS}=\mathrm{INCLUDES} \mathrm{SEX}$

$\mathrm{I}=\mathrm{R}=\mathrm{RESPECT}$

$\mathrm{I}=\mathrm{GR}=\mathrm{A}$ GOOD RELATIONSHIP

$\mathrm{I}=\mathrm{CA}=\mathrm{COMPLETE}$ ACCEPTANCE, WARTS AND ALL.

$\mathrm{I}=\mathrm{IA}=$ BEING INTELLECTUALLY AUTHENTIC

$\mathrm{I}=\mathrm{EM}=\mathrm{BEING}$ EMOTIONALLY AUTHENTIC

$\mathrm{I}=\mathrm{T}=\mathrm{TRUSTING}$ ANOTHER

$\mathrm{I}=\mathrm{MS}=$ MUTUALLY SUPPORTIVE

$\mathrm{I}=\mathrm{SI}=\mathrm{SHARED}$ INTERESTS 


\section{$\mathrm{I}=\mathrm{STT}=$ SPENDING TIME TOGETHER}


APPENDIX J

CHAPTER 4 QUESTION 2 CODES

COMBINED M-F

CHILDHOOD-ADOLESCENCE

PARENTS

PEER RELATIONSHIPS

FRIEND RELATIONSHIPS

NO IDENTIFIED SOURCE

LONG-TERM RELATIONSHIP

EARLY ADULTHOOD

MARITAL RELATIONSHIP

CASUAL FRIENDSHIP

FRIEND RELATIONSHIP

OBSERVING OTHERS

LONG-TERM COMMITTED RELATIONSHIP

MIDDLE ADULTHOOD

MARITAL RELATIONSHIP

FRIEND RELATIONSHIP

CASUAL RELATIONSHIP

HEALTH PROBLEMS

LONG-TERM COMMITTED RELATIONSHIP 
FUTURE TIME

\section{OBSERVING OTHERS}

HEALTH PROBLEMS

MARITAL RELATIONSHIPS

FRIEND RELATIONSHIP

CASUAL RELATIONSHIP

PEER RELATIONSHIP

LONG TERM RELATIONSHIP 


\section{APPENDIX K}

\section{QUESTION 3 FUTURE TIME INTIMACY CODES \\ COMBINED M-F}

INT-NS $=$ NONSEXUAL RELATIONSHIPS

$\mathrm{I}-\mathrm{MS}=$ MUTUALLY SUPPORTIVE

$\mathrm{I}-\mathrm{C}=\mathrm{COMMUNICATION}$

$\mathrm{I}-\mathrm{F}=\mathrm{FRIENDSHIPS}$

$\mathrm{I}-\mathrm{PT}=\mathrm{PHYSICAL}$ TOUCH

I-MPC $=$ MUTUAL PHYSICAL CONNECTION. I.E. HOLDING HANDS, HUGS, HOLDING EACH OTHER, TOUCH, CARESS, KISS

$\mathrm{I}-\mathrm{SI}=$ SHARED INTERESTS

$\mathrm{I}-\mathrm{INTL}=\mathrm{INTELLECTUAL} \mathrm{CONNECTION}$

$\mathrm{I}-\mathrm{STT}=\mathrm{SPENDING}$ TIME TOGETHER

$\mathrm{I}-\mathrm{CA}=\mathrm{COMPLETE}$ ACCEPTANCE

I-IA = BEING INTELLECTUALLY AUTHENTIC

$\mathrm{I}-\mathrm{AFF}=\mathrm{AFFECTION}$

I-LTR = INCLUDES A LONG TERM RELATIONSHIP

$\mathrm{I}-\mathrm{T}=\mathrm{TRUSTING}$ ANOTHER 


\title{
APPENDIX L
}

\section{QUESTION 4 INTIMACY AND SEXUAL EXPRESSION CONCERN CODES}

\section{M-F COMBINED}

\author{
LTC-ESE $=$ EXPECTATIONS FOR SEXUAL EXPRESSION
}

LTC-EI $=$ EXPECTATIONS FOR INTIMACY

PR-C $=$ PRIVACY CONCERNS

HEALTH CONCERNS

IMP/ED = IMPOTENCE/ERECTILE DYSFUNCTION

$\mathrm{SD} / \mathrm{A}=\mathrm{SELF}$ DIRECTION/AUTONOMY 


\section{APPENDIX M \\ QUESTION 5 PARTS ONE AND TWO CODES \\ COMBINED M-F}

PT. 1

PR-C $=$ PRIVACY CONCERN

LTC-ESE $=$ EXPECTATIONS FOR SEXUAL EXPRESSION CONCERN

LTC - EI $=$ EXPECTATIONS FOR INTIMACY

IMP/ED $=$ IMPOTENCE/ERECTILE DYSFUNCTION

HEALTH $-\mathrm{C}=$ HEALTH CONCERNS

LTC - NSENI-MC $=$ NO SEXUAL EXPRESSION, NO INTIMACY EVEN WITH MARRIED COUPLES.

LTC-SD/A = SELF DIRECTION/AUTONOMY. ABILITY TO MAKE DECISIONS

AND ACT TO MEET ONE'S OWN NEEDS INDIVIDUALLY OR

COLLABORATIVELY.

PT. 2

$\mathrm{S}=\mathrm{SC}-\mathrm{SE}=$ SOLUTIONS FOR SHARED CONCERNS ABOUT SEXUAL EXPRESSION IN LTC

S-SC-INT - SOLUTIONS FOR SHARED CONCERNS ABOUT INTIMACY IN LTC. 


\section{CURRICULUM VITA \\ C. S H A W N O A K}

\section{EXPERIENCE}

May 2007 - PRESENT Oak \& Associates, LLC Louisville, KY $\mathrm{CEO} / \mathrm{Owner} /$ Therapist

- Provide marriage and family therapy services for couples, families, and individuals.

- Provide mental health counseling for individuals and families.

- Provide sex therapy and education for individuals, couples, and families.

- Research and locate evidence based practice treatment models and methods to assist families to achieve their individual goals and objective.

- Provided in-home family therapy contracted services with Impact Plus.

- Provide humans systems consulting services

- Provide family business consulting services

October 2014 - PRESENT SAFY, INC Louisville, KY

Diversion/FPP Supervisor

- This position is responsible for the treatment and quality of care for youth/families for all counties assigned and for the fiscal viability of the area assigned

- Ensure that staff is implementing the program based on its design and ensure that documentation meets the established standards

- Determine eligibility of referrals for assigned staff and maintain caseload numbers according to programs design

- Oversee and manage all staff to provide direct services to identified families, 24 hours a day and 7 days a week

- Provide backup to on-call response for team members, this includes clinical and crisis intervention as well as problem solving consultation

- Interview applicants for positions, recommends hiring and disciplinary action, when necessary

- Prepare reports as required or instructed for supervisor, corporate office, and other agencies in a timely and accurate manner regarding progress of program outcomes/accountability to structure/and integrity of budget/finance structure. 
- Authorize leave time and establishes work schedule for staff under supervision, perform evaluations, conduct supervisory meetings with staff, and fill in as necessary providing service to clients.

Ensure staff receive necessary training and perform according to best practices.

- Build relationships with court and county agencies to market the program

EXPERIENCE (CONT):

July2012-September2013LexingonAcademy/Sequel/TSI,Inc

Lexington, IN

Clinical Director

- Conduct individual, family, and group therapy; perform psychological evaluations within licensing capabilities, formulate treatment plasn, document in clinical record, facilitate treatment team, and complete CANS assessment.

- Provide clinical supervision and clinical consulting services.

- Respresent the facility at workshops, conferences, seminars, court, including presentation of articles, paper, etc.

- Assist program with JCAHO preparation in clinical areas, including evaluating, assisting, skills teaching, and composition of documents.

- Assure that performance reviews are completed annually for staff under direct supervision, including establishing specific, individual professional development goals.

- Oversee day-to-day clinical operations of the academy.

August 2009 - December 2014 University of Louisville

Louisville, KY

Part-time Lecturer/Research Assistant

- Graduate Level Human Diversity, Human Sexuality \& Treatment of Sexual Dysfunctions, Social Work Advanced Practice I and III Courses.

- Responsible for integration and teaching of critical thinking skills.

- Assessing and evaluating learning.

- Develop teaching materials, prepared and gave examinations, and graded examinations, papers, and presentations.

- Research and identified methods of assessing case loads for child welfare workers across the nation. 
June 2007 - July 2009

University of Louisville

Louisville, KY

Graduate Teaching Assistant

- Assisting Professor by performing teaching or teaching-related duties.

- Co-teaching Humans Sexuality and Treatment of Sexual Dysfunctions.

- Designed and created new Human Sexuality and Treatment of Sexual Dysfunctions course syllabus in compliance with the Council on Social Word Education (CSWE).

- Developing teaching materials, prepared and gave examinations, and graded examinations or papers.

\section{EXPERIENCE (CONT):}

October 2006 - May 2007 Boy’s Haven, Inc Louisville, KY Therapist

- Providing in-home family therapy services to families with children atrisk of removal by the Department of Community Based Services.

- Conduct initial and follow-up family assessments employing the North Carolina Family Assessment (NCFAS) instrument.

- Supervising two staff members as part of a comprehensive treatment team to provide case management and therapeutic support services for client families.

- Research and locate evidence based practice treatment models and methods to assist families to achieve their individual goals and objectives.

May 2005 - May 2006 Arch Diocese of Louisville

Louisville, KY

Therapist/Social Work Intern

- Counseled a wide range of individual, couples, and family multicultural clients regarding personal, social, marital, academic, and family difficulties.

- Conducted research and implemented strategic interventions and services based upon evidence based practice ranging from psycho-social educational methods through systemic therapeutic modalities.

- Collaborated with case managers, social workers, child protective services workers, developmental rehabilitation professionals, teachers, educational administrators, health care professionals, researchers, legal professionals, and clients to maintain an effective team approach for successful client outcomes. 
August 2004 - May 2005 Maryhurst, Inc Louisville, KY

Clinical Therapist Intern

- Counseled adolescent females and their families in this residential treatment facility.

- Co-created and facilitated a domestic violence group with another therapist intern.

- Co-facilitated an anger management and a substance abuse education group.

- Co-developed a proposal to implement a post-care mentoring program for residents exiting residential treatment program.

October 2000 - September 2002 Middlefork Christian Church

DuPont, IN

Minister

- Prepared and presented weekly sermons and Bible studies.

- Performed marriages, baptisms, and conducted worship services.

- Organized and managed special events and activities

- Provided pastoral care and counseling

- Served as an assistant spiritual director on two Walks of Emmaus for South Eastern Indiana Emmaus.

EXPERIENCE (CONT):

September 1999 - September $2000 \quad$ Lexington Christian Church

Lexington, IN

Ministerial Intern

- Prepared and presented sermons, Bible studies, and conducted worship services.

- Conducted visitation, special events planning, and personal evangelism.

- Developed and conducted a Men’s Leadership Training program.

$1998-2000 \quad$ Wal-Mart, Inc Scottsburg, IN

Assistant Store Manager

- Increased sales $10-13 \%$ in each area rotation under my management. Increased grocery and fresh department sales by $18 \%$ in one quarter.

- Increased customer service efficiency reduced absenteeism by $20 \%$, and implemented scheduling strategies that improved front-end customer services ratings by $25 \%$.

1996-1998 Woodmen of the World Scottsburg, IN

Field Representative

- Serviced existing customers.

- Expanded sales to include group health insurance accounts. 
Planning Director

- Created, developed, and implemented human services programs for this non-profit community action agency.

- Authored and/or co-authored over 18 million dollars in private, state, and federal grants.

- Created, developed, and implemented the first child care resource and referral service in the State of Indiana covering 13 counties.

- Successfully funded and managed four community housing assessments and strategic plans for four counties within the HVEOC service delivery area.

- Successfully funded and managed 10 home-owner rehabilitation projects in Clarksville, Indiana.

- Developed and produced HVEOC child care and Head Start program videos.

- Created, developed, and implemented a substance abuse program in collaboration with the Jeffersonville Public Housing Authority known as the Stepping Stone Project, now operated by the NACCP of Clark County.

- Co-authored one of 13 national Head Start three-year demonstration grants through the U.S. Department of Health and Human Services.

- Developed and authored five successfully funded home-ownership counseling programs in collaboration with several area financial institutions and local governments.

- Successfully managed corporate facilities rehabilitation and expansion.

- Successfully authored, obtained, and administered two Community

Development Block Grants through the Indiana Department of

Commerce Small Community Development Program.

2007-2015 University of Louisville Louisville, KY

- Ph. D Raymond A. Kent School of Social Work

- Inducted into the Golden Key International Honour Society October 2007

2003-2006 University of Louisville Louisville, KY

- M.S.S.W. - M.F.T. Master of Science in Social Work-Marriage \& Family Therapy Specialization.

- Who's Who Among Students in American Universities \& Colleges 2004-2006.

1997-2001 Louisville Bible College Louisville, KY

- M.S.L. Master of Sacred Literature-Practical Theology 
- Graduated with High Distinction

1989--1993 Indiana University Southeast New Albany, IN

- B.G. S. Bachelor of General Studies

- A.G. S. Associate of General Studies

- Graduated with High Distinction

- Outstanding Student School of Continuing Studies (Bachelors)

- Pinnacle National Honor Society

- Alpha Chi National Honor Society

LICENSES \& CERTIFICATIONS

Licensed Marriage and Family Therapy,

Exp. 10/21/2015

Certified Social Worker, KY-5144

(Inactive)

Licensed Marriage and Family Therapy, Indiana 35001769A

Exp. 04/01/2016

Social Work License, Indiana 33006299A

Exp. 04/01/2016

Prepare /Enrich Certified Facilitator

Certified Life Coach

Certified Master Coach

INTERESTS

Freemasonry, Eastern Philosphy, Greek Philosphy, Intimacy in Relationships, Alternative Relationships, Appreciative Inquiry, Participatory Action Research, Grounded Theory, Substance Abuse, Ericksonian Hypnotherapy, Couples/Marital Therapy, Sex Therapy, Geriatric Sexuality, Gerontology, PTSD, and Chronic Major Depression.

TRAINING/SEMINARS

Michael White-Narrative Therapy

Sue Johnson-Emotionally Focused Therapy

Stephanie Carnes-Sex Addictions

Ecological Structural Family Therapy - Philadelphia Child

Guidance Center

Collaborative Coaching Seminar - Harlene Anderson

Coaching Academy of North America, Inc

Prepare/Enrich Facilitator-Life Innovations, Inc

David Schnarch-New Perspectives on Sexual Desire

Casey Truffo Building - The Business of Therapy

Standardized Patient Training-Comptency in Dementia Management InterDisciplinary Teamwork 
Scott Sells - 7 Step Approach to Treating the Out of Control Adolescent and Child

\section{ACADEMIC MANUSCRIPTS PUBLICATIONS}

Farley, A. J., Feaster, D., Schapmire, T. J., D’Ambrosio, J.G., Oak, C. S., and Sar, B.K. (2009). The challenges of implementing Evidence Based Practices: Ethical considerations in practice, education, policy, and research. Social Work \& Society,(7) 2.

Faul, A. C., D'Ambrosio, J. G., Farley, A. J., Feaster, D. Oak, C. S., and Schapmire, T. J. (2009). Promoting sustainability in frontline health care workers: Understanding factorsaffecting job retention in home health care. Home Health Care Management Practice.

NON-ACADEMIC MANUSCRIPTS PUBLICATIONS

Oak, C. S., (2008) The silent killer of freemasonry, The Philalethes Volume LXI, 6, Pages 132-133, 143.

\section{CONFERENCE PRESENTATIONS}

Faul, A. C., D'Ambrosio, J.G., Farley, A. J., Feaster, D., Oak, C. S., and Schapmire, T. J. (2008, October). Problem-Based Learning: Integrating gerontology with research to develop new doctoral scholars. Paper presented at the $54^{\text {th }}$ Annual Program Meeting of the Council on Social Work Education, Philadelphia, PA.

Faul, A. C., D'Ambrosio, J. G., Farley, A. J., Feaster, D., Oak, C. S., and Schapmire, T.J., (2008, November). An aging society: Job risks and opportunitites facing the frontline caregivers fo elders who prefer to age in place. Paper presented at the $61^{\text {st }}$ Annual Scientific Meeting of the Gerontological society of America, National Harbor, Maryland.

PRESENTATIONS SELECTED-UNABLE TO ATTEND

Faul, A. C., D’Ambrosio, J. G., Farley, A. J., Feaster, D., Oak, C. S., and

Schapmire, T.J., (2009, July). An aging society: Job risks and opportunitites facing the frontline caregivers fo elders who prefer to age in place. Paper presented at the $19^{\text {th }}$ International Association of

Gerontology World Conference, Paris, France.

\section{PROFESSIONAL AFFILIATIONS}

American Association of Marriage \& Family Therapists (AAMFT)

Former Kentucky Association of Marriage \& Family Therapists (KAMFT) 
American Association of Grant Professionals (AAGP)

Society for the Philosphy of Sex and Love (SPSL)

PERSONAL AFFILIATIONS \& HONORS

Scottsburgh Lodge \#572, Grand Lodge of Indiana, F. \& A. M.

Offices:

- Worshipful Master, 1996, 1999, 2001.

- Junior Warden, 2008, 2014

- Chaplain 1997, 1998, 2000, 2002, 2003, 2004, 2005, 2006, 2007, 2008, 2009, 2011.

- Senior Deacon 1994

- Senior Warden 1995

- Junior Deacon 1993

- Ambassador Indiana Masonic Home

Seymour Chapter Royal Arch Masons \#85, Seymour, Indiana Jeffersonville Council of Cryptic Masons \#31, Jeffersonville, Indiana Jeffersonville Commandery \#27, Jeffersonville, Indiana Ancient and Accepted Scottish Rite, Valley of Louisville, $32^{\circ}$ Grand Lodge of Indiana, F. \& A. M.

- Area Representative 2003-2006

Knights of the North, K.O.T.N. by Invitation (International)

- Knight

GRRAND-Golden Retriever Rescue \& Adoption of Needy Dogs, Louisville, KY. 